Portland State University

PDXScholar

1979

\title{
The idea of progress: Its rise to power and prominence
}

Robert Ray Schmaling

Portland State University

Follow this and additional works at: https://pdxscholar.library.pdx.edu/open_access_etds

Part of the Theory, Knowledge and Science Commons Let us know how access to this document benefits you.

\section{Recommended Citation}

Schmaling, Robert Ray, "The idea of progress: Its rise to power and prominence" (1979). Dissertations and Theses. Paper 2954.

https://doi.org/10.15760/etd.2947

This Thesis is brought to you for free and open access. It has been accepted for inclusion in Dissertations and Theses by an authorized administrator of PDXScholar. Please contact us if we can make this document more accessible: pdxscholar@pdx.edu. 
AN ABSTRACT OF THE THESIS OF Robert Ray Schmaling for the Master of Science in Sociology presented July 27, 1979.

Title: The Idea of Progress: Its Rise to Power and Prominence. APPROVED BY THE MEMBERS OF THE THESIS COMMITTEE :
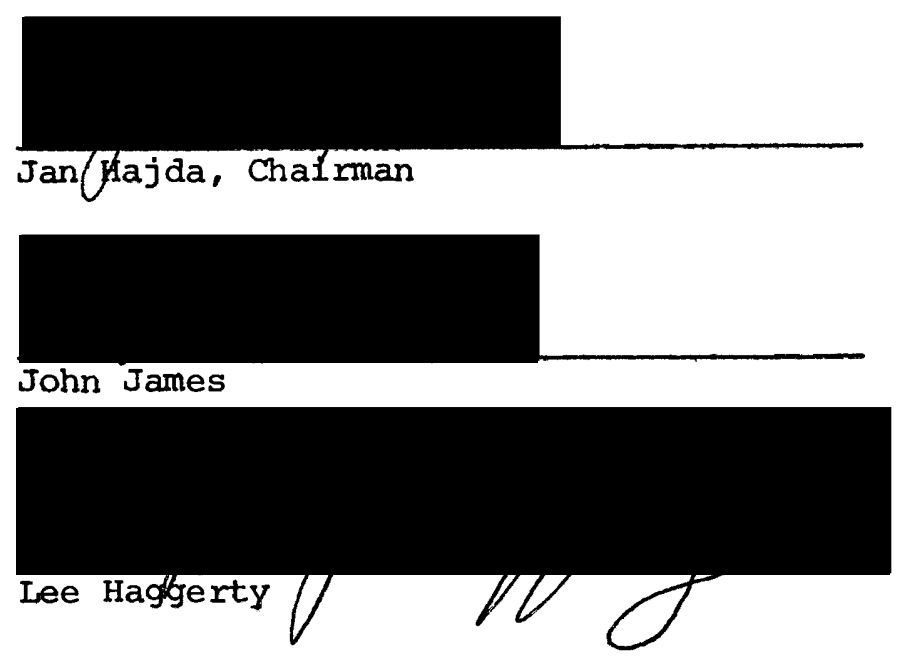

The purpose of this thesis was to come to understand the

fundamental character of the idea of progress by studying the manner in which the idea emerged. This study, however, embodied more than simply those ideas that comprised its nature. The sociology of knowledge approach emphasizes the importance of understanding that the development of ideas can be strongly affected by the social structure. Taking such an approach into consideration in the task of understanding the fundamental character of the idea of progress, it was necessary to also attend to the influences of the social structure as well as the ideational factors upon the development of this idea. The thesis had a twofold approach in which the majority 
of work was devoted to ideational changes where the character of the idea was formed, but attention was also turned at appropriate times to the influence of the social structure upon the idea of progress.

The ideational development of the idea was as much a battle to overcome ideas that blocked its development as it was the creation of new ideas. The cyclical view of history and the suspicion of change precluded the idea of progress in the Greek and Roman periods. The Medieval period, while seeing the rise of a linear view of history, was dominated by the idea of Providence which precluded the secular notion of change in the idea of progress. The Renaissance saw the emergence of Bacon's principle of utility and the growth of modern science whose fortunes have since been closely tied with that of progress. The period from the Renaissance to the Enlightenment saw the establishment of a secure foundation for modern science, an end to the authoritative position of the Greeks and Romans dating from the early Renaissance, and an increased valuation of the everyday life. All were factors necessary for the development of the idea. The Enlightenment saw progress assume its fundamental character with a belief in the possibility of perfecting man and society, a belief in an environment that fostered freedom and equality and that sought to destroy ignorance.

The social structure of the Medieval period exerted an influence on the idea through the lack of an economic structure and the domination of the Church. Moslem control of the Mediterranean Ocean radically changed the social and economic dynamics of European 
society. The Church emerged as virtually the sole source of power, which meant that Christian orthodoxy came to dominate every aspect of the individual's life. With its eyes turned to the hereafter, the Church fought the emergence of any idea of the betterment of the secular world.

Another influence of the social structure appeared in 18th century France. While it was the bourgeoisie that were the most dynamic element in society and who largely supported the monarchy, they were systematically discriminated against by the formal structure of French society. To remedy this, the bourgeoisie used the idea of progress to justify the social changes they desired, particularly changes initiated in the revolutionary period. They associated the inevitability of progress with their assumption of social power.

The concern of this thesis with the idea of progress ended with the revolutionary period in France. The idea has certainly played a continuing role in the affairs of men but by the revolutionary period it had acquired its basic dynamics and its use during this period marked a maturation of the idea and its assumption of a preeminent position in the ideational realm. 
THE IDEA OF PROGRESS: ITS RISE TO POWER AND PROMINENCE

by

ROBERT RAY SCHMALING

A thesis submitted in partial fulfillment of the requirements for the degree of

\author{
MASTER OF SCIENCE \\ in \\ SOCIOLOGY
}

Portland State University 
TO THE OFFICE OF GRADUATE STUDIES AND RESEARCH:

The members of the Committee approve the thesis of Robert Ray Schmaling presented July 27, 1979.
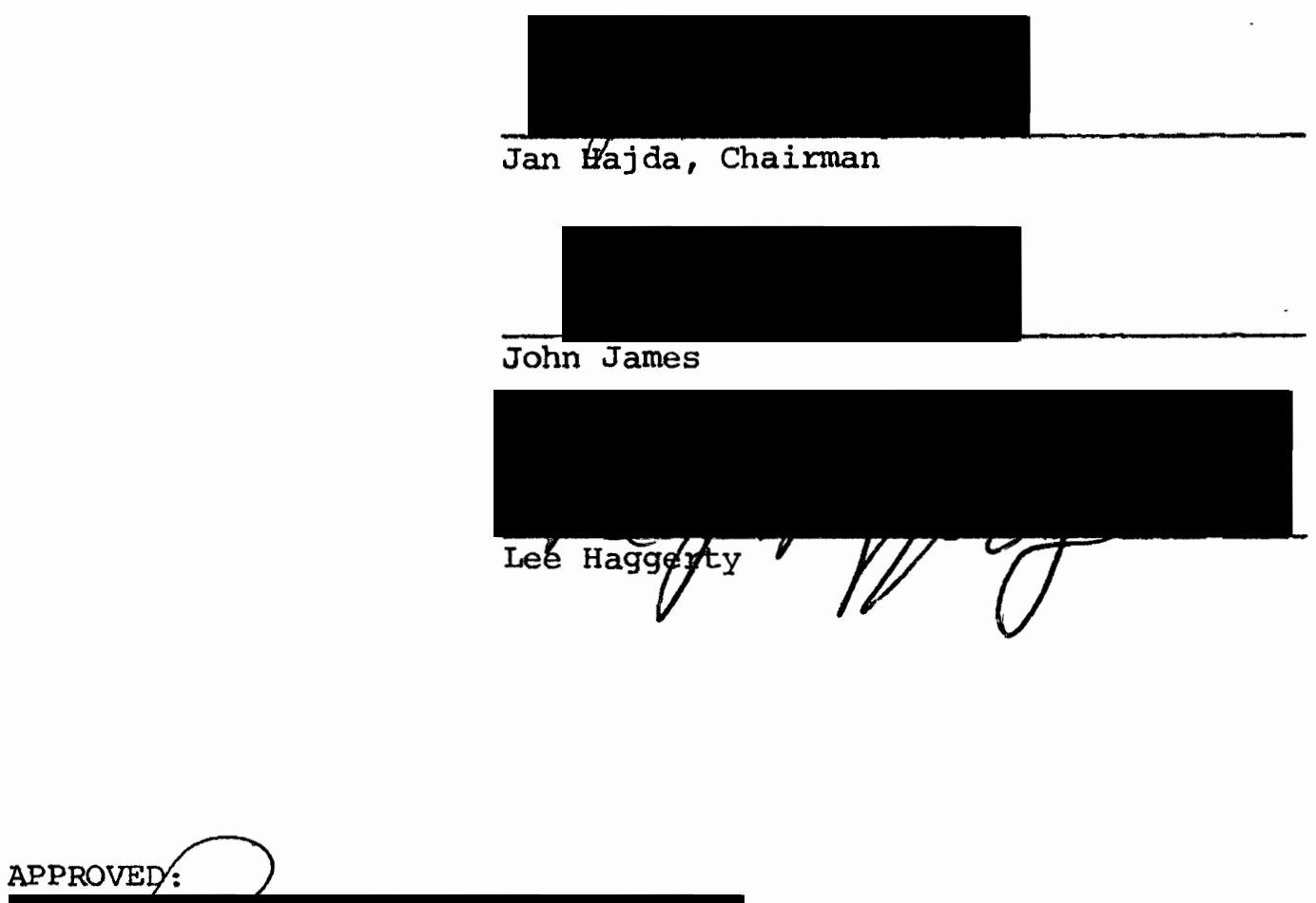

Robert W. Shotola, Acting Head, Department of Sociology

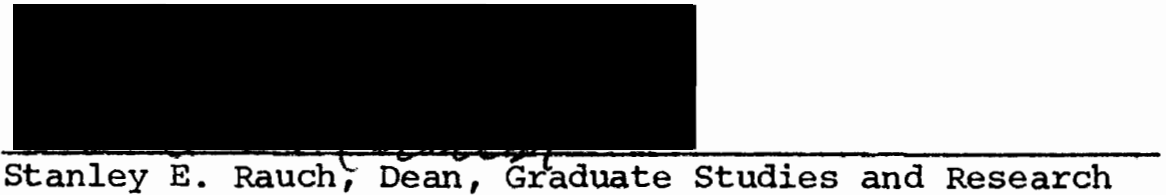




\section{ACKNOWLEDGMENTS}

Having perused the acknowledgments of numerous theses submitted by fellow students, I found them ranging from the spartan to the effusive. In undertaking such a perusal, I had hoped to find a model by which I might organize the acknowledgments to be contained herein. The variety encountered, however, has forced me to fall back upon my own personal proclivities. They are proclivities that impel me through a certain sense of detachment and understatement toward the spartan.

Due to the power that they command, the members of my committee have had a great influence upon the length and breadth of this thesis and should be duly recognized. I must first of all express my appreciation to Dr. John James for steering me toward the idea of progress in the first place and for exposing me to the kind of awareness that made the idea a question of first rate importance rather than merely an accepted element of the social heritage. Such an exposure is part of a system of education in the broadest sense of the word that is regrettably fading away today. As chairman of the committee Dr. Jan Hajda has had a special input into the nature of the final draft of this thesis. His criticisms and suggestions were most productive. All too often students have trouble translating the needs and desires of their committee members directly into the body of their theses, but the help I received from Dr. Hajda was always clear, practical, and productive. While from 
a somewhat different philosophic bent than myself, I must thank Dr. Lee Haggerty for his objective reading of this thesis and for his helpful suggestions.

Concerning the technical aspects of this thesis, I want to thank Sherri Schmaling and Judie Payne for proofreading various elements of this thesis and for making the effort to constrain my somewhat cumbersome style of writing. Without doubt, a great deal of appreciation goes out to kathy Grove for her first rate work in typing this thesis.

There are certain acknowledgments that are less directly tied to the nature of this thesis, but are of no less importance. I want to thank Dave Jermain for what I feel is his contribution to the completion of this thesis. That contribution has been to provide a model of discipline and determination that has often provided a guidance and motivation that was much needed. Finally, I must thank my parents who have, during the duration of writing this thesis, virtually provided me with food and shelter. While not directly affecting the direction of the thesis, their generosity has been the single greatest contribution to its completion. 
TABLE OF CONTENTS

PAGE

ACKNOWLEDGMENTS . . . . . . . . . . . . . . . . .

CHAPTER

I INTRODUCTION . . . . . . . . . . . . . . 1

II GREEK AND ROMAN PERIOD . . . . . . . . . 10

Greeks ........... . . . . 10

Romans .............. . . 18

Summary . . . . . . . . . . . 20

II MEDIEVAL PERIOD . . . . . . . . . . . . . 22

Saint Augustine . . . . . . . . . 22

Development of Orthodox Christian Thought

Influence on Period and Idea of Progress

Moslems

Control of the Mediterrean Sea

Loss of European Economic Vitality

Rise of Feudalism

Crusades and Revival of European Vitality

Release, Individuation, and Secularism

IV RENAISSANCE PERIOD . . . . . . . . . .

Humanism . . . . . . . . . . .

Veneration of "Ancients" and Revival of Classic Culture 
Rise of Modern Science . . . . . . . . .

Calvinism

Jean Bodin

Francis Bacon ................

$\checkmark$ NECESSARY CONDITIONS FOR RISE OF THE IDEA OF PROGRESS

Two Main Axioms $\ldots \ldots \ldots$

New Method of Reasoning . . . . . . . 85

Contribution to Idea of Progress . . . . . 89

VII CONFLICT BETWEEN THE ANCIENTS AND THE MODERNS

Question of Nature's Permanence and Invariability . . . . . . . . . . . 96

Contributors in Conflict ... . . . . . 96

Desmaret de Saint Sorlin

Charles Perrault

George Hakewill

Conflict Results . . . . . . . . . 101

VIII

BERNARD DE FONTENELLE ... . . . . . . . . . 104

Primary Works .. . . . . . . . . 104

Proof of Invariability of Nature ... . . . 106

Analysis of Difference Between Ancients and Moderns .................... 108

IX ABBE DE SAINT PIERRE ............. . . 116

X ENLIGHTENMENT PERIOD . . . . . . . . . . 125

Replacement of Cartesian Science with Natural Science . . . . . . . . 126 
vii

Rise of Critical Posture . . . . . . . .

John Locke and Etienne de Condillac . . . .

Philosophes . . . . . . . . . . .

Nature of Pexspectives, Goals, Methods

Conflict with Christianity on Morality

Philosophy of History

Voltaire, Montesquieu, Turgot

Progress as Secular Heaven

\section{Encyclopedie \\ Reason \\ Nature \\ Progress}

Essential Ideas of Enlightenment . . . . .

Apex of Naive and Optimistic Thought . . . .

Uses of the Study of Civilization . . . . .

Determination of Social Laws

Nature of Tenth Period of Progress

Elements of Progress .............

Nature of 18th Century French Society . . .

Nobility

Bourgeoisie

Peasantry

Bourgeoisie and Society

Bourgeoisie Influence Upon the Idea of

Progress . . . . . . . . . . . . .

Nobility and Social and Economic Changes . . 256

Bourgeoisie . . . . . . . . . . . 264 
Inevitability of the French Revolution . . . 270

Reforms Needed

Prosperity Existent

Necessity of Change

Factors Leading to French Revolution . . . 277

Influence of Jean Jacques Rousseau . . . . 287

Criticism of Contemporary Society

Self-Love vs. Selfish-Love

Nature of Freedom and Liberty

Influence of the American Revolution . . . . 301

Phases of the French Revolution . . . . 305

Bourgeois Liberal Revolution (1789)

Popular Uprising (1792)

Popular Uprising (1793)

Fall of Robespierre

Effects and Accomplishments of the Revolution 314

French Revolution and the Idea of Progress . . 317

XIV CONCLUDING REMARKS . . . . . . . . . . 336

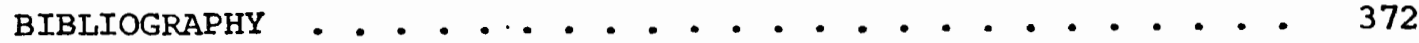

APPENDIX . . . . . . . . . . . . . . . . . 377 
CHAPTER I

\section{INTRODUCTION}

Throughout the greater period of human history the prevalent belief was that the future would repeat the past, that the life of mankind was best described by a circle. In this perspective life went ever on but never really went "anyplace." Under the influence of the Christian idea of salvation men began to believe that real change in the human condition was possible. Such change however was to be brought about rather precipitously by the action of supernatural powers rather than human action itself. Any hope of "improvement" in the human condition through such change was not thought of as a change for the better here on earth but rather as a deliverance from this world. What the idea of progress represented historically was a great change in the outlook of mankind, a reevaluation of the nature of this world as well as man's role in it.

With the idea of progress the idea of linear change emerged, change that was going "somewhere." Progress involved the idea that this world could be changed to make it a heaven on earth, and in that respect marked something of a secularization of the Christian millenial notion. With the emergence of the idea of progress it was no longer necessary to "leave" the planet to be free and 
fulfilled, the idea promised such a state of being not only could be brought about but must eventually occur. With the idea of progress and hope for a heaven on earth no longer was there a reliance upon the supernatural, mankind now took the reins of his own destiny. This act required a new perspective of mankind's role and power. What emerged was a self-image of man as a powerful force, capable and creative in his own right. This all amounted to dramatic changes in the history of mankind, changes brought about directly or indirectly by the idea of progress.

What actually is progress? How should it be defined? A dictionary gives a definition: "to advance toward something better," or "intellectual or moral improvement" (Thatcher, 1971:664). The vagueness encountered here underlies the fact that there is no single definition that precisely covers all facets of the idea of progress. There are perhaps as many definitions of the idea of progress as there are books written about it or men who have thought about it. This potential variety results from the fact that there are many ways to "measure" progress and there are many subjects that are thought to progress. Through the course of history progress has meant very different things at different times. Men of the late 17th and early 18th centuries thought of it as the movement of knowledge and the benefits that such increased knowledge could bring to mankind. In the latter part of the 18th century the improvement of human nature was added to the idea of progress. The second half of the 19th century say the emergence of the technological process as the prime focus of the idea of progress. It is also 
quite true that the idea of progress has meant many things to men of the same historical period. The French for instance in the lith century tended to think more often of the social man, of changes to society in general, while the Germans were primarily concerned with the moral improvement of mankind.

The idea of progress is a member of a small group of ideas that everyone seems to believe in but no one can ever clearly and definitively state. In this respect it belongs with such fundamental ideas as life, death, right, and wrong. The important thing in attempting to define such ideas in general, and the idea of progress in particular, is to capture the essence of what the idea is attempting to express. For the idea of progress the definition given by Sidney Pollard in his book The Idea of Progress comes as close as any to capturing that essence. Pollard (1971: 9-10) stated that:

- . a belief in progress implies the assumption that a pattern of change exists in the history of mankind, that this pattern is known, that it consists of irreversible changes in one general direction only, and that this direction is towards improvement from a less to a more desirable state of affairs.

However one may wish to define the idea of progress, belief in it still remains an article of faith and not fact, and in that respect ranks with such ideas as providence and immortality. The "factuality" of progress is typically established by an analysis of past historical periods and the determination of some lawful character to the changes that have occurred. But such an interpretation of the past in no way binds the future to a similar 
path, and in no way defines a law of social change. The great length of human advance in the past and the great period of time that modern science has assigned to this celestial body impels one to carry the path or advancement from the past, through the present, and on into the future. One must always remember however that point at which one passes from the present to the future is the point at which faith takes over.

Even the interpretation of the past events of history as defining a progressive movement is in a sense an act of faith. Knowledge seems to have undoubtedly advanced but, considering what has been done both to man himself and the physical world, does that movement of knowledge really represent progress? Mankind has more activities to engage in presently, and more toys to occupy time, but has the basic human character changed any from the beginning of recorded time? These questions are still open to debate.

The idea of progress represents both an interpretation of history and a philosophy of action. The intexpretation of history arises from the basic way in which, we understand the nature of history. As it was brought out in the definition by Pollard, there is an interpretation of the events of history as describing an ordered path, a rational or coherent history. History is not merely the movement of actors and environment through an endless succession of cause and effect, rather it is a teleological movement to some positive goal. This is an important point, for the idea of progress is in its essence a positive interpretation of the past which is then carried over to the unknown future. 
The interpretation of history that underlies the idea of progress, the idea that there is a pattern to its movement, also implies the belief that generalizations can be made from history and applied to the present and to the future. There is the belief that a "science" of history is not only possible but has already been attained. Underlying this is the assumption of the permanence of historical generalizations, that the generalizations derived are applicable for all of humanity.

Finally, the idea of progress as an interpretation of history implies that there are values of human action and social change that exist outside the actual arena of history. Such values are necessitated by the fact that the actual historical arena is constantly changing. If there were not some set of values, some goals that were not themselves changing then there would be no sense of advance, no goals toward which the movement of history was tending. If there were no such goals the actual "measurement" of progress would not be possible for with every changing historical period the criteria would change. Whether there actually exist such values or goals is questionable, but each period feels that it knows such unchanging entities.

The idea of progress must also be considered a philosophy of action as well due to the effect which it has upon the outlook of those that believe in it. The Christian eschatology of the medieval period for example was not a philosophy of life that would motivate someone to strive to make the world a happier place to live. If nothing can be improved in this world and the focus of 
life is the afterworld, the best attitude is simply to endure what earthly life has to offer. In fact, it was construed to be working against the dictates of God to try and improve one's condition here on earth, after all it was God who placed each individual in their respective positions. On the other hand if one's belief was that a better Iife was possible here on earth, and that through one's own actions it was possible to bring about that better life, then the motivation for an active participation in the affairs of life was certainly present. A belief in progress was a call to action. In spite of the problems in clearly defining what is meant by the idea of progress (within its various manifestations), and the problems encountered in attempting to "measure" in any manner the degree of progress, and in spite of the effects both positive and negative upon humanity because of its belief, the idea of progress became an idea whose veracity was not widely questioned. Mankind continually assured itself of the reality of progress by publicizing the "advances" of the various arts, the sciences, the organizational and industrial capacities of society, and any other area it felt fitting. Each generation passed, relatively unquestioned, the idea of progress on to the next, not only as a means of justifying the activity of their own generation but also as a means of motivating the coming ones.

Thus mankind has come to take the idea of progress for granted, and while one may question the veracity of the idea, its overall influence in the history of mankind in the last 200 to 300 years cannot be doubted. 
The development of the idea of progress to the position of great social import that it enjoys is the result of the convergence of two trends, one ideational and the other social. The ideational trend can be traced through numerous developments: the reascension of the human individual into a place of prominence in the universal scheme of things and a greater place for the individual in the control of his own destiny; a basic redefinition of the nature of "history" and the historical process with history emerging as a linear process whose basic direction was in the hands of man; an increasing secularity and a rationality of thought derived from a fundamentally anticlerical movement in thought, the ascension of reason (1inked to experience) as a dominant idea, the revitalization of classic literature and thought, and the growth of science and the nature of the knowledge that it generated. The social trend was the rise to power of the bourgeoisie and was manifested in the utilization of the idea of progress, primarily by the French bourgeoisie of the 18th century, as a means of motivating and legitimizing the fundamental social changes involved. The idea of progress may thus be said to have achieved a position of importance as a result of (1) the existence of the idea itself that was a product of ideational changes that emerged in the Renaissance, and (2) the utilization of this idea primarily by the French bourgeoisie of the 18th century as a means of motivation and legitimation of fundamental social change.

While the French bourgeoisie was not the only social class; or society, to think about or have recourse to the idea of progress 
it was the French that had the opportunity and the need to make the greatest use of the idea of progress, and were able to make the most significant contributions to that idea. A symbiotic relationship was engendered between the needs of the bourgeoisie and the development of the idea of progress. The idea of progress aided the French bourgeoisie in their assumption of power and the social reforms that they were attempting to institute. Reforms such as an end to the deterimental affects upon the operation of the government and the economy of the Medieval based system of tradition and privilege existent in France, a change in the nature of the social hierarchy, and the introduction of a system of equal taxation for all members of society. The idea of progress also served as a means of justifying many of the social ideas that were gaining popularity and which tended to support the causes of the bourgeoisie. Ideas such as freedom, equality, and the value of effort and initiative. In turn the greater utilization of the idea of progress necessarily brought the idea ever more frequently into the public's consciousness, into their views of the present and the future. The result of this relationship was to thrust the idea into a preeminent position, a position that it has scarcely relinquished today.

The growth of the idea of progress from Seneca's first simple notion of the continued growth of knowledge to the complexity and power that it has achieved today is the result of a potential for such an idea, the growth found in the ongoing ideational changes, 
as well as a receptive environment and a bona fide need manifested by the French bourgeoisie. The ongoing movement of ideas had brought an idea of progress into reality (for example Bernard de Fontenelle's idea of the progress of knowledge and Abbe de Saint-Pierre's idea of the progress of society), but it was the utilization by the bourgeoisie that thrust the idea into its preeminence. The convergence of these ideational and social trends was Iike a seed falling upon fertile soil.

The direction of this thesis, in light of these two trends, will be to trace the paths of the ideational elements and changes that were influential in the development of the idea of progress, the social developments that were influential in the ideational development, as well as the social influences that placed the bourgeoisie in a position to utilize the idea of progress. 
CHAPTER II

GREEK AND ROMAN PERIOD

\section{GREEKS}

In The History of the Philosophy of History Robert Flint (Sklair, 1970:87) stated that practically all modern ideas may be discovered in some form in Greek and Roman thought. In light of such a sweeping statement, with particular reference to the reputation and aura that has developed particularly around Grecian though, it seems strange that the Greeks or Romans should not have more fully captured the spirit and the idea of progress. This is particularly the case in light of the great many advances in knowledge that they were responsible for and considering the "obviousness" that the idea of progress has assumed in modern thought. There are some individuals, Ludwig Edelstein (1967) for example, who contend that the Greeks did in fact have an idea of progress. What is offered in this thesis is not a denial of the possibility of any idea of progress on the part of the Greeks, but rather that any concept of progress could only have been a vague representation of that idea of progress that emerged in the 17th century, the one that has captivated modern man. The difference is exposed when one looks at the respective definitions of progress that are used. Edelstein used the notion of progress developed by Lovejoy and Boas (1965:6) which defined progress as: 
- . a tendency inherent in nature or in man to pass through a regular sequence of stages of development in past, present, and future, the later stages being--with perhaps occasional retardation--superior to the earlier.

The essence of this definition is the idea of developmental improvement, such an idea was no doubt an aspect of Greek thought.

Aristotle, for example, felt that the movement from the earlier more primitive forms of social and political organization to that of the polis was a change for the better. Edelstein mentioned numerous other "improvements" which were construed as examples of a belief in progress. With the idea of developmental improvement as the central core of a definition of progress then it much be accepted that the Greeks believed in progress, in some form. The point of importance though is that the idea of progress this thesis is operating under goes beyond the Lovejoy and Boas definition and includes a philosophy of history, a law of the development of history, a belief in the power of deduction drawn from history, as well as a belief that the movement of history was toward a better life, defined by some criterion residing outside the actual movement itself. The intellectual and philosophical foundations necessary for such beliefs were barely to be found, if at all, before the 17 th century.

Upon closer examination of the Greek culture it becomes apparent that there are a number of factors that mitigated the evolution of a concept approximating the idea of progress and embodying the elements just mentioned. The first factor that precluded such an idea was that while there was a great number of 
intellectual and practical advances made by the Greeks there was no long period of recorded Greek culture in which there had been a continual series of advances that might have suggested a trend line continuing into the distant future. Such a trend line simply did not accord with their experience. There had of course been advances but not with the rapidity and continuity which modern man was experienced and which solidified his belief in progress. In the periods preceding Greek culture important changes, discoveries, and inventions had occurred. Events such as:

- the permanent settlements of formerly nomadic
peoples; the creation of the empires of the river
valleys with their hydraulic engineering, their
mensuration and, soon, their writing; the metallurgy
of bronze and iron; or the introduction and extension
of slavery (Pollard, 1971:16).

These occurrences took great peridds of time and so the movement that they represented was too slow to foster a larger view of progress. There appeared no overall sequence or direction to such changes. Thus the point is not to deny that there existed change in Greek society or Greek history, only that the rapidity and extent of change that captured the imagination of the men of the 17th and 18th centuries was absent, both in the periods preceding the development of Grecian civilization as well as during the apex of Hellenism. Several other elements of Greek philosophy and the Greek mind in general precluded the idea of progress from developing fully.

One of the most telling factors was the general suspiciousness, though not total rejection, that the Greeks displayed toward 
change in general. Change, when it occured, was usually abrupt and external rather than inherent in the nature of things. This suspiciousness, which focused primarily upon the natural world, carried over into speculations concerning the social order. Plato in particular portrayed the Greek tendency to idealize that which was unchanging as displaying a higher value than that which did change. Under the Platonic conception the enlightened leader would establish an ideal order in society and any deviation from that order could only be defined as degredation of the ideal. The society must, if it was to stay viable, preserve as many of the institutions established by the enlightened lawgiver as possible. Even Aristotle, whose system of thought often conflicted with Plato's, felt that in the social order changes from those established by custom and culture should be as few and as slight as possible. While Aristotle did see the emergence of the Greek polis as a change for the better, he did not see that political change as entailing related growth in other areas, technology or human nature for example. Within such conceptions as these the seed of the idea of a civilization progressively advancing through ongoing change found meager nutrients for growth.

The connection between ongoing change in society and history has been one of the chief distinguishing factors between concepts of progress in antiquity and modern times. 1 "History" for the Greeks did not include a type of inquiry embodying a philosophical

1

History in the sense of a narrative of the past that it tied together through some organizing principle which gives it coherence. 
stance but rather dealt with concrete events, the "day-to-day struggles of cities and empires, good and bad rulers, in which some rose and others fell" (Pollard, 1971:16). History thus viewed had no sequence or direction that gave it a sense of continuity. Thus while the Greeks may well have had a belief in some connection between social change and history, that history did not approximate the modern idea of history as a coherent, directed, whole. The Greeks simply had no philosophy of history as it is known today, and that precluded them from using such a philosophy for interpreting the past, the present, as well as the future.

Another aspect of Greek thought that mitigated the evolution of an idea of progress was the primacy of the concepts of degeneration and cycles in civilization. These two concepts were often linked together in the belief of history as:

- . an endless series of cycles--an inevitable
regress from some golden age to a state of utter
despair and misery, and then just as surely society
would be regenerated and progress to the golden age
once more (Sklaix, $1970: 4$ ).
But while they might have often been linked together the concepts of degeneration and cycles were not synonymous. It was possible to have a belief in the degeneration of civilization while still not maintaining a belief in cycles. Such a belief would entail a conception of regress, that is, an onward movement of degeneration from a previously higher life with no provisions for the reascension of that higher life. Alternatively it was also possible to reject degeneration in the form of a long term regress from a previous golden age and still believe in the cyclical nature of civilization. 
These concepts of degeneration and cycles arose out of two great anti-progressive myths that go back to at least the time of Hesiod, the myths of the Golden Age and of Eternal Recurrance. These myths manifested themselves in various ways throughout Greek history, and even were in evidence to the time of Augustine. In an early belief the cycle of civilization would last approximately 72,000 years, in which the first 36,000 years would be a Golden Age where men lived simply but happily. The next 36,000 years would be a period of decline and degeneration. At the end of the 72,000 year period the deity that had created the universe in the first place would return, restore the original happy (but simple) conditions, and start the whole process over again. In this view the idea of Eternal return did not preclude the possibility of limited progress within any particular period. The Pythagorean belief in the cyclical nature of the universe, in Eternal Recurrance, was somewhat different than earlier conceptions in that each cycle was bound inexorably to repeat exactly what had taken place in the preceding cycles. There was no reason for the Pythagoreans why one cycle should be any different than the preceding one, this meant that "an endless number of Plato's would write an endless number of Republics" (Bury, 1960:12). With each period exactly like the precedilng periods the notion of Eternal Recurrance left no room for any human initiative that was innovative and new. The Stoics came to believe the theory of cycles where human civilization was periodically destroyed by alternating catastrophes of fire and flood. Following each catastrophe there was an age in which men lived in simplicity, gradually succumbing to luxury 
and vice, which led to the destruction of the world again. According to Marcus Aurelius (1956:140) a man of forty may be considered to have seen all that has occurred, and because of the cyclical nature of the world, all that is to come for "all things from eternity are of like form." Interestingly enough Plato puts forth a concept of the cyclical nature of things in Laws in which a theory of partially recurrent catastrophes was advanced as a means of reconciling what was seen as a contradiction between the metaphysical necessity of the perpetuity of the human race and the relatively recent origin of civilization. In surveying the period of history up to his own time Plato (1936:196) saw no clear cut case of progress or regress but rather societies "passing from better to worse and from worse to better."

A third factor that entered into the preclusion of the development of the idea of progress in Greek though was the concept of Moira. For the Greeks behind all of the achievements of human kind there resided divine supernatural powers, powers that were instrumental in the accomplishments of man. It would have seemed audacious, even dangerous, to the Greeks for men to take great pride in their achievements because they were not alone responsible for them. These supernatural powers that were thought to be luxking behind the advances of man were known to the Greeks as Moira. Moira has been defined in a variety of ways, the most applicable one sees Moira as destiny. This use of destiny meant a rigidly fixed order to the universe in which all must bow. Thus the achievements that man could produce were due to the "will" of Moira rather than to inherent 
creativity or productiveness. To conceive of mankind progressing toward the accumulation of all knowledge, or toward complete control over the events of human life, would have seemed nearly sacrilegious for it would have connoted a breaking down of the distinction between the mortal (man) and the immortal (Moira). When one combines all three of these factors of Greek thought it can be seen that they conditioned an attitude of pessimism about mankind and its relation to the flow of time and events in the universe. If change was most often viewed with suspicion, if civilization was condemned to continually repeat itself incessantly, and if mankind must do what Moira ordained, what basis was there for the birth of an optimistic spirit which motivated the idea of progress? It seemed that much of the Greek spirit was inculcated with the very antithesis of the progressive spirit. There was an exception to this particular tone of pessimism, one system of thought that seemed to come closer than any other Greek system to the necessary superstructure required for an idea of progress. The Epicureans rejected many of the generally accepted aspects of Greek thought; in particular they rejected the idea of a Golden Age of mankind from which there had been a steady decline. Besides discarding the idea of degeneration the Epicureans made a step toward the development of an idea of progress by the acceptance of the idea that man had reached the present state of civilization through a series of improvements in life which were brought about solely through the effort of mankind without supernatural powers. The Epicureans did not however extend this idea of civilization 
growing and progressing into the future, a necessary step for the development of the idea of progress, but thought of it as "simply one item in their demonstration that man owed nothing to supernatural powers" (Bury, 1960:20).

Such an exception to the generally. pessimistic tenor of the times was not to impact greatly upon the idea of progress for instead of a steady amelioration of mankind's plight in the future the Epicureans believed that the universe would eventually fall into ruin. So while Epicureanism differed in several respects from other systems of thought in the Greek culture it still was by no means an optimistic philosophy, but attended primarily to making living in this world as tolerable as possible for the individual.

Thus regardless of the great creative and original nature of the Greek mind it did not fasten upon the idea of progress primarily because of the pessimism that Greek thought engendered. While the Greeks did believe in the capacity of man to use his abilities to get along in the world, they were, in contrast to modern man, "never, by their achievements in art or literature, in mathematics or philosophy, exalted into self-complacency or lured into setting high hopes on human capacity" (Bury, 1960:17).

ROMANS

There was one person worth noting in the Roman period regarding the development of the idea of progress, that was Seneca (Marcus Annaeus Seneca, 54 B.C. - 39 A.D.). Seneca saw clearly 
that there had been increases in knowledge over the past history of civilization and expected that such increases would continue in the future. Seneca however did not assume that there would be any clear cut social advantages nor practical uses for the improvement of the world emanating from such an advance of knowledge, only more wisdom and the intrinsic pleasure taken from such intellectual activities. Any substantial optimism that might arise from these views was mitigated by Seneca's adherence to stoic philosophy. Seneca, in accordance with traditional stoic thought, believed in the corruption of humankind, and periodic destruction of civilization. In surveying the life and beliefs of Seneca it is possible to state that he fulfilled some of the prerequisites of the idea of progress used here while falling short on others. Seneca appreciated the fact that progress (or at least the "advancement" of society) took place in all fields of human endeavor, and that the moral, technical, political, and intellectual aspects of man were all involved. Seneca also believed in the future progress of man and speculated on it, a definite characteristic of a more modern idea of progress. While both of these characteristics place Seneca in the camp of modern man, there were other elements that returned Seneca to his contemporary milieu. Seneca did not relinquish his belief in the periodic destruction of civilization, which distinguishes him from modern thinkers who are open to the question of the destruction of civilization. The cyclical theory of history that was represented by Seneca's belief in the periodic destruction of civilization clashed with the linear view 
characteristic of modern thought and essential to the idea of progress. Another element was Seneca's lack of belief (or possibly even understanding) in the future as presenting the potential for an indefinite movement toward perfection. Finally, the idea of destiny or fate still pervaded seneca's view of history and the future. The course of events in the future was still in some measure up to the whims of the supernatural powers. In contrast, modern conceptions of progress rest upon an almost religious certainty about the inevitability of progress in the future, and the belief that the future is predictable on the basis of a rational interpretation of the past and the present. Thus regarding the idea of progress one should rightly place seneca above the men of his time in the ability to entertain the fundamental notions necessary for an idea of progress, yet very much a man of his time in other areas related to progress.

\section{SUMMARY}

In summarizing the relationship of Greek, and in the person of Seneca, Roman thought, to the idea of progress one must take account of the number of instances that could be marshalled in defense of the existence of an idea of progress in these early periods. 2 In spite of these instances however one is compelled to side with Bury in the belief that the idea of progress could not have arisen prior to the Renaissance. Robert Flint (Sklair, 1970; 9) stated this opinion: 
It was only with that radical change in the attitude, direction, and methods of thought, of which the Renaissance and the Reformation were first conspicuous manifestations, that the idea of progress could enter into the stage of development in which its significance in all departments of science and existence has gradually come to be recognized. 
MEDIEVAI PERIOD

The period of time from the passing of Rome and Roman power to what has become known as the Renaissance is commonly known in toto as the Middle Ages or the Medieval period. If one were to examine the wide spectrum of activity, social, commercial, and intellectual, that took place during this period it would be readily apparent that one term seems sadly inappropriate for the entire period. There were massive differences between the world of the 9 th century and that of the 13th century. The period as a whole though may be more readily understandable in light of two factors which were most responsible for its character. Those two factors were religion ${ }^{3}$ and commerce. These are not distinct but rather intertwined entities. The following discussion will disclose what influence they had upon each other as well as the influence that both had upon the total society.

\section{SAINT AUGUSTINE}

The greater part of the Medieval period was marked by the dominantion of Christian theology, with its powers diminishing only in a sense it must include Islam as well because of the influence of the Crusades and the influence of Islam upon them. 
during the period that preceded the Renaissance. In particular the period was dominated by the idea of Providence, the divine plan that bore a resemblance to the Greek idea of Moira. The Christian view of the world was much more "historical" than the Greek and Roman views. History was not simply the passage of time and events, ever to be repeated, it was the unfolding drama of a divine plan. History became linear in the sense that it acquired a beginning and an imagined end, it was no longer cyclical. The course of history was not an unfolding of events wrought by the hands of man but rather it was a series of events that were ordered by divine will and simply executed through individual human beings. This linearity of history and the concept of Providence are best expressed in the works of the celebrated bishop of Hippo, Saint Augustine (Aurelius Augustinus, 354-430), and it was the Augustinian view that most clearly was represented in orthodox medieval religious thought.

Development of Orthodox Christian Thought

In developing a conception of human history, Augustine dichotomized history into separate paths, one sacred and the other gentile. Augustine's sexpartite periodization of sacred history 4 was both convential and symbolic. It was conventional in its adoption of the long held popular milestones in sacred history. Augustine

\section{4}

These periods were marked by: Noah, Abraham, David, the Babylonian captivity, and Christ. 
could incorporate these popular milestones into his particular perception of history because historical periodization was not the primary intent of his work, it was rather the story of salvation that was the ultimate focus. The six segments of sacred history were also symbolic in the sense that they paralleled the six days of creation. For Augustine the sixth period, that marked by Christ, had begun and would continue until that future point when Christ returned. What came after the sixth period of human history would be everlasting bliss for those who were saved and everlasting torment for those poor souls not saved. Gentile history was of negligible interest to Augustine. It was divided into only two segments, that of Babylon and Rome. Their combined reign was to cover all of history. Augustine believed that the history of Rome would mirror that of Babylon, and so the fall of Babylon foretold the fall of Rome.

Augustine's perception of the purpose and duration of the history of man, the timing of its termination and the arrival of what came after, differed from many theologians of the time. Augustine's concept gained credence as the time of the predicted return of Christ and the supposed end to earthly history passed and life went on as usual. The Augustinian view was as detailed as any of the other perceptions but what set it apart was the fact that the timing of the end, the end of the sixth period and the beginning of the bliss (or torment) that was to follow ever after, was flexible. Augustine did not set a specific date, he only stated that Christ would return when the history of mankind had 
fulfilled the purpose that the creator had set for it, a purpose elaborated by Augustine in his work The City of God (412-427).

It was in The City of God that one not only finds the purpose and direction of human history but also it was in this work that the Augustinian notion of Providence could also be gleaned. Originally the City of God was a community of saints (or angels), a place where innocent men such as Adam (before his fateful indulgence) would have been admitted. However when the angel Lucifer "rebelled" he and his cohorts were cast into Hell which was part of the earthly city. When Adam committed his act of disobedience he paid for his sin by being sent to the earthly city as well. All the descendents of Adam (the whole of mankind in oxthodox thought) were condemned to live in the earthly city as well, prey to the intrigues of the outcast angels. Since many angels were cast out with Lucifer the number of angels in the City of God was depleted. The history of mankind was the time and the events that took place until the depleted angelic roll had been replenished by saints drawn from the earthly city. When the predetermined number of saints had been reached, judgment day would come. When that occurred the bodies of the damned would be raised, united with their souls, and then cast into eternal Hell. The bodies of the saints however would arise, be united with their souls, and then be reunited with the faithful angels that remained in the City of God. With the heavenly roll at full strength a timeless felicity would begin in heaven. According to Augustine (Manue1, 1973:29) after judgment day "the boundaries will be laid out of two cities: one of Christ, 
the other of the devil; one of good, the other of the bad; yet both made of angels and men." Until judgment day however both saints and sinners would live side by side in the earthly city, not knowing when judgment day came with direction they would be headed. The time spent in the earthly city until the judgment day came was a time spent in a life that was neither totally good nor totally bad. In a sense it may be said that in the earthly city the cities of God and the devil overlapped.

From this slightly oversimplified explanation of the City of God it is possible to understand the Augustinian perception of man and his stay on earth. Because of the original sin of Adam all mankind from thereafter had been marked as sinners, condemned to live in the earthly city as well. The time span of human history was the time required to redeem the correct number of souls, the correct number of saints. The direction of civilization, if it may be conceived as having a direction as opposed to simply being non-circular, was towards judgment day when civilization and history as such would end. While civilization was not really going "anywhere," it may be conceived of as linear in the sense that it had a beginning (Adam being cast out of the City of God), a middle (what had occurred since that event and what was still occurring), and it had an end (judgment day), moving inexorably from one to the other.

The conception of Providence that operated within the Augustinian perspective was exemplified by drawing an analogy between earthly life and a play. In this case God was the author, creator, and was the only one in the audience. In this play, as in any play, the actors merely repeated the lines that had been given to them. 
Each actor played but a small part in a great drama. What distinguished this from any other play was that the actors did not know how the play ultimately ended, they only knew that there was to be a tremendous finish. So in this sense the history of mankind was the drama of life that the Creator had written and directed, and only the creator knew the ending for all of the actors. For Augustine the great folly of mankind was to attempt to determine the course of the acts to come and the disposition of all characters at the final curtain. The disposition of each individual when judgment day came could not be determined from past history. Pain and suffering did not necessarily beget bliss and salvation anymore than a life of good deeds and comfortable living did. The only certainty was that the end would come and that a certain number of human souls would be redeemed to take the place of the fallen angels. One may say that the "script" of this great drama represented Providence, it carried out the will of God. In this sense Providence was quite similar to the Greek conception of Moira, a kind of guiding hand behind the manifold world. Though God knew what would happen he chose to carry out his desires through the wills of men. Augustine thought the individual should submit to what would come during his lifetime because it was the hand of the Creator that was guiding all action. The failures and the disasters that befall man, even the vile machinations of the devil, might seem to be deficiencies in God's power or violations of the total goodness that Augustine ascribed to God as a primary characteristic. But should the individual view these events in light of the overall divine plan it would be 
understood that they all had a divine purpose, that their evil or misfortunate character was only the result of the ignorance of man. Knowing that he was supremely ignorant of the divine plan the individual must place his faith in the eternally good and loving nature of God. To submit to all that would come in life, the good and particularly the bad, was Augustine's advice because he believed there was a divine plan behind everything that was working for the good of man.

Within the Augustinian view all people were sinners, immoral, without chance of redemption until God would take those to be saved into heaven. Thus strongly in the early Medieval period and to a lesser degree as the period went on there was a pessimism conditioned that rivaled that which was produced by the Greek concepts of change, degeneration, and Moira. It may in fact be said that the pessimism conditioned in the early Medieval period was even more overpowering than that of the Greeks, for while the Greek pessimism arose out of rational reflection on the nature of the universe the Medieval pessimism arose from the emotional resignation to the authority of the Deity and a deference to the divine plan (Providence). Where earlier periods of antiquity had been dominated by the idea of decline from a Golden Age, Medieval society had its idea of the apocalyptic end of civilization. Both provided the same lack of motivation to the individual. Medieval man spent his time in cultivation of spiritual needs in order to secure salvation in light of the early end of the world that they foresaw when Christ returned. Medieval man saw the existence of mankind as "a rise from a sinful 
fall to ultimate grace, saw the whole of terrestial history as merely an interlude between two forever unchanging eternities" (Pollard, 1971:19). He also saw that "God, who had created the world and determined its purpose, intervened actively in its running, and the purpose of man and of his history was to fulfill His commandments in the brief span of his existence within it" (Pollard, 1971: 20). Even within this brief period there was an ambivalence toward the historical process. In one sense it signified all that was bad and sinful, it marked the fall from heaven of both angels and men. History was the path ultimately to the judgment day, a path that was marked by suffering and corruption that could not be escaped until the last saint was "crowned" and all the saved were called "home." Yet at the same time the historical process was the period in which the grace of God touched man, a time when saints were recruited and the City of Godwas being prepared for repopulation. Viewed as a process itself, history on earth was "a narrative of miseries, and yet, viewed in the providential design, it conspires for the good, as willed by God for his creation-etiam peccata, even including sin" (Manuel, 1973:32).

\section{Influence on Period and Idea of Progress}

In light of these beliefs it was not surprising that there arose no idea of the progress of mankind. As long as beliefs such as original sin, the finitude of the earthly life, and the power of Providence were maintained there was no room for the widespread development of a dynamic idea such as progress. The eschatalogical 
veil inherent in the Christian, particularly Augustinian, view of the world descended like a dark cloud over the medieval individual precluding the necessary belief in the future prospects of mankind. and the power of the individual that are necessary for the development of the idea of progress.

While it is true that the Greek theory of degeneration of civilization was maintained in form by the Christian belief in original sin and the fall from grace, at least the cyclical aspect of Greek thought disappeared. Christianity introduced the idea of sequence to history, even though that sequence only included the short "interlude between two forever unchanging eternities" (Pollard, 1971:19). The Christian notion of sequence represented at least a germ from which the modern conception of history and progress could spring. But if Christian thought was more aware of history as a movement of events towards some definite end, a movement with some coherence, it was at the same time aware of the impossibility of real secular change. 5

This should not leave one with the idea that the Christian view precluded the possibility of change for the better whatsoever. There was a belief that the secular conditions of man had noticeably improved with the ascension of Christianity. The point being that secular conditions could never be obtained on earth that would in any way approximate the paradise of heaven. In fact there was a concerted effort to discourage extensive attempts to reform secular 
life for fear that such actions might distract men from the quest of spiritual salvation. The motivation for Augustine's The City of God may provide an excellent example of this. ${ }^{6}$ Theodor Mommsen (1951: 346) contended that a school of Christian scholars had arrived at the view that the mission of Christ had not only been to provide salvation for the next world but also to provide a happier life in this world. Confirmation for this belief was drawn from the security and civilization of the Roman Empire since the coming of Christ. Augustine objected to this belief for two reasons. The first being that such a belief tended to confuse mere secular happiness with the eternal bliss to be found in heaven. The second that such a belief tied the Church too closely to the changeable fortunes of worldly empires. 7 Augustine felt that the decline of the Roman Empire would, given such a tie between the Church and the Empire, threaten the credibility of the revealed Word. For Mommsen then The City of God was written expressly to combat the idea of the ability of the secular, mundane, world to progress. Instead of concentrating upon a secular progress, which would never bring real or lasting happiness, all individuals should take care to prepare themselves for the imminent end of this world.

\section{6}

I say "may" here because the motivation which drove Saint Augustine to write the book is still a point of conjecture.

7

It should be remembered here that Saint Augustine posited that the history of Rome would follow that of Babylon, thus attempting to foster the belief in the necessarily transistory nature of the Roman Empire. 
To reiterate, while the linear philosophy of history that was the Augustinian view was couched in beliefs with religious processes and with religious goals, the point remains that it provided an excellent structure from which secular philosophies and secular histories developed. The idea of progress is above all a philosophy of history itself and the ground breaking role of medieval, that is Augustinian, theology in elaborating this particular perception must not be overlooked.

It was the second of the two intertwined factors, commerce, that comprised the truly dynamic element in medieval history. The death and rebirth of commerce played a great part in medieval history and was the cauldron from which great change emanated, change that is still being felt today. This rebirth marks the break between the bulk of medieval history and the latter more dynamic period of its history.

\section{MOSLEMS}

\section{Control of the Mediterrean Sea}

From the time of the earlier civilizations the Mediterranean served to nurture the needs of those who lived on its borders. It served as a means of travel, communication (both of material and nonmaterial elements of culture), and of course commerce. Even after the Germanic invasions and the decline of the Empire the Mediterranean continued to play its important role as the highway that linked the various civilizations that ringed it, from Asia Minor to the Iberian Peninsula. The accessability of the Mediterranean to the West was 
abruptly interrupted in the 6th century when the expansion of the Moslem world resulted in the capture of the eastern, southern, and western shores of this essential souxce of social intercourse. With the exception of the Aegean and the Adriatic Seas and the southern coast of Italy from which the Byzantine navy had managed to repulse the Moslem incursion, the Mediterranean was closed to the societies of the West. While the economic structure of the West had survived the downfall of the Empire and the Germanic invasions and occupation, the blow wrought by the Moslems spelled the death knell for European commerce. While the outermost ports of the Byzantine Empire on the Italian Peninsula traded rather consistently with the Moslems in the lands around the Mediterranean, the hatred between the Christians of the West and the Moslems of the East kept these two civilizations in a constant state of war.

\section{Loss of European Economic Vitality}

As a result of this antagonism and the closure of Mediterranean trade the merchant class and the urban life that it had fostered disappeared in the 8th century. Cities, particularly the Roman cities, where Church administration was centered continued to exist, but the economic and municipal functions that in the past had gone hand in hand with the ecclesiastic functions were now lost. Though the populace of the north of Europe was not as strongly affected by the closure of the Mediterranean as that of the south and the west were, due to the trade that was carried on in the Baltic area, there nevertheless arose a general impoverishment of the entire European population. 
As a result of the collapse of trade and commerce and the near disappearance of most towns by the end of the 8th century a society largely based on agriculture returned. Land then became not only the source of subsistance but the basis of wealth as well. With the merchant class gone and artisans, with the ability to support themselves from the sale of handiwork, declining as well, an individual's social and economic condition was determined by his relationship to land. The possession of land guaranteed freedom from want and servitude, but the great majority of land was in the hands of a minority of lay and ecclesiastical landlords. The lot for the rest of the population was the use of the land owned by this minority at the price of freedom. Such "tenants" tilled the soil owned by the landlord in exchange for duties that were to be owed and privileges ${ }^{8}$ that could be exercised. In such a relationship the tenant was both protected by the landlord as an obligation of ownership and exploited by the landlord as a prerogative of that same ownership.

The return to an agrarian society, the reliance upon the soil for sustenance and wealth conditioned the return of the large estates that had been seen in earlier times, during the Empire and even before in Gaul. In earlier times the large estate had sufficient production, capabilities of transporting that production, and markets outside of its own confines such that it constituted an element of trade and commerce, selling to and buying from the outside world. But with the return to the estate this reciprocity ceased, there simply were

8 and death.

These privileges often included literally the power of life 
no markets for commerce. The estates were thus forced to become selfsufficient economies, supplying everything needed from tools to clothes.

\section{Rise of Feudalism}

The return to an agrarian society with all wealth and power contingent upon the land, the subsequent return of the large estate as a fundamental social foundation, and the fragmentation of society conditioned the feudalism that has so persistently characterized the Medieval period.

The philosophy of life that was embodied in Christian orthodoxy played an important role in the structure of feudal society. Feudal society was a very structured one; the structure being organized around the relation of men to the land. Within the hierarchical arrangement of feudal society the Church was at the apex, both because it was a large land owner ${ }^{9}$ and also because of its preeminent moral role in society. Because of the unique role it played in society the Church was also beneficiary of some important powers and privileges in the troubled feudal times. Due to the contributions made to the Church by its followers and the alms that were left by travellers the Church was nearly alone in the possession of sufficient wealth that in times of scarcity it was capable of lending to the needy. Perhaps more importantly, the Church was the seat of learning and literacy. Because of the stagnation of the general populace in the Medieval period the education of the masses nearly disappeared. It

9

The Church, taken as a single unit, owned more land than aid the nobility. 
was the Church that kept alive the powers of reading and writing. When the nobility or the secular state sought competent men to administer their affairs it was from the Church that they had "to recruit their chancellors, their secretaries, their 'notables,' in short, the whole lettered personnel without which it was impossible for them to function" (Pierrene, 1937:12). During the period which spanned from the 9 th to the llth centuries the administration of government was, de facto, carried out by the Church.

Whether by coincidence or by adaption the Church's perception of social dynamics and its conception of economic functions was particularly fitted to medieval society and the static agricultural economic structure that characterized it for a great period of time. For the Church the economic life of the individual (or the economic life in general) was subsumed under the real business of life, namely salvation. Economic activity was thought to be an aspect of personal conduct, and as such the rules of Christian morality were applied to the commercial life. Economic motives were thought by the Church to be very powerful appetites, and like such strong passions in other areas of life, had to be dealt with through repression, both by the individual and the Church as a unified body. This perspective of economic activity by the Church did not preclude men from engaging in economic activity, for it was considered right that the individual seek wealth as was necessary for his station in life. However, wealth beyond that which was necessary for a livelihood, wealth beyond wages for labor, was considered avarice and thus sinful. Poverty was of divine 
origin, 10 wealth might well be a hindrance to salvation. Economic activity seemed to the Church to be questionable in direct relation to the pecuniary motives that were commonly associated with the various phases of commerce. As Tawney (1954:37) stated "labor--the common lot of mankind--is necessary and honorable; trade is necessary, but perilous to the soul; finance, if not immoral, is at best sordid and at worst disreputable."

The medieval Church's perception of the world and its commercial activity was firmly grounded in the peasant agriculture of the period, firmly grounded in piety, asceticism, poverty, and even the rigid stratification that guaranteed order and tranquility. The harmony between the model social structure espoused in Christian theology and the actual world should not come as a surprise because the Church was only justifying and supporting a structure in which it was among the first to benefit. The Church was in want of nothing, it had enormous holdings of land, it had perhaps more financial power than any other group, and it played a central role both in the spiritual and secular worlds. So strongly did the Christian outlook impress itself upon the minds of men that it took them "centuries to grow used to the new practices demanded by the economic revival of the future and to learn to accept as legitimate, without too great a mental reservation, commercial profits, the employment of capital, and loans at interest" (Pirenne, 1937:14).

10

This belief strays somewhat from orthodox Augustinian thought for he believed that neither the good life nor the bad life on earth truly indicated the chances of one entering heaven. 
While the demise of commerce had all but destroyed trade and urban life in Europe and the influence of Christianity meant a domination of the concern for salvation, the Moslem world provided a great contrast. It was alive with trade, travel, and intellectual activity. While the intellectual activity of medieval Europe was almost exclusively given over to scholasticism and the rather restricted domain that it entailed, the Moslem world made many advances in a variety of intellectual and practical areas. They made advances in the study and treatment of diseases, advances in the science of optics, chemistry, and mathematics, in historiography and geography, as well as an immersion in a much broader spectrum of Greek and Roman philosophy. A fundamental difference in the two cultures may be found in the greater secularity of Moslem thought, that it, a greater concern for finding a satisfactory life on this earth. Philosophy, science, and the arts were geared to show the way to a successful and satisfying life rather than a sanctified death. In short, it was the difference between a concern for life here or in the hereafter. The secular foundation in thought had been lacking in the West since Christianity became a dominant force. The emergence in Europe of those aspects of the social structure, of the commercial and intellectual activity that charactexized the late Medieval and Renaissance periods began with the fertilization of European culture by elements of the Moslem culture. As the cause of the decline of urban life and the sedentary nature of medieval life had been the closure of the Mediterranean sea to European trade so the emergence of vitality and change in Europe 
was also fundamentally the result of the gradual reestablishment of that trade. Even during the period in which the West was denied the use of the Mediterranean for commercial activity the Venetians had been able to continue to maintain their commercial enterprises through the trade that existed with the Byzantine Empire, for as it was mentioned the Byzantine navy had been able to maintain control over the Adriatic and Aegean Seas. From the 9 th century on the Venetians renewed trade relations with areas in Africa and Syria even though these areas were now in the control of the Moslems. The love of gain had great sway among the Venetians, leading them to trade without regard to with whom they were dealing and without regard to the nature of their trade. Timber and iron for example provided profitable trade, even though there was little doubt that those products would be used to build ships and to forge weapons that would be used against the Venetians themselves. On the othex side of the Italian Peninsula the cities of Pisa and Genoa, seagoing traders in their own right, sought to free themselves from the yoke of Moslem influence, but unlike the Venetians they hated the Moslems and sought to forcibly expel them from the Tyrrenhian Sea. By the Ilth century they had succeeded in liberating the Tyrrenhian Sea.

\section{CRUSADES AND REVIVAI OF EUROPEAN VITALITY}

When the Crusades to liberate the Holy Lands began it was the Venetians, and to a lesser degree the maritime concerns of Pisa, Genoa, and the regions of Provencal and Catalonia, who were capable 
of transporting the Crusaders east. After the First Crusade, Frankish states were set up in Syria, ${ }^{11}$ and with the protection afforded by them and the vast needs of the Crusaders, trade flourished between Syria and the West. Ships would haul one type of cargo from the West to the crusaders and a different type from the East back to Europe. In supplying the Crusaders and bringing trade goods back the traders grew wealthy, investing that wealth in more ships and established permanent trading colonies in the East.

As a result of the offensive taken by the navies of Pisa and Genoa, by the attack upon the Moors in the Iberian Peninsula, and of course by the crusades themselves in Syria, the latter 11th and early 12th centuries saw the Mediterranean Sea again open to commerce and navigation for all. Even the Moslem counteroffensives in the 12th and 13th centuries which expelled the crusaders and crushed their kingdoms did not threaten the viability of the Mediterranean again. The expulsion of the Crusaders and their subsequent return to Europe only served to boost the demand for goods from the East. In returning the crusaders brought back with them a cultivated taste for goods grown or made in the East. This cultivated taste and the superior craftsmanship evident in the Eastern goods spurred an increase in trade with the East. Such trade could continue in light of the return of Moslem control because the Moslem counteroffensive was instituted only on land, an attempt to recapture the Mediterranean was never initiated. The Moslems also realized that trade with the west could only serve to strengthen their own economic 
structure. Spices and other commodities that arrived from China and Mongolia became part of regular commercial traffic to the West.

The renewed vitality of the shipping trade in turn stimulated industries in Europe that had been lying dormant or, as in the case of agriculture, had not been traded beyond the local area. This stimulation of the commercial activity by maritime industries spread inland from the important centers of trade. Northward through Provence into wider areas of France came the commercial stimulation from the ports of Marselles, Genoa, and Barcelona. It spread west from Venice through St. Bernard Pass into the valley of the Saone and north into Germany via the Brenner Pass through the Rhine Valley. Contemporaneously with the gradual revival of commerce in the Mediterranean area had been events in the North Sea and the Baltic Sea area that had kept a modicum of trade existent such that the revival taking place in the south of Europe was being mirrored, though varying in character and extent, in the north of Europe. Trading colonies were being established, commercial centers were forming in the estuaries of the Rhine, the Meuse, and the Scheldt rivers. Thus in a northerly direction from the Mediterranean and at the same time in a southerly direction from the North Sea and the Baltic sea a revival of comercial activity was beginning to sweep over Europe, bringing with it social change. The most notable of the changes that accompanied this revival was the rebirth of cities and towns. As the death of commerce had spelled the death of the towns so the revival of commerce supported those factors that arew people to the towns again. While the coastal areas of the North Sea and the Baltic Sea on one side and the Mediterranean Sea on the other saw the growth of ports and trading 
centers, for they were the first to feel the increased tempo of trade, deeper in the heart of the continent towns were also being repopulated or forming anew. Forming most often at junctions of trade routes, where a change in the mode of shipment was necessitated, or in areas rich in a particular resource. Towns offered shelter and protection to the merchants and provided a point at which both market and merchandise met. The protection and the market attracted more people to towns, which in turn attracted more commerce, and the cycle went on. Often the commercial section of a town would blossom outside the wall of an old fortress city, soon exceeding the size and population of the old city.

Release, Individuation, and Secularism

The revival of commerce, the repopulation of towns, the rise of a merchant class, and the quickening pace of life that accompanied these changes were not simply quantitative changes of medieval life but qualitative changes as well. There were substantial changes that emerged in the outlook that men had concerning their lives and their relationship to this world. There were three main processes that animated these changes; release, individuation, and secularization (Becker and Barnes, 1961a:263). All three of these in some manner can be connected to the renewal of trade, in particular trade with the Moslem world. The contact that occurred between the East and the West was a result of the Crusades primarily, but also was due to some degree to the trade relations that had been cultivated by the Italian maritime cities. 
When speaking of the process of release one must start with the fact that medieval society was highly organized and structured yet relatively isolated. As new elements were introduced into European culture, rigidity began to give way to variety, customary modes of action and thought were gradually supplanted by the new. Under this influence the persuasive force of accepted customers diminished, and a mental mobility arose from the contact of varying and sometimes contradictory ideas. The critical activity of thought that was stimulated resulted in a sense of "release," of an expansion and a liberation of heretofore restricted thought. People were willing to try new things, whether those things were foods, material, or scientific and philosophical thought. It may well be that the highly structured character of medieval life had made such a period of release inevitable, that the trade with the Moslem world was just one of many possible catalysts for such expression. However, regardless of its cause the sense of release helps to explain the vitality that became invested in the economic and eventually social changes that occurred in the late medieval period.

The process of individuation was closely related to the process of release. The changes mentioned above had broken many of the traditional ties that had bound men to the land, to the local area, and to their Church. The psychological sense of release was mirrored in the individual's willingness to attempt to escape the traditional station of society into which he had been born, and in which it was previously thought he would die. The freedom that men began to enjoy with the breakdown of traditional roots was manifested in a willingness 
to exercise personal initiative and individual action, that is, to take control of their own lives. During the commercial revival it was not unusual to find common men with only a modest investment taking advantage of some trade inequality to gather a large amount of wealth and prestige. This individuation was also manifested in the willingness of men to leave home and strike out as a seaman or as a traveller. The emerging sense of liberation and freedom and the personal exercise of it went hand in hand.

The third aspect or process that operated during the revival of commerce, and one that has continued to the present, was secularization. At the beginning of this juncture in time the west was essentially an isolated Christian society. From the beginning of Christianity, and particularly since the time of Augustine, the overwhelming focus of Christian life was salvation. All other earthly concerns palled in the face of the question of salvation. As a result of this milieu and the persuasive power of the Church, religion controlled all other areas of life, the arts and the sciences as well as the everday expression of life. This influence was particularly felt in the sciences, the facts of this world had to correspond with the accepted view of God, His creation of the world, and its operation under His guidance. At mentioned earlier, the Moslem world operated under'a much more secular approach to life. The concern of science and philosophy for example were the attainment of the most satisfactory life that could be attained here on earth rather than how to live in order to die with salvation guaranteed. 
Perhaps the most influential factor in this secular pose was the great degree of tolerance that was manifested, particularly in the Abbasid Dynasty, towards a variety of human expression. Though Moslem religious practices had their influence over the lives of the individual, 12 he was on the whole accorded a much greater latitude in the scope and variety of his thought. As a result of this, one saw advances in many fields (notably medicine, chemistry, and mathematics) that were essentially stagnant in medieval Europe. The freedom of thought also allowed the translation and study of many Greek and Roman authors that were unknown or little read in the West.

As the contact between the West and the East increased as a result of the Crusades and the growing trade between the two civilizations, the influence of the Moslem view of life and how to approach it began to be felt in the West. The returning Crusaders brought back with them habits and tastes that they had encountered in the East. But they also brought back with them ideas that they had been exposed to, ideas of science as well as ideas of life. At first the ideas and the merchandise only amounted to a trickle, but as more individuals were exposed to new cultural traits, as the Moslem science became accepted as a better way of looking at the world, and as the process of release motivated more people to experience these new elements and experiment on their own, the material and non-material elements from the East began to flow in ever greater amounts into the west. The inherent secular nature of as such bans as those against the study of anatomy. 
many of these elements in addition to the response that the resultant social changes generated, most of which went counter to the accepted orthodox proscriptions of the Church, had the effect of breaking down the power and the influence that the Church exercised. This in turn aided the growing sense of individuality and freedom of thought and action that were growing in Europe.

The processes of release, individuation, and secularization generated changes that were to launch Europe into a new direction. It is interesting to note however that these influences began to operate at the same time in which the religiously organized society of Europe was reaching its acme. With the Moslem as the common foe the Christian world had been able to generate a unity, and in a sense an integration. The power of the Church had grown steadily in the preceding years. The Crusades had also provided a viable outlet for a certain amount of restlessness that existed in the sedentary society of medieval Europe. But what the Crusades also did was to bring the "infidel" back home and the sacred society of the earlier medieval period was never to be the same. 
CHAPTER IV

RENAISSANCE PERIOD

The growth of the urban areas, the decline in the power and extent of the feudal system, the expanding influence of commercial activity, and the increasing secularization of all aspects of life interacted to condition a disenchantment with the ideals that had operated in the Medieval period. The religious milieu that had dominated all aspects of life was no longer sufficiently attractive to maintain voluntary adherence nor powerful enough to coerce it. This disenchantment came forth initially in the maritime cities of Italy, those places which had been the vanguard of the initial changes in the Medieval period. Men began to look elsewhere to replace their religious ideals, look elsewhere for guidance and council. The period of change in society that grew from this disenchantment and search for other sources of guidance has become known as the Renaissance. It is important to realize that much of the changes in society, in art, literature, and scholarship, that have been attributed to the Renaissance were simply the continuation of changes that first emerged in the late Medieval period. In fact, the idea of delinating a point at which the late Medieval period ends and the Renaissance begins is a misconception. It was not until the latter part of the Renaissance that genuinely innovative and ground-breaking thought began. 
The Renaissance represented a period of transition between the mode of thought existent in the Medieval period and that of the latter 17 th and 18 th centuries. It was in many respects a progressive period in which the trends that first emerged in the Medieval period matured and developed. While conceiving of the Medieval period as a stultifying and unanimated time the Renaissance men looked to other periods of human history in which the human spirit had been allowed to soar, soar to heights of experience from which they had since been kept for centuries. It was widely believed that the ancients $^{13}$ represented the acme of wisdom and consequently the study of classic literature and its authors was undertaken as an attempt to revive the type of educated and cultured individual that lived in ancient Rame.

HUMANISM

Perhaps the element most readily associated with the Renaissance was the emergence of the humanist movement. The humanists were directly connected with a resurgent interest in and veneration of the ancients. The term "humanism" was derived from the phrase "studia humanitatus" 14 that had been used by Latin authors and scholars to mean a liberal education. By the 15th century the humanities included the study of history, grammar, rhetoric, poetry,

\section{3}

The term in general refers to the Greeks and the Romans. It is a term that will appear with much greater force in the 17th and 18th centuries where it becomes a part of the "battle of the ancients and the moderns."

${ }^{14}$ This may be translated into the more modern term of "humanities" as it is known in the educational realm (Wallbank, et al., 1960:439). 
and moral philosophy. Thus through the power of the humanist movement, and the later proclivity of man to view humanism as the essence of the Renaissance, one of the defining characteristics of the Renaissance became the renewed interest in the work of the classical Greek and Roman authors.

Veneration of "Ancients" and Revival of Classic Culture

To speak of the renewed interest that was shown these authors is not to intimate that the study of the classical authors was an entirely new subject to the men of the Renaissance. During the Medieval period the works of Aristotle, Vergil, Cicero, and Caesar were well known, but they were almost exclusively interpreted within the framework of Christian theology. Despite their inherent pagan character many works of the classical authors, in particular Aristotle, were convoluted to the point where they could be used to support elements of Christian dogma. This resulted in much distortion and misunderstanding of their work. What represented the new element in the interest of the humanists was the desire to rid themselves of the Christian framework and attempt to know and understand these works in the essentially secular, and pagan, tone in which they were written.

Functioning partly as a cause and partly as an effect of this renewed interest in classical thought was the discovery of unknown or forgotten old manuscripts. As interest in the ancients rose, monastic libraries were combed in the hope of uncovering literary treasures that had been filed away and forgotten. In addition to these treasure hunts, precious manuscripts of Greek authors were 
brought to the Italian cities from such places as Constantinople. It should be remembered that the Moslem countries had, even during the most stagnant times of the Medieval period in the West, maintained a library of Greek works of far greater depth and variety than any that had lexisted in the West. By the 15th century most of the important Latin authors were available, and by the beginning of the 16 th century both the works of the Iatins and the Greeks were available to the Welst. Secondary benefits that accrued from the interest in and the discovery of old manuscripts were the emergence of critical scholarship necessitated by the task of identifying and organizing these works, and the emergence of works of grammar and dictionaries that were the result of the task of interpreting the manuscripts.

The fact that the printing press made it possible to disseminate classical works to an ever wider audience contributed as well to a renewed interest. The wealthy had always been able to own books or collect old manuscripts, but with the printing press there was created a much wider base of interest in the ancient works. But any great influence attributed to the printing press in the dissemination of innovative or enlightened aspects of Renaissance thought must be tempered. The great majority of books that were printed in the first century or so after the invention of the printing press were religious in nature rather than secular or scientific. The printing press was usually so severely censored that new and divergent material was rarely published until long after its invention. It was not until the 16 th and 17 th centures that scientific material began emerging in publication. 
In their veneration of the Greeks and Romans the humanists attempted to cultivate the habits of thought and expression associated with them. They attempted to make their own life as much like that of the Greeks and Romans as they could. This meant the acquisition of a certain clarity and elegance of literary style. Where much of the literature of the Medieval period was devoted to symbolic expression of themes (most often religious), the secular, and somewhat more "earthy," style of classical works represented a clarity in a more straightforward and less symbolic style. The influence of the ancients found its way to the more visual arts as well, and it was in the arts of sculpture and painting, particularly of the Italians, that the sentiments of human expression associated with the Renaissance are most vividly found. The arts of sculpture and painting partook of the renaissance of classical culture because with the rebirth came 1) the utilization of a more natural subject matter, the human figure from live models for example, 2) a more developed sense of harmony and of grace, and 3) technical improvements such as the establishment of the laws of perspective.

The veneration and emulation of classical thought and habit also fostered a greater sense of dignity and freedom for the individual. The importance of $\operatorname{man}$ and his place in this world were ideas that gained credence as. well. Medieval life had stressed the importance of salvation over the pleasures of life; it had viewed the everyday life as a source of evil and sin, something to be tolerated but not relished. As Symonds (Harding, 1920:303) stated: 
Beauty is a snare, pleasure a sin, the world a fleeting show, man fallen and lost, death the only certainty; ignorance is acceptable to God as a proof of faith and submission; abstinence and mortification are the only safe rules of life: these were the fixed ideas of the ascetic medieval church.

The individual played a minor role in society, both in its conceptualization and in its functioning. It was the guild, the commune (or town), and above all the Church that were the foci of life. The basic humanistic approach was to encourage expression where the Medieval milieu had sought to discourage it. The humanists saw something of value in the ancient's desire to write about the joys, sorrows, and adventures of this world, and they sought to emulate this by encouraging the writing about personal experiences of this world and by giving support to the exploration of one's own personality and the emotions resident there. Petrarch (Francesco Petrarca, 1304-1374), often labeled the "father of humanism" (Wallbank, et al., 1960a:449), portrayed these tendencies very well in his poetry and his famous work Ascent of Mont Ventoux (1336).

The increased concern with the individual, the impetus to expand the human experience, and the results that came from these movements conditioned in the Renaissance an increased confidence in human powers (vis a vis Providence) and reason, albeit a confidence that was initially based upon art and literature rather than some rational science. This strong sense of confidence also fostered the belief in man's power to deal with the problems that existed in "this" life. Man was capable of anything if he would simply try. While the humanist movernent and its veneration of classical authors did much to foster the sense of individuality and of human 
power, its acceptance of the superiority of the ancients led to the retracing of paths that had already been trodden instead of attempting to strike out on their own. While they condemned the Medieval period for the restrictiveness it manifested, the Renaissance in its preoccupation with the classical works constructed its own boundaries. Humanist scholars and literary men were often so concerned with accurate reproduction and manipulation of classical form that content suffered. The emphasis was on imitation rather than creation. Even when the scholars attempted to break the shackles of their medieval training and heritage they were only moderately successful for the "terms employed in philosophical discussion, the problems posed, and the characteristic solutions remain(ed), in basic outline, Aristotelian" (Gilbert, 7, 1967d:177). The most optimistic of the humanists hoped at best that the new phase of culture and knowledge in which they were participating might "rival that of classical antiquity. in brilliance, learning, and glory" (Boas, 1962:9). Equal yes, but not surpass.

As a result of this zealous belief in the perfection of the past many of the best minds of the period were engaged in studying, criticizing, and elaborating knowledge and beliefs that were centuries old. 15 In addition veneration of the past led many to hold ancient dogmas and prejudices that had lain dormant in the intervening centuries. A good example of this was Niccolo Machiavelli

15

For example, Giovanni Boccacio (1313-1375), perhaps most noted for Decameron, gave up writing prose and poetry in his native Italian to study the ancients, funneling his talents into such work as an encyclopedia of classical mythology. 
(1469-1527). Machiavelli was undoubtedly one of the best minds of the Renaissance, but his ideas and beliefs showed clearly the influence of "ancient" thought. For Machiavelli the movement of human society, apart from certain differences that he saw existing between one part of the world and the other, had always been fundamentally the same. Human society was in continuous motion with some segments advancing and others declining, while one segment reached its apex and began to decline, another reached bottom and began to ascend. Events within one phase of this cyclical motion would correspond to events in the same phase at another time, thus events in the advancing phase of society in ancient times would correspond to events in the advancing stage of modern society. This correspondence was for Machiavelli the result of the fact that throughout the course of human history man had been subject to the same passion and vices. Thus the cause of events in human history and their effects corresponded between different periods because human nature remained steadfastly the same. The cyclical nature of history and the permanence of human nature made the study of history of vital importance for it allowed men to see the future by studying the past.

Another Machiavellian belief that connected him to the past was the belief that the best organization for society was that which had been designed by the wise legislator, the enlightened lawgiver. The enlightened lawgiver built such a plan upon the unchanging nature of the human spirit, consequently what was good for one generation must be good for another. While any plan for a particular social organization was good only for a specific period, due to the 
fact that all societies are finite entities in a state of constant rise and fall, the greatest survival value for a socięty was found in the adherence to the original plan with as few exceptions and alterations as possible. The connection in both of the preceding examples between ancient Grecian thought, Plato in particular, and that of Machiavelli is unmistakable. In both instances history was considered cyclical, human nature immutable, and change most often represented corruption.

Thus in Machiavelli there existed an example of the prejudices of the Renaissance period; prejudices that were brought forward through the adoration of the "ancients." They were prejudices that for a second time blocked the emergence of the idea of progress. The Medieval period's belief in the power of Providence, the value of the after life, and the inability of man to control his own destiny, had successively blocked the emergence of the idea of progress. With the decline of the idea of Providence and the concomitant rekindling of a belief in the power of mankind that came with the Renaissance movement, the obstacles impeding the growth of the idea of progress were seemingly removed. But like a ghost that had arisen from the dead the very ideas that had precluded the idea in the ancient periods of Greece and Rome, the negative value of change and the immutability of human nature, came forth again to block the idea of progress.

Many of the changes in thought that had captured the hearts of the artisans and the writers, that life on earth had value, that man could arrive at a more natural state both with the world and himself, 
and that man was capable of and ought to control his own destiny, did not find equal fruition in the hearts and minds of the scholars, philosophers, and the scientists. It would seem surprising that the humanist movement should not also be the starting point for the numerous and far reaching scientific changes that occurred from the 16th century on, however its fundamental inclination was not scientific at all but rather mystical and pagan. The humanists were much more inclined towards ancient works that dealt with aesthetics, with the emotions and sensibilities that had for so long been submerged in the Christian world; much more inclined to be interested in the woxld of Platonic and Neo-Platonic writers than the scientific world of men such as Aristarchus and Archimedes. However while one would be mistaken to attribute a direct influence of the humanist and early Renaissance in general to the scientific advances that followed they did ultimately contribute to that advance in an indirect manner. Though they may have preferred aesthetical to scientific writing the thorough search for ancient manuscripts of all kinds did result in the discovery of scientific works by early Greeks that displayed more modern scientific approaches than those of most Medieval scientists. In an oblique way, by reviving the interests in the secular world and a secular orientation to life the humanists were important contributors to the emerging social milieu that found value in the work of the scientists.

It was the history of the latter part of the Renaissance that the emancipation of the human spixit took hold in philosophical and scientific thought as well and that the classicism that had served 
as the channel marker for emergence from the Medieval period was surpassed and thinking men turned to the open seas and charted their own course.

\section{RISE OF MODERN SCIENCE}

During the 16th century there began a movement in rebellion against the absolute authority of the ancients; a movement that represented a belief in the progressive movement of human knowledge. During this period one finds Copernicus challenging the authority of Ptolemay, Vesalius challenging the authority of the great Galen, and perhaps most importantly, Giordano Bruno and others attacking the Medieval, Aristotelian, system of scientific thought. The main technique of such science had been to "start from propositions of the highest order of generality and then, assuming their incorrigibility, to deduce propositions of lower generality from them" (Jones, 1969c: 77). Thus what had passed for true scientific explanation in the Medieval university had often been little more than semantic manipulation. Others as well as those mentioned were the harbingers of a revolution in the study of natural phenomena, harbingers of a new science. It was a science that actively sought in natural phenomena the answers to the mysteries of the universe; and it was this scientific viewpoint that marked the real movement away from the influence of both the ancients and the Medieval period.

Seeking the answers to the mysteries of the universe in natural phenomena was only a part of the revolutionary aspect of this new science. Perhaps the most revolutionary aspect was the new 
function which this science attributed to the powers of the human mind. The rigidly organized terrestial world and the various spheres of the Aristotelian heaven gave way to an infinity of worlds, worlds that were:

- . constantly springing from the womb of becoming, each one of which embodies but a single transistory phase of the inexhaustible vital process of the universe. (Cassirer, 1951:37.)

But how was it possible for the mind to comprehend that infinity? Not by attempting to equal or parallel that infinity but by using the mind's power of reason to come to an understanding of that infinity and by an understanding of the all-inclusive law that animated the infinite process. It was the discovery, or the formulation in thought, of the universal law that provided the mind with the cognitive correlate of the cosmological infinity.

The new concept of nature and the method to comprehend it derived its defining characteristics from two seemingly contradictory tendencies of thought. On one hand there was the tendency towards the particular, the actual substance of this world, the urge to seek nature in nature. This was in distinction to the medieval thought in which reason operated in the realm of high generality. It was in the face of the emerging belief of the boundlessness of the universe that the desire to retain a firm terrestrial grip arose. On the other hand was the opposite drive to escape the particularity of natural phenomena and this world and to fly to the universally unbounded. That is, to retain that measure of coherence and control that had characterized preceding thought in light of the changing perception of the world and the heavens. 
There was a dual desire to know the particulars of this world but to be able to rise above them and to organize the phantasmagoria that the universe presented to the senses.

The changes in the conception of nature and the method by which knowledge of that nature was sought also involved a new perception of the nature of being. In the Medieval period the task of the men of knowledge had been to uncover the design by: which the Divinity had given all being its rightful place in the scheme of things. There was a unique place and value for all being. Knowledge of being came not from the critical investigation of that design but from understanding its formal organization and its acceptance. This approach did not preclude knowledge of the actual items of the natural world but meant that such knowledge was not of the creative process, which flowed from the Divinity, but was knowledge of the created and was limited to sense perception. It was the realm of nature set against the realm of Grace, with natural knowledge being that which could be procured through human reason alone. The limit of knowledge and the capability of understanding the "being" of the objects of that knowledge were found at the borderline between the realm of nature and the realm of Grace. The term "nature,"

- . does not so much signify a given group of objects as a certain 'horizon' of knowledge, of the comprehension of reality. (Cassirer, 1951:39.)

The realm of nature was understood through the perception of the senses and the processing of the information contained in those perceptions. The realm of Grace was understood through revelation alone. The two realms were not mutually exclusive for the realm of 
Grace overshadowed the realm of nature and, in the sense of providing the keys to its creation, completed its being.

Medieval thought was the attempt to bring about a complementarity to these two realms and to reconcile the exclusivity that necessarily existed between them. There existed in each of these realms a set of laws that governed the activity of each, there existed divine law as well as natural law. The latter was the only one accessible to human reason, but as the realm of nature was overshadowed by the realm of Grace so was natural law subordinate to divine law. Thus reason which was the tool of knowledge in the realm of nature retained its subordinate position and was overshadowed by revelation. No science or other mode of inquiry derived from natural knowledge could be developed autonomously from divine intervention, for divine law alone was capable of having perfect knowledge since the fall of Adam.

The emerging conception of nature rejected the idea that the true being of the natural world was to be found in the notion of the "created," and looked instead to the process of "creation," implying the creative process of nature itself. Nature was not simply a static structure that had been created, rather nature became part of the Creator through the divine power which was thought to pervade the entirety of nature. No longer was there the dichotomy and the subordination between the divine creator and the created, nature was now embued with creative power, and creation took place within the bosom of nature and not outside. Divinity now entered into all the process of nature. In what amounted to raising nature to the level 
of the divine, the whole of nature acquired an animating life of its own. What was true for the whole was also true of all of tho particular elements as well for they assumed a special importance as messengers of the divine essence, or divine creation. While in the past nature was used as the term to signify a divinely created realm which relied upon the superordinate realm of Grace to complete the totality of its being, it now came to signify:

- . the integration of all parts into one allinclusive whole of activity and life which, nevertheless, no longer means mexe subordination. For the part not only exists within the whole but asserts itself against it, constituting a specific element of individuality and necessity. (Cassirer, 1951:41.)

Similarly the realm of nature was no longer set against a realm of Grace. There was now no longer a dichotomy of lawfulness, no longer was there natural law and divine law. The totality of nature came to be entirely knowable for it was in nature that the animating force, the divine essence, was resident. As Giordano Bruno (Cassirer, 1951: 44) commented:

Nature is nothing but a force implanted in things and the law by which all entities proceed along their proper paths.

It was in this new conception of nature, and the role of the divine to it, that one finds the objections that the Church leveled against the new science. It was not, as generally accepted, in the simple inversion of the center of the universe that the new thought was problematic, either the Ptolemaic or the Copernican system could have been reconciled to orthodoxy, but what could not be accepted was the new source of truth and knowledge that was found in nature itself. No longer was revelation needed to complete the knowledge 
that was gained in the direct investigation of nature. Nature, with the conception of it being imbued with divine spirit, was a coequal source of truth with divine revelation. Thus not only could truth be found, as it had always been, in the word of God but it could now be found revealed in the work of God as well. But the revelation of truth through God's work could not be expressed in words as could that of God's Word, it must be found in the numbers of mathematics. In these figures however the truth presents itself in much more clarity than could be achieved by words alone for the precision of mathematics bypasses the ambiguity inherent in the written or spoken word. At the intersection of the beliefs of the multiplicity and infinity of the universe, the power of reason to cope with that infinity, the creative force that was nature, and the ability of mathematics to precisely convey that force one found the keystone of modern science, the search for the truly universal laws which would provide the key to unlocking the universe as a whole in all of its possible forms. 16 Underlying the same process of thought that gave rise to modern science came the movement to emancipate not only nature from the yoke of the divine but also the emancipation of human intellect. Both have become viewed as sufficient unto themselves and thus required no intervention or intercession. No longer was there the need for the

16

One such law was believed to have been found in Newton's law of gravitation. The great veneration that was accorded Newton stemmed from the belief in the great intellectual leap that his law of gravitation constituted. It firmly cemented the power of man's intellect to cope with the boundless universe. 
realm of the divine to "complete" nature, nor was there the need for any divine revelation so that human knowledge might be completed as we11. Mankind had begun to stand on his own.

It was in this new system of science that the first stirrings of an idea of progress arose for in destroying much of the old world, both in secular theory and religious domination, science presented itself as a major integral aspect of life. It provided not only concrete benefits but an orientation to life and the world. As science moved forward each generation would add to the knowledge and accomplishments of the previous generation, society would thus be moving "forward" with each successive generation. This movement, created and sustained by science, was the first manifestation of the idea of progress, the first manifestation of the seemingly inexorable movement of progress.

The emergence of this new science, particularly in the face of the long standing opposition of the Church, was not a matter of the sudden superiority of science nor of an equally sudden case of tolerance on the part of the Church, rather the factors that supported the emergence of modern science were to be found in large part in the economic and religious changes that occurred in the Medieval period and during the Renaissance. The revival of trade in the late Medieval period fostered the emergence of a merchant class that occupied a position in the social hierarchy between the nobles and the peasants. In addition to the rise of this middle class, the bourgeoisie, the revival of trade led to an encroaching secularity of society. A secularity that came about by the nature of the articles 
that were fundamental to that trade, those with which trade was conducted, as well as through the very nature of business relations themselves. As pointed out previously the orthodox position of the Church on such matters of commerce were quite restrictive, for example, commercial activity was condoned as long as it resulted in the acquisition of only the amount of wealth that was necessary for one's station in life, profit beyond that baseline was considered avarice. Within such perspectives the internal motivations that drove each individual to save a little more money, to produce another item for sale, to develop new commodities, and above all to invest in business, found very little support. In the developing cities, and particularly among the rising class of merchants, traders, and financiers, the contradiction between the necessary attitude towards business, in order to insure success, and the attitude required by the Church resulted in great tension. There was a need for a new theological foundation, one that was as grounded in the new commercial activity of the age as Medieval Catholicism had been grounded in peasant agriculture.

\section{CALVINISM}

The Protestant Reformation, specifically the teaching of John Calvin (1509-1564), more than adequately fulfilled this need. Clavinism was fundamentally an urban movement, appealing most to those who had found the Catholicism of the day irrelevant and who had been most alienated by its teachings. Calvinism turned what had been an alien, sordid, aspect of life into the very core of a body of 
religious beliefs. The influence of Calvinism stemmed from the fundamental belief that the salvation of man was a question whose answer had been predetermined by God. God had controlled the destiny of man from the time of Adam and Eve in the garden of Eden, and would control that destiny to the very end of mankind. God had already determined who among the living, and those to came as well, would find salvation. Those who were not to be saved had no recourse but to accept their fate. Neither the "chosen" nor the "unchosen" knew truly the fate that was to await them, they only knew that some would be saved and some would not. 17 Accordingly, the aim of life was not the acquisition of salvation but the glorification of God, which was accomplished through both prayex and action.

With the belief that the aim of life was not acquiring salvation but glorifying God, life on earth no longer was looked upon as a source of $\sin$ in and of itself, but rather now became a place where the majesty of God may be proclaimed to all. The goal of man became to Iive in the world and embody Christianity and glory of God. But such a task required great discipline by the individual, he must conduct the business of life (which in most cases was business itself) with a gravity and a seriousness that was becoming of a religious event. In viewing the successes of life and society as the glorification of God business often actually

17

The Calvinists, however, did not in actuality believe themselves to be in total ignorance about the divine judgment of salvation; success in life, be it in the clergy or in the world of business, was taken as a sign of being one of the chosen. 
became such a religious event. In this framework the qualities that led to business success--thrift, diligence, sobriety, and frugality-were turned into the very foundation of Christian virtue (Tawney. 1954:97). The economic drives that were for the Medieval Church passions to be repressed, now became, with the requisite amount of religious temperance, avenues for the glorification of God.

Calvinism had a tremendous liberating effect, particularly upon the bourgeoisie. Calvin may have done for the bourgeoisie of the 16th century was Marx accomplished for the proletariat of the 19th century (Tawney, 1954:99). Calvinism provided the bourgeoisie with a coherence and a unity of purpose. It gave them a justification and a sanctification for the values that they held and lived by, and it gave them a religion whose fundamentals were soundly anchored in the machinations of modern life.

The revival of trade that had occurxed in the late Medieval period blossomed into a full scale commercial revolution with the meshing of the elements of a fundamental commercial substructure, the oxthodoxy of Calvin, and the exploration and exploitation of the "New World." The result was the rapid growth in wealth and power of the bourgeoisie, where the bourgeoisie had once sought protection through local privilege and restriction of trade, they now sought independence from such encroachments. With the concentration of financial power in their hands they realized that their power and prestige could be used to influence the nature of the social and political institutions. The bourgeoisie realized that what success they had obtained, and their hope for greater success in the future, 
resided in the ability to achieve concrete results, that is, the actual production of goods and services. Such results were best obtained when unhampered by mythology and antiquated ways of viewing nature. In their attempts to secure such results it was the bourgeoisie:

. . who took the methodology of science to be a reasonable way of looking at the world and who, in turn, gave the scientists the confidence that their thinking was correct and was socially desirable, and the material backing to continue in the same direction. (Pollard, 1971:28.)

As a result of this "patronage" one finds that often applied science provided the foundation for the famous scientific discoveries that occurred. Galileo's studies of ballistics and the mathematics that were required are classic examples of the practical utility of science leading to quite important theoretical discoveries. The workshops of the craftsman and the artisan as well as the laboratory of the "scientist" were important in providing a fixm foundation of support for the new science.

The hostility of the Church could be overcome and safety insured for the scientist only when a sufficient number of the powerful and rich merchants, businessmen, and nobles found the ideas and products of the new science both reasonable and promising. Thus what called for and supported the new science were the needs of:

. . the merchants and traders and manufacturers, the owners of mines and mills and of banks, and their technicians and managers and doctors and clerks... (Pollard, 1971:30.)

Regardless of the contrasting character of this latter period it still maintained a connection with the early phases of the Renaissance in that it was still part of the attempt of the 
Renaissance to emancipate man, to set him free to develop his talents and his capacities in this world. This latter period, marked by the emergence of "modern" science, represents an emancipation of the philosophic groundwork of human knowledge, completing in form the emancipation of the human spirit begun in the arts in preceding years. The Renaissance contributed to the emergence of the idea of progress in several ways, some direct and some indirect. The indirect ways included the increased influence of the bourgeoisie and the practical, secular, optimistic manner in which they came to approach life. This did much to diminish the apocalyptic sense of the future that had been an important aspect of Medieval religion and its domination over society. Related to the rise of the bourgeoisie was the economic vitality that emerged in the Renaissance which created demands from science that fostered its growth, and in so doing aided the notion of the progressive movement of knowledge that arose with it. In more direct manner the Renaissance contributed to the rise of the idea of progress in creating a milieu of thought in which the actions of the individual were important and in which the power of the individual, or man in general, to take control of his life were brought forth.

More direct contributions to the rise of the idea of progress were thwarted during the Renaissance because of the adoration that was bestowed upon the ancients. Dante (1256-1321), in the opening sentences of his late Medieval work Monarchy (1313) delivered the quintessential statement that could have provided the insight for Renaissance thinkers to look away from the past and on to the future. Dante (1955:3) wrote: 
All men on whom Higher Nature has stamped the love of truth should especially concern themselves in laboring for posterity, in order that future generations may be enriched by their efforts, as they themselves were made rich by the efforts of generations passed.

But one can understand the contemporaries of Dante being little moved to labor for the sake of posterity for they knew quite well that posterity, and for that matter all of mankind from the beginning, had its fate settled long before by the creator. To be saved or to be damned on judgment day was the only fate, the only future worthy of contemplation. One might have expected more from the humanists of the Renaissance given their belief in having been delivered from the darkness of the Medieval period, but they were too busy paying homage to the Greeks and the Romans for their deliverance to understand that the greatest homage they could have paid would have been to show the same creativity and boldness of thought that had so characterized those adored ancient times. The substantial contribution to the idea of progress, and to mankind itself, could not be made until the men of the Renaissance came to understand that the ancients could indeed be equalled and even surpassed, that their own generation was superior to any that had preceded it, and given the contribution that they had to make, future generations would be even greater.

\section{JEAN BODIN}

In the period of overlap of what, with perhaps undue historical periodization, may be called the late Renaissance and the beginning of the modern period were two additional figures who were part of the dawn of modern thought that the latter Renaissance represented, and 
yet important enough in the history of the idea of progress to warrant privileged positions. These two figures were the Frenchman Jean Bodin (1530-1596) and the Englishman Francis Bacon (1561-1626). One of the essential elements underlying the idea of progress was the perspective of history as a linear process. Augustine had taken a positive step in this direction with the formalization of the Christian view of history which was linear instead of cyclical, but the apocalyptic end to which that linearity headed all but negated this positive character. What was needed was a linear view of history that was devoid of this apocalyptic nature and which embodied a greater role for man in the movement of history, that is, embodied the spirit of the Renaissance. ${ }^{18}$ This change in perception was first held by the French historian Jean Bodin. Bodin attempted to substitute a new concept of the historical process of mankind for that which had existed in the Medieval period and the early part of the Renaissance. Bodin was among the first scholars, particularly in Europe, to change the study of history and social philosophy from a deductive discipline to a "factual" one, to change it from Aristotelian science to "modern" science. He made this change through his appeal to historical facts and ethnographic data rather than assumed principles. He took recourse to historical facts, their factuality a matter of his opinion, and ethnographic data embodied

18

The importance of this attention to the perception of the historical process assumes its rightful importance when it is realized that the idea of progress is above all simply an optimistic philosophy of history. 
in the descriptions of habits and customs of peoples around the world gathered by the ancients or by contemporary explorers. 19

Bodin rejected the idea that there were Golden Ages to the various civilizations or a Golden Age to the whole of human civilization. He rejected as well the usually concomitant belief that there had been a subsequent degeneration in mankind, in civilization. The reason behind Bodin's rejection of these beliefs was of prime importance for the idea of progress. Bodin believed that there had been no Golden Age of man and no degeneration because the powers and laws of nature were, and always had been, uniform and invariable. Holding this belief it was not reasonable to suppose that at one time in the course of time nature was able to create men of superior capacities, of superior potential, and yet not be able to produce such men at another time. Nature produced men of comparable capacity and potential throughout time.

In postulating the permanent and undiminished power of nature and its laws Bodin shifted the emphasis, the responsibility, for the

\section{9}

Bodin's work is embodied in two sources, Methodus ad Facilem Historiarum Cognitionem (Method for the Easy Comprehension of History, 1566), and Les Six Livres de la Republique (Six Books of the Republic, 1576). Bodin's interest in ethnographic data highlights the point that he developed much more than simply a new look at history. Bodin developed a new conception of sovereignty embodying traditions from both Roman law and the French monarchy through which he hoped to demonstrate that the monarchy (particularly that of France) was the best political structure. The ethnographic data facilitated his development of an anthropogeographic theory of the behavior of people, how it is that geographical factors (topography and climate for example) came to influence human society. 
course of history from nature to man himself. This meant that history, instead of being contingent upon the varying natural potentials of men, was due to the will of men. This will, which now became postulated as the motive force in the course of history, was always changing, "every day new laws, new customs, new institutions, both secular and religious, come into being, and new errors" (Bury, 1960: 39). These changes in history may occur either by alteration, which was similar to a slow adaptive process, or by conversion, which was like a rapid mutation. Under this view history could not be circular or cyclical but rather must be linear for the conditions that impelled the wills of men to make certain decisions were never the same twice, they were always changing.

Within this continuous change however there was a regularity that was discernable, a regularity that Bodin referred to as the law of oscillation. Rise in a civilization would always be followed by decline. While the decline was inevitable it was a mistake to think that the decline represented a continual deterioration of civilization as a whole or to think of this oscillation as a cyclical perspective. For Bodin there had been a continual, though gradual, ascent in the whole of human civilization through the various oscillations, each oscillation bringing civilization a little "higher."20 Thus contrary to the generally held view of the preeminance of the ancients, civilization of his contemporary period was thought by Bodin to be superior, the result of a gradual ascension from a primitive state.

20

The linearity and gradually ascending nature of human civilization that was developed by Bodin was derived from his study of the movement of knowledge. 
One may refer to this assumption of the linearity of history as a domain assumption, an axiom, of the idea of progress. This linearity, precluding the possiblity of the decline of civilization that was embodied in the cyclical view, asserted the continued "improvement," the "upward" movement of civilization. Without such an assumption of this linearity, whether by means of direct movement or a gradual ascension through numerous spirals, history would lack the coherence and the direction that allowed it to be construed as a dynamic, creative force. It was this coherence and direction that was crucial in the development of the inexorable character of history and the association of progress with it.

The denial of degeneration and the affirmation of the gradual ascent of man that Bodin was expressing was not entirely new or unique. In earlier centuries the Epicureans as well as Seneca had believed in the slow growth of human knowledge. What made the statements of Bodin important was that they were made within the context of a linear perspective to history and that they could be made after the passage of so many centuries. With earlier views of the movement of knowledge the eventual decline of civilization mitigated any real advance that had been accomplished, but with the linear view of history knowledge would not have to be regenerated periodically. The ability to make a statement about the continual advance of knowledge after so many centuries was important because of the generally dim view that Renaissance man showed toward the Medieval period, the so-called "Dark Ages." The fact that Bodin still believed in the ascent of knowledge, and the movement of 
civilization that it indicated, in light of such prejudices represented a major change in attitude.

To modern thinkers the inference from. Bodin's concept of the law of oscillation would be that since there had been a gradual ascent of civilization from the very beginning of man to the present, barring the destruction of the world, it should be expected that the future would also see such ascension of civilization, new inventions made, more discoveries made and knowledge generated. Bodin however did not draw what appears to be the obvious deduction. He was concerned really with the past and the present, but was conspicuously lacking in interest about the future. Bodin was trying to bring human history into closer accord with the course of the rest of the universe, that is, to elaborate a view of human history that would be consonant with a view of the world as following some sort of universal plan: A plan in which all parts, human history included, were interrelated.

Bodin's view of history was new in the sense that it offered an optimistic view of civilization on earth, in contrast with the resignation and pessimism that had pervaded thought for many centuries. Within Bodin's optimistic view there were two important points for the idea of progress that need to be reiterated and emphasized. The first point was the idea that there had been an ascent of civilization as a whole, that in spite of the rise and fall of a number of particular societies the movement of mankind as a single unit was ever upward. This idea explicitly rejected the notion of the Golden Age of the ancients and the subsequent degeneration of mankind as 
well as the cyclical perspective to history. In their stead Bodin posited a linearity of history, a linearity without the apocalytic end that the Christian view of history contained. The second point was the assertion of the invariability and the permanence of nature and its laws. Such an assertion provided a cornerstone for the idea of progress, it insured the "rules of the game" would be the same in the future as they were in the past and the present, and that the changes in civilization would not be due to the unequal potential of the human being but rather in the variation of the development of an equal potential.

\section{FRANCIS BACON}

Another figure of the latter part of the Renaissance whose work represented the real beginning of the idea of progress was Francis Bacon. Bacon was in consonance with modern thought in many respects, his realization of the need to leave the content and style of Medieval thought behind and his whole experimental approach to knowledge for example. Yet in other respects Francis Bacon was undoubtedly a member of the early Renaissance style of thought, attested to by his belief in astrology and dream reading, as well as his maintenance of a belief in the geocentric theory of the universe. It must also be remembered that Bacon's experimental based science, they key to his program for the reformation of science, was not a new idea. Roger Bacon (1214-1294) had preceded him by some 300 years in the assertion of the need for a solidarity in the sciences and the need for the adoption of an experimental base to 
science. Nor was the direct interrogation of nature for the sake of acquiring knowledge a unique revelation of his. As it was brought out earlier, this was a general part of the awakening of science in the 16th century. What stands Francis Bacon apart from other men was the fact that he formulated the idea much more clearly than others had done and he insisted upon it much more strongly than others had. Francis Bacon's belief in the progressive movement of knowledge was, as earlier discussions have shown, not an idea unique to his work either. What separated Bacon from men like Seneca and Bodin was the end to which this progressive movement was moving. Seneca, for example, saw the exploration of nature and the knowledge that was gained as a method of occupying oneself, it was intellectual activity. Bacon's own conception of the purpose of knowledge was utility, the use to which such knowledge could be put. It was this belief that really connects Bacon to modern thought, and to the idea of progress.

The Greeks had construed the satisfaction which resulted from the elaboration of true knowledge to be the object of scientific investigation, it was a metaphysically oriented experience. Under Bacon's principle of utility the object of scientific investigation was to insure man's subjugation of nature. As Bury (1960:15) recounted this idea:

The principle that the proper aim of knowledge is the amelioration of human life, to increase men's happiness and mitigate their sufferings--commodis humanis inservire-was the guiding star of Bacon in all his intellectual labour. 
This utilitarian view of the object of science and knowledge was to contribute to the emergence of an atmosphere that would foster the development of the idea of progress, for if science was for the betterment of the human race then as the sciences advanced so the human race should advance as well.

Bacon believed that knowledge could continue to grow and progress in the modern period if the errors and obstacles that had impeded the continuity of this progress in the past could be understood and overcome. 21 such obstacles had been the result of the misunderstanding of men as to the proper object of investigation. As Bacon (Becker and Barnes, 1961b:461) stated:

Again there is another great and powerful cause why the sciences have made but little progress; which is this. It is not possible to run a course aright when the goal itself has not been rightly placed.

That goal for Bacon was found in the principle of utility. Once the principle of utility as the guiding ideal of knowledge was understood there was the hope and the opportunity for even greater advances in science and further growth of knowledge in the future.

What did Bacon see in the distant future for men? Bacon did not look into the future for more than a few generations. As a result of the belief that the present period (the modern period) represented the "old age" of mankind, Bacon did not see a great expanse of time existing before the end of civilization. Though Bacon never clearly stated the amount of time that man still had upon

Bacon had divided history into three periods; the antiquities, the middle period (including Greece and Rome), and the modern period (including the Medieval period). 
earth he did seem to infer that a sound knowledge of nature could be extracted in the matter of a few generations. This conception of Bacon's that mankind was in its old age precluded him from looking to the remote future and postulating an openendedness to the growth of knowledge and the progress of civilization. This open characteristic to the possibility of future progress becomes a basic element of modern ideas of progress. As with the other thinkers dealt with here, Bacon approached the conceptual and emotional requirements for the idea of progress, but like the others he was precluded from truly developing such an idea by the nature of thought in the period in which he lived.

Francis Bacon's import for the idea of progress resides in the elaboration of the principle of utility as the object of human science and human knowledge. The goal of knowledge was to increase and secure man's dominion over nature, and to provide man with inventions and discoveries that would increase comfort and happiness. The elaboration of this principle was truly of profound importance for it implied not only that comfort and happiness were attainable here on earth but also that they were something that mankind ought to as a whole strive to secure, and that comfort and happiness were things that were valuable in themselves.

The import of Bacon's contribution, and that of Bodin's as well, can be better understood when attention is turned to just what conditions had to successfully be met before the idea of progress could actually come forth. 


\section{CHAPTER V}

NECESSARY CONDITIONS FOR RISE OF THE IDEA OF PROGRESS

Prior to the 17th century there did occur some precursory elaborations of an idea of progress, the works of Seneca, Bodin, and Bacon are exemplary. These elaborations however were confined usually to statements acknowledging the fact that throughout the course of history there had been advancement in knowledge, and perhaps to some degree the arts, and that one might expect some advances in the future. None of these pronouncements could be considered a complete idea of progress, whether it was because of a disinterest in the future, an insufficient view of the progress that was yet to come, or even the adherence to a cyclical view of history. While many of the fundamental ideas that were essential to the idea of progress were existent (the linearity of history, probability of advance in the future, and the utilitarian motive to knowledge for example) the social and intellectual milieu was simply not at a point where these elements could congeal into a viable notion of progress. Certain conditions, all of which had at least begun in the late Renaissance, had to be firmly met and accepted before men's attention could be turned toward the future and the chances of progress that lay ahead.

The first of these conditions was the eradication of the "tyranny" of the past, the ancients. As long as the Greeks and/or the Romans were considered to represent the apex of civilization, 
as long as the authority of individuals that lived in these "Golden Ages" was thought to be infallible, and as long as the idea of degeneration which was implicit in this veneration of the past persisted, the idea of progress had no base of support nor stimulus to emerge. The authority and power of the ancients began to be challenged by the emergence of "modern" science in the latter Renaissance, and as that movement gained support so the power of the ancients diminished. Once men stopped believing that the apex of civilization had been reached centuries ago their attention could be turned to the possibilities that still existed for mankind and the part that could be played in the advances yet to come.

The second condition necessary for the development of the idea of progress was the valuation of everyday life and the shift from knowledge for the sake of knowing to knowledge for human needs. The domination of Christian theology, particularly its eschatological aspect, led to a diminished appreciation of the mundane life. The individual's attention was directed toward life in the hereafter. Where there was little appreciation and attention paid to everyday life there was little initiative to make that life a better one. The idea of progress lives and breathes by the belief that men can make a better life for themselves in the future. Take away the future and the idea of progress becomes meaningless. Christian theology took away the future in the sense that it was out of the control of mortal men. The future was in divine hands and the only way to make a better life in the future was to do all that was possible to secure salvation, but the world of salvation (if the term world is even appropriate) was very far removed from the mundane world. 
The secularity of the Renaissance worked to undermine this view of the future and to give it back to men, to make men more in control of their own destiny. Bacon gave a viable focal point to this concern through his utilitarian interpretation of the purpose of knowledge. No longer was the advance of knowledge merely a case of men finding personal satisfaction from intellectual activity. With the aim of knowledge the "amelioration of human life" (Bury, 1960:15) the potential betterment of the whole of mankind was embodied in each step forward that knowledge made. The advance that seemed to accrue from science began to support the belief in the ability of men to make a better life. 22

The first and second conditions were such that their consummation would allow men to look forward to greater eras in human history, eras that would mean advances in the human condition. There could, however, be no guarantee that such advances would necessarily be forthcoming, no secure optimism about the future, unless the science upon which so much of the notion of advance depended was placed upon a solid base. Science and progress formed complementary ideas, in that they both shared the idea of reason as a prime mover, they shared the belief in the power of the individual to influence his own destiny, and of course, they both shared an implicitly evolving character. The grounding of the foundations of science and the generality and applicability of its products constituted the last major condition preceding the emergence of the idea of progress. ultimately signify advances for civilization as a whole in the long run of time. 
Placing science on a firm base came to mean the acceptance of the invariability and the permanence of nature and its law. ${ }^{23}$ so Iong as those conditions under which men lived and science was based were not open to change then science and its ameliorative benefits could continue to make life progressively better into the future. While the permanence of nature must in actuality always remain in the realm of faith, until that point at which the future can be foretold, the conditioning of the sense of security that accompanied the belief in the continued power of human knowledge was the important point and the need to be fulfilled by this last condition.

As the following discussions will point out, the history of the 17th century amounted to the gradual accomplishment of these three conditions, and the coalescence of the intellectual and social factors that were involved in the development of the first viable idea of progress.

This is assuming that there really are such laws and that they are not simply artifacts of the technique of science or certain tendencies and needs of the human psychological make up. 
CHAPTER VI

RENE DESCARTES AND CARTESIANISM

The field of knowledge and thought in general in the 17 th century marked the beginning of what may rightly be called the modern period. In it one finds a maturing and development of the tendencies that began in the latter stages of the Renaissance period; the increasing abandonment of the authority of the ancients, new criteria for the "truthfulness" of knowledge that was based on reason and not authority, a new interpretation of the meaning and direction of human history, and the beginning of organized scientific cooperation. These ideas which set the tempo of the future direction of science and society were epitomized by the system of thought developed by the French mathematician and scientist Rene Descartes (1596-1650).

\section{TWO MAIN AXIOMS}

Cartesianism could be characterized by the two axioms that animated the entire system, the supremecy of reason and the permanent and invariable character of nature's laws. The supremecy of reason meant that reason and not authority should be the only judge of the truth of knowledge. Descartes (Jones, 1979:171) felt that "we should never allow ourselves to be persuaded of anything excepting by the evidence of our reason." Reason for 
Descartes was a sort of eternal truth, a body of knowledge and truth that the human intellect could tap. It provided "the power of forming a good judgment and of distinguishing the true from the false" (Descartes, 1955:81). Though reason was to be the supreme tool of the human intellect a thorough examination of the Cartesian view of reason would reveal a certain ambivalence in regards to its essential characteristics and power.

Like other men of the period Descartes was desirous of an autonomous character to reason by which reason was to be free of sanctions of the Church. Descartes, however, could not bring himself to accept an autonomy that was totally secular, a reason that was sufficient unto itself. The sufficiency that he saw as giving the ultimate power to reason lay beyond reason itself and was for Descartes the power of a transcendent God. Thus while Descartes usually viewed man's use of his power of reason, through the "clear and distinct" 24 intuitions that will be discussed shortly, as an active agent in the seaxch of truth there were times when reason's autonomy was deferred to the power of God who through revelation lit the path to truth. In these instances Descartes (Jones, 1969: 172) conceived of the clear and distinct intuition as:

- . an illumination of the mind by which it sees in the light of God those things which it pleases Him to have the mind discover, by a direct impression on our understanding of the divine light. So far, the mind cannot be considered as an agent; it only receives the rays of divinity.

\section{4}

This is a phrase used throughout much of Descartes' discussions. It is found for example in Meditations on First Philosophy (Descartes, 1955:180) or in The Principles of Philosophy (Descartes, 1955:231). 
There were thus times when man was divinely guided to truth and times when the power of reason found its own way, the latter always deferring to the former. Thus Descartes was a man who developed a vast system that represented nearly the antithesis of religious reasoning and power, and yet was not willing to make the necessary break, wishing to retain some of both worlds. Despite Descartes' timidity, or religious conviction, 25 his focus upon a highly rational approach to knowledge and truth brought the conception of an animated "reason" to the forefront, not only in his own system but in science and philosophy in general for centuries.

\section{NEW METHOD OF REASONING}

Along with this belief in the supremacy of reason there came a new method of reasoning, a new method of inquiry. Descartes felt that the key to the advance of science and human knowledge lay in the

\section{5}

In the course of Descartes' work one finds a certain ambiguity in his allegiance to God and to reason. One notes this in Principle CCVII of his Principles of Philosophy where he stated:

At the same time, recalling my insignificance, I affirm nothing, but submit all these opinions to the authority of the Catholic Church, and to the judgment of the more sage; and I which no one to believe anything I have written, unless he is personally persuaded by the force and evidence of reason. (Descartes, 1955:302, emphasis added,)

One cannot be sure how much of this ambiguity and how much of the time and effort that he devoted to nature and existence of God during the course of his work was the result of his genuine devotion to God or simply the expression of the fear that he had for the power of the Church. 
development of the correct method of inquiry. While others such as Roger and Francis Bacon had also focused upon the same need, Descartes differed greatly from the others in the form that this new method was to take. Descartes was from an early age, very taken with the power of mathematical demonstration and the clarity of mathematical reasoning. He was ultimately led to the belief that mathematical knowledge was absolute, irrefutable, and essential. Descartes also believed, derived from his perception of reason, that the human mind had the power to know truth from falsity through recourse to its ability to have clear and distinct intuitions. That which the mind could perceive with clarity and distinctly must be accepted as true. The reason for the necessity of such an acceptance derived from the source of those intuitions. The capacity of:

- . knowing given us by God, can never compass any object which is not true, in as far as it attains to a knowledge of it, that is, in as far as the object is clearly and distinctly apprehended. For God would have merited the appellation of a deceiver if He had given us this faculty perverted, and such as might lead us to falsity for truth when we used it aright. (Descartes, $1955: 231$.

Combining the belief in the power of mathematical (geometric) reasoning and the ability of men to apprehend truth Descartes developed a method in which the human mind, through a system analogous to geometric proofs, 26 used its access to truth (the clear and distinct intuitions) to develop a comprehensive system of knowledge. Descartes

\section{6}

In this geometric method "reality must consist in a set of entities every one of which is implicatoraly related to various other entities" (Jones, 1969:194). Geometric proofs begin with what are considered self-evident metaphysical statements and subsequent truths are developed from their direct or implied relation to these intial statements. The initial statements are equivalent to axioms in a formal geometric proof and the subsequent truths that are derived are the theorems that are believed to follow from those axioms. 
believed in a rational, objective order to the universe and believed that his method of inquiry provided unmistakable access to that universe.

This method of inquiry combined the best of both the Greek (though Descartes intended to break cleanly with the past) and Christian traditions (though the system is implicitly anti-religious). To the Greeks reason was an adequate instrument to find truth, but, reasoning powers were not distributed equally among all men. For the Christians all men were created equal (at least in the moral sense), but little account was taken of the power of reason. The Cartesian method of inquiry amounted to a statement of the belief in the equal capacity of all men to have access to truth and knowledge, for the instrument of that inquiry was the power of the mind to form good judgment and to distinguish right from wrong which was equal in all men. The fact that some excelled above others was the result of the diversity of opportunity to develop and exercise the capacity to form judgments.

The second axiom was the invariability and permanence of the laws of nature. Jean Bodin elaborated a similar idea some years before Descartes, but in the Cartesian system the idea gained wider acknowledgement and acceptance. The fact that it gained a greater measure of importance in the system of Descartes resided among other things in the fact that it existed as an integral element of a broader system. It was a system that not only became immensely popular but a system in which each of the elements were fitted together in a highly organized and highly rationalized manner. 
In addition, Descartes' argument for the invariability of the laws of nature was built upon the unchanging nature of God. For Descartes God was unchangeable and eternal. The unchanging quality that was attributed to the laws of nature stemmed from the fact that God was the creator of nature, and thus in part nature reflected His unchanging and eternal nature for:

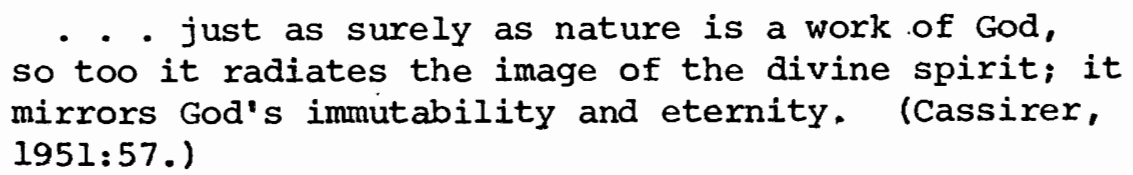

The unity of the Divine with nature assured the invariability of the laws that govern nature.

The integrated system of thought that Cartesianism represented was the first coherent and systematic attack upon what was seen as an oppression of thought that had existed up to and through the first part of the Renaissance. In the attempt to break the bond with the ancients that restrained modern thought, a task that was begun in earnest by Bacon and others, Descartes was a much more assertive and uncompromising figure. One of the underlying motivations for his work was the attempt to break clean with antecendent thought and to construct a new system ${ }^{27}$ that would be superior to, yet independent of, all previous thought. Descartes believed that his new system would pave the way for future advances in knowledge. These advances would have a marked effect upon the nature of all mankind for he felt that not only would science, and knowledge in general, be affected by a new mode of thought but moral and material thesis.

A statement of this system is appended at the end of this 
improvements could be expected as well for these depended upon science and philosophy in general. Thus the new system would beneficially affect the totality of society, not only putting all knowledge on a new, more firm, foundation but reaching into the very physical and spiritual lives of men as well.

Descartes' almost maniacal desire to eliminate all connection with the past may have been the very thing that kept him from personally developing a clear idea of progress. 28 Descartes certainly had many of the requisite beliefs fundamental to the idea of progress, but his denial of the past precluded him from viewing the movement of mankind as a continuous striving, progressing forward. In order to develop an idea of progress the past actions of mankind as well as an expectation of the future must be combined with the present to form a coherent path from past to future. Descartes' view of the necessity of eradicating the past and the necessary uniqueness of his system of though kept him from doing that.

\section{CONTRIBUTION TO IDEA OF PROGRESS}

In spite of the fact that Descartes himself was incapable of drawing together the necessary elements and perspective to develop an idea of progress, the ideas that were fundamental to his system were not so limited and Cartesianism as a general system in the hands of others came to exert a considerable influence upon the development

\section{8}

Descartes was proud of the fact that he had forgotton the Greek that he had learned in his early schooling. 
of the idea of progress. Cartesianism's contribution has been threefold. First, there was the contribution of fundamental ideas, z. ideas such as the power of reason (and the method by which it was to be used) and the invariability of the laws of nature. As noted earlier these two ideas were the cornerstones of Cartesianism and were destined to become cornerstones of the idea of progress as well. While not new ideas, the force of his exposition and the power and comprehensiveness of his system brought to them an acceptance they had not experienced before.

The second contribution was the relegation of the idea of Providence to a secondary position. In the face of a rising secularization, the invariability of natural laws, the supremacy of reason, as well as the whole mechanistic nature of the world that developed from the Cartesian system of thought the idea of Providence declined. Though Descartes accepted that God had created the world, that God still existed (a point to which he gave considerable attention), and that through revelations He deigned at times to guide men, the whole of the Cartesian system was quite capable of operating without God. As Cartesianism spread in the 17th century the power of reason alone usurped the underlying role that Descartes had invested in the Divinity. Reason attained the self-sufficiency that Descartes was unwilling to give it.

It became apparent that the idea of Providence and the idea of progress were incompatible. Progress assumed an invariability to nature and a prime mover in reason while Providence held the possibility of change at the hand of the divine mover. Progress 
could not fully develop until it had dethroned the concept of Providence. By doing away with the need for Providence the Cartesian system (but not necessarily Descartes himself) paved the way for the ascendence of the idea of progress as the principle explanation of the movement of mankind. By dethroning the idea of Providence as the explanation of the movement of history, Cartesianism also removed the illusion of finality that: was implicit in that idea. Without the spector of an impending end of the world hanging over the head of man it was possible to look forward with optimism to the future.

The third contribution to the rise of the idea of progress was the influence that Cartesianism exerted upon the popularization of science and the scientific perspective. The fortunes of the idea of progress have been from the beginning tied closely to the fortunes of science. The notion of an ever growing and expanding source of knowledge was easily expanded into the larger impact that this growing knowledge would have upon civilization. Equally important for the idea of progress was the secular spirit that science was imbued with. Science with its reliance upon reason and not faith, ${ }^{29}$ on human and not divine power, tended to negate the influence of Providence and divine will. As the power of Providence decreased, the influence of the idea of progress increased. It was

29

One must grant the fact that the axioms upon which utilizes its reason are are accepted as matters of faith as well. In this respect it is a faith once removed, and the two have much in common, but there still exists the trust upon the exercise of one's own reasoning power that is deferred or suppressed in the religious faith. 
not a coherent and clearly stated notion of progress that gained influence at this point for there was yet to exist such an expression, but there was nevertheless the notion of the advance of human knowledge and the benefits that accrued from that advance and it was this precursory idea of progress that was gaining adherents. The role of Cartesianism in the popularization of science stemmed from the individual character of its method and its adaptability. Relying upon the ability of each individual to have access to knowledge took science out of the reserved realm of a select few and placed it, potentially at least, in the hands of everyone. The Cartesian method was more than a purely scientific method, it was a method of inquiry for any question that could be approached in a rational manner. The egalitarian nature of Descartes' method, the breadth of its applicability, and the seemingly irrefutable nature of its proofs made the science that it represented very attractive. The famous salons of Paris, in which many of the intellectuals were frequent visitors, contributed to the popularization of science. The new discoveries and theories were often discussed in these salons, frequently they were presented in predigested versions for the benefit of the ladies. 30 The attractiveness of the Cartesian method of reasoning and the apparent power of logical proof that it contained made it a natural source of interest in these salons.

\section{0}

Fontenelle's Conversation on the Plurality of Worlds (1686) in which the philosopher attempts to explain the Copernican system of the solar system to a lady was one of the first published attempts at this "popular science." 
George Sorel (1947-1922) contended however that it was not any inherent value but rather the superficial nature of Cartesianism that appealled to an aristocracy that believed heartily in its own powers of reason. For Sorel (1969:19):

Cartesian science was not so confused with mathematical technique that men of society, having received a good liberal education, could not converse with professionals.

The heart of Cartesianism was that truth could be obtained by any individual if only sufficient attention were paid to "clear and distinct" intuitions that each individual found within himself. Thus $\mathrm{a}:$

- . good intellect familiar with Cartesian reasoning could find an answer to anything: this characterized a good philosophy for habitues of salons. (Sorel, 1969:19.)

Regardless of the degree of truth in Sorel's opinion of the profundity of the Cartesian system, the fact of its great influence and the popularity that it brought to the idea of a rational science cannot be denied. The exact impact of the Cartesian contributions became more clear as its influence spread and its ideas became part of the public consciousness. The effect of Descartes and his system were to be found even in areas not generally associated with him through the influence of his method. Books of high repute in varying areas of interest are characterized by a coherence and a precision of exposition that can be traced to Descartes' infatuation and utilization of "geometric" reasoning, l'esprit geometrique.

Thus at this point one can begin to see the elements in the development of the idea of progress coalescing into a more coherent form. The emotional and intellectual mood of contemporary society 
becoming more receptive to the dynamic nature of thought and image of man that was embodied in the idea of progress. Obstructing ideas (Providence, the apocalyptic end to mankind, the quality of ancient thought) were on the wane and fundamental ideas for the idea of progress (the power of man's reason, the movement of knowledge, the permanence of nature's laws) were on the rise. Cartesianism had a direct influence upon both of these trends, and its influence was to be felt upon the idea of progress for some time to come. 
CONFLICT BETWEEN THE ANCIENTS AND THE MODERNS

While the conflict between the authority of the ancients and the power of modern man had existed since at least the beginning of the 17 th century, ${ }^{31}$ it did not occur on a large, that is public, scale until the foundations of modern thought, principally embodied in Cartesianism, began to gain widespread acceptance. What precipitated the expansion of the conflict between authority of the ancients and the moderns was a debate over the literary merits of the respective periods. The literary aspect of the conflict, however, was gradually left behind as the discussion of the merits of the ancients and the moderns turned to areas of science and knowledge in the attempt to obtain a decisive outcome. In leaving behind the literary aspect and focusing upon knowledge many of the supporters of the ancients were likewise left behind. This shift of focus to the advance of science and the movement of knowledge in general was important for it was in these areas that the advances that had the greatest impact upon society and were most visible had occurred. It was factors such as these (impact and visibility) that made such advances capable of supporting an idea of progress. Literary change and "advance" on the other hand operated in a much more subjective realm and thus its impact was much more a matter of personal taste.

${ }^{31}$ The earliest known comparison between the ancients and the moderns was found in Miscellaneous Thoughts (1620) by Alessandro Tassoni. 
The idea of progress has often been traced back to this conflict and the subsequent discussions that it engendered, with the assumption made that the conflict itself was the source of the idea of progress. This in part has some merit for the serious attempts at enunciating an idea of progress had their beginning in the attempts to support the preeminance of the moderns; but that assumption neglects all of the necessary social and ideational changes that had occurred in the preceding centuries that made it possible for such an idea to emerge.

\section{QUESTION OF NATURE'S PERMANENCE AND INVARIABILITY}

The central and underlying question in this conflict between the ancients and the moderns was whether the powers of nature were invariable and inexhaustable or whether in fact nature had lost the power to produce the kind of world that had existed in the past. To prove the supremacy of the moderns would discredit the theory of degeneration, to uphold the supremacy of the ancients would discredit the theory of the invariability of the laws of nature and nature's power. Due to the connection between the invariability of the laws of nature and Cartesianism it was not surprising to find that the proponents of the moderns were by and large Cartesians.

\section{CONTRIBUTTORS IN CONFLICT}

\section{Desmaret de Saint Sorlin}

Typical of these men was Desmaret de Saint Sorlin (1596-1676). For Saint| Sorlin, the modern age was really akin to something of a mature old age of mankind. It possessed all the best of the 
of the preceding centuries as well as the experience and power to judge the inventions, discoveries, as well as the errors of earlier civilizations, and to be able to profit by such judgment. In consonance with his belief in the invariability of nature, Saint Sorlin believed that nature reproduced itself exactly in all ages, but that the works of man did not partake of the same type of invariability. The creations of mankind must be continually refined and corrected, and so it followed that those who Iived in the later periods had the greater capacity to refine and correct. In Saint Sorlin one not only finds another expression of the belief in the invariability of the laws and power of nature but another expression of the belief first found in Francis Bacon that the modern age may be compared to the ancient age as mature and experienced old age may be compared to immature and inexperienced youth.

\section{Charles Perrault}

Another proponent of the moderns was Charles Perrault (16281703) who published his work Comparison of the Ancients and the Moderns in four parts during the years 1688 to 1696.32 Perrault discussed the focal points of the conflict between the ancients and the moderns and expounded on the beliefs that have been proposed by the champions of the moderns; knowledge advanced with time and experience, those individuals in the latest periods of mankind have inherited much from their predecessors and will bequeth much to those who follow, and of course the idea that the ancients did not 
necessarily represent the apex of civilization. What was of importance in Perrault's work was that he addressed the Medieval period, a conceptual stumbling block to both the case for the moderns and ultimately for the idea of progress as well.

Ideally it seemed quite true that those who lived in the later periods had gained from previous periods and that through accumulation and refinement the later periods were more knowledgeable than earlier ones, but when confronted with historical evidence there seemed to be some room for debate. It would seem that the Medieval period, the so-called "Dark Ages," did not follow this trend, that it represented a regression from an earlier period that was superior. Perrault would not dispute this apparent truth, for though he believed in the progressive ascent of mankind, the progressive march of knowledge with time and experience, he did not contend that this march was one unbroken continuous movement. There had been and would be breaks in the continuity of advance. For Perrault there were external factors that caused lulls or regressions in this march, external factors such as wars or natural catastrophes that required men's attention to be turned away temporarily from the pursuits of science or the arts and concentrate upon the task of survival itself. There were thus certain periods in time that were quite receptive to the increase in knowledge and the betterment of mankind and yet there were those periods which stalled the ascent of mankind, but though it might be stalled it was not stopped.

In the midst of his belief in the advancement of mankind Perrault did not claim that the moderns had any real superiority in 
natural capacity. This was in line with a belief in the invariability of nature, for while nature may have created men with as great a capacity as those of earlier times it did not create men with greater capacity. Like Saint Sorlin, Perrault believed that while natural capacity may remain the same actual creations may be unequal, and that under similar conditions that latest creations must be the best because knowledge, particularly scientific, was dependent upon the accumulation of knowledge and must increase with time.

Like men such as Bodin, Bacon, and Descartes, Perrault embodied many of the necessary elements of an idea of progress but fell short of all the necessary elements. Like the thinking of Bodin and Bacon, his major shortcoming was that he did not concern himself with the prospect of a long advance for mankind in the future. For Perrault believed himself to be living in the twilight of civilization, he (Bury, 1960:87) stated:

Our age has, in some sort, arrived at the summit of perfection. And since for some years the rate of the progress is much slower and appears almost insensible-as the days seem to cease lengthening when the solstice is near--it is pleasant to think that probably there are not many things for which we need envy future generations.

What motivation was there to work elucidating an idea of progress when one lived at the "summit of perfection" (Bury, 1960:87)? In fact, what impact could there be for such an idea as that of progress under such an assumption? A secular idea of progress can only arise where there exists a parallel belief in the extended future of mankind. If that future does not exist, as it did not for Perrault, the idea of progress loses all of its impact. 


\section{George Hakewill}

The battle between the ancients and the moderns was enjoined somewhat independently in England in 1627 by George Hakewill (15781649). Hakewill directly confronted the theory of degeneration with a general argument in favor of the moderns, or perhaps more appropriately, modern Christendom. Hakewill's dislike of the veneration of the ancients was founded upon the belief that such admiration was conducive to the opinion that civilization had decayed. For Hakewill the idea of decay meant something more than the notion of degeneration and he took the conflict between the ancients and the moderns on a much broader scale than it had taken on the continent. For Hakewill the discussion not only included science, art, and literature, but moral and physical qualities as well. In addition to attempting to show that not only had the mental (arts, sciences) and physical qualities of modern man not decayed, Hakewill sought to demonstrate that the moral quality of modern man was of no less quality than that of the ancients. Hakewill also argued that in fact because of Christianity the moral quality of modern man was superior to that of the ancients, and that Christianity had actually led to social progress.

One argument of note that Hakewill used in his attack against the theory of degeneration was that the acceptance of such a concept would have a detrimental effect upon human motivation. Hakewill felt that the widespread belief in the continual decay of the world would blunt the creative drive of man to improve his life, a person with no hope for a better tomorrow will not stxive for improvement 
that he does not believe will come. Hakewill felt that it was the duty of man to imbue civilization with the spirit to improve itself. While in general it may be said that Hakewill did not add anything substantially different to the conflict between the ancients and the moderns, he did make two contributions to the conflict and to the idea of progress that bear repeating. The first contribution was enlarging the scope of the conflict to include morality among the other elements that were considered. Earlier thinkers on the subject of the conflict between the ancients and the moderns, as well as the theory of degeneration, confined themselves primarily to discussions of art, science, or knowledge in general. Though the analysis that he undertook may have been biased by Christian chauvinism it was of importance in that it was a clear cut expression of the belief in the possibility of progress in social morality. Thus Hakewill is worth noting for the fact that he anticipated in some form the questions that were ultimately to arise concerning the question of social progress.

The second contribution was the anticipation of the motivational role that the idea of progress was to assume in more modern times. The desire to innovate, to improve, to move forward, are all supported and nourished by a firm belief in the possibility, and necessity of progress.

\section{CONFLICT RESULTS}

There were three important results of this conflict between the ancients and the moderns, a conflict that did not "end" but came 
to dominate less and less public attention. The first result was that by gradually bringing public opinion to their side the "moderns" succeeded in ridding modern thought of a great deal of the residue of not only ancient thought that had obstructed man's forward movement but early Renaissance thought that had caused the same obstruction, principally scholastic thought and logic. As a result greater clarity and greater support were secured for the "modern" modes of thought, Cartesian logic and Baconian science for example.

The second result of this conflict was that it forced people to focus upon the idea of the differences between the past and the present and the changes that had occurred in the intervening periods. It forced men to think more seriously about the movement and changes that civilization had gone through. The conflict forced them to approach the idea of progress if they were to lend support to the side of the moderns, for if the moderns were to be considered better than the ancients then some form of progress had to have taken place.

The third result of this conflict is samewhat secondary to the previous point, that is, in the attempt to find support for the ascendency of the moderns over the ancients it was necessary that supporters investigate a variety of facets of modern life. In so doing it opened up thought to the idea that changes, progressive changes, had occurred in all aspects of civilization, not merely in knowledge of the arts.

These three results served to coalesce modern thought closer to the emergence of an idea of progress that embodied the elements 
mentioned in previous discussions, an idea that first emerged in the thought and works of Bernard Fontenelle. 
With the increased public interest in the difference between the ancients and the moderns, and with intellectual interest directed toward the nature of these differences and the processes by which they had occurred, statements of greater precision and comprehensiveness concerning the progress of modern man began to appear. One of the first complete statements of the idea of progress was made by Bernard le Bovier de Fontenelle (1657-1757). It may be termed a complete statement of the idea of progress because among other things (to be discussed) it dealt with the past, the present, and the future in the proper progressive perspective. It may be termed a complete idea of progress because of its proper perspective even though it dealt only with the progress of knowledge.

\section{PRIMARY WORKS}

Fontenelle published two books that touched upon the conflict between the ancients and the moderns: Dialogues of the Dead (1683) and Digression on the Ancients and the Moderns (1688). The first was a compilation of the author's satirical criticisms of life, built around imaginary conversations between luminaries of the past and present. While not dealing directly with the conflict, Dialogues of the Dead touched upon it in several conversations, 
particularly in the one between Socrates and Montaigne. In this dialogue Socrates voiced the expectation that the period of Montaigne would manifest great improvement over the period in which he lived, basing his expectation in the belief that lattex periods profited by the experience of earlier ones, that as men grew wiser with age so did mankind. Montaigne, however, responded that such was not the case, that the great men of the past such as Pericles or Socrates himself had no equal in modern times. Socrates counterposed in turn the argument of the permanence of the powers of nature, that nature had not degenerated in its other works and so there was no reason why there should not continue to be men of such capacities. Socrates asserted that there was "no difference between our ancestors, ourselves, and our posterity" (Bury, 1960:100). Again Montaigne displayed disbelief, maintaining that change was always occurring, weren't there periods in which knowledge advanced noticeably and yet periods in which it moved little or not at all? Didn't this indicate the changing nature of mankind? Socrates replied that many changes had occurred and that change was occurring, but that such change was only external in nature, "the heart of man does not change with the fashions of his life" (Bury, 1960:100).

While the conclusion of Dialogues of the Dead, principally the assertion of the permanence of the powers of nature, supported the case of the moderns in essence, Fontenelle was not overwhelmed with the power and advancement of modern man. He saw such modern discoveries as Harvey's on the circulation of blood and the whole change in the view of celestial motions as of little or no use for 
they did nothing for the felicity of mankind. At the time he wrote Dialogues of the Dead, Fontenelle held the belief that in the early history of civilization mankind had acquired a body of useful knowledge, to which little of use had been added. It seems unlikely that a man with such views would come some time later to actively support the superiority of the moderns, but that was precisely the case with the publication of Fontenelle's Digression on the Ancients and the Moderns.

The permanence of the powers of nature had been used as a defense of the moderns by both Saint Sorlin and Perxault. Fontenelle, being a good Cartesian, 33 had asserted it through the voice of Socrates as well. All others had only asserted its validity, but Fontenelle came to believe that if this fundamental tenet of Bodin and Descartes could be irrefutably demonstrated once and for all then the case of the moderns would be won and any further argument would be futile. Fontenelle offered a classic Cartesian proof to support the assumption of the permanence of nature's powers.

\section{PROOF OF INVARIABILITY OF NATURE}

Fontenelle (Van Doren, 1967:38) stated in Digression on the Ancients and the Moderns that nature possessed a:

\section{3}

Fontenelle was thoroughly Cartesian in the acceptance of the basic tenets of the supremacy of reason, the permanence of the powers of nature, and the precise stringent method of reasoning. He did more than most other men to prove the utility of the Cartesian system, but he was not so captivated by either the man or the system to be reticent about.criticising Descartes or Cartesianism. In regard to Descartes he stated that "he should be held in esteem at all times but followed only now and then" (Fellows, 1967:209). 
- . kind of paste which is always the same, which she ceaselessly moulds and remould's in a thousand ways, and of which she forms men, animals, and plants; and certainly she did not form Plato, Demosthenes, or Homer of a finer or better kneaded clay than our philosophers, our orators, and our poets of today.

He reasoned that if the powers of nature had changed over time such that modern man was potentially less intelligent or creative than the ancients it must mean that the brains of the ancients were of superior quality, formed of this "finer or better kneaded clay" (Van Doren, 1969:38). But if such a difference were in fact existent then it should be the case, as Socrates alluded to in the Dialogues of the Dead, that other products of nature should also be the recipients of nature's greater power during that period. Framed in such a manner, Fontenelle's proof of the permanence of the power of nature hinged on a single question: were the trees in ancient times of greater quality than those in modern times? If brains were different then trees should be different as well, and if trees were the same then brains should be the same as well. Fontenelle dismissed the argument that there was a difference between the material world of trees and the non-material world of the mind and its thought processes. He believed in the connection between the body and the mind through a material bond that determined the quality of the mind, a belief that was drawn directly from Descartes who suggested that the connection between the world of sense perception and thought or emotion lay in the pineal gland (Descartes, 1955:345-347).

Fontenelle was never able to complete this proof in any substantive form for there was no way for him to check the quality 
of the trees in the ancient periods. 34 The proof essentially assumed the permanence of the powers of nature, that it, it was at heart another "a priori" argument this time put in a quasi-scientific form. It was little more than the previous assumptions of the validity of the idea once removed.

This shortcoming however did not restrict Fontenelle from assuming that he indeed had demonstrated the permanence of nature's powers. Thus having "demonstrated" this permanence Fontenelle felt that the equality, at least the equality of potential, had been established between the ancients and the moderns. But establishing the natural equality of talent did not mean for Fontenelle that there were in fact no differences between the ancients and the moderns. Differences did exist, but they were differences that were due to conditions that lay outside the human being. The two principle conditions were for Fontenelle the passage of time and the particular character of each period.

\section{ANALYSIS OF DIFFERENCES BETWEEN ANCIENTS AND MODERNS}

It was important to Fontenelle that the first cause of differences, the relation of time to the advancement of knowledge, be fully understood. One must credit the ancients with being responsible for the first inventions, however one must not ascribe

\section{4}

Even if he had been able to check the quality of trees in other periods there was always the possibility that favorable climatic conditions would in fact have rendered the trees of that period of better quality than those existent in the period in which Fontenelle lived and wrote. 
an intellectual superiority to them for this fact. If men of the modern period were to be placed in the ancient period they too would have made the same discoveries. The point was that modern thinkers were more advanced than the ancients precisely because they were modern, that is, because they followed the ancients in time. Knowledge was gained not only by the elaboration of truth but also by the uncovering of falsity as well. The ancients made the advancement of knowledge possible not only because they bequethed to modern man numbers of ideas but also because they uncovered scores of false ideas as well, thereby eliminating unnecessary paths of investigation which modern thinkers might have unfruitfully pursued. Realizing what an intellectual gift the ancients had passed on to modern man, Fontenelle thought it would be very surprising if modern thinkers did not intellectually surpass the ancients.

Following the reasoning embodied here, Fontenelle felt that it was assured that future generations would certainly surpass the modern one, through both the processes of the improvement of scientific techniques and modes of reasoning as well as through the very knowledge that would be gained from experience. Fontenelle thought that this process of advancement of knowledge would be endless, that the latest thinkers and scientists would be the most competent. Fontenelle realized that this endless advancement of knowledge would probably entail leaving behind the work of Descartes and going on to something else, and in his readiness to look to future advances for mankind, he showed a receptivity to change and a realization of its inevitability. 
It is important to note though that Fontenelle felt that this advancement of knowledge did note apply to all modes of human expression but only to the scientific disciplines, disciplines which dependend upon reason and experience. The arts of poetry and literature, for example, did not depend upon correct reasoning so much as upon a productive imagination. Where correct reasoning and experience were required for the perfection of the sciences, the movement toward such perfection of necessity would be a slow process requiring much experimentation and the elimination of false ideas. 35 However the perfection of such arts as poetry and literature required not sound reasoning but great imagination, and as such perfection could be reached in a shorter time, perhaps only a few centuries. It was thus possible that the ancients may well have reached perfection in the arts, and if that was the case then it would not be possible for the present or the future generations to surpass them, though it would be possible to equal them.

The second cause of differences between the ancients and the moderns was the particular character of the different periods of history. In accordance with the belief in the permanence of the powers of nature each age produced men of great potential, but each age did not allow those men to develop and to use their great potential. Men of peace did not often have opportunities to exert great influence in periods of long warfare, and vice versa, men of war had no opportunity to show their skills in periods of peace.

${ }^{35}$ For Fontenelle, Descartes had been the single most influential person of the modern period for the introduction of his method of reasoning. Descartes had introduced precision into the process of analytical reasoning where before such reasoning had been less coherent and less impelling. 
A great scientific mind would be kept from fully developing in a country or in a period in which science was held in low esteem. Thus to understand the differences that existed not only between the ancients and the moderns but between all periods one must not only take the specific time frame into consideration but the specific character of each period as well. The great men and the great periods are combinations of the potential for greatness that nature provided and fortuitous circumstances that men provided. The conflict between the ancients and the moderns was for Fontenelle not simply a question of old talent versus new talent but a question of the ongoing influences of time and external social conditions, factors that would always be operating.

The analogy between the ongoing movement of civilization as a whole and the life of a single individual had been an integral aspect of the discussions of many thinkers before Fontenelle. For these thinkers, civilized man grew through the characteristic periods of infancy, youth, and finally maturity. In infancy man was absorbed with the necessities of mere existence and there was no real development of culture. In youth, through imagination, man began to develop the axts of literature and poetry, and even began to reason. The period of maturity, which was thought to be the present day (that is Fontenelle's contemporary period), man reasoned very well, which in a sense was both the cause and the effect of this greater enlightenment. This analogy was a useful one for elaborating ideas about the development of civilization, but Fontenelle pointed out that it contained a dangerous implication. What seemed to be inferred 
from this conception of the growth of mankind was that civilization was approaching "old age," an inference Fontenelle thought to be unjustified. Old age in civilization as well as in human individuals seemed to infer that besides the wisdom that came with experience, which was what other thinkers were attempting to develop, civilization was entering a period of decay. Such an inference was contrary to the underlying foundation of the moderns argument, that is, the permanence of the forces of nature. Fontenelle insisted that it must be the case that mankind would have no old age. Civilization would always be able to accomplish the feats that it did in its youth, but in addition civilization would become more and more enlightened in areas which were neglected in contemparary times. Contrary to the inference from the "life" analogy, mankind would never degenerate, mankind would never have an old age similar to that of the human individual. One of the necessary conditions for the development of the idea of progress mentioned earlier was the eradication of the veneration of the past to the exclusion of interest and optimism in the present. Fontenelle believed this to be such a powerful obstruction to man's advancement that he felt that even if the much admired Descartes were to become the object of such veneration the result would become just as destructive as it had from the veneration of the Greeks and the Romans. With the diminution of the conflict between the ancients and the moderns this obstruction was finally overcome. The acceptance of the quality of the modern period, however, was not in itself enough for the emergence of an idea of progress. What was needed, in addition to the acceptance of the 
present, was an acceptance of the advance of civilization that was to take place in the future. There were two elements of this look to the future, the first was the general acceptance of the prospect of future progress, the second was the belief in the necessity and certainty of this future progress. Fontenelle played a central role in the establishment of both these elements.

Through the work of men like Bacon and Descartes, and all of those authors that had championed the cause of the moderns, the case for the existence of progress in the past and up to the present had been established. Fontenelle provided the first of the necessary elements of extending progress into the future by the rejection of the idea of an old age to civilization, the human intellect would never degenerate. Further.substantiation of that claim and the elaboration of the necessity and certainty of progress was accomplished through an appeal to nature's permanence and the manner in which knowledge was generated. If it were true that the human mind was, in its potentiality, the same throughout time and that each generation built upon the knowledge of preceding generations, as Fontenelle said, "the sound views of intellectual men in successive generations will continually add up" (Bury, 1960:109), then progress in knowledge must continue to occur as long as human civilization continues to exist. Progress was a natural function of the permanent capabilities of the mind and the cumulative nature of knowledge. In fact, since each generation did build upon what had been brought forth from the past, the bigger the bequest from the past the greater the potential for advance in the future. The concept of progress 
extending in the future in a necessary and certain manner was a crucial aspect of the idea of progress. An idea of progress that established its movement upon chance, external influence, or some divine will would be of little real value, it would lack any of the self-directing and self-motivating aspects that provide the larger ramifications of the idea of progress.

With the elaboration of these last aspects Fontenelle estabIished the first complete idea of progress, an idea of the progress of knowledge. Fontenelle's idea of progress was grounded in the Cartesian manner of thought, particularly in the permanence of nature's powers, but while this provided a foundation for his notions about the progress of knowledge, it at the same time excluded Fontenelle from believing in the possibility of other types of progress. While the Cartesian system allowed for the development of an idea of the progress of knowledge because of the necessity of believing in the impossibility of degeneration, the very belief in nature's permanence precluded Fontenelle from developing an idea of the progress of society, including man himself. Fontenelle conceived the permanence of nature to mean that the emotions and the will of men were immune to change as well. Thus human nature would always be the same, unalterable and invariable. The world would always be inhabited by only a small number of reasonable men and a large number of fools. For Fontenelle the unalterable character of human nature meant that there would always be the same blights upon civilization as there had been in the past; jealousy, strife, and war. The effects of civilization upon the nature of man made no difference 
upon that nature, save perhaps to mask its blunt expression. Needless to say this was hardly an atmosphere in which the idea of the progressive amelioration of man's lot, including his own character, would emerge. It was hardly conducive to an idea of general social progress.

It is important to note that one must not overestimate the importance that the idea of progress had for these early thinkers. It often appeared not to have been a tremendously profound conclusion of its own but one means of defending the case of the moderns against that of the ancients, or perhaps even a justification of the pursuit of amusement and happiness for the idea of progress:

\footnotetext{
- permits the enjoyment of the good things today in good conscience without worrying about tomorrow's difficulties. (Sorel, 1969:21.)
}

\section{. . it established the right to amuse oneself}

without fear of consequences. (Sorel, 1969:12.)

Regardless of the esteem, or lack of it, that men like Fontenelle and his predecessors had for the real import of the idea of progress they were developing, it cannot be denied that their work and attention was an important step in the emergence and the ascendency of the idea of progress in all of its manifestations and ramifications. 
CHAPTER IX

\section{ABBE DE SAINT PIERRE}

Not all of those that may be called Cartesians were as orthodox in their views as Fontenelle was; not all were equally willing to accept the necessity of the permanence of human nature with the permanence of nature and its laws. One such individual was the Abbe de Saint-Pierre (1658-1743). In the period between the last decade of the 17 th century and the first several decades of the 18th century the notion of the progress of man's knowledge had become an accepted belief in the community of intellectuals, particularly the French intellectuals. As the philosophy and writings of Descartes had become topics of interest in the salons, so the idea of the progress of knowledge, of the ongoing enlightenment of man, became an oft discussed topic as well. Fontenelle was a habitue of such salons, as was his friend, the good Abbe. The idea of such a progressive movement taking place within civilization made its impression upon the Abbe for he was to take it much farther than anyone had taken the idea before.

Though occupying a position of authority and power within the Catholic church, the Abbe de Saint-Pierre was fundamentally a Cartesian rationalist and a deist. 36 He had, however, little

Bury relates the story of how on his deathbed, and in the presence of his household, the Abbe received the appropriate rites of the Church, only to tell the priest in private that he did not believe a word of it (Bury, 1961:129). 
aptitude for philosophy and held the physical sciences in esteem only insofar as they could directly aid the expansion of human happiness. His reserved appreciation of the physical sciences disclosed a fundamentally utilitarian perspective to the Abbe's thinking. His was a narrow concept of utility formulated around the criterion of happiness, and one that he applied quite stringentfy. His lack of understanding of the power and impact of science and a lack of appreciation for the impact of popular historical figures results in the deletion from his list of great and influential men of history many who had by general consensus earned premier positions. The great men of scientific theory such as Newton were held in less esteem by the good Abbe than men who had bent their scientific talents to the invention of some creature comfort or some feat of engineering.

The Abbe was in many respects a man who was ahead of his time. His concern with the happiness of civilization betrayed a humanitarian spirit that did not become a powerful social force until the middle of the 19th century. His humanitarianism led the Abbe to work hard at social reform, and his analysis of the reforms that were needed led him to elaborate the first statement of the utilitarian criterion of the greatest happiness for the greatest number. In keeping with his humanitarian and his reform tendencies, nearly the whole of the published works of the Abbe de Saint-Pierre were concerned with practical projects for the alleviation of social ills or the improvement of social development. Such concerns included: 
Project for Making Roads Passable in Winter, Project for Making Dukes and Peers Useful, and perhaps the most ambitious of them all, $\underline{A}$ Project for Making Peace Perpetual in Europe (Becker, 1965:39). In view of the Abbe's many projects it was not surprising to find that his own conception of progress would be found within such projects. It was through the work Project to Perfect the Government of States $(1773)^{37}$ that his fundamental perspective on the idea of progress was to be found. In this "Project" the Abbe discussed how the previously commonplace idea that man had originally lived in a "Golden. Age" of happiness and then subsequently had to endure the hardships of the silver, bronze, and iron ages was in reality an inversion of the historical process. For the Abbe men had progressed through the iron age, then the bronze age, and were presently still in the midst of the silver age (perhaps he was motivated by the vast amounts of silver that had closed to Europe in the period of colonial expansion). The power of human reason, however, had now reached the point that it was on the very border of being able to push man into the Golden Age, which like its imagined counterpart in the past would be a paradise on this earth. But while the power of reasons may have been at the verge of a new period, there were obstacles that blocked its acquisition. Chief among these obstacles was the lack of development in the arts of government and social control. These deficiencies were due to the misplaced concern on the part of the ablest thinkers. The great minds of history had all been turned to was published quite some time after his death in 1743 . 
the physical sciences in the belief that through their augmentation the general happiness of society would eventually be achieved. The Abbe felt that the talents of these men could have been put to incomparably better social use had they tackled the problems of ethics and politics with the same fervor and the same powerful intelligence that they expended on the problems of the physical sciences.

The plan that was embodied in the Project to Perfect the Government of States required that there emerge a Political Academy much the same as there was a powerful and respected Academy of Sciences, fostering the study of politics as its scientific counterpart fostered the study of nature. If the suggestions that were included in this project were carried out, the Abbe believed that all that was needed for the Golden Age to commence would be "a short series of wise reigns in our European states" (Bury, 1960: 135).

Embodied in the Project was the view, central to the Abbe's idea of progress, that the movement of civilization in its passage through the various "metallic" ages was ultimately moving towards the goal of human happiness. That is, that the goal of progress was not merely the accumulation of knowledge but civilization's acquisition of a felicitious state. In 1737 the Abbe de SaintPierre published Observations on the Continuous Progress of Universal Reason in which he sought to elaborate more clearly this specific character of the movement. The Abbe, like so many in this discussion of progress, had returned to the analogy of the human life when 
describing the progress of civilization. There was an important difference however in the Iife spans of these two respective entities. While the body of the single individual eventually degenerated and the precision of its reasoning degenerated as well, the body of the social organism remained forever intact through the infinite and perpetual succession of generations. While men such as Bacon viewed civilization as being in a period of old age, and Fontenelle had thought of civilization as being in an indefinite period of virile maturity, the Abbe viewed civilization at the present as perhaps no more than 8,000 years old, virtually "in the infancy of human reason" '(Bury, 1960:136), when compared with the time and advances yet to come. The Abbe looked specifically at civilization's progress extending tends of thousands of yeaxs into the future, and implicitly at an infinite advance, and in so doing was the first to take such a view of the vast periods of civilization yet to come.

In comparing the works of morality and politics of plato and Aristotle with those of the most recent French and English authors, the Abbe was convinced that there had been at least discernable progress in these areas. There would have been, however, much greater progress had it not been for wars, superstitution, and rulers who were fearful that the changes brought about by such progress would endanger their power. Such factors were, at various times and places in history, the causes of a slowing or actual regression in the progress of civilization. Only since the time of Bacon and Bodin had civilization made headway in overcoming these obstacles and progressed beyond the point reached in the time of Plato and Aristotle. 
Understanding that social causes had inhibited progress, the Abbe also realized that there were social as well as intellectual factors that had sustained the recent acceleration of progress. The Abbe saw that the expansion of trade and commerce had allowed the increase in wealth which led to greater leisure for a larger number of individuals, which in turn afforded more time for the pursuit of the refinement of tastes and the pursuit of knowledge. There were also more writers to create works and more individuals with time to read them. The Abbe also acknowledged that the subjects of mathematics and physics commanded a greater role in the universities and that their advances and the underlying beliefs that accompanied them facilitated the rejection of the authority of the ancient writers. The scientific academies, whose motivating effect upon science impressed him, had served to:facilitate new discoveries and to communicate those discoveries to wider areas. Finally the recent acceleration of progress was also aided by the invention of the printing press and the increasing tendency to write in the vernacular, both of which were influential in making the fruits of reason and knowledge more accessible.

While the Abbe was willing to admit to progress in speculative reason, practical reason as he referred to it had not made a comparable advance. The general happiness of civilization was no greater in the present time than it had been in ancient time. The intellects of the present knew many times more than the great intellects of the ancient periods, but contemporary men were no more virtuous than those of the past. Morality, ethics, politics, and the general 
happiness of mankind simply had not partaken of the same progress. The reason of this was the same reason that modern civilization had not reached the Golden Age; the most competent minds of the times had concentrated upon the physical sciences believing them to be the avenue for the most rapid advancement in the human condition. The Abbe, however, saw the disciplines of ethics and politics as the foci upon which the drive for human happiness should revolve. For the Abbe, a degree of progress in ethics and morality, as well as politics, that equalled or exceeded that of the physical sciences, and thus accelerating the advance of civilization toward social felicity, was simply a matter of directing the attention of the great intellects back to the important domains of thought. For the Abbe there were no insurmountable obstacles in the path of the progress of civilization toward happiness, no obstacles that could not be overcome if only men would follow his suggestions, the suggestions found in Observations on the Continual Progress of Universal Reason. Should ethical and political academies be founded and should the great intellects. affix their attention on these domains, there would be advances in human happiness far exceeding that possible through a filtering down from the physical sciences. Moral and political problems could be solved within the span of a century. Such progress was simply a matter of placing the value and attention in the correct domain of thought.

In viewing the importance of the transition that the Abbe de Saint-Pierre effected from an idea of the progress of knowledge to one of the progress of the entirety of civilization, one is apt to 
ascribe undue credit to the intellectual powers of the good Abbe. He was often quite cavaliex in attacking the most complex problems of man armed with only a vague belief in the power andiutility of the "reason" he wielded, displaying a lack of understanding of the depth and the complexity of the problems that he dealt with. Even the expansion of the idea of progress itself displayed no inordinate intellectual power. The Abbe was living in an age that was permeated with Cartesianism, the ideas of the supremacy of reason, the progressive movement of knowledge, the value of the temporal 1 ife, and the principle of utility were everywhere in thought. Combining these with the Abbe's beliefs in the possibility of the existence of truly enlightened governments and the power of the state and its laws to mold the moral character of its subjects, as well as the belief in the infinite future of civilization, the expansion of the idea of progress to include man's moral and social character falls short of a quantum leap.

Regardless of how one measures the intellectual strength of the Abbe de Saint-Pierre, his particular accomplishments, indeed if only for the fact that he was the first to openly proclaim them, have earned him a place in the historical movement of the idea of progress. He did clearly attach the happiness of the entirety of civilization to the movement of progress, proclaiming it a creditable goal for mankind, one worthy of approaching directly through the most expedient means possible. Viewing the vast future that still lay ahead for civilization the Abbe saw the capabilities for the 
"perpetual and unlimited augmentation of reason" (Bury, 1960:140), and in so doing marked the beginning of the truly modern conception of progress, that of unlimited social advance. 
CHAPTER $\mathrm{X}$

ENLIGHTENMENT PERIOD

The expansion of the idea of progress to the social world as found in the work of the Abbe de Saint-Pierre was perhaps indicative of the broader shift in the whole of philosophical thought that began in the latter parts of the 17 th century but came into its own in the middle decades of the 18th century. The 17 th century was dominated by Cartesian metaphysics and the abstract rationalism that it represented. Cartesian philosophy, as earlier discussion broight out, found its way into nearly every mannex of intellectual endeavor, from physics to poetry. The science that it represented, for in the 17th century and into the 18th century science and philosophy were still intimately connected, operated through a method in which knowledge was derived by reasoning "geometrically" from the highest known generalities to the lowest. Science was in reality more metaphysics than science, that is, science as it emerged under such men as Francis Bacon. Though the world of thought and the empirical world were mutually exclinsive, the truthfulness of the knowledge that theumind had of that world was still valid through the divine origin of both worlds. Reason operating in the mind and the structure of the empirical world could not fail to correlate for they sprang from the same divine essence. 
Occurring contemporaneously with the spread of Cartesian thought was a competing philosophy that was based on the methods of the scientific investigation of the physical world. This physical, or natural, science (vis a vis abstract science) derived its fundamental form fxom the experimental approach to knowledge that had been an aspect of natural science since perhaps the time of Roger Bacon. It represented the epistemological antithesis of the science of Descartes for it sought first the facts of the empirical world and then organized these facts so as to describe (vis a vis explain) nature. Knowledge was represented by an understanding of how nature worked rather than the essence of nature or why it worked. The growing influence of this empirical approach was represented by the founding of the Royal Academy in England (1660) and the Academie des Sciences in Paris (1666), and was epitomized in the work of Newton on the laws of motion and gravity.

\section{REPLACEMENT OF CARTESIAN SCIENCE WITH NATURAI SCIENCE}

The history of the 18th century in large part amounted to the supplanting of Cartesian philosophy with the philosophy of Newton, disposing of the abstract, a priori, metaphysical science of Descartes and placing in its stead the empirically based methods gleaned from the natural sciences. This isupplanting of the Cartesian philosophy, the Cartesian system of science, referred to the discarding of the abstract character of his thought as well as the notions of two substances and innate ideas but did not include the two most important ideas that motivated his philosophy, the supremacy of reason and the permanence of nature and its laws. 
While commanding the major focus for activity of the period, this transition of thought must share that focus with the trend toward criticism and reform that began to emerge in the latter years of the reign of Louis XIV and continued to mount until the outbreak of the revolutionary period in 1789. It was the combination of the desire for reform, shaped by the method of reasoning of the natural sciences, at the hands of a motivated group of men that have become the characteristics elements of this 18th century period. It was the work of these men, the philosophes, to bring about positive change through the use of reason embodied in natural science that has become the mark of the period known as the "Enlightenment."

\section{Motivation from England}

Returning to the major foci of the period in greater depth one must return to the elemental intent to leave behind the metaphysical systems found in the 17 th century and which carried over into the 18th century. It perhaps originated first in England where men such as Newton had made profound discoveries in the natural sciences, and also where the influence of the Cartesian system was not so strong. Voltaire (Francois Marie Arouet, 1694-1778) has been given credit for introducing and proselytizing the methods of natural science in France through such works as Letters Concerning the English Nation $^{38}$ (1733) and Elements of the Philosophy of Newton (1738), having become acquainted with the field and with English

It was published in French in 1734 as Lettres Philosophique. In it he praised the work of Newton and Locke, as well as English civilization in general. 
philosophy during a period of exile in England. 39 The essence of the movement was that instead of philosophic thought being circumscribed within a specific and definable system of axioms and deductive corollaries, 18th century thought was interested in setting philosophy free to investigate reality in whatever form and in whatever place it might be found. This was in part. responsible for the notion that 18th century thought was not so much a system as a spirit, that is, a desire to investigate through the methods of natural science and to go wherever that investigation might lead.

\section{Views of Certainty and Nature}

The belief had been gaining credence that the proper path of scientific investigation, physical investigation at least, was not from the top to the bottom, or from the most to the least general, but in precisely the opposite direction. The proper path of investigation it was believed was not to go from a priori beliefs about the character of the particular elements of nature to assumed knowledge of those elements but rather to allow the character of the elements themselves to present their nature to the observer. As the earlier discussion of the Cartesian philosophy disclosed, this first method of investigation was typical of the systems of the 17th century that the true path of knowledge was traversed when: - . thought, staxting from a highest being and from a highest intuitively grasped certainty, succeeded in spreading the light of this certainty over all derived being and all derived knowledge. (Cassirer, 1951:6:)

While earlier translations of the major English works had existed in France, it was perhaps Voltaire's influence in popularizing the work of such men as Newton and Locke that has brought him recognition for his contribution in this area. 
Spreading this "certainty" was accomplished by a system of rigorous proof and inference in which additional propositions were necessarily connected to the "highest intuitively grasped certainty" (Cassirer, 1951:6), and eventually exhausted the realm of knowledge. The geometric form of reasoning, of which this took part, safely guided thought through the entirety of nature for nature was pure extension (capable of explanation by recourse to the qualities of extension) and thus the mathematias of extension (geometry) provided an infallible expression of the nature and the pxopexties of the corporeal world. To say the Cartesian system was dominated by metaphysics meant that it was contingent upon the establishment of a first principle, the intuitive certainty, from which other elements of the system may be deduced, as well as that the science that it represented issued forth from an initial establishment of the certainty of being. The most basic question of the validity of the knowledge so derived, of the correspondence between knowledge as an operation of the mind and the objects of that knowledge (particularly in light of the dichotomy that Descartes constructed between the two worlds), was answered by the reference to the source of both worlds. The knowledge that the mind had could actually be explained only through recourse to the ideas that the creatox gave to man, ideas that were innate. These were ideas such as being, number, and duration, as well as the ideas of extension, form, and motion. The correspondence between these innate ideas and the empirical world which they claimed to have knowledge of was guaranteed by the fact that both the innate ideas and the corporeal world were created by God and were differing expressions of the same eternal essence. 
As representative of the antithetical philosophy, Newtonian philosophy (the philosophy of natural science) presented a combinatior of the positive and the rational. The point of investigation became one in which the lawfulness of nature was sought through the investigation of the actual phenomena of nature in their necessary activity. It meant not approaching such an investigation with a predetermined lawful relation but rather developing that lawfulness through the progressive familiarization with the facts as they presented themselves. 40 Only by allowing the actual phenomena of nature to dictate the pace and form of knowledge could there be a necessary correlation between the object of knowledge and the knowledge itself. Using such an approach one must leave behind the hope of being able to penetrate the actual being of matter, one must give up the search for the why, for the ultimate cause, and be satisfied with description, albeit in mathematical terms, derived from empirical facts not imposed upon the empirical world as an explanation. Within this philosophical perspective the relationship between the principle and the fact were reversed from that of the metaphysical systems. of the 17th century. In the latter the principle came first because of its relation to the source of truth, namely God. As the methodological approach of the natural sciences gained credence, the empirical fact became primary. Nature and the knowldge that was derived from it were thought of as autonomous from the intervention of God (that is once he created the world, no intervening element,

\section{0}

It is doubtful, however, that such openmindedness has been a singularly driving element in the investigative methods of modern science. 
not divine intervention nor any organizing a priori principle, must be allowed to intercept the direct investigation of nature).

The respective idealizations of reason provide an additional insight into the differences between these two competing perspectives. Reason, for the men of the 17th century, was an eternal body of truth, or knowledge, which the mind in its deductive power could tap. The 18th century, on the other hand, saw reason more as a force that served to guide the search for truth rather than as the body that contained that truth. Being conceived as a force, it was possible to comprehend the nature of reason only through its utilization, as a process not as a thing. The 17th century conception implied that there was a body of truth that could be tapped, like a sharp stick might tap a goat skin full of water, and truth would flow out. The l8th century made truth a more elusive entity, requiring a much greater initiative on the part of the investigator. It required man to make the determination of truth from falsity, albeit guided by reason, but still reliant upon his own abilities.

The underlying differences in the shift of thought between the 17 th and the 18th centuries was not a radical transformation but rather a continuation of the movement. of thought from the general to the specific, from the divine to the secular, that emerged even before the first manifestations of modern science.

It was not until the 18th century that this movement emanating from the natural sciences began to fully exert itself beyond the citadels of science (the academies and the scientific societies) and become an influential force in society at lärge. No longer was it 
merely the men from the more empirical of sciences that were interested in the movement but all modes of intellectual endeavors became enthralled with the empirical approach (as it became termed). It was believed that the method of the natural, the empirical, sciences. would serve to provide greater insight into the studies of politics and law, of society itself. It was often hoped that the methods of the natural sciences could provide the universal statement in a variety of fields as it had done for Newton in the areas of motion and gravity. As the Cartesian philosophy had spread to all parts of society, scientific and social, a half century before, so the method of natural science too spread its influence. It engendered a new enthusiasm for the application of this "new" method of philosophizing. As d'Alembert (Cassiex, 1951:47) stated:

Thus, from the principles of the secular sciences to the foundations of religious revelation, from metaphysics to matters of taste, from music to morals, from the scholastic disputes of theologians to matters of commerce, from natural. law to the arbitrary law of nations . . everything has been discussed, analyzed, or at least mentioned.

The feeling was engendered that nature, long held in awe by men who were mystified by its machinations, had at last become willing to give up the battle and open herself up to the penetrating light of reason and divulge her innermost secrets.

In order to accomplish this, however, it was necessary that the bond between science and theology as sources of truth finally be broken. The methods of the secular sciences that were gaining such power and prestige made no room for knowledge by revelation, either from inspired individuals or from biblical accounts. Those 
facts that could not pass the empirical test were systematically excluded from scientific investigation. The power of "theological" science, however, did not diminish immediately in the face of this onslaught by the natural sciences. There were many attempts at accommodating the facts generated by science with biblical and orthodox beliefs. In the first decades of the 18th century there were published works on such topics as The Theology of Water, Astronomical Theology, and Insect Theology (Cassirer, 1951:48). Even in the midale of the century the power of theology was still entrenched in many places of academic and intellectual power. Buffon's first two editions of Histoire Naturelle published in 1749 met with severe criticism by the Sorbonne for their views which ran counter to the book of Genesis, forcing Buffon to sign a statement of submission.

RISE OF CRITICAI POSTURE

In spite of such eddies of theological/scientific thought, the midale of the century saw the general recognition of the belief that the principle which explained a body of knowledge must be found in that body of knowledge, and that body of knowledge must belong to the realm of the observable and the factual. The principle of knowledge must not transcend the sphere of which it seeks to explain. As important as this movement of philosophical/scientific thought was, it would be myopic to construe it as the sole source of change in the 18th century. As the introduction to this discussion pointed out, the motivations for the social changes that occurred in 
this period and the milieu in which the idea of progress was to find its nourishment were also found in the changing social situation of the latter 17th century and early 18th century. That changing social situation, both for the good as well as the bad, centered primarily around the reign of Louis XIV and the several decades after his death.

During the first two to three decades of the reign of. "Le Roi Soleil," thanks in great measure to the economic policies of Jean Colbert (1619-1683), France had experienced a period of prosperity. The bleak economic conditions that had prevailed earlier had, with the initiation of the requisite economic reforms, been replaced by a fundamentally sound economic structure. A fundamentally sound economy was to be the greatest necessity of the reign of Louis XIV, for it was a pexiod unparalleled in luxury and extravagance. It was a period that saw great expenditures on a lavish court life, a period that saw the building of the great palace of Versailles. It was a period which, like no other in modern times, marked the apex of political absolutism. The power of Louis XIV was quite literally absolute; he was revered as a God on earth. Such an apex was not to be maintained indefinitely. In addition to the great expenditures to support the court life, the great territorial ambitions of Louis XIV led to numerous wars over many decades; wars that coupled with the extravagances of noble life and the death of Colbert brought bankruptcy back to the nation in the final decades of the 17th century and into the 18th century. 
During the years of prosperity all had seemed acceptable to the people; there was a period of acquiescence. The firm hand that Louis XIV had over the country, the excesses of the court, and the king's territorial ambitions were tolerable so long as his reign brought about internal peace and a measure of prosperity. But as the reign wore on and the prosperity was squandered away, a critical spirit began to make itself felt. The death of the monarch was met with jubilation instead of sorrow. The subsequent rule of the Regent (the duc d'orlean) and eventually Louis $x V$ proved to provide little change for the better for the mass of citizens. The dissolute life of the Regent and the essential indifference of Louis XV provided none of the leadership that France needed at the time. Times were hard and the stability of the nation in question. In spite of the hardships that the mass of people were having to endure, the movement of knowledge and. the advance of science was continuing. The 18th century was well aware of the advances that had been made, and were being made in the physical sciences, in the fields of medicine and chemistry, and even in industry. Few periods in history up to the middle of the 20 th century have been imbued with the same degree of awareness of the intellectual advance that it'was experiencing, of the progress of thought. But the intellectual advance which it experienced brought attention again to the very seat of knowledge and thought, back to man himself. It was, after all, the existence of man that made the advances worthwhile, that gave them value. Many were struck, however, with the contrast between value of man, his central place in the universe of 
human thought, and the actual conditions that the majority of men were forced to endure. The effects of poverty, ignorance, intolexance, and oppression were all the common lot of men. How hollow the advances in science and knowledge were if they did not actually ameliorate the living conditions of the great mass of people. One goes back to the thought of the Abbe de Saint-Pierre again and his pioneering thinking.concerning the connection of man's advances and his actual happiness, between the simple advance of knowledge and the use of such advances for the betterment of mankind.

This contrast between the advances in knowledge and the lack of advance in the amelioration of the human condition helped to bring about the realization on a broader scale that the mere expansion of reason, the mere accumulation of knowledge alone was not sufficient to bring about the general progress that had been hoped for. It was at this point that there came a movement away from the macroscopic and detached questions of knowledge that had captivated earlier intellects toward a concern with the more practical subjects of politics and ethics, a movement to turn the advance of knowledge into a more positive social force. One finds for example, David Hume (1711-1776), a man who explored the very frontiers of human knowledge, abandoning the more speculative aspects of philosophy in order to study politics, economics, and history.

In addition to the contrast between intellectual advance and the regretable conditions of the mass of people, another contrast served to stimulate a burgeoning concern with social conditions and 
an increasing desire to change those conditions. Perhaps because of Voltaire, more than any one other individual, the French people were made aware of the nature of English society. After spending two years in exile in England, and in the process diligently studying the political, social, and intellectual institutions of that country, Voltaire returned to France and shortly thereafter published his accounts of those institutions. From these accounts as well as the reports of travellers going both ways across the English Channel, the French populace was made aware of the greater civil liberties, religious tolerance, economic freedom, and better government that existed in England. Many saw in the English society what social amelioration really meant, what French society was capable of becoming, given the correct impetus and guidance.

JOHN LOCKE AND ETIENNE BONNOT DE CONDILLAC

In such contrasts, one finds the primary motivations for a concern with social life, the motivation for a movement to change the present conditions and bring to society the same inexorable advance that had been postulated for the movement of knowledge. The belief that such changes were possible, that such a progress for society was really a possibility, came from the work of John Iocke (1632-1704) and his French interpretor Etienne Bonnot de Condillac (1715-1780). The fundamental optimism that real social change was possible came from the idea of the malleability of the human character, an idea denied by previous men (e.g., Fontenelle) because of their belief that the permanence of nature and natural 
law precluded such change. A notion of malleability found its first scientific basis in the sensationalist epistomology/psychology of Locke, and it was the work of Locke that went unchallenged in the first half of the 18th century on matters of epistomology and psychology. It was also Locke whose ideas were at the root of the basic conceptions of man and society. for those men who embodied the. spirit of the Enlightenment.

Locke undertook the writing of his principle work, Essay Concerning Human. Understanding (1690), as much because of a desire to refute the Cartesian idea that men were born with innate ideas as to establish an empirical basis of human knowledge. 41 In this work Locke demonstrated how all that. was known to the human intellect could be derived from experience, that men came into the world knowing nothing and it was only in the course of their experience with the external world that they came to have what knowledge they were capable of knowing. He advanced the famous "tabula rasa" argument that likened the mind of the newborn to a blank sheet of paper upon which were impressed the representations of the external objects received through the senses. There were two sources of knowledge actually, either the sensation of external objects (the representations brought through the senses) or the mind's reflection upon its use of these representations. Thus the mind, in addition to the direct sensation of external objects, was capable of genexating

41 Though denying the existence of certain innate ideas, Locke would allow for the existence, prior to experience, of the faculty of feeling and thinking. In addition, in the respect that Locke as well as Descartes accepted the idea of reason as a power that all men were endowed with and that through the exercise of this power they would be able to build for themselves a better life, both Locke and Descartes may (with some required flexibility) be considered "xationalists." 
knowledge from the observation of the operations (doubting, reasoning, believing for example) that the mind brought to bear upon these representations. The mind was thus capable of generating one kind of knowledge from another. In either case the ultimate source of knowledge was experience, the sensations of the external world impressed upon the mind. It seemed to follow from this that if one could control the experience (the sensations) that the mind received one could influence the formation of the mind, and thus in turn human nature.

Condillac took Locke's ideas and welded them into a system that fit more closely the nature of French thought during this period, and in so doing extended the power of "sensation" beyond that which Locke would have allowed. Condillac asserted that all ideas that men have were the results of sensations alone, that the reflection that Locke allowed to form subsequent ideas and knowledge was nothing but a vestige of the notion of innate ideas that Locke had sought to eliminate. Condillac believed that Locke had stopped halfway in his analysis of the mind, that in not continuing to trace the origins in sensations of the faculties of attention, judging, memory, will, and others, he had failed to remain true to the method with which he began. For Condillac such mental operations were nothing that could not be explained through recourse to an analysis of sensation, that they were not indivisible qualities but rather subsequent developments of sensation manifesting a particular organization and relationship. As Condillac (1930:45) succinctly stated: 
If we bear in mind that recollecting, comparing, judging, disceming, imagining, wondering, having abstract ideas, and ideas of number and duration, knowing general and particular truths, are only different modes of attention; that having passions, loving, hating, hoping, fearing, wishing, are only different modes of desire; and finally that attention and desire have their origin in feeling alone; we shall conclude that sensation contains within it all the faculties of the soul.

With sensation as the basis of all activities of the mind, of the feeling being, the malleability that played so crucial a role in Condillac's notion of the perfectability of human nature, for the notion of malleability was really only a mask for the desire to "perfect" mankind, arose obviously enough from the source and nature of these sensations. While accepting the unchanging biological capacity of the human mind and the permanence of its functions, it was also apparent to Condillac from observing the nature of society over past historical periods that changes had occurred in habits, in customs, and in the nature of intellectual thought. In light of these changes, and yet accepting the unchanging nature of the mind, the only source of such change had to be different sensations that emerged from a changing environment. Following the basic Lockian causal chain, a different environment would provide different sensations that would result in different habits of action and thought. There seemed to be a problem, however, in that if the biological capacity of the mind stayed the same and the operations through which sensations were subjected remained fixed then how was it that the environment came to be changed in the first place? The answer came from the fact that humans, in the very activity of civilized 
life, exerted an influence upon the environment, material was both created and destroyed, individuals were both born and died, and unique events at given points in time occurred. There was a reciprocity conditioned between the mind and the environment, a certain environment resulted in a certain frame of mind with its own ideas. Now this particular frame of mind embodied in a particular group of peöple in turn lived within and acted upon the environment which then presented a changed set of sensations to those individuals that followed. In his Treatise on Sensations (1754), Condillac developed the idea that in understanding the manner or the law by which the environment acted upon the mind, which would have to include an understanding of the laws of human behavior as well, it would be possible to so structure the environment so as to infiuence the formation of men's ideas in a desired direction. Condillac (Pollard, 1971:44) believed that:
- . there was thus the potential here for a virtuous, upward spiral, the minds of each generation being improved by the improved conditions created by their predecessors, and in turn, as a consequence of this better start, being enabled to make the conditions still better for the next generation.

Condillac was convinced of the possibility of this because of his belief, shared by most in the Enlightenment period, that both the external world and the mind were rationally oriented and, as he stressed in Treatise on Systems (1746), they both operated upon the same rational principles.

Lockian thought, through the influence of Condillac, provided the perfect source of expression for the rationalist's ever present belief in the reforming and illuminating capabilities of reason. 
These capabilities of reason in addition to the advance of knowledge and the malleability of human nature as presented by Condillac provided the essential mechanism by which the most optimistic of 18th century men thought progress operated. The clearer use of reason, which for the men of the 18th century included the dissemination of the methods of natural science, meant that better understanding of the essential elements of human behavior and the principles that guided human action could be developed. Through the knowledge of these principles it would be possible to manipulate the environment, and in turn the formation of the mind, such that each successive generation came closer to a state of earthly bliss, each generation more capable of allowing more of mankind to live :a happy, fulfilled life. This notion of progress represented a confluence of an optimism steming from the perceived power of natural science and reason, an awakening of the power and possibilities of man in the Renaissance tradition, and a need for social change.

\section{PHILOSOPHES}

\section{Nature of Perspectives, Goals and Methods}

The most famous and the most characteristic perpetrators of change in the l8th century were the philosophes mentioned earlier. It is misleading to think of these men as composing a coherent and organized body of like-minded individuals for in actuality the term philosophe was a very vague one that was applied to a variety of men with a generally similar temperment and outlook toward science, society, and reason. The most important were: Voltaire, 
Montesquieu (Charles-Louis de Secondat, Baron de La Brede et de Montesquieu, 1689-1755), Denis Diderot (1713-1784), Claude Adrien Helvetius (1715-1771), Paul Henri Dietrich, Baron d'Holback (17231789), and even Jean Jacques Rousseau (1712-1778). 42 The 1ist may, without undo manipulation, be expanded to include such men as Cesare Bonesana, marchese di Beccaria (1738-1794), and Benjamin Franklin (1706-1790). One must be careful not to translate the French term directly into "philosopher" for while these men dealt intimately with the philosophy of the day, they had a great many other roles in society. They would more aptly be characterized as men of letters who through a belief in science, in the power of reason, and a genuine humanitarian interest were led to critically analyze all aspects of society and become persistent advocates of reform. As Baron d'Holbach (Wallbank et al,, 1965b:73) related their mission:

Let us endeavor to disperse those clouds of ignorance, those mist of darkenss, which impede Man on his journey, which block his progress, which prevent his marching through life with a firm and steady step. Let us try to inspire him . . with respect for his own reason--with an inextinguishable love of truth . . . so that he may learn to know himsëlf.. . and no longer be duped by an imagination that has been led astray by authority--so that he may renounce the prejudices of his childhood--so that he may learn to base his morals. on his own nature, on his own wants, on the real advantage of society. . . so that he may learn to pursue his true happiness, by promoting that of others.. . in short, so that he may become a virtuous and rational being, who cannot fail to become happy.

\section{2}

While Rousseau must be considered one of the philosophes in respect of his desires for a reformation of society and his concern for tolexation and freedom, he did differ quite widely from the others in many respects. 
While individually holding a variety of beliefs on subjects of concern, the philosophes were by and large unified in the belief of the progress of mankind given the guidance of reason. But this guiding reason was not the reason that had animated the systems of the previous. century, it was not used in a metaphysical and a priori sense but as a powerful heuristic tool that could guide the investigation of men. Again, this guidance was made possible because it was believed that the nature which natural science investigated and the mind which organized the information gathered from such investigations operated according to the same rational principles.

In their belief in the forward movement of knowledge and the advance of the use of reason in life, and the benefit of both for the progress of mankind, the philosophes were adament in their opposition to all manner of superstitution, myths, enthusiasm (in the sense of blind faith), and tradition that served to block that advance. While this critical aspect of the philosophes has been the one most focused upon by history they did not conceive of it as a purely negative function but. rather as the positive movement to clear away the obstructions to the enlightenment of man that would help bring about a better life, a happier life. In reference to these sources of obstruction, it was not mere ignorance that they found to be offensive, the advance of knowledge would eventually take care of that. It was the deviations from the true path of knowledge because of misplaced and knowingly misguided measures of truth and standards of knowledge. Such erroneous standards 
only led men farther and farther from the truth, and thus only served to delay the real progress of mankind.

Conflict with Christianity on Morality

The deviation from the true path of knowledge, the false standard of truth that the philosophes attacked most vehemently, was revealed religion, particularly Christianity. Religion had for so many centuries been the fount from which knowledge had issued, knowledge about all subjects known to man, from physics to politics and ethics. The truth of such knowledge was certain because it was derived from the Bible; it was knowledge "revealed" through the Bible and its various translators and interpretors. 43 In this capacity. as sources of knowledge, the leaders of religion had not sought primarily to advance the condition of men but to extract their allegiance. The priests had believed that unquestioned faith was the sign of the true believer and so endeavored to keep from the majority of people those ideas that were believed capable of eliciting doubt or of contradicting the dogma of truth that the Church projected. Revealed religion was thus guilty in the eyes of the philosophes of a double crime of not only advancing a false standard of truth but also of conspiring to keep men in ignorance, deceiving them into believing that submission and deference to the will of the priest were the true conditions of men.

\section{3}

Hence the term "revealed" religion, for the knowledge of God and the rules by which God desired men to live was "revealed" to the clergy, and their interpretation of the divine message were a necessary intermediary. 
These qualities of the revealed religions composed all that was offensive to the spirit of the Enlightenment and the philosophes in particular, a spirit that saw man's natural stance as active, the vigorous search for truth and the belief in God. The philosophes countered the abuses of revealed religion with the doctrine of natural religion, for while desirous of changing the nature of present day religion few were willing to do away with the concept of God all together. Natural religion came to stand for two new ideas. The first was that instead of the dominant notion about there being Christian beliefs of one sort, Judaic beliefs of another sort, and Islamic beliefs of a third sort, there was simply an essential core of religious and human values that were the root of all the various religions and it was toward these essential values that all religions and religious believers ought to strive. The second, and more radical of the two, was that as the various fields of intellectual endeavor had one after another come to view the empirical basis of natural science as the truist form of investigation, so the concept of natural religion was based in the belief that nature presented a more direct accessibility to the divine through the contemplation of His creations. The result was a belief that God had indeed created the universe, according to immutable natural laws, but had subsequently relinquished direct intervention in its operation, leaving it to run in accordance with those laws. The nature of the divinity and His wishes for the universe were capable of being understood in a much more straight-forward manner without the mysticism of 
Church ritual and without the necessary submission and sublimation

of the human will. Natural science was thought to provide the firmest

foundation for religion because:

Our views of Nature, however imperfect, serve to represent to us, in the most sensible manner, that mighty power which prevails throughout, acting with a force and efficacy that appears to suffer no diminution from the greatest distances of space or intervals of time; and that wisdom which we see equally displayed in the exquisite structure and just motions of the greatest and subtilest parts. (Beckex, 1965:62.)

And that:

These, with perfect goodness, by which they are evidently directed, constitute the supreme object of the speculations of a philosopher; who, while he contemplates and admires so excellent a system, cannot but be himself excited and animated to correspond with the general harmony of nature. (Becker, 1965:63.)

Understood in its fundamental form, the conflict that the philosophes were engaged in was against superstitution and not merely faith, that is, against the Church not religion per se. Enlightenment religion merely took a new form, a form which was determined by the question of certainty. The philosophes found their unquestioned certainty of religion (as. with their other sources of truth) not in the handed-down revelation of the church but in the direct creation of God, the natural world. 44 In such a conception the individual must of his own will seek out the certainty of his beliefs, and in so doing the religious convictions that result become an active force within the individual. Within revealed religion it was the

\section{4}

The "natural world" as used. in this sense did not simply denote the "wilds" of nature but was intended to include the activity of civilization as well. The history of mankind and the institutions that man has built in coping with life were part of the natural world as well. 
unquestioned acceptance of the Church's dogma that was taken as the measure of true faith, a passivity that ran counter to the spirit of the Enlightenment, a spirit that saw man's active participation in the world as a natural element of his nature.

In relegating God to a position of simply the initial Creator, knowable through his works, and in the attempt to regale the priesthood for its mystery mongering, the philosophes had used the argument of the greater power of reason and common sense not only to find truth but to make the whole of society stronger morally. But problems arose in this line of reasoning for if God, and presumably his goodness, were knowable through his works, then how would it be possible for them to find a basis for human morality in God's works if those works included evil, pain, and suffering? Thus the dual problems of the existence of evil and the source of morality necessitated some additional thinking on the position of natural religion. Traditional Christian dogma had accounted very well for the existence of evil with the notion of Lucifer's fall from grace and the subsequent sin of Adam and Eve. But from the position of natural religion, the existence of evil presented an important stumbling block since it was believed that God had created the world in accordance with immutable principles. Did this mean that such principles included evil? There were numerous responses to this question. One response was that evil served a positive function in that it prevented men from becoming too complacent with the world as it was, that such evil served as a source of motivation like other appetites and drives pushing men constantly on 
to make the world a better and better place to live. Another response was that while God had created the world according to certain immutable principles or laws the whole of creation was still in a process of development, that is, that God had created the material and the processes but the carrying out of those processes was as yet an unfinished matter. In light of this it was not surprising that the yet unfinished world would harbor such imperfections as evil, pain, and suffering. This idea fit particularly.well with the idea of the increasing progress of knowledge and its power to increasingly give men control over their environment as well as the idea that was gaining credence about the potential progress of the whole of human characteristics, virtue and happiness, as well as knowledge.

While the question of evil may have generated various ideas that could reconcile the problem, there was the additional problem of the source of a sense of morality. In seeking to destroy the myths of religion and the subjegation of the mass, the philosophes had managed to discredit the fundamentals of Christian morality as well. Placing God in the role of the Creator but not the intervener, and replacing the will of God (in the sense of Providence) with the power of reason was seen by many as moving steadily away from the divinity altogether. The atheism of Baron d'Holback represented to many observers the necessary result of replacing a personal divinity with a deification of nature and a veneration of the ameliorative and enlightenment powers of reason. In such a course they saw: 
Reason, writing on the wall the appalling judgments that there is no God; that the universe is only matter in spontaneous motion; and; most grievous work of all, that what men call their souls die with the death of the body, as music dies when the strings are broken. (Morley, 1897:175.)

Thus in undermining the very foundations of what was previously thought to be good, the philosophes had laid themselves bare for the accusations of their opponents that they were in reality the antithesis of all that was good and virtuous. If they could present no moral code based upon their own principles, they would drive men either back to the traditional religious beliefs, and all that they had fought to destroy, or on to atheism which most were likewise unwilling to accept. Not wanting to be thought of as unvirtuous men, and realizing that if their work were to be taken as anything but the writings of a negative and wicked force, then it was necessary for them to provide an alternative justification for moral behavior, a justification that could be found in the natural world.

Finding such a source of moral behavior in the natural world required recourse to the behavior of man himself, as Holback had commented earlier, man must learn to have "respect for his own reason - . so that he may learn to base his morals on his own nature". (Wallbank et al., 1965b:73). To base his morals on his own nature meant to determine what was essential and lasting in human nature and what was merely a passing phenomenon. The essential and lasting in human nature were to be determined by searches to the very comers of civilization, both living and dead, that would allow the men of the Enlightenment to distill out those qualities of humankind that were common to all men in all times and places. 
These qualities it was believed would present the essential core of human nature and allow for the comparison of what beliefs and customs were in consonance with this essential core, the natural order of mankind. These searches were in fact looking for "man-ingeneral," a beast that did not exist in time and space but was the abstraction of all men of all times, the qualities that all men shared.

\section{Philosophy of History}

The search for man-in-general required recourse to historical information if it was to find those essential qualities of man in the past ages. This did not entail a break with the past as Descartes attempted nor a veneration of the past as the Renaissance had seen, but rather it was the attempt to simply make use of it. In light of this task, however, the philosophes were much less than satisfied with the traditional form of historical analysis which had concentrated on the accumulation of facts and more facts. If the search for man-in-general was to succeed it was going to have to be undertaken by the philosopher who would be able to ferret out the useful information from the unnecessary facts. The ideal method for this detective work was:

- .to note the ideas, customs and institutions of all peoples at all times and in all places, to put them side by side, and to cancel out as it were those that appeared to be merely local or temporary: what remained would be those that were common to humanity. (Beckex, 1965:100.)

It was an attempt to follow at least the spirit of the natural sciences, an attempt to develop a method that was: 1) comparative in its application to the study of all men at all times and the 
analysis of the differences and similarities between them; 2)

objective in its attempt to allow the facts that emerged from

history to guide the analysis; and 3) inductive in that the facts

that did emerge were to be utilized to reason from the multitude

of human qualities those that were believed to represent the natural

order of mankind. The purpose in essence of the "new history"

represented here was to decipher the criteria of moral behavior that

could not be accomplished by the exercise of reason alone. In leaving

behind the abstract rationality of the previous century the philosophes

also left behind the belief in the power of reason cut free from the

natural world as a source of knowledge able to distinguish between

the good and the bad. Reason, granted, would be used in this new

historical method but it would be a reason that would be validated

by the mass of human experience. In reality, however, the grand

plan outlined here was rarely, if ever, adhered to as the following

examples will show.

Voltaire, Montesquieu, and Turgot

Three of the more important men in this new approach to historical analysis were Voltaire, Montesquieu and Turgot (Anne Robert Jacques. Turgot, Baron de 1'Aulne, 1727-1781).45 Each one approached their task from a slightly different perspective and with slightly different motives. It was Voltaire that first coined the term "philosophy of history," 46 and it was Voltaire that was among

${ }^{45}$ Condorcet's historical analysis was in the same vein but it came at a much later date.

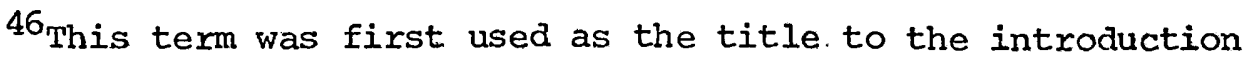
of the 1756 edition of Essay on the Manners and Spirit of Nations. 
the first to undertake a study of history in the more philosophical manner of the 18th century. Such a philosophical approach was first found in his initial two historical endeavors, Charles XII (1731), and The Age of Louis XIV (1751), works which perhaps displayed his innovative approach to historical analysis better than later attempts. It was, however, the work entitled Essay on the Manners and Spirit of Nations (1756) which was most pextinent to the subject at hand. While Jacques Bossuet's (1627-1704) famous Discourse on Universal History (168I) had chronicled the movement of civilization fxom the time of the Bible to the period of Charlemagne within the perspective of the process as an unfolding of the divine will, Voltaire's own history contained in Essay on the Manners and Spirit of Nations began where Bossuet had ended and carried the process on through the Renaissance, but this time explaining the unfolding in purely naturalistic terms. Voltaire wanted to utilize the persuasive powers of historical documentation for the advancement of the idea of the rationalism he believed in, that is, to put history at the service of the movement of reason and to show that history was in fact the story of the movement of reason. This was to be accomplished by tracing the movement of the idea of reason through the ages up to the present, tracing both the triumphs of reason and its struggles and defeats. The movement was a struggle between reason and unreason. On the side of reason there was eternal moral law and the power of judgment that led the way to truth, on the side of unreason there was folly, ignorance, and superstition. Voltaire (Meinecke, 1972:61) saw reason as: 
- . the gold that was to be had at small price; unreason the combined mass of all other earthly materials God had given to men along with the gold; and from these men had now to cleanse themselves step by step. In this work of purification man was left to his own resources and, as we have already seen, could not expect any further direct assistance from God. For the machine once created by God now had to pursue its own serene course according to the laws controlling it.

Voltaire without doubt believed in the idea of progress and saw the period in which he was living as displaying that progress more than any other period in history. But his view of progress was somewhat different than that held by the majority of his contemporaries. While believing in progress and the changes that it involved Voltaire nevertheless still believed in the permanence of human nature. The changing face of mankind which had been construed as progress was in reality merely the expression of transitory customs and habits. As Voltaire (Cassirer, 1951:219) stated:

- . it is clear that everything which belongs intimately to human nature is the same from one end of the universe to the other; that everything that depends on custom is different, and it is accidental if it remains the same. The empire of custom is much more vast than that of nature; it extends over manners and all usages, it sheds variety on the scene of the universe; nature sheds unity there; she establishes everywhere a small number of invariäble principles.

But the question of where the real change occurred in progress and the movement of history in light of the fixity that voltaire provided for the human character led to the additional question of the value of historicäl analysis and the search for social causality in history if all change and development merely resulted from habit. If the moment that one penetrated the appearance of change the principles derived all operated in the name of fixity and 
permanence what did this portend for the movement of progress, and the goals that were hoped for it?

This problem was reconciled by the fact that while there was a fixity to human nature the limit that was presented by the fixity was not to be reached all at once. Humanity constantly came closer to this limit, constantly strove against the obstacles that were obstructing this movement. When speaking of human nature and that which was permanent, Voltaire was referring primarily to reason. While reason was everywhere in everyone the same (apropos of its eternal nature) it did not manifest itself outwardly in this uniform mode but rather was deflected and distracted by the powers of custom, habit, and superstitution. The history of man, the tale of human progress was then the struggle that reason underwent in overcoming the weight of these obstacles as it strived to assert itself in a purer form. Thus one must see that:

- real progress does not concern humanity as such;
it refers only to the objective, empirical manifestations
of humanity. But the process by which reason emerges
empirically and becomes comprehensible to itself, represents
the fundamental meaning of history. (Cassirer, 1951:220).
Thus the attempt to find in history the same sort of fixed laws that were displayed in the natural sciences one would not look to the action of men and the chronicles of empires throughout history for they were extremely variable. That lawful behavior must be found in the fixed character of human nature, in the character of reason, and so the true object of historiography should not be the tales of mankind's adventures but the minds of men. 
As the knowledge of the mechanics of nature removed natural science from the realm of theology and the providential teleology that clung to it, so could the knowledge of human nature remove history of mankind from the same realm of teleology that has been a part of it at least since the time of Augustine. With the mind of men as the object of historical investigation, it followed naturally enough that psychology must be the discipline that took up the torch and led the investigation. What mathematics did for the natural sciences so psychology could do for historiography. It was psychology that had the power to determine what the essential character and dimensions of progress were. It could explain and justify its movement and it could elaborate the limitations of progress as well, thereby keeping the idea of progress from acquiring the excesses of myth and superstitution that became fundamental to the idea of Providence.

In his specific analysis of history, Voltaire was very much taken with the vast variety that history had to offer. He delighted in describing just how relative the nature of men's habits and customs were, and what role was played in history by the forces of accident and circumstance. In spite of the varying factors affecting the course of history, Voltaire did believe that the variety of phenomena that occurred would be calculable products of a combination of both stable (human nature, reason) and variable factors if one could attain all the necessary data. In reality, however, one had only a small amount of actual data to illuminate the causal 
interlinking of all things. For Voltaire the world operated like a kaleidescope where things changed mechanically (i.e; according to climate, human nature, etc.) but not calculably.

In construing history as the emancipation of reason, voltaire was able to evoke an idea of world history as a unified whole, and while this had been accomplished before in the work of Augustine for example, it was the first time that it had been accomplished without recourse to Providence or divine will. The unified history of mankind was the history of the perfection of reason.

In Montesquieu's major work, The Spirit of Laws (1748), the approach was somewhat different than that of Voltaire. Of course there was the difference in the fundamental topic itself, law versus universal history, but beyond this there was the fact that the focus of Montesquieu was much more centralized than that of Voltaire. For Montesquieu political events were the primary focus of the work, for he saw in political history world history in general. As Cassirer (1951:212) noted Montesquieu's perception of the relation between these two histories:

The kind of education and justice, the form of marriage and family, the whole structure of domestic and foreign politics, depend in a certain way on the fundamental form of the state; these aspects of the state cannot be arbitrarily altered without affecting the form of the state and finally destroying it.

The focus was smaller for Montesquieu than for Voltaire. Voltaire took the advances of religion, arts, science, and philosophy as having an autonomy of meaning that was implicitly repressed in The Spirit of Laws. For Voltaire one would have to look beyond merely the spirit 
of law and the subsequent changes that it caused to the advances in the various sectors of human activity and expression if one was interested in understanding the full nature af human progress, for it was in the advances of these sectors that the advances in reason could be traced.

In another sense, however, the approach of Montesquieu must be considered broader and more comprehensive than VoItaire in that he was more committed to finding the general law behind the manifold world. For Montesquieu the whole of history may have first seemed but a mass of unrelated events, but upon further investigation, further penetration into the depth of those events the more it became apparent that there were underlying tendencies to the seemingly unrelated events. The more that one penetrated and understood historical events the more that the underlying tendencies appeared and the unrelatedness disappeared. What those tendencies betrayed was an underlying rationality to the historical process, with law as the bond that united this rationality to the individual and individuals to one another. Montesquieu's task was not simply an empirical description of the various forms of political constitutions. (republican, aristocratic, monarchical, despotic) but also to find the constructive forces behind them, the general laws that governed. the empirical variety. It was a task that sought:

- . to combine the empirical sense of the manifold variety in human affairs and their. unnumerable specific causes, with the sense of a rational unity presiding over this multiplicity and ultimately explaining it. (Meinecke, 1972:111.) 
The factuality in which he dealt was, in light of this greater task, not the central concern of The Spirit of Laws but rather was the medium that allowed him to grasp the general laws that governed the various facts. It was only in the concrete factual expression that the general laws became manifest and comprehensible. Montesquieu in fact had little concern for the facts as facts. They were illustra-" tive rather than definitive and so conveying them with absolute accuracy was not as important as conveying the implications that they carried. Montesquieu's concern with the underlying lawfulness of history and not the factuality of its structure was clearly shown in the title of the work, the "spirit" not the structure of laws.

In the course of history there were both general and particular causes. The overthrow of a specific government may be the result of a coup that was a particular cause but there was also general causes that led up to the coup in the first place. In this manner Montesquieu allowed for the existence of both particular and genexal causes to historical events but deferred the particular to the general, it was the general causes that drew the particular causes along.

There were for Montesquieu physical factors as well that influenced this general trend of causality, physical facotrs found primarily in the climate and the soil. These factors would operate to condition particular temperments in the people of a region and in so doing predispose them to one type or another of political structure. Poor soil for example would inspire industry, frugality, and independence perhaps disposing those people toward a democratic 
structure. Purely geographic factors had their influence as well in that such factors as mountains that tended to isolate one group from another also tended to protect the independence of those isolated groups, protect their particular structure of political institutions from outside influences.

Even though such factors as these were capable of influencing the general causal trends that led to one form of political structure or another, there was no necessary relation between physical factors and the general laws of history. In fact, Montesquieu often subordinated them to the spiritual factors in mankind, that is, that men could recognize the influence of physical factors (geography, climate, soil, etc.) and exert counteractive measures to neutralize or change those physical factors for their own good.

The fact that different climates of the world conditioned individuals toward different temperments and different intellectual capacities, and yet there still existed viable systems of laws in all cases augered well in Montesquieu's mind for the existence of general laws in mankind's activity just as there were such laws in nature. The stage of human development, however, was not such that men followed these fundamental laws in the same degree of consistency as nature followed its laws. This was partly due to the limited understanding of men which led them into error, and partly due to the power of individual wills and ideas which led them away from the fundamental laws of human process. Even though Montesquieu saw that men did not fully grasp or make use of laws that operated in 
human history, he was true to the spirit of the Enlightenment and felt that the continued advance of knowledge would at some point change this and mankind would lead itself to the emergence of a new moral order, and thus a new era of political and social history. The influence in the previous instances of both general and particular factors, and a certain ambivalence as to the exact relationship between the two served to indicate an underlying factor in Montesquieu's historical analysis. As the thought of Voltaire had been dominated by the struggle of reason and "unreason," the thought of Montesquieu was strongly influenced by the interplay of what may be termed naturalism and rationalism. It was the interplay in nature of:

- - an irrational or supra-rational power over all life and the source of all reality, or a rational power that worked in and through the mind of man. (Meinecke, $1972: 107$;)

This in part helps to explain the view that Montesquieu had as to the dynamics of history. There was for Montesquieu a mutual interaction of the general and the particular as well as the environmental and the individual, that is, nature as acting on man and nature as acting through man. It was an understanding of the dual importance of the causality arising from individuals acting with deliberate purpose as well as the causality that resided outside the individual's command.

In regard to the ideal method that was originally espoused as the means of finding this man-in-general outlined earlier, Montesquieu came the closest to following it. First, in the sense that he sifted through the mass of factual information looking for 
the general laws that operated beneath the surface and which gave to the manifold world its form. Second, Montesquieu was the first to grasp and make use of the "ideal type" as a means of generalization and comparison. The search for man-in-general was really an implicit attempt to derive such an ideal type construction of lasting characteristics of civilized man. It is interesting to note that though Montesquieu perhaps followed the ideal method more closely than others, his results were often received less warmly than others because of the fact that the results he arrived at were often not the ones that the men of the Enlightnement period wanted and knew in their heart must come from history. It was often thought that Montesquieu gave undo influence to such relative factors as the influence of climate and geography on the evoluation of human institutions, though these were the very findings that the venerated method of the day led him to.

In the work of Turgot one finds bits and pieces of the systems and methods of Montesquieu and Voltaire, but Turgot's general approach and conclusions were not the same as either of the previous two. Turgot published no specific book that dealt with his analysis of history and his views of progress, so much of the perspective from which he operated and the views that he arrived at have been gleaned from a variety of sources. The most productive of these was his lecture at the Sorbonne in 1750 entitled On the Successive Advances of the Human Mind. Turgot saw its purpose as tracing the movement of civilization specifically in light of the idea of progress. 
Turgot believed that general conditions were responsible for the general course of history, first in the nature of human nature and reason, and second in physical environment, geography and climate. But for Turgot the specific course of history was still to be construed as a sequence of particular causes and effects. The influences on the movement of civilization that had been attributed to physical causes, however, were often misunderstood and exaggerated. For him physical causes could have an influence only if they acted upon the formation of the mind and its character. It was the psychical and moral causes that were primary in the movement of civilization, and only after exhausting these should one turn to the physical causes for explanation. For Turgot the valid method of studying the development and movement of civilization was one that was based upon the study of the mind, upon psychology, and that meant the psychology of Locke. In this vein human communication was the primary medium of transmitting progress. Turgot (Vyverberg, 8, 1967d:165) thought that:

- . ideas deriving from sensations are developed through the use of signs, pictures and especially language, by which knowledge and experience are transmitted and augmented from generation to generation.

Turgot was optimistic toward progress as a whole, viewing the progress of mankind as a slowing advancing whole that steadily moved forward toward perfection, indeed Turgot did believe in the perfectability of mankind and his institutions. This forward advance moved through periods of strife and calm. Each generation learned from the previous ones, and each generation bequeathed to the 
following generation its share of social wisdom. Particular empires and societies may rise and fall but there was something of a positive social value that remained, a fact which enabled mankind as a whole to move inexorably, though slowly, forward. This continual augmentation of the store of social wisdom and experience provided a continuity where "all the ages are linked together by a chain of causes and effects which unite the existing state of the world with all that has gone before" (Becker and Barnes, 1961b:471). But while the entire whole of civilization moved ever onward it was not the case that all units of that whole, the various societies as well as the various areas of human endeavor (science, morality, technology), all moved at the same pace. Progress was uneven with the variations. in pace being caused by an infinite variety of causes and circumstances, not the least of which were the facts that:

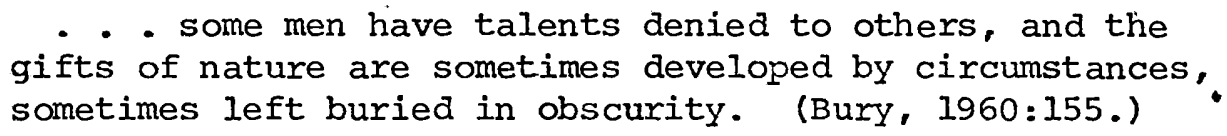

An interesting aspect of Turgot's conception of the advance of civilization was his conception of civilization as having been guided not by reason so much as by passions such as greed and ambition. In following these passions men had not made happiness the conscious $: . \cdot$ goal of their actions, in fact men had never really known to what goal they were moving. If. reason had been the supreme guide then it was quite possible that there would have been an early halt to progress, for men would have taken greater care to protect themselves from dangerous situations, both the threat of invading armies and ideas that were dangerous to the status quo. As a result there 
would have been in all probability a withdrawal from interaction among the various societies of the world and the growth of civilization through the exchange of ideas would have ceased. The very passions that men sought to subordinate to reason were for Turgot among the very factors that had been operating to keep civilization moving until the time when it was enlightened to the point that it could use reason productively. The curious conclusion thus arose that if it had not been for the lack of reason and the baser passions then there would not have been the progress existent at the time.

The interesting note in this conception of the role of the baser passions resides not so much in their operation as the fact that they served to guide the course of civlization. Others who had the greatest belief in reason also felt that the baser passions had an important role in the movement of civilization. Voltaire, in his Treatise on Metaphysics (1734), stated that without the desire for fame, without greed and ambition, thexe would have been no progxess to civilization. Voltaire (Cassirer, 1951:107) stated that:

It is with this motivating force that God, whom Plato called the eternal geometer, and whom I call the eternal machinist, has animated and embellished nature: the passions are the wheels which make all these machines go.

The power of the mind stemmed from the balance of the passions and reason not from the complete eradication of the former. Thus while other thinkers of the period may not be willing to give quite the decisive role in the direction of civilization that Turgot did, they were nevertheless more than willing to give the passions a substantial motivating and creative role. 
While the role Turgot ascribed to the passions differed slightly from the mainstream of Enlightenment thought there still. resided a fundamental belief in the power of reason for Turgot was ultimately willing to let reason take over when it could guide men "productively." His connection with the mainstream of thought was also reinforced by such ideas as the biological fixity of human nature. Turgot must rely upon the same mechanism for the movement of man towards perfection in light of this fixity that was found in the works of Locke and Condillac, a successive reciprocity between the formation of the mind and the environment which brought the mind ever closer towards perfection.

Turgot's conclusion about the role of the passions led him to regard all the occurrences of civilization, both the great discoveries and inventions as well as the great catastrophes and mistakes as being indispensible elements of the movement of progress. Those events that were thought to be disastrous for civilization have in fact had a productive influence as well for civilization has gained greater experience and has become wiser for it. Movement and change, whether they arose from good sources or from evil, error, calamity, and passion, gave rise to new relationships and new experience, all of which could be instructive for civilization. Turgot believed for civilization as a whole much the same as Fontenelle believed for knowledge, that progress was made as much be the eradication of error through experience as by the great discoveries.

Turgot provided historians with another means of dealing with historical periods that had heretofore been thought of as regressive and thus detrimental to the idea of the forward movement of 
knowledge and civilization. Historians could see periods previously thought regressive as periods of growth, at least in experience, albeit growth that may have been barely discernable. Many types of growth however, in commerce and some mechanical axts for example, did not develop their full effect until a passage of a great deal of time. so that the rate of progress was deceptive. It may take decades or centuries for ideas and changes to come to fruition, thus one must be particularly careful in analyzing the progressiveness of any one historical period.

Turgot developed two laws of the development of civilization. The first was that in the progress of civilization each step of that progress provided an accelerating effect to the whole rate of progress. The movement of civilization was a cumulative affair, each advance augmented the cultural base from which further advances could be derived, thus making a greater number of advances possible, which in turn accelerated the potential for progress even more. The process continued to gain speed with each advance. The second law of development dealt with the evolution of the intellect, at least the rationalizing structure of the intellect, to its present level of development. There were three steps in this evolution of intellect. The first step was for men to construe natural events as being caused by the intervention of intelligent beings, beings which were invisible but who had a human form. The second step was to explain events, or the cause of events, with abstract statements dealing in essences. The final step was that in which events were capable of being explained in terms of mathematics and 
mechanics. It can be seen that Turgot anticipated Auguste Comte's three stages (theological, metaphysical, positive) of evolution, and while Turgot did not develop it to the sophistication and profundity that Comte did he still deserves credit for being the first to have announced it.

In regards to the study of history. Turgot made the idea of progress more alive by using it as an organizing tool around which historical events could be understood and organized. It gave a wide variety of events in history a meaning and unity much in the same manner that Providence had been capable of in earlier periods. For Turgot history represented a whole, with the fortunes and advances of each particular society studied in its relation to the progress of civilization in general. The historical movement of civilization was one continuous movement made dynamic generally by the movement of ideas and their effects from generation to generation, and more specifically by a myriad of othex causes (technology, art, etc.) and their relation to society.

In these three men, Voltaire, Montesquieu, and Turgot, one has a representative sample of the nature of historical analysis in the 18th century. Though in the beginning objectivity was professed to be an important element of such analysis, as time bore on the objective content of these and other historical studies was seen to be of a secondary importance. Each author in their own way sought to substantiate their. own beliefs and those of the entire Enlightenment period. The men of the period really had 
too strong a belief in the rightness of their own convictions about the nature of man and his advance to come to value any other period of time or any other set of convictions. In a real sense the great majority of the historical analyses that were written in this period were just means of proselytizing the rationalism of the 18th century and 18th century social reform. Rather than intending to add substantively to the corpus of knowledge these works were by and large to be used as tools by which the ancien regime, and the Church which was so much a part of it, might be done away with. Montesquieu (Becker, 1965:116) brought this to the fore when he stated in his Defense of the Spirit of Laws how the work was received by contemporaries:

They have regarded the Esprit des lois as a useful work; they have thought its morality sound, its principles just; that it was well designed to make good citizens; to refute pernicious opinions, to encourage good ones.

Explicitly or not the historical analyses of the period often used the perceived high points of civilization, the time of Pericles, Augustus, the Renaissance, and the reign of Louis XIV on into the 18th century, ${ }^{47}$ to contrast with the nature of civilization during the Medieval period when Christianity was in complete control. The contrast between the vitality in the former, where it was believed reason and common sense prevailed, and the stagnation in the latter was thus meant to indicate that Christian philosophy, theology, and all the superstitutions and myths that accompanied it were not in the best welfare of civilization.

\section{7}

Voltaire called them the "quatre ages heureaux," which roughly translates into the four happy (blissful) ages. 
In this period history became removed from the passive role and was plunged into the thick of ideological debates, into the struggles of the world of the present and the future. History in the future would be on the move, active. From the time of Voltaire on struggles over the nature of civilization to come would be fought in part on the battlefield of history. The appeal to history in the 18th century brought about the emergence of the idea that history was not something that existed in some pure state external to men, but that it was created by each new interpretor and the needs that each interpretor had. One additional accomplishment of this period of historical interest and the men who concerned themselves with the topic was the spread of the notion of history as some manner of. lawful movement, a movement that manifested an inner order and purpose once one was able to look beyond the manifold variety that first presented itself to men.

In viewing the results that came from the search for man-ingeneral the men of the Enlightenment might well have saved themselves the time and enexgy. They managed to find that the qualities that they were looking for almost exactly corresponded to those qualities that they cherished the most and those qualities that most characterized the period in which they were living. They "somehow" also arrived at those characteristics that were most potent in their conflict with Christianity. Thus while intention, perhaps honest enough, was to allow those qualities as should be found in history and in investigation of the diverse points of the contemporary world that presented themselves as universal to determine the nature 
of man-in-general, the philosophes were much too concerned with their struggle against the Church to allow those investigations to produce anything but what they needed. That struggle required that they provide the necessary perspective to historical analysis in order that the whole of human experience should justify their beliefs in reason and nature (and natural law). Reason alone had not been sufficient to completely dislodge the potent adversary and now the full force of ages past was to be mustered into the fray.

Thus the underlying purpose of these historical analyses, and other such undertakings of the period, ultimately had been to provide a grounding for the rationalist approach to knowledge, morality, and the meaning of life. But such a grounding, inorder that it might directly refute the doctrines of the Church, necessarily had to be developed on a common ground with Church thought. Meeting on a common ground meant that the philosophes had to present a competing interpretation of the past, the present, and the future as well. It was this connection with the future that the idea of progress found one of its most potent uses. Christianity had the whole of existence from the very beginning to the very end of the mortal Iife and all that lay beyond defined and categorized to the smallest detail. It was perhaps the promise of the future that provided the Christian interpretation of the historical process with its most potent defensive weapon and the incentive that had drawn men to its breast from the very beginning. The cyclical interpretation of history had nothing to offer but continuous repetition, as Marcus Aurelius $(1956: 140)$ related: 
- . our children will see nothing fresh, just as our fathers too never saw anything more than we. So that in a manner the man of forty years, if he have a grain of sense, in view of this sameness has seen all that has been and shall be.

Such a cold and bleak view of history provided little sense of reward for the endurance of what was for the vast majority of men a mercilously hard life. Christianity in at least holding out the possibility of eternal bliss provided for most the potential reward for the hardships that they were daily having to endure. It also promised that at one day in the future all the wrongs that had been perpetrated against the oppressed would be righted, that the unjust and the undeserving would spend eternity in hell and the good and deserving of men would be rewarded, the scales of justice would be balanced. While Christianity did not offer to make this life less unhappy (for this world would still have to be endured until judgment day) nor any less predetermined (for the doctrine of Providence guided the every move of men) it did provide a means of understanding and accepting the hardships and injustices of life. Perhaps the coup de maitre of Christianity was that all that was required of men to qualify for the eternal salvation was obedience to the dictates of God's representatives on earth (the Church proper) and a resignation to the will. of God as carried out in Providence. Obedience and resignation, the two qualities most familiar to the subjected mass. Above all the power of the Christian interpretation of history was that it provided hope for men surrounded by a pessimistic milieu. 


\section{Progress as Secular Heaven}

The world of the philosophes, the rational world, had provided its own competing account of the past and the present, but if it was to "ecrasez l'infame"48 it: was necessary that it provide an alternative future, a heaven of its own, one that held out the same hope, the same potential for happiness that was found in Christian salvation. In presenting such an alternative, however, it was necessary that it be in accordance with the fundamental beliefs of Enlightenment thought. Such a heaven had to be located, if such a term was appropriate, here on earth because of the fundamental belief that the end of life was the perfection of the temporal Iife. Such a heaven on earth was necessarily located in the future as well because of the accepted fact that the temporal life was not perfected as yet. Lastly, in deference to the belief in the enlightening powers of reason (but a reason tempered by sentiment and experience) this heaven on earth was not to be brought about by the intercession of God or any other external agency but by the successive improvement of the social whole through the effort of each subsequent generation.

The need to find a naturalistic substitute for the theological conception of heaven disclosed one of the primary motives for the greater expansion of the idea of progress in the 18th century, and thus ultimately its greater acceptance. The need of the philosophes and the existent idea of progress keyed perfectly together. The 
possibility of social progress was built upon the principle of the advance of reason, whether that reason was thought to lead to the "perfection" of human nature through the successive refinements of the social environment following the Locke/Condillac notion of the formation of the mind, or whether the power of reason was conceived. of as being. capable of simply leading to a more enlightened government. In either case it was the progress of knowledge, conceived of as the advance of reason, that led to the greater social progress. In the first instance the greater knowledge of human behavior, the laws by which human nature was formed, and the methods by which men might change their environment would lead to the ability to "tailor" the environment so as to create the kind of felicitous human nature desired. In the second instance at least an advance in the knowledge of human behavior and human needs might lead to an understanding of how best to govern society, or how best to establish those social institutions that would be most advantageous to society. In either case it was the knowledge generated by man through the methods of natural science and under the guidance of reason that would eventuate the state of social felicity on earth.

The men of the Enlightenment thus constructed their alternative to the Christian interpretation of history, of the world, of reality. As Becker (1965:130) phrased it:

For the love of God they substituted love of humanity; for the vicarious atonement the perfectability of man through his own efforts; and for the hope of immortality in another world the hope of living in the memory of future generations. 49

${ }^{49}$ Voltaire echoed this in his own style when he stated that "nothing is more annoying than to be obscurely hanged." 
The future now became more than simply the "place" in which events would take place. The future became animated with a force and a morality of its own. Men no longer appealed to the word of God as a means of justifying their actions. They turned, rather, to the supposed judgment of future generations to see the universal and truthful character of their work and their beliefs. This appeal to future generations can be seen to have still existed later in the century in the emotional speech made by Robespierre (Becker, 1965: 142-143) in 1792. before the Jacobin Club:

o posterity, sweet and tender hope of humanity, thou art not a stranger to us; it is for thee that we brave all the blows of tyranny; it is thy happiness which is the price of our painful struggles: often discouraged by the obstacles that surround us, we feel the need of thy consolations; it is to thee that we confide the task of completing our labors, and the destiny of all the unborn generations of men! - . May the matyrs of liberty.. occupy in thy memory the place which the heroes of imposture and aristocracy have usurped in ours . . .

As they believed their analyses had been able to distinguish the universal and the everlasting from the fleeting temporary so the analyses of future generations would be able to distinguish their actions as partaking of this eternal characteristic in the face of their opposition who were motivated by the particular customs of the day. It mattered not if the mass of men might look upon them as the enemies of conventional morality if their beliefs would be vindicated by the judgment of humanity in the future.

\section{ENCYCLOPEDIE}

The epitome of 18th century thought, particularly that of the philosophes, was to be found in the work of the famous, or infamous, 
Encyclopedie. It was in the Encyclopedie that one found the attempt to put into practice the ideals embodied in the idea of progress. One finds amid its articles the essence of 18th century thought; Lockian epistemology, the belief in the enlightening power of reason and the natural sciences, the inexorable progress of knowledge, the possibility of the progress of mankind toward a state of social felicity, as well as articles extolling the need for tax reforms, greater personal and political liberty, and religious tolerance. It should not be surprising to find such a sampling of 18th century thought, nearly all of the important minds of the middle decades of the 18th century were called upon to contribute articles for publication, contributions such as Montesquieu on "tastes," Quesnay on "grains," and Turgot on "existence" (Wilson, 1967b:506).

To say, however, that the Encyclopedie characterized the essence of the thought of the 18th century was not to infer that those involved were sufficiently in agreement on the nature of reality, religion, and progress to form a distinguishable school of thought. There did exist considerable variation even among those closely involved with the undertaking. The most advanced position was occupied by Helvetius. Following Lockian thought Helvetius believed that the function of the mind was the recording of sense impressions that arose from the external world, a capacity he called "sensibilite physique."50 Not only the intellectual and moral capacities of the individual but also his system of values and motivation were the result of education, by which Helvetius meant 
the total environment from birth. Such an environment, however, excluded biological differences, because they were considered to be constant among all individuals, and the effect of climate which was not thought to be of sufficient influence. Thus for Helvetius the character of men was totally a result of social circumstance. Change the "education" that an individual experienced and one could change the character of men, change their moral as well as intellectual character. The unlimited progress of civilization was straight forwardly a question of education. With such a view of the mechanism of progress Helvetius believed there to be no insurmountable obstacle. to the advance of the so-called backward races of the world, all races were capable of contributing to the advance of civilization and partaking of the fruits of progress.

On the other side of the coin were the views of Denis Diderot, the main force behind the Encyclopedie and perhaps the most diverse thinker of the period. He was adept in the fields of mathematics, chemistry, and biology, as well as being informed in the realm of medicine. Differing from his contemporaries, Diderot held the universe to be a single physical system which obeyed the laws of matter in motion. This system was in a constant state of becoming rather than static or created.. As Diderot (1964:117) stated:

The world is forever beginning and ending; each instant is its first and its last; it never has had, it never will have, other beginning or end.

All change in the universe, not merely the random motion of elements but the apparent movement from chaos to order, was explicable in terms of the interaction of the fundamental material particles. In 
postulating sensitivity as well as motion to these fundamental particles Diderot felt he was capable of explaining all experience and all natural phenomena, mental as well as physical.

From his conviction of the notion of matter in motion and the constant change that it entailed as fundamental facts of the universe, and yet faced with the obvious fact that amid this constant change there was continuity of form, Diderot developed a notion of evolution that anticipated that of Lamarck and Darwin. This was particularly the case with the notion that bodily organs could be produced by the "needs" that the body felt in reaction to some stimulus. Most important for the question of the malleability of human nature was the acceptance by Diderot that subsequent generations inherited the characteristics that were acquired by previous generations. He hypothesized organic development through a system of fibers, similar to the nervous system. Thus contrary to the advanced environmentalism of Helvetius, Diderot was positing that there were genetic, inherited, factors that entered into the development of human nature. All of this did not mean that Diderot did not believe in the progress of man, his biological studies had in fact convinced him that the individual was moving toward a state of perfection; the rise of science indicated to him that nature "wanted" man to improve. But while he was convinced of the perfectability of man, he was not equally convinced of the inevitability of the perfection of civilization and its social institutions. While he felt civilization was capable of progress Diderot, like Rousseau, had cultivated an admiration for the "noble savage" and a belief in 
the corrupting capacity of modern civilization. Of his belief in perfectability and progress one might say that of evolution he was certain, but of the progress of social man he was little more than hopeful.

While disagreeing on the extent to which man could be molded and perfected and the mechanism to accomplish such change the Encyclopedist all did agree on the enlightening value of education, as Charles Duclos (Cassirer, 1951:15) stated, "it seems to me there is a certain universal fermentation whose progress one could dixect or hasten by the proper education." Part of this fermentation was the desire for progress and greater happiness, and the education that Duclos spoke of was to play an important role. The possibility of perfecting society and human nature, if it was to occur at all,. was to reside in the ability of men to change the environment within which they lived. The notion being, as mentioned before, that if one changed the environment the sensations upon which the mind was formed would be changed as well, change the environment in a humane and virtuous direction and the nature of men would change in a like direction. It was obvious that contemporary society provided nothing like the necessary character of a morally fit and humane society, and thus the immediate task of the philosophes, and the particular task of the Encyclopedie, was to bring about change in a positive direction.

While the progress of knowledge had been taken for granted, it was realized that such progress had been actually limited to a relatively small segment of civilization. If modern society were 
to be changed for the better it was necessary that this progress and its fruits be distributed to a wider segment of society, and it was the Encyclopedie that was to serve as the medium by which a wider number of people could be reached. The Encyclopedie sought to create a wave of public opinion against the present monarchy and its influence, coupled with the Church, over the affairs of the society. In so doing, it hoped to create sufficient pressure to force social change. This public opinion was to be brought about not only by general enlightenment of society but by specifically educating the public as to the oxigin and the characteristics of the problems that had befallen society, andtrusting reason to guide them in the necessary direction of change. Within this attempt to hasten progress through education even those who put no store in the notions of the perfection of human nature or society could see progress in the changes that would come in the structure and functioning of society. If nothing else, reason would lead to a sane reorganization of society.

The Encyclopedie would serve one other end for the philosophes and that was taking some of the task of education out of the hands of the Church. While not attempting to totally supplant existing educational institutions, the philosophes did realize that if reason were to work its wonders it was necessary to provide as many alternative sources of information as possible. It would be information that was not contradicted in large part by the bulk of scientific knowledge as the greater portion of that taught in the Church schools was. 
Though the Encyclopedie came to be used for such auspicious ends, it did not begin in such a manner. The Encyclopedie first emerged as a commercial venture to translate Ephraim Chamber's work Cyclopaedia (1728). At first the Encyclopedie was entrusted to the Englishman John Mills, then to the German Godefroy Sellius, and then to the French Abbe' Gua de Malves of the Academie des Sciences. It was not until 1747 when Denis Diderot was named editor in chief that; in collaboration with Jean ie Rond d'Alembert (1717-1783), the world of the Encyclopedie was expanded to the larger aims just spoken of. It was the Encyclopedie of Diderot and d'Alembert that has been remembered through time. From the beginning of their association with the Encyclopedie, it encountered a a great deal of opposition and suspicion, particularly from the religious sector. It was officially suppressed in 1759 for a period, forcing it to be published in secret. The Encyclopedie encountered such opposition because it:

- constantly attempted to expose vulgar errors, to be as precise in definition as possible, to make exact. technological explanation an accepted part of the language, to suggest social reforms or greater civil liberties, and to weaken dogmatism. In biblical criticism or in articles touching upon political theory or materialism the Encyclopedie proved itself to be adventuresome and bold. (Wilson, 2, 1967b:521.)

In essence the Encyclopedie was devoted to the accumulation and widespread dissemination of knowledge rather than to the actual creation of such knowledge. The Encyclopedie served several functions; it was a guide for practical instruction, a format for speculative thought, as well as an organ of propaganda for the rationalists in 
the attempt to spread the apostle of reason. The breadth of the Encyclopedie can be seen in the fact that craftsmen as well as scientists and philosophers contributed articles. In the approach taken by the Encyclopedie it would function not only to disseminate knowledge to the populace and campaign against traditional authority, superstition, and ignorance, but it would also help to bring about the cooperation of the various branches of knowledge and perhaps even a cooperation between the arts and the sciences.

The idea of progress and the path to its fulfillment had for those involved with the Encyclopedie a decidedly social characteristic to it. They felt that they could entrust themselves to the progress of culture for in its movement they saw the power to transform society and thus to bring about a happier life. In light of this there was the belief that not only the growth of knowledge but the improvement of manners and such refined graces could and would transform the social mores and place them on a more enlightened foundation. It is within this perspective that the role of the fashionable salons of France comes into clearer focus. The urbane environment that was fostered in these solons was not only meant as an indication of social status but also as an indicator of the advancement of culture, that is, progress. These ideas in time led to a belief in the synonymity between the nature of society to which progress was heading and the concept of "sociability" which was essential to the atmosphere of the salon.

Aside from this belief in the advancement of culture as indicative of the movement of progress the social character of the 
Encyclopedie emerged in the genuine attempt to make the world of the scientist and the philosopher available for general consumption. But making such works available for general consumption often meant "translating" the works into a writing style and a terminology that was digestible by an educated, but not scientifically trained public. Typical of such applications was Voltaire's Elements of the Philosophy of Newton (1738).51 Such a trend in writing style, however, was not exhausted by the translation of scientific or philosophic work but extended to the actual creation of ideas as well. One finds social and political, scientific and philosophical ideas formed specifically for and often by the patrons of these salons. The belief in the necessity of popularizing knowledge, particularly that of science, and the belief in the advancement of culture as partaking of general social progress fostered the belief that the ability to withstand such popularization was a barometer of the profundity of such ideas. The ability to be expressed clearly in the language of the salons and yet retain its importance was thought of as a test of the clarity and incisiveness of an idea.

The role of popular expression and acceptance of leading ideas revealed the belief of the Encyclopedists that the movement of progress and the advancement of knowledge did not take place in isolation from the greater populace. but were intimately involved with it. It revealed the belief in the social character of knowledge and its movement and the necessary contribution that a

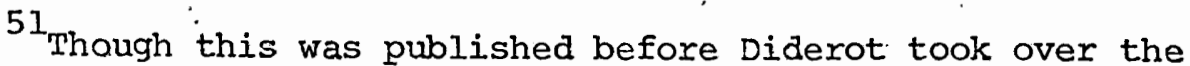
Encyclopedie, it is apropos for it was a classic example of the translating notion, the predigestion of works for dissemination to the lay public. 
receptive social structure could make to knowledge. Nature, in the undiminishing character of its power, created men of equal intellectual capacity in all ages, but these men were not all capable of making the same use of their talents nor of making the same contributions to society. A society that isolated its men of genuis and repressed their work diminished theix capacities when compared with a society that encouraged the utilization of their intellectual powers and made use of those powers. It followed then that the real fruits of reason and the enlightenment of man that the Encyclopedists, and the philosophes in general, believed they were a part of could be expected only when there was created a receptivity and an understanding of ideas, only when the populace could sufficiently appreciate then movement of thought could that movement produce real progress.

By their very involvement with the Encyclopedie project, those who worked on this undertaking reflected an enthusiasm that existed toward reforming society in the guiding light presented by reason and science, but their enthusiasm by and large did not sway them to the belief that such reformations could be accomplished with the sweep of a wand. They realized that it was a long way from the formulation of the necessary changes and actually realizing those changes. Even Baron d'Holbach, among the most politically active and radical of the philosophes, did not advocate the immediate institution of the changes that he had speculated on. In his Social System (1773) he advised against revolutionary solutions to social problems stating that the results of such revolutions are 
often of more detriment to society than the original solutions. 52 With reason as the guide, the reforms that were sought by the philosophes were to be gradual in their realization and as a result of their patience, they were to be more effective and long lasting.

\section{ESSENTIAI IDEAS OF ENLIGHTENMENT}

As each historical period seems to have those ideas which predominate and manifest themselves variously in all fields of thought and creation, so the 18th century had its ideas and the variations that radiated off of each. For the 18 th century there were three such ideas; reason, nature, and progress.

\section{Reason}

In the sense of a guiding principle and a force into which men placed theix being "reason was to the philosophe what grace was to the Christian" (Brinton, 2, 1967a:521). While being conceived in various manners and having varying power, reason was generally thought to be a kind of "common sense" that, by the permanent character of the powex of nature, was possessed by all men and operated in the same manner in all men. As earlier discussion brought out, reason in the 18th century was thought of as a force that was capable of guiding the quest for truth and knowledge rather than as a depository of them. In part, the power of the

\section{2}

He seemed to be somewhat prophetic about the results of the revolution to come in France. 
reason that men utilized to bring about knowledge of the universe resided in the fact that it was believed that the rationality of the human mind and the rationality in reference to which the universe operated were the same. For those who believed in the existence of God this synonymity was an expression of the fact that both were the creation of God. For those who did not believe in God, it was simply a manifestation of the rationality that was inherent in the universe.

While construing reason as a powerful source in its own right it was believed that training in such areas as logic and science would allow men to more effectively use that power. But likewise, as training in these areas would allow the more effective use of reason, so was it possible that factors emerging from the social realm would be capable of stifling the effectiveness of reason, would prevent men from. leaming how to use the power of reason. Not only was this possible but the men of the 18th century believed that was exactly what had happened. Social factors had corrupted the normal functioning of this common sense, corrupted it by replacing the standard of truth that was provided by reason with alternative and misleading standards, thus the influence of superstitution, prejudice, ignorance, and vice had impeded men from being able to utilize fully the power of reason that they wexe all endowed with.

The belief in the inherent power of reason and its corruption provides the most adequate explanation of the aggressive reform characteristics of the philosophes, their vehement dislike of 
revealed religion (for counter-posing the myth of the Bible against reason), and their initiative (the Encyclopedie) to facilitate the operation of reason by enlightening people to the nature, the power, and the uses of reason.

\section{Nature}

The second essential idea of the century was that of nature, with its attendant idea of natural law. As with the idea of reason, nature was an idea that wore many faces. The conception of nature was in essence the antithesis of two other ideas, supernatural and unnatural. The idea of nature as operating in conjunction with reason was opposed to the idea of the miracle and the revealed truths of religion, that is, the supernatural manifestations of a transcendent God. Nature was also thought to be antithetical to the unnatural, that is, the artificial and irrational trappings of society that had accumulated over time through the machinations of custom and habit. In this respect nature and reason were closely tied together, reason, operating unencumbered by superstitution or ignorance, would allow man to find "nature" beneath these trappings of society.

In spite of the anti-religious overtones of this concept of nature the belief in nature and natural law was not restricted to the atheists but to men of all religious (or non-religious) persuasion. The Christian Bishop Butlex stated that "the whole analogy of nature - . most fully shews that there is nothing incredible in the general doctrine of religion, that God will reward and punish men for their actions hereafter" (Becker, 1965:52). There was the deist 
Voltaire who stated (Becker, 1965:52) that "natural law. . which nature teaches to all men" was the element "upon which all religion is founded.". Even the atheist Baron d'Holbach believed that "the morality suitable to man should be founded on the nature of man" (Wallbank et al., 1965b:73). They were all in basic agreement that the "book" of nature was the authority and that whatever the question, the test of truth was nature. What they did disagree upon was the question of whether nature's "book" merely substantiated or supplanted the "other" book, the Bible. This disagreement aside, perhaps the archtypical conception of nature and its laws was presented by the Comte de Volney (1757-1820) (Becker, 1965:45) when he stated:

The regular and constant order of facts by which God rules the universe; the order which his wisdom presents to the sense and reason of men, to serve them as an equal and common rule of conduct, and to guide them, without distinction of race or of sect, towards perfection and happiness.

The appeal to nature and natural law was not a phenomenon that was particular to the 18th century. From the time of Aristotle, through Marcus Aurelius, Calvin, Grotius, Hobbes, Locke, Montaigne, and a host of known and lesser known individuals writing untold numbers of works, appeals have been made to these ideas of nature and natural law. Thus the idea of nature and its harmonious operation through the mechanism of natural law were not new to the 18th century. What was new, however, was the specific character of these ideas, particularly natural law. In earlier periods the design of nature had been derived a priori from the assumed characteristics of God. Instead of being a system of laws or lawful behavior that 
was actually observed, natural law was a "logical construction dwelling in the mind of God and dimly reflected in the minds of philosophers" (Becker, 1965:55). But as natural science made significant advances in the 17th century the image of nature changed commensurate with science's penetration into the physical universe. As natural science became more capable of describing the actual behavior of the universe (reflected in the work of Galileo and Newton for example) the concept of nature and natural law came to be identified with that actual behavior. Nature was no longer a construction of logic, derived from divine qualities, but was thought of as a substantive reality. Natural law became the ordered behavior of that substantive reality. In spite of this shift toward the physical as a manifestation of the power of natural science and its influence in the whole of human thought these ideas of nature and natural law retained some of the ethereal qualities of their earlier conception. The idea of the harmony that was a quality of nature was in great part a hypostatization of the ideas of good and beautiful, and in this respect nature operated as a set of ethical and aesthetic standards that were reflected in the structure and function of the world.

Shifting to a more physical definition of nature and natural law did not mean that the spiritual character of man was forever cut off from the harmony of nature. As :Locke had demonstrated that the spiritual character of man was determined by the environmental character, the possibility was demonstrated that men could bring their ideas, their conduct, in short their social institutions into harmony with nature, with the universal natural order. In this 
manner it was shown that the physical and the spiritual man were but two different manifestations of the same overriding harmony, the harmony of nature.

\section{$\underline{\text { Progress }}$}

The third essential idea of the 18th century, and the one around which this thesis is occupied, was the idea of progress. Building up in the preceding centuries and coming to fruition in the 17th and particularly the 18th centuries were the necessary conditions for an idea of progress, be it the movement of knowledge per se or the greater movement of the civilized whole. These conditions, as mentioned earlier, included: the eradication of the adoration of the past, the value of the mundane life, and the permanence of the power of nature and natural law. The first condition emerged in the latter part of the Renaissance and reached its broadest scope in the quarrel between the ancients and the moderns in the latter half of the 17th century. The second found its expression with the introduction of the principle of utility, and found fertile ground in the 18th century, particularly among the philosophes, with the beliefs in the power of the natural sciences and natural religion. The idea of the permanence of nature's power and natural law took greater root as well in the 18th century as the methods of natural science became dominant and the attempts to express the quintessence of nature as Newton had done became more numerous. Not only were these preconditions of the idea of progress accepted and further. solidified in the 18th century, but the fundamental characteristics 
of the idea of progress, the broad expanse to the future of mankind and a belief in the necessity of man's movement to that future, found new substantiation and acceptance as well. With the emergence of the idea of natural religion, ithe philosophes turned to the future in an effort to provide an alternative to the other-worldly heaven of the Christians. Positing a potential heaven on earth brought about by the movement of reason, and yet realizing that the existence of evil indicated that. the movement of reason had not as yet reached its goal, it was necessary that the coming of this heaven on earth be put off into the future. at some point, undefined, where reason would reach its goal. The necessity of the advance that was to lead to this heaven on earth was in part an a priori belief from the assumed characteristics of reason and in part derived from observing the movement of knowledge through the past centuries of human history and seeing that in good times and bad knowledge always moved onward.

As stated earlier, the most optimistic of men saw progress as not just the movement of knowledge (or reason) onward but saw in that movement the potential for the gradual perfection of both man and civilization through the influence of the environment upon the formation of the mind, and in turn human nature. The more conservative of men saw progress as the gradual control over social and physical environment brought about by the ever more effective application of reason, which really amounted to a belief in the possible perfection of society but not of man himself, not of human nature. 
Though guided by the progress that they saw in society and sustained by the progress that they believed would come, the men of the Enlightenment were often more concerned with the immediate task of social amelioxation than the intellectualizing of fundamental ideas, and thus one finds that the idea of progress often existed in the period in a vague form of definition. It was an idea that often found its most frequent expression couched in the terms of the other ideas that predominated the period, the ideas of reason, nature, and illumination (lumieres, enlightenment). Thus while all that the idea of progress connotes today is succinctly stated in that word "progress," the idea in the 18th century did not possess quite the autonomy that it manifests today. Even though the single term progress may not have had the same denotative and connotative meanings that it has today, the movement that was embodied in that term and the implications for man of that movement were understood and exerted a powerful influence.

In the desire for change (stemming from the nature of existent conditions in France and the liberties found elsewhere), the belief in the possibility of that change (from the belief in the enlightening power of reason and the malleability of human nature, the belief in progress in general); and the attempt to instrument that change in society, one finds the quintessence of the Enlightenment period, particularly in France. 


\section{CHAPTER XI}

\section{MARQUIS DE CONDORCET}

\section{APEX OF NAIVE AND OPTIMISTIC THOUGHT}

To climax the discussion of the Enlightenment per se, the philosophes, and to perhaps mark the apex of the idea of progress itself, 53 it is necessary to skip ahead chronologically and postpone the discussion of the French Revolution for the moment. The focus of this movement forward is the single most representative individual of the ideas that motivated the Enlightenment and represented a most aggressive and optimistic development of the idea of progress. That individual was Marie Jean Antoine Nicolas de Caritat, Marquis de Condorcet (1743-1794). Due to the nature of the Revolution and the effect that it had upon the naivete that had surrounded a measure of the thought of the Enlightenment, it might be said that condorcet was one of the last heirs to the optimism of the nature that permeated the Enlightenment, the last dean of the age of innocence.

Written while Condorcet was still in hiding from the Terror, his major work on the topic of progress was the Sketch of a Historical Picture of the Progress of the Human Mind (1795). 54

$53_{\text {That }}$ is, the apex in the sense of naive optimism about the nature of that progress and the kind of world that it would bring.

${ }^{54}$ It is amazing to note that condorcet wrote this without access to source books. 
It was a very optimistic historical discussion that sought to determine the direction and goal of progress, as well as to lay out the prospects for the future. The "Sketch" was to be a demonstration of man's progressive emancipation, emancipation initially fxom the physical environment and then from the social constraints that man himself had created. It was an emancipation that ultimately depended upon the cumulative ability of man (reflecting the domination of Lockian thought) to combine sensations and ideas for his own benefit. In this work condorcet sought to show the influence that each age had upon the successive ages and the advance of civilization toward happiness. This did not mean so much to the growth of progress itself as the destruction of the obstacles that diverted the natural movement of progress. Condorcet divided history into ten different periods, each different from the others in that they marked important steps in the progress of civilization. The first three of these periods form something of a unit in that they portray the progression of mankind from a nomadic to a settled life style. The first period was marked the formation of primitive societies, ensuring existence through hunting and fishing. In the second period societies began to retain a constant supply of sustenance by the domestication of animals, changing from nomadic hunters and fishers to the semi-nomadic life of the shepherd. The third period represented the natural progression that was inherent in the first two and was marked by the turn to the soil. Thus mankind moved from the hunter and fisher to the shepherd to the farmer. Characteristic of this period of human 
development were the permanent settlements around which the tilling of the soil took place. The most lasting contribution that this period had to offer posterity was the invention of the alphabet. The next period, the fourth, was that period of time dominated by Greek thought. One of the great contributions of this period was the separating out of the specialized sciences that was accomplished by Aristotle. But while advancing knowledge through such an accomplishment, Greek science as a whole was cast in a language that was not specific enough to allow for the development of the kind of scientific certainty that became possible in the modern period. The fifth period saw knowledge progress for a while and then suffer a stagnation at the hands of the Romans. The sixth period, that of the Medieval period and the height of Christian power, saw more stagnation of knowledge until the time of the crusades. In their contact with the "infidels" the Crusaders were reacquainted with the spirit (and the body) of Greek science that had been kept alive in the Moslem world. In the seventh pexiod the slow reemergence of science began, in spite of the opposition of the Church to the rationalism that it represented. The seventh period truly marked a decisive turning point in the history of mankind for it was in this period that the invention of the printing press was made. The eighth period witnessed the discovery of the New World, with its influences on the industry and commerce of Europe, the arts, and science with the "natives" of the new world providing a means of comparing the influence of civilization and social institutions and the vast new array of fauna and flora. The eighth period also saw 
the tyranny of authority attacked by the likes of Luther, Bacon, Galileo, and Descartes. The human mind was not yet free of its yoke of authority, superstition, and prejudice, but it did realize that it was destined to be set free. In the ninth period men set about making themselves free and pursuing the happiness of civilization. The pursuit of freedom was founded upon the discovery of the true power of man derived from the fact that "man is a sentient being, capable of reasoning and of acquiring moral ideas" (Condorcet, 1955: 128). That power was found in the fact that man, by his own reasoning, could cast off the prejudices and superstitions that had shackled him. The ninth period saw men set about attacking all that was offensive to enlightened men, driven as they were by the desire for liberty in thought and action and the desire to lessen men's suffering. They were less concerned with actually expanding man's knowledge than with destroying the obstacles that prevented truth from being realized and accepted. They set out on this task under the banner of reason, tolerance, and humanity. This great movement, and with it the ninth stage, ended with the rise of the French Republic. The tenth period lay in the future and promised to be the greatest in the history of man.

The historical periods of the "Sketch" can be seen to follow no consistent criteria or logical:unity with subjects of very different natures being grouped together. The earlier periods tend to deal with systems of production while the periods of the latter part of the book focus upon the progress of science. The periods represented perhaps no more than convenient divisions of 
historical time. 55 In spite of the apparent lack of logic to the content of the periods Condorcet developed, an important concept was the emergence of the idea of history as a sequence of a number of different types of societies. In this sequence each society "arises logically and necessarily from the preceding one, and each inevitably carries within itself the seeds of the next one to come" (Pollard, 1971:90).

One interesting aspect of Condorcet's periodization of history was the fact that the periods, which were for the most part in the earlier sections accounts of the suffering and human error in civilization, should come to be endowed with the capacity for enlightenment in the latter sections of the "Sketch." The answer to this puzzle lies in Condorcet's conception of progress as possessing a gradual, developmental nature. There was a necessity that errors occur because as it was indicated earlier, progress was as much the elimination of exror as the extension of the frontier of knowledge. The error was necessary to motivate the full development of reason and progress, it provided the dynamic character to progress. The existence of error was for condorcet a necessary condition for the fulfillment of the law of progress, he asserted that "according to the general laws of the development of our faculties, certain prejudices had to arise at each period of our progress" (Sampson, 1956:120).

\section{5}

One must allow Condorcet some latitude on such questions of form and perhaps even content bearing in mind the conditions under which the work was written, and also realizing that Condorcet had originally intended it to be an introduction to a much lärger work on the history of science and its impact upon society. 
The question arises as to why error should continue so forcefully after reason has brought forth the truths necessary for the eradication of those errors. For Condorcet the degree of enIightenment that a society displayed was the result of the specific nature of society and the professions within it. Thus reason and truth suffered at the hands of the less intelligent because they were by nature conservative. It was, however, not solely a lack of intelligence that caused men to oppose reason for the philosophers were motivated to do so by virtue of their commitments to systems of thought that were not necessarily reasonable or logical. There was another group that condorcet saw as perhaps the most significant in its ability to successfully oppose the movement of reason, who had a material interest in opposing reason. This group was the priestly class who opposed reason by virtue of their attempts to keep the mass of people in ignorance of the world as uncovered by reason, placing in its stead the "revealed" truths of biblical accounts or "theological" science. By keeping the mass in ignorance the role of the priest as the source of truth and guidance would be protected. As Condorcet $(1956: 185)$ stated:

These castes took possession of education, in order to fashion man to support more patiently chains identified, so to speak, with his existence, in order to take from him even the desire to break them.

Again as a part of his belief in the role of errox in motivating the development of progress Condorcet saw that the role of these opponents of reason, particularly the priest because of the size of their impact, was necessary for the emergence of the law of progress and a complete understanding of its influence. 
USES OF THE STUDY OF CIVILIZATION

For Condorcet the study of the history of civilization had several uses; first, it allowed one to establish the existence of progress, and second, the study of civilization allowed one to determine the dixection of progress in the future and thereby accelerate its movement. Through the study of civilization Condorcet had determined that there were no natural time limitations to the process of human progress, that the progress of man was only. limited by the physical duration of the earth. As long as there were no natural catastrophes that destroyed the earth there would. always be advancement toward greater perfection. There may be changes in the rate of that advance but there would never be a regression.

\section{Determination of Social Laws}

Another benefit that Condorcet saw as accruing from the study of history was the determination of the general laws of social phenomena. If such laws could be determined then it would be possible to anticipate changes coming in the future. Condorcet, however, was not strictly deterministic in his assessment of general laws and their influence. Man was indeed subject to the general laws of nature but man also had the power to modify those general laws and use them to his advantage. Such power was rather feeble in the individual, but when exercised by the whole of mankind over a long period of time it could actually balance that of nature. This power in mankind could actually be regarded as the work of nature itself because: 
- . if nature had endowed man collectively with the capacity to learn from experience, to understand it laws, and to modify their effects, the progressive emancipation of man from nature is itself natural, and the growth of freedom is a natural law. (Baker, 2, 1967a:184.)

Though Condorcet did study history with an intent to determine such 1aws, he was nevertheless not able to deduce any general laws of social phenomena. This did not stop him, however, from attempting to determine what was to occur in the coming period, the tenth. He stated (1956:173) that even if one did not know the laws that governed phenomena one "can still with great expectation of success, forecast the future on the basis of his experience of the past." He stated that the sole foundation for modern man's belief in the natural sciences came from the assumption of the constant and necessary character of nature and nature's laws, both known and unknown. If such an assumption was sufficient for the natural sciences then why could it not be sufficient for the intellectual and moral development of mankind as well?

Condorcet saw that the foundations of an acceleration in the rate of progress had been laid. For Condorcet (Baker, 2, 1967a: 184):

- - elitism and tyranny on the one hand; popular prejudice, ignorance and social and political subjection, on the other--were finally being destroyed under the joint impact of scientific, technological, and political revolution.

As better scientific generalizations and laws were developed, the knowledge of science would be disseminated with greater ease and to a greater extent, there would be advanced technologies that would allow increases in economic output and individual welfare. The 
progress in medicine would reduce the ravaging effects of disease, and progress in the knowledge of hygiene would prevent epidemics. One benefit that Condorcet saw accruing from these advances in medicine and hygiene was the possibility of extending the human lifespan. Being both "realistic" and optimistic he stated (1956: 200) that:

. . certainly man will not become immortal, but will not the interval between the first breath that he draws. and the time when in the natural course of events, without disease or accident, he expires, increase indefinitely?

Condorcet felt that sensationalist psychology had made it possible to elaborate the fundamental principles of a social science and so new philosophers, would be more aware of the natural rights of men, and they would free men's minds from superstition, and the political and moral errors based on it. The capacity of future generations of children would be expanded by a more rational education, which might include the adoption of a universal language. Progress would occur in morality as well because the growth of virtue was aided by the growth of true knowledge. As a result of such advances in the social sciences and the probable advances in morality, new mental and moral attitudes might arise.

\section{Nature of Tenth Period of Progress}

For Condorcet the tenth period of humanity of which he spoke was a serious attempt on his part to make scientific predictions about the future from the knowledge of the past and present. But Condorcet's attempt in reality amounted to little more than what was 
represented by the daydreams of contemporaries about the nature of the Golden Age to come. The attempts of Condorcet, as well as many of the utopian writers of the day, attested not so much to the success at deducting general laws of human development from. history as "to the felt needs and wish fulfillments of the writers concerned, to the intensity of their frustration at the present, and to the urgency of theix nostalgia to escape from it into the future" (Sampson, 1956:125). In spite of this "flaw" one must still give credit not only to the sincerity of condorcet's desires but also to their character. Many of these desires still form the backbone of the liberal-democratic perception of the unalienable rights of man, the goals that are still hoped for and to which people still strive to achieve--in particular, Condorcet's emphasis upon universal suffrage, equal justice before the law, not only legal equality for all (including women) but actual practical equality perhaps born of an economic redistribution, and even the provision for pensions by the state for the old and the infirm. In part, a measure of vagueness in Condorcet's work about the future was the result of his belief that the acquired characteristics, intellectual and moral, would be inherited by future generations, so that faculties would be capable of indefinite improvement. Thus in the Iong run such great changes would occur that it would be impossible to predict the actual achievements, as well as being impossible to predict the limits of human achievement.

The fact that Condorcet also predicted an emerging equality among the sexes disclosed a concern on his part with the larger 
question of equality. The aim of social and political progress should be equality. In fact he believed that the future condition of mankind rested on three issues, two of which dealt with the question of equality. Those three issues were "the abolition of inequality between nations, the progress of equality within each nation, and the true perfection of mankind." Condorcet added the hope that someday all nations would reach the degree of freedom, enlightenment, and lack of prejudices that were presently manifested by the French, the English, and the Americans.

Condorcet did realize though that equality was no simple idea or easily attainable goal, for one may be able to establish equality in the eyes of the law and yet have a situation that was far from true equality. Condorcet attributed this problem of equality to three causes. The first two causes were the inequalities of wealth and position, that is the inequalities between men who inherit their means of subsistence and can thus pass it on to their heirs, and men whose means of subsistence exists in their ability to do work which cannot be handed down to future generations. The third cause of real inequality resided in the inequality of education. Condorcet realized the power of these forces of inequality, but he had been too influenced by the Physiocratic conception of the Natural order to advocate any radical reordering of society. There were, however, less than radical changes by which these inequalities might be dealt with. The inequality of wealth might be reduced by removing the many rights that $\epsilon$ xisted for the acquisition and transmission of property. The inequality of position might be 
dealt with by the introduction of a system of annuities and insurance, as well as the extension of credit. The inequality that existed in the educational system may be dealt with by advances in the selection of subjects and improved methods of instruction, 56 and in the distribution of the opportunity for education equally throughout the society. However, the present system of social inequality was bound to continue so long as the present means of production existed, a situation in which there was a large number of men who had nothing but their labor to offer and a small number of men who owned or controlled the land as well as the capital.

\section{ELEMENTS OF PROGRESS}

It has been shown in earlier sections of this thesis how the idea of social progress, evolved from the idea of the continuous progress of knowledge at the hands of men such as the Abbe de Saint-Pierre. This connection between the two progresses was highlighted by the form of Condorcet's treatment of human history, for him the history of civilization was the history of the growth of knowledge. This belief was underscored when Condorcet stated that there was an "indissoluable union" (Bury, 1960:210) between the progress of knowledge and the growth of liberty, respect for rights, and the destruction of prejudice. Condorcet saw that the errors that

\section{6}

Such improved methods included the widespread dissemination of synoptical tables, which amounted to something like a student's crib sheet. He (Condorcet, 1955:197) stated that: "With the aid of a small number of these tables, which can be easily mastered, we will show how men who never rose above the most elementary education will be able to find at will the knowledge of details useful in ordinary life whenever they need them ..." 
had occurred in the political arena and in the field of ethics had been the result of false ideas which came from ignorance of the laws of nature.

What did Condorcet really understand as progress? He envisioned three separate aspects of advance, separate but linked: 1) the simple linear accumulation of ideas, 2) a struggle in which reason defeated its enemies one by one, and 3) the power of the scientific method to deal with the accumulated body of social ideas. But these three ideas were in essence merely the intellectual underpinnings for the faith that was his belief in progress, a faith that envisioned the advance of happiness and/or the reduction of pain. This was not, however, a simple desire for the greatest good for the greatest number but rather:

- . it associated art, knowledge, and spiritual greatness with physical satisfaction and bodily health, and it made the process of becoming, of achieving and moving toward a better society, the operative element in "happiness." (Pollard, 1971:93.) 


\section{FRENCH BOURGEOISIE}

Much of the discussion up to this point of the movement of the idea of progress has focused, at least implicitly, upon the influence of French thought. This focus has not been one without justification for a great number of the influential minds that have pondered the idea of progress and have made significant contributions to its development were French; Descartes, Abbe de Saint-Pierre, Fontenelle, Turgot, and Condorcet to name a few. But an underlying reason for this predominance, and ultimately more important for our discussion, was the fact that it was French society, particularly the French bourgeoisie, that had the opportunity and the need to make the greatest use of the idea of progress. There was a unique confluence of circumstances that engendered something of a symbiotic relationship between the needs of the bourgeoisie and the interest in and development of the idea of progress. The idea of progress provided the French bourgeoisie with a rationalization and a justification for the social changes that they were desiring, particularly changes in their status and their social import. One thus has at least a major part of the explanation of the greater interest in the idea of progress by the French simply by understanding the coincidental emergence of an idea and a need for such an idea. As the following discussions will bring out in greater depth, the bourgeoisie made 
great use of the inevitability of change and the supposed direction of the change that was embodied in the idea of progress.

No such confluence of ideas occurred in England or Germany for example because the conditions of "supply and demand" were not existent as they were in France. The English bourgeoisie had been assured of political powex long before a clear and effective idea of progress emerged. The "Glorius Revolution" and the Bill of Rights (1688) had provided them with the rights and freedoms desired and. consequently, in the latter parts of the 18th century when the idea of progress really emerged. on the Continent, the English had no need of it as a means of justifying political and social changes as the French had. The German bourgeoisie could not even present a unified German state let alone use the persuasiveness of the idea of progress as a mechanism of power and social reform.

These distinctions between England, France, and Germany were also reflected in the modes of thought that were exhibited by each in the latter parts of the 18th century and on into the 19th century. The English mind had come to focus upon political economy and the development of a free capitalist economy. The national interests were turned to the establishment of commercial and industrial freedom with the realization that the economy of a commercial nation was an object that needed attention and careful handling. Such interests ushered in the science of economics with works by such men as Adam Smith (1723-1790). 57 The English bourgeoisie had been

57

The primary reference here is to Smith's Inquiry Into the Nature and the Causes of the Wealth of Nations (1776). 
brought into the political process nearly a century earlier than the French. They had become part of the status quo and as such harbored little motivation for revolutionary or radical change. Progress for the English was a slow process that could insure the advancement of society through the preservation of the stability of existing institutions. The proper function of the government was not thought to be positive as the. French theorists had believed but rather was negative; that is, to preserve the existent order and secure the sovereignty of life and property which would allow men to pursue their own fortunes.

French thought on the other hand was becoming increasingly emersed in a radicalism of sorts, in the process of attempting an adjustment of the social structure. The French were looking for great change, using the nature of English society as an example of the possibilities of change. The rights of equality before the law, freedom of political expression, the right to trade freely, the right to choose one's own profession, and the right to the protection of one's person and property from the arbitrary abuses of the King, were examples of the human freedoms that the French had noted in the English society and moved to institute in France. In consonance with an urgency. that the French felt for the need to change society, their concept of progress was of a much more accelerated and radical process than was the case in England. Exemplary was the belief in the power of social institutions, once they were correctly organized, to swiftly bring about changes in human nature, or the French belief that once the correct changes had 
been made in the structure of society natural law would take over and the economy would essentially take care of itself, harmony with natural law insuring economic progress.

While the English mind turned to political economy and the French to a radicalism, the German mind turned to idealistic philosophy. Due to the jumbled political situation existent in Germany, there were no specific societal goals as the English had and the French were forming, there was no unification of bourgeois thought behind concrete manifestations of progress. The result was a turning of energy toward the ideal, "to concentrate on a conversion of the spirit" (Pollard," 1971:94) rather than working out an enlightened social, political, and economic structure for dozens of autonomous polities. It was a turn to the theoretic because the concrete manifestations of the movement of progress, existent in England and emerging in. France, were only in embryonic form in Germany.

Thus the focus upon the French manifestations of the movement of the idea of progress was the result of the fact that they were so actively immersed in its development and in its utilization, they were driven by the desire for the social fxeedoms that they saw in the English, and later to some extent in the Americans.

Up to this point, the body of this thesis has dealt by and large with the ideas and the trends in thought that have coalesced to form and support the idea of progress. This has included ideas such as the progressive nature of knowledge, the permanence of nature's powers, the power of science, the unlimited vista of 
civilization in the future, and the supremacy of reason. It has touched such movements as the classicism of the Renaissance and the rational empiricism and sensationalism of the Enlightenment. But at this point the intention is to shift the focus fxom the operations of these ideas and movements as such to the social situation and the social pressures that reside behind such ideas. The point is to illuminate more clearly how the social situation, specifically that of the French bourgeoisie in the 18th century served to impute into the idea of progress a spirit and force, to broaden its scope, and to bring it to the fore in the realm of ideas.

\section{NATURE OF I8'TH CENTURY FRENCH SOCIETY}

In order to understand the role of the bourgeoisie in the development of the idea of progress it is necessary to understand the nature of the social situation in general in which they lived, and also to understand something of the character of the bourgeoisie in France. The specific character of the ancien regime had much to do with the nature of the acceptance and support of the idea of progress; as well as Enlightenment thought in general.

\section{Nobility}

The most outstanding feature of French society, not simply in the 18th century but in the preceding centuries as well, was its rigidly structured nature. Politically speaking there were three divisions among the French people, the three "estates" of the clergy, the nobility, and the roturier, or the commoners. 58 In actual 
practice there was only one dividing line that marked all of the populace in one group or the other. At birth a person was either a nobleman or a commoner, ${ }^{59}$ and while it was possible to become enobled, in the eyes of the vast majority of people the true nobleman could only be born as such. Within the nobility there were gradations as well, with differential status accorded to each. Those of the highest social status were the nobles that had acquired their nobility by inheritance, that is, by birth, and could theoretically trace their aristocratic heritage back to time immemorial. These noble statuses were usually derived by decree from the king for military service rendered. the crown in feudal times, decrees that gave both land and the political rights that accompanied such land. It was in reference to this military source that the highest status of nobility was referred to as "noblesse d'eppe," the nobility of the sword. The next level of the nobility acquired their noble status at a more recent time through the assumption of an adminisitrative position, which could be acquired by appointment or by purchase. The monarchy had entered the practice of selling public offices for the purpose of resupplying the perpetually drained treasury. 60 In the 16 th and 17 th centuries this practice of seling offices began to include the conferring of nobility so as to increase the price of purchase. Such confirmation of nobility was also used by the king to reduce the power and prestige of the

\section{9}

The respective size of these groups was approximately 4 percent noble and 96 percent commoner (Lefebvre, 1973:41).

${ }^{60}$ Up for sale were judicial, military, financial, and municipal positions. 
noblesse d'eppe, traditionally rather recalcitrant in submitting to the will of the monarchy. The fact that this second level of nobility generally controlled the legal and the administrative positions led to the title "noblesse de robe," nobility of the robe, for the garments traditionally worn in many of those positions. Due to the price of purchasing one of these offices and the title that accompanied it, it was usually the wealthier of the bourgeoisie that would, in the desire to improve their social status, acquire such nobility. For the noblesse d'epee the centuries of noble status, and the refinement and cultivation of aristocratic : values that had occurred in those centuries, had convinced them that true nobility was in the blood as an inalienable characteristic of aristocratic lineage, and barring some heinous crime against the aristocratic customs, was a permanent status. The fact that the noblesse de robe had acquired its nobility simply by purchase, and that they were of recent common status created an underlying sense of resentment between these two noble factions. In actuality, what distinguished the noble from the common elements of society were the privileges that accompanied title (nobility), and it was often these special privileges as much or more than the social status of nobility that made enoblement so attractive. Many of the privileges were honorific such as the right to carry a sword. There were, in addition to this formal privilege, many informal honorific pxivileges as well, including the custom of wearing brightly colored or certain styles of clothes. Beyond these honorific privileges there were the useful privileges which set the 
nobility off even more from the mass of the populace. First and foremost the nobility was free from the majority of the taxes that so burdened the rest of society. In addition, they were excused from the requirements of quartering troops on command and of maintaining roads. In the courts the nobility had the right to be tried by a court of its peers, and was excused from humiliating punishments. While comprising only a small minority of the total population, the nobility owned approximately 20 percent of the land in the kingdom and the majority of "manors" with their feudal rights. While the nobility saw themselves as the heads of society, they were able, through such privileges as were just mentioned, to exempt themselves from nearly all of their duties to society as a whole. Such privileges were retractable should the noble engage in demeaning activity, activity such as engaging in occupations unbecoming their noble status. Nobles were expected to enter careers, if they chose to have a career at all, such as high political and ecclesiastical positions, or the military or diplomatic fields. The nearest thing to work that was allowed was an interest in intermational trade, which was not the same thing as common commercial activity. Anything that was truly commercial or industrial, anything that was forth rightly concerned with making money was thought of as common, and so those nobles who might have sought the wealth that was available in these areas had to take into account the possibility that they were endangering their noble status. Such a value system prevented the aristocracy from participating in the industrial advances of the period in the same 
fashion that the aristocracy of England for example had been able to do, and this fact had dire consequences for the French nobility.

This contempt for the commercial, coupled with the increasing cost of living and a financial apathy born of an essentially idle existence operated to render many nobles into great financial difficulties in the 18th century. It was interestingly enough the noblesse d'eppe of the city that most dearly felt such financial pinches. While the noble of the provincial and rural areas had never approximated the fortunes of the great urban noble, neither did he feel the financial difficulties so hard. The provincial noble had rarely attempted to live the life of glitter that had existed in the cities. In addition the provincial nobility was usually in a more feudal relationship with the locals, directly in contact with the necessities of life because of the fundamentally agricultural character of the rural areas. The noblesse d'epee suffered more in contrast with the noblesse de robe as well because of the fact that the latter had generally kept contact with the higher bourgeoisie and the commercial interests therein, as well as being generally more able to manage their financial interest. After all the bourgeoisie who largely filled the ranks of the noblesse de robe were required to have some wealth with which to acquire the position, and such wealth rarely came with a habit of free spending and fiscal mismanagement.

The increasing financial. plight of the nobility resulted in a slight lessening of the distaste for commercial activity. Some nobles attempted to ride the capitalist tide by taking advantage of 
the minerals and natural resources that existed on their estates, others became more directly involved in industry such as the naturalist Buffon setting up a fcundry and the duc d'orleans (blood relative to the King) building apartment houses in Paris. The more traditional landed aristocracy attempted to reform their agricultural holdings according to the principles of the Physiocrats. All such attempts were replete with threats to status and privilege, and the majority of the nobility attempted to cope by more vociferously demanding privileges and dispensations from the state.

One additional avenue out of financial problems that was taken by some nobility, in this case primarily the noblesse d'epee, was the intermarriage between wealthy and recently enobled bourgeoisie and older, higher ranking, nobility. By asking, and receiving, large doweries the nobility could climb out of financial problems by simply marrying off some of their children. 61 Frequently such marriages, given a sufficient amount of funding, could be arranged between insolvent nobles and wealthy high ranking bourgeoisie. The status of the nobility often suffered in this latter marital situation, but the return of their financial solvency often compensated them for the loss.

\section{Bourgeoisie}

The nobility manifested relatively hard and fast lines of demarcation between the various noble gradation due to the demands

\section{1}

This occurred sometimes between the lower roturier and the bourgeoisie as well. 
of court etiquette. 62 The roturier class did not, however, display such accessible delineations, and as a result determining such questions as who were to be considered bourgeois and who were to be considered simply as laborers or peasants was not a black and white question, either for contemporaries or for subsequent historians. While still a question of interpretation, one accepted opinion was that the bourgeois:

- . were those owning real estate, engaged in commerce and the liberal profession, as well as those having careers in the official financial administration--treasurers of France, controllers of the king's domain, receveurs de taille, etc. (Barber, 1955:16.)

In general one may draw the lower limit of the bourgeoisie just about those occupations that were simply engaged in manual labor, with the upper limit being just short of the noblesse de robe.

Within these guidelines one can circumscribe two general social realms that belonged to the bourgeoisie. As it was mentioned in the section on the nobility, the world of business, which encompassed industry, commerce, and finance, were considered to be in the bourgeois world. Considered part of the bourgeois world as well were the professions, within which were included lawyers, doctors, intellectuals, and the lower clergy. What these two realms represented were two parallel.hierarchies of bourgeois activity, each with its own internal statuses and hierarchies.

62

Gradations derived for example from the number of years of noble status on the paternal side. The relation of such gradations to court etiquette was found, for example, in the fact that the queen was to be dressed by the highest ranking noblewomen present. 
The hierarchy, in terms of the status accorded them and usually the size of their respective fortunes, that existed within the business community was as follows:

Financiers/Negociants
Industrialist/Merchant Manufacturers 63
Wholesale Merchants
Retail Merchants/Shopkeepers (Barber, 1955:20) The prestige accorded the financier ${ }^{64}$ and the negociant, as well as the wealth they were capable of amassing, made them the head of the hierarchy. The negociants and the financiers were found only in the large commercial centers. A negociant might be distinguished from a general merchant in that the negociant would only be selling in a large warehouse and would be dealing only in large lots of goods. It was the negociants and the financiers, together with the large shipowners, that became the wealthiest of the bourgeoisie, and it was this group of businessmen who, through that wealth, most lived like the nobility. While this higher echelon of the business community served the same sort of functions as all of the other businessmen. did, the scale at which they worked placed them nearly in a quantitatively different category than the rest of the business world.

\section{3}

In actuality, the industrialist in the modern sense of the term was rare. The merchant-manufacturer was most often found. The merchant-manufacturer was a person who was a large scale merchant but also maintained a small scale manufacturing business on the side. In contradistinction to England, industry in France was, in the 18th century, subordinate to commerce. It was the merchant that was the chief beneficiary of economic productivity.

${ }^{64}$ In the class of financiers one should include the wealthy fermier-general, who were fxanchised by the state to collect the taxes, the state having literally "farmed out" the duties of collecting taxes for a percentage of what was collected. 
While the lower bourgeois merchants and professionals treated themselves roughly as equals, they did not extend such courtesy to the upper level bourgeoisie, the financiers, negociants, and perhaps the shipowners (armateurs). Outwardly they were treated with respect, but the rest of the bourgeoisie took no pride in the work that they did nor did they extend any measure of loyalty to them. Inwardly, this upper echelon of the bourgeoisie was generally disliked, often times even hated. Conservative bourgeoisie were more adament in their dislike for the financiers, with the intellectuals being less disposed to think harshly of them. Henri Thirion (Barbex, 1955:30) expressed the strong sentiment against them when he stated:

- . these men not only controlled the national purse-strings directly, but also influenced the monarch by mistresses out of their ranks, the nobility by family ties, and the intellectuals by their subsidies.

The reference to "purse-strings" revealed the fact that much of the power and prestige that the financiers particularly maintained was due to the fact that they consistently had bailed the failing financies of the state out of bankruptcy, sometimes at great profit and sometimes at the cost of bankruptcy. 65 It was this association with the crown and their general dislike by the rest of society that at the time of the Revolution cost many financiers their heads, Lavoisier for example.

Below the financiers and the merchant manufacturers were the wholesale merchants. They may be considered generally of somewhat lesser prestige because, although they were capable of amassing 65 void.

Sometimes the state would declare all debts null and 
large fortunes and existing on equal basis with the financiers, they generally carried on business of a lesser scale and with less pecuniary rewards than the financiers and the others.

Rounding out this abbreviated framework were the shopkeepers and the retail merchants. While they were within the definition of bourgeois, they had to live rather frugally to maintain a bourgeois style of life. Efforts that they expended in attempting to move their children up the social ladder, by education or by dowry, were made at great cost as well as inconvenience.

Within the professionals there was erected a hierarchy as well, though in this one the prestige that was associated with the various elements was perhaps more important than the respective wealth of those elements. In general the professional hierarchy went as follows:

\author{
Intellectuals \\ Lawyers \\ Doctors \\ Lower Clergy \\ Law Clerks, Assistants \\ (Barber, 1955:20)
}

In this scheme the intellectuals and the lower clergy presented somewhat of a problem when it came to classification. Legally speaking the clergy formed the first estate, and thus in view of the law were legally separate from the nobility or the roturier. But in actual practice there was a bifurcation between the upper and the lower clergy, with the higher ecclesiastical positions being reserved for the nobility and the lower clergy being. composed of the roturier. There existed little or no mobility between these two elements of the ecclesiastical order. Though the life of a cleric 
must be considered as fundamentally different than the other professions, the lower clergy enjoyed a life that was in prestige and style similar to that of the lawyer or the doctor.

The intellectuals presented even more disturbing a problem to classification in that they could not be placed categorically in either noble or non-noble realms. With the intellectual the hereditary segregation of occupations broke down, most of the intellectuals were of roturier origin, yet there were many that came from the noble ranks as well. For example, from the roturier came Rousseau (laboring class) and Voltaire (wealthy bourgeoisie), and from the nobility came Montesquieu. The intellecutals; as a result of these differences, gained their financial support from a number of sources. The noble Baron de la Brede et de Montesquieu was comfortably taken care of by a family inheritance. Voltaire was able to amass a large fortune through his business adventures and financial speculation. Rousseau, in addition to being housed and supported by enlightened nobles, made somewhat of a living copying music in a system of notation that he developed. While all of these men, and all of those they represented, may be considered intellectuals, their styles of life different in relation to their wealth.

Another factor that confused the position of the intellectual in society was the nature of the prestige that was accorded the intellectual profession. Nobles were often thought of derogating themselves if they devoted themselves to learning. Excelience in the intellectual realm often exposed the noble to ridicule of 
his peers. It was thought that:

- . learning and intellectual perception were in some sense roturier qualities; in ranging himself among writers, a man of rank seemed to lower himself into an inferior class. (Barber, 1955:18.)

As a result of this, men of rank often attempted to play down their intellectual roles and hide their intellectual pursuits.

In returning to the hierarchy of bourgeois professions one can now understand that the preeminent status of the intellectual was a manifestation of the intellectual's function and not social oxigin. The status of the intellectual was particularly high in the 18th century due to the role that they played in a situation in which changing social and intellectual elements had disrupted the previous stability. The intellectuals played a particularly important role in defining and expressing social values. This role was in part thrust upon them as a result of the abdication by the nobility of the traditional role of providing intellectual and moral leadership. This abdication was largely brought about by the abandoning of the nobility of the feudal estate for the life of the court. At first this was expedited by the King himself, perhaps beginning with Louis XIV, as a means of diminishing the power of the nobility by removing. them from their native territory, separating them in spirit if not substance from the source of their power and wealth. During the course of the 18th century, however, the nobility gravitated to the court of theix own accord, first drawn by the glitter and excitement of the court and later, as the financial plight of many noble families worsened, in order to receive a high military or civil position that would provide them with a state 
pension. Presentability at the court of the King became, in the latter part of the 18th century, the mark of "true" nobility, as well as the only means of influencing state affairs.

Such an exodus had ever so important social ramifications. The nature of the social role of the nobility, the result of this exodus, and the vacuum that the nobility had created, were succinctly stated by Tocqueville (1955:142) when he wrote:

A powerful aristocracy does not merely shape the course of public affairs, it also guides opinion, sets the tone for writers, and lends authority to new ideas. By the eighteenth century the French nobility had wholly lost this form of ascendancy, its prestige had dwindled with its power, and since the place it had occupied in the direction of public opinion. was vacant, writers could usurp it with the greatest of ease and keep it without fear of being dislodged.

This particular usurpation of roles by the intellectuals and the essentially bourgeois character of the intellectual stratum will be discussed at length later but suffice it to say at this point that the intellectuals, particularly in the middle and later decades of the 18th century gained a great measure of social importance.

of additional importance in the bourgeois professional hierarchy were the lawyers and the doctors. 66 A legal career was especially attractive because of the contact that it brought to the noblesse de robe and the pomp that was part of the decorem of the courts. Practically speaking, however, the legal profession was overcrowded and the chances of making a great deal of money were slim. In light of this, the attractiveness of the legal profession was one

\section{6}

Under the term lawyers may be included such professionals as "judges, solicitors, notaries, and barristers" (Iefebvre, 1973: 45). 
of prestige and not pecuniary gain. For the doctor the long period of study that was required necessitated that the prospective doctor came from a family with sufficient income to underwrite those years of study, usually a well-to-do family of bourgeois origin. Once the young doctor had become established he could expect to live in a comfortable but not grand style. The families of the medical profession intermarried with the good legal families and with the families of the commercially successful, thus indicating an equivalence of status between them.

Perhaps what has most traditionally distinguished the bourgeoisie from both the rest of the roturier class and the nobles as well was their attitudes and values toward life and work. The fundamental task of all religions is to give meaning to life and to define man's position and destiny in the grand scheme of things. For most religions that destiny lies in a world quite different from earthIy life, attainable only through prescribed means, and occurring only after the end of the earthly one. Part of defining the meaning to life lies in interpreting the nature of everyday life in relation to the orthodox theology, how should the true believer view his everyday life in its relation to his destiny? For the Catholic Church 67 this interpretation of everyday life had seen it as merely a preparatory period in which men made themselves ready for salvation, and that all eaxthly functions should be subordinated to that salvation. Another aspect of interpreting that everyday life was the definition

\section{7}

The Catholic Church is singled out here because France was predominantly Catholic and the Catholic Church was greatly more influential than the Protestant Church. 
of the true character of man himself. The Catholic Church saw man as an innately sinful creature, driven by his baser passions. In the Medieval period when the Church's power was at its height it exerted a great control over both the religious and the secular institutions. This dual role followed from the fact that if the purpose of all life was to prepare for salvation then in order to best be prepared, in order to best avoid the sinful life that man was driven toward, it was necessary to submit all facets of life on earth unquestioningly to the authority of the Church. The economic world which presented the most potential for moving away from the other-worldly orientation of salvation to the this-worldly life of sin was a particular object of ecclesiastical scrutiny. The Church elaborated proscriptions for commercial activity (against usury, against gathering wealth above simple need or in excess of one's station in life) that sought to limit wealth and thereby reduce the temptation of this world and preserve the good Christian life.

By the 18th century many of the French bourgeoisie found the religious restrictions of the church to be overly restrictive on one hand and simply not reflective of the social reality as they saw it on the other harid. The businessmen of the Medieval period had been, with some strain, capable of carrying on a commercial venture within the prescriptions of the other-worldly theology of the Church. They had been capable of being both good businessmen and good Christians. But as the secularism of the Renaissance period spread over wider areas of human endeavor in the following centuries, and as the bourgeoisie became ever more successful in commerce, it came to be 
correspondingly difficult for the bourgeoisie to carry on their everyday Iife within the Church's other-worldly posture. Their approach to life and the prescriptions for living came to increasingly reflect this secularism, the values by which they lived came to be increasingly influenced by secular ideas.

The growing secularization manifested itself in a shift of responsibility. Where before men unhesitatingly turned to the Church and God for their definition of virtue and for the prescribed means of living the good Iife, they now began to turn to themselves and to one another. Within this stance the responsibility was upon man, applying his own rational powers, to find the right ways and means to achieve these ends. Reflecting this shift men began to strive to live the good life within the limits of this life on earth, a thisworldly posture rather than the traditional other-worldly one. Virtue was no longer defined in terms of mere adherence to orthodox beliefs, but rather in terms of fulfilling a meaningful existence in this life, of exercising the opportunities that existed in this life. The virtuous life becomes a focus of rational rather than suprarational concern, something that emerged from calculated action rather than something that came from "beyond" rational thought. While the utilitarian calculus of such rational concern may dictate the postponement of pleasure, in contradistinction from traditional orthodoxy, that postponement would not reach beyond the earthly life.

Within this secular approach to both the material and the spiritual worlds it was possible for the bourgeois to find a meaning 
to their Iives. ${ }^{68}$ The aristocracy had long since acquired such a meaning with the divine ordination of their exalted role as the apex of society. For the bourgeoisie, however, their life was not glorified by divine recognition and an exalted position, but rather by the labor and the drive that was their essence, a glory. wrought of their own hands. They could find a sense of fulfillment in the satisfaction of work well done, in the respect that came from that accomplishment, as well as the wealth and the comfortable life that it might afford them.

To state that the good bourgeoisie entered into a more secular approach to the direction of Iife was not to infer that on the whole they abandoned the Chuxch entirely. While they may have felt the need and desire to exert more control overlife, this did not require the discarding of the desire for heavenly salvation. The reason that the good bourgeoisie could turn to more secular values and at the same time retain their religiousity was that they bifurcated their lives into different compartments. This was not so much the case of a conscious choice to act one way in one's personal life and another in one's business life, but rather an emergent compartmentalization that grew from the quite different requirements of each. In the area of business for example, the secular values were in their own woxld, in this woxld success was measured in terms of quantity, money, products, ships, etc., and not in terms of goodness or purity. The secular orientation with its calculation and common

68

Reflecting the bourgeois quality that this appraach came to acquire, there was room in the list of vices for the sin of abstinence and for the neglect of this world as well as the traditional sins of overindulgence. 
sense was not only good for business, it was necessary for success. It was an orientation that had a rationale and an ethic that had been tested by its success or its failure. In the world of business, religious law and ecclesiastical reasoning were simply out of place. In their personal life, however, the bourgeoisie still turned to the Church for security and meaning. Family crises always brought the appeal to the creator for aid. The head of a good bourgeois family rarely missed taking his family to high mass. All of the important events of the human life cycle were accompanied by religious sanctification. Family births, marriages, and deaths, were all occasioned with the correct religious cexemonies and sacraments. The church took on extreme importance when death was concerned, and it was at this time that the sacraments of the Church took on extreme importance as well. Many enlightened bourgeoisie received the rites of the Church at their death beds, perhaps most notably was Voltaire. These events were de facto statements that the idea of salvation was not totally supplanted by the satisfaction that one might find in the earthly life, or that the rational calculation so revered in the daily life of the businessman was capable of dealing with all facets of life.

There were variations in the degree, to which the bourgeoisie were aware of this compartmentalization and the amount of success that was manifested in keeping the two areas separate, and hence out of conflict. Until the midale of the 18th century there was only a small degree of conflict, in large part because there were no clear formulations of their ideas and values in these respective areas, and 
little to being about such formulations. But the discussion of the ideas of the Enlightenment, particularly those of the philosophes, often brought the acknowledgment of conflict to the surface. For in the Enlightenment was found what had been missing before, explicit formulations of a more secular approach to life. Such formulations often struck a receptive chord in the bourgeoisie, making them aware of the affinity between their everyday or business ethic and the all-inclusive secular approach represented by the philosophes. One might accept or reject the secularism of Enlightenment philosophy and still not perceive it as a danger to religious beliefs, in short maintaining the compartmentalization of each. On the other hand, the compartmentalization might be perceived and the conflict squarely faced. Even this realization, however, did not determine in which direction (religious or secular) the perceiver might tend, nor would it even indicate a rejection of the compartmentalization but only the acknowledgment of conflict. Some good bourgeois believed that, focusing upon the ideas of the philosophes, the Enlightenment was immoral and that its ideas were to blame for the decline in traditional Christian morality that they detected. A few, though never a sizeable number, accepted the secular ideas of the morality of man to the complete rejection of religious beliefs. Still others, in the finest bourgeois tradition of moderation, felt that too strong an acceptance of either was to be avoided. Regardless of the variety of responses to this secularism, after the midale of the 18th century there were very few who could accept the revealed truths of religion unaware that there were alternatives available. The 
existence of such alternatives indicated that the philosophy of the Enlightenment had made its presence felt.

While the majority of the bourgeoisie generally accepted the ideas of the Enlightenment, irrespective of how that affected their religious beliefs, most followed at some distance from the advanced positions of the philosophes. In actuality it was probably the case that more of the bourgeoisie were inclined to be anti-clerical than to be anti-religious, nevertheless there was a noticeable diminution in the 18th century of the degree of religious conviction. As it was mentioned earlier, part of the function of religion was to provide a meaning to the everyday life. As religious conviction began to wane, the bourgeoisie came to turn to the other force in their lives, populax philosophy and the secular orientation to life that it presented, to provide the meaning that they were now less willing to accept from. the religious sphere.

In addition to the question of secularism, in the 18th century at least, the values and attitudes of the bourgeoisie ran the whole gamut from the quiet austere life of the "old" bourgeoisie, to the more luxurious yet fundamentally traditional life of the "midale" bourgeoisie, and on to the great lavishness of the wealthiest of financiers, mexchants, and an occasional lawyer. 69 Just what were the traditional values to which the old bourgeoisie clung more tightly? These may briefly be elaborated by characterizing the

\section{9}

The term "old" not only refers to bourgeois of long standing but also refers to their acceptance of the traditional bourgeois values. The term "middle" refers not only to bourgeois of more recent extraction and moderate wealth but also to the fact that they were more mobile and therefore stood midway between the values of the bourgeoisie and the nobility. 
traditional bourgeois values as: simplicity, sobriety, industry, frugality, austerity, and orderliness. In part these characteristics may be laid to the necessary process of capital accumulation which in times prior to the 18th century, but still existent, was accomplished through thrift and austere living. In light of these characteristics, the old bourgeoisie were preoccupied with the elimination of waste and saving: money. In part, this was still a good business practice that helped to maintain business solvency, but beside the beneficial business consequences, the elimination of waste and the thrifty life were felt to be part of a moral obligation, in part a demonstration that they took the task of living as a serious matter and that this world was as valuable as the other world. Thus while the austere life that pervaded the bourgeoisie, particularly the old bourgeoisie, grew out of a business necessity, it was also viewed as a virtue. The original necessity of the austere life in relation to work, and its generalization to all phases of life, indirectly betrayed a devotion of the old bourgeoisie to work above all else. All other activities, short of devotion to the family, were relegated to secondary status in relation to work. In the midale bourgeoisie one begins to enter another world, for while there were sufficient pressures to retain the old values of austerity and thrift, toward hard work, business, and toward. success as a bourgeois, there were also powerful pressures away from this traditional style of life and toward a more lively style. This second pressure rose as the tide of business fortune turned in favor of the bourgeoisie and great amounts of money were made. As 
the contrast between the respective wealth of the bourgeoisie and the nobility became less great, and with an awakening to what this wealth might buy, the caste character of society began to weaken. Such outward signs of status as bright clothes, coats of arms (carrying swords as well), particles to names (e.g., monsieur, madame), expensive houses and country estates, wexe soon being displayed by both bourgeoisie and noble alike. The middle bourgeoisie were thus prey to contradictory influences; on the one hand, there were the influences that sought to perpetuate the more traditional bourgeois values of thrift, sobriety, etc., and at the same time there were the influences on the other hand that sought to pull the bourgeoisie to the luxury, extravagance, and the idleness of the noble way of life.

The wealthiest of the bourgeoisie, the financiers, shipowners, great merchants, and even a handful of Parisian lawyers, had all but lost contact with the traditional life style of the bourgeoisie. This was particularly true of the financiers and the lawyers of Paris for they sat at the very feet of the royal court. It was this group that was most desirous of displaying its wealth, most desirous of disassociating itself from its roturier origins, and most desirous of being accepted into the noble circle. While the other elements of bourgeois society felt some manner of conflict over an "enoblement" of their style of life, and were weary of the repercussions should they display too much pretension, the financiers had no reservations about their social pretensions and" their attempts to live the courtly life. These wealthiest of the bourgeoisie built 
great houses, particularly in Paris, many acquired by nobles when hard times destroyed the financial success that had underwritten such a noble way of life for the bourgeoisie. In the attempt to acquire the preeminant symbol of nobility the financiers bought land. Some bought noble estates and fiefs of hard pressed nobles, others simply speculated in land for future profit. Some of these wealthy bourgeoisie were lucky enough to find areas in which nobility was a part of real and not personal property, thereby purchasing nobility along with the land.

This wealthy stratum of the bourgeoisie displayed the variety and contradictory nature that seemed to pervade the whole of French society. On the one hand, there were those who were so concerned with displaying their wealth that they lost all contact with good taste. Though their expenditures could certainly equal the nobility, they lacked the taste that one would expect from the nobility, with its concern for refinement and manners. Many a dinner in overwhelmingly luxurious settings were punctuated by very picturesque roturier speech. One must be quick to point out, however, that there were numerous bourgeoisie who surpassed the nobility in terms of their intellectual and aesthetic sophistication.

As it was alluded to earlier, the attitudes and the values of the bourgeoisie were in large part tied to their desired, and actual, mobility. The old bourgeoisie were not greatly concerned with mobility but rather saw their bourgeois style of life as valuable and rewarding in and of itself. As a result of this, they saw little need to abandon the traditional values and ideas and 
rather strongly retained the orderliness, frugality, simplicity, and a certain religiousity that circumscribe traditional bourgeois values. It would be misleading to infer that the old bourgeoisie were able to totally escape the tantalizing life of the nobility. One can show some "enoblement" in their lives with the purchase of land, the tendency of the bourgeoisie to retire early given the accumulation of sufficient wealth.

The middle bourgeoisie were more interested in the mobility that their money could afford them than the old bourgeoisie, but unlike the wealthier financiex, they were more cautious in their attempts to engage in the mobility. While fundamentally retaining the thrifty character of bourgeois life, they were slowly integrating the aristocratic way of life. into that fundamentally bourgeois style of life. More time was devoted to recreation and the new ideas of the day, more concern was given to the nature of dress and appearance, in general more luxury was allowed in the household and austerity and thrift were becoming less influential canons of behavior. The middle bourgeoisie, while desirous of a certain enoblement of their lifestyle were nonetheless careful not to appear too pretentious. It was perhaps the middle bourgeoisie who most clearly felt the contradiction between desiring to retain the fundamental values of the bourgeoisie, and the fundamental distinctions between the various social classes, and the desire to approach the noble life with its less restrictive character and its free thinking. The latter desire implied a certain social mobility that ran counter to the traditional structure of society. 
The very wealthy bourgeoisie were the most willing and the most successful at abandoning most of the traditional style of life and living the life of the noble. Their unabashed desire to court the favor of the nobility left them unconcerned with the pretentiousness that they displayed and the disrepute that was accorded them both by the bourgeoisie and the nobility alike.

The conflict between one's. own status and the desired status, between one's own power and wealth and social prestige also varied with the desire for mobility. The old bourgeoisie acquiesced to the "inferior" status that was accorded the roturier class and the differential esteem that they were accorded because they were by and large content with their lives and were not concerned with changing that life greatly. The wealthy bourgeoisie were likewise willing, though to a lesser extent, to acquiesce to the status that the bourgoisie were accorded by society because they believed in the possibility of soon becoming noble themselves or simply being close to the nobility and by association share the superior status that they enjoyed. The middle bourgeoisie were, however, caught in between these two points and the conflict of the two styles of living affected them the most. The middle bourgeoisie was caught in the schizophrenic situation in that they were close enough to the old bourgeoisie and the bourgeois style of life to still honor its values and attitudes and yet they were desirous of changing their social status to something that was commensurate with their social import and their self esteem. However, in spite of their desire to move up the social ladder, they were not, like the wealthier 
bourgeoisie, at the very edge of nobility.. Thus the midale bourgeoisie were in a position in which they were close enough to the traditional bourgeois values, which included the acceptance of social stratification, that they could not readily abandon them as the financiers had in large part done; yet they were not close enoughito the nobility to feel in some mannex a part of it, again as the financiers had done. What they wanted was to change the status and life style accorded them without disrupting a social order that was built upon the rigid restrictions of class. They wanted to change the social structure and yet keep it the same, to both have it and not have it at. the same time.

To understand how the bourgeoisie could feel conflict about the contradictory influences they were under, one must come to know more about the nature of stratification in French society and the problems that it posed for the bourgeoisie. There were three traditions that served to circumscribe the structure of French society. The first was the medieval/feudal tradition that placed the emphasis upon political authority (which emanated fxom the king), the ownership of property, and the military career. This tradition tended to push society toward a caste-like arrangement in which, fundamentally, one was born either a noble or a commoner. Within this medieval tradition, mobility was disapproved of, though not totally barred, for there had to be allowances made for those whose extraordinary qualities had become apparent through their military prowess and their excellence on the field or battle. With the Church suppoxting such a caste system, it took on the appearance of a divinely ordered system. Within this caste 
system, there was no niche for the bourgeoisie, which resided somewhere between the traditional nobility and the peasants. The mobility born of the success of the bourgeoisie was, in earlier times, viewed as a direct challenge to the divine order of society.

The second tradition that served to define the structure of French society was the values and beliefs of the Christian tradition in regards to the view of all men in the eye of God. While the Church accepted and supported the lay definition of the social hierarchy, it still maintained the traditional Christian beliefs in the universalistic values of religion, that is while the lay society was ordered according to the three estates, all men were ultimately equal in the eyes of God. All men were capable of sin and all men were capable of redemption. Sainthood, instrumental roles in the Church, as well as the blessed sacraments, were not reserved for the nobility alone but were open to all men. The Church also presented a freedom of opportunity for those, of whatever birth, who heard the call, though as stated before, the highest offices were usually reserved for those of noble birth. The third tradition that operated to define French society and social structure emerged from the acceptance of the advancement that was accorded to success and extraordinary performances. This tradition had existed from the Medieval period, as mentioned above, but in the 18th century this tendency to accept the mobility of men who excelled and to accord them prestige commensurate with their accomplishments was focused primarily upon the men of business. Often the successes of these men of business were so striking and theix contributions to the total economy, to the stability of the 
state as a whole, so important that the traditional contempt for the bourgeoisie (or for "businessmen") was secondary to their recognition. These bourgeoisie, like the knights of the Medieval period, were mere "self-made" men, but they were on occasion accorded a recognition that befitted nobility. It was through the successes of the business world that a measure, limited no doubt, of mobility was introduced into French society in the 18th. century.

These traditions can be seen to have fostered a rather. incoherent structure in the society. There were factors that fostered a very closed system with virtually no mobility, and yet there were other factors that circumscribed a sense of mobility as well. The paramount fact that conditioned a caste-like nature to society was the fact that at birth one was either of noble heritage or non-noble (roturier) heritage. This means that as a noble such prestigious positions as high political and religious authority, as well as military and diplomatic careers were openly available. Being a roturier meant limitation to less respectable and prestigious positions in the commercial, professional and laboring fields. The strictness with which these occupations were hereditarily kept to the respective classes varied during the course of the 18th century, in accordance with varying economic and social factors. Nevertheless, the nobility, barring some precipitous occurance, had a relatively unchanged superior status which was determined by noble birth.

A certain quality of openness, with limited approval accorded to some mobility between the noble and roturier classes, emerged 
from the influence of these traditions as well. This limited mobility took two basic forms, one formal and the other informal. The formal channel was the legal bestowal of nobility by the King for the fulfillment of important social roles to the country 70 or important military victories, an enoblement reminiscent of the Medieval period. Such a conferral of nobility might also be acquired by the purchase of certain legal or political positions. Appointment to certain judicial or administrative positions often carried the benefit of nobility with them. As mentioned earlier, this formal channel was largely the source of the noblesse de robe. The informal channel to class mobility was not legally binding but was often in practice nearly as potent. Many of the bourgeoisie who had gained great wealth were able to court equal status with the nobility (albeit informally) by the style of life which that great wealth afforded them. The wealthiest of the bourgeoisie might gain intimate standing with the nobility by "marrying up," that is, by marrying into a noble family. This was, however, a dangerous proposition for the noble; with their prestige on the line, it was a measure that was usually undertaken only under financial duress.

There were accompanying systems of values that were attached to both the open and the closed characteristics, value systems that were often in conflict as the opportunity for mobility appeared. The stronger of the two, even generally among the roturier interestingly enough, was the characteristic that surrounded the caste-like

70 This actually meant important roles to the monarchy, which was often quite different from the country. 
social structure, the system of values that opted for rigid class distinctions and that tended to disapprove of interclass mobility. But the open aspect of French society, which approved of the potential for upward mobility into the nobility, or at least into the noble style of life, was operational as well. This tentative acceptance of both the correctnessi of the caste system and yet the possibility for mobility became institutionalized into a fragile adaptive mechanism by which upwardly mobile roturier's (wealthy bourgeoisie) could beccme enobled by prescribed avenues. But the conflict implicit in the acceptance of two inherently contradictory values eventually. took its toll with the feudal reaction of the late 18th century in which the nobility, frightened by the degree to which the bouxgeoisie had become enobled, had occupied traditionally noble social positions, and the degree to which the wealthy bourgeoisie had been capable of living the noble life, sought to close the second estate by preventing as little mobility as was possible. In light of this rejection, the bourgeoisie sought to break down the social system as it was presently comprised and to reconstruct it around their own values. and merits.

\section{Peasantry}

At the bottom of the roturier class were the peasants. The peasants were not to be confused with the serfs, for while the serfs were still tied to the soil in a feudal tradition and were subject to the justice of the lord, the peasants of 18th century France were free to move about, to own land or other forms of property, as well as being able to bring suit in the courts. There were a surprisingly 
large number of peasants who indeed did own land. The size of these holdings and their number varied in the different parts of France, varying from 75 percent of the land in some areas to little over 1 or 2 percent in others. On the average for the whole of France, the peasants owned probably 30 percent (Lefebvre, 1973:132). There was, however, always a sizeable proportion of the peasantry that owned no land. This did not stop them from working the land. With the exception of the wine regions, the clergy, the nobility, and even many of the bourgeoisie who owned land did not directly manage its cultivation. What usually occurred was a parcelling out of the land either to peasant farmers who leased or rented the land or to sharecroppers who worked the land and then divided the produce of the land with the owner. In the areas where feudal law still prevailed, the feudal lord directly exploited that part of his fief which was called the domain. It was comprised of the house of the manor, a park around the house, meadow or forest land, and land that was parcelled out to sharecroppers and tenant farmers. The rest of the fief was in the hands primarily of peasants but under different conditions. In this latter land, the lord had legally granted the peasant perpetual title to the land, but retained imminent domain which required the peasant to make payments to the lord of the fief. These payments were to be fixed and could not be changed without consent. Perpetual title gave the peasant the right to pass the land on as an inheritance or to sell the title at any time.

In spite of their ability to procure land, either by purchase, lease, or sharecropping, the vast majority of the peasants found it 
quite difficult to actually support themselves and their families from this land. There were two reasons for this. The first reason was that the land was usually in very small parcels and the methods of cultivation were reminiscent of the Medieval period. The second reason was that the great burden of taxation fell directly upon the peasant. It was the peasant that paid the majority of the taille, the poll tax, and the twentieth tax. It was the peasant virtually alone that accounted for militia service, for transporting the military, and for the upkeep of roads. While these taxes and duties were for the benefit of all, it was to the peasant that the greatest burden fell. Burden both in the sense of more peasants having to pay the taxes and render the duties and in the sense that the peasant was the one least able to cope with the cost of such responsibilities. What made things even worse was that the peasant was becoming increasingly isolated fxom the other elements of society. The peasant became isolated from those who could serve not only as an example but also those who might be able to supply guidance and counselling in times of trouble. This isolation was in part due to the exodus of the nobility from the country to the royal court that was spoken of earlier, as well as the desire of the bourgeoisie who were involved in agriculture to leave the countryside as soon as they had acquired a modicum of wealth. The bourgeoisie who should have had common cause with the peasant with regard to social inequalities and privileges and the abuses of both, rather turned his back on the peasant as the nobility had turned its back on both the bourgeoisie and the peasant. Instead of attempting to reform the 
inequalities in taxation, in service due the lord and the king, and in the ability of the peasant to support himself and his family, the bourgeoisie sought only to impose additional injustices that would benefit themselves rather than the nobility. The bourgeoisie was eager and willing to secure the preferential treatment for itself that the nobility obtained and protected for so long, a treatment that had been despised when it directly affected the bourgeoisie in an adverse fashion. However, with the chance to be on the receiving end of such treatment, the common sense of misfortune and injustice that should have been felt with the peasant was often forgotten.

In many respects the peasant of the 18th century was in worse condition than the peasant of the Medieval period. Granted the latter day peasant enjoyed many freedoms that the Medieval peasant could only dream about, but the latter day peasant had to endure a great many abuses both real and personal. In feudal times, though Iife was harsh, the lord and the peasant nevertheless had a closer relationship. The Iord was more aware of the mood and the needs of peasant serfs that lived within his domain. While the feudal lord may have demanded a great deal from the serf, he also was aware that they were his "resource" and something not to be destroyed else he endanger himself. In addition the feudal lord felt something of a moral obligation to look after the less fortunate. As Tocqueville (1955:124), cogently observed:

- . the fourtheenth-century peasants had been at once more oppressed and better cared for; the great seigneurs may have sometimes treated them harshly, but they never abandoned them to their own resources. 
But in the 18th century abandoned to their own resources they were, and what meager resources they were left with after their manorial, feudal, or royal obligations were taken care of. The peasants of the 18th century were treated for the most part as just so many tenants by the absentee noble. The peasant became viewed only as a source of revenue, little concern was actually given to his welfare. The economic and social progress that had enriched and enlightened most of society in the 18th century had at the same time nearly crushed the peasant. They were being impoverished in a period that was conceived of as being one of great progress. The peasant had no share in the commercial advance of the 17th and 18 th centuries that had allowed the bourgeoisie to cope with rising prices and rising taxation. The nobility had made things worse by coping with such pressures through squeezing more out of the already hard pressed peasantry. While the majority of society saw their lives rise, the peasantry saw theirs fall.

This situation was not limited to the physical world alone. In a period that was so overwhelmed with its intellectual advance, it seems a serious omission that the peasant was completely disassociated from this advance. One is reminded of Voltaire's statement that "we never intended to enlighten shoemakers and servant girls, that is the portion of the apostles" (Dawson, 1975:29). It was not until the peasant rebeliions of the revolutionary period that there was any attempt to reäress these grievances. 
Bourgeoisie and Society

Officially the bourgeoisie were represented to the king in a legislative capacity only through the operation of the Estates General and then as part of the third estate, the roturier. In spite of this, in practice they lacked a direct influence in the affairs of state for the Estates General, having been dismissed in 1614. when Marie de Medici decided that the hall in which they met was needed for a dance, had not been reconvened for over a hundred years. Though effectively lacking a direct influence, the bourgeoisie came to represent a major source of motivation, direction, and spirit in French society. This was indirectly a result of the increased wealth that they had experienced in the preceding years. A wealth that afforded them both the leisure time and the required finances to become educated, a wealth that gave them a greater interest in their position in the social hierarchy, and a wealth that served as a symbol of what they were capable of accomplishing. In the I7th century it had been the nobility that had lived the life style of a rather lax moral code and had developed a tendency towards a freedom of thought. This latter phenomenon was in part the function of the popularity, in a faddish sense, of science, particularly the science of Descartes. 71 . Cartesian science was such that almost anyone with a good education (affordable only to the nobility) could competently converse with the professional scientist. But in the

71

The nobility was much more inclined to support the philosophy of the day when it was dominated by Cartesian science than when it was dominated by the reformist ideas of the philosophes. 
18th century with the economic successes of the merchant class, 72 the opportunities presented by careers in the legal and administrative system, the luxury of leisure time and the financial. resources for education, the free-thinking tradition and the secularization that so often accompanied that freedom in large measure passed over to the bourgeoisie. In addition to affording an education, the bourgeoisie could afford to buy the books and literature through which the leading ideas of the day were formulated and promulgated. The bourgeoisie:

- could afford to mingle in society, to attend the
fashionable salons, and to join clubs, where they discussed
the latest radical literature, aired their grievances and
propounded their panaceas. (Gottschalk, 1929:43.)

It was the bourgeoisie that took over from the nobility the role of the chief supporter and consumer of philosophy, in part due to thè abdication of the moral and intellectual leadership role by the nobility that was elaborated earlier. In spite of this ascension by the bourgeoisie, the nobility still saw themselves as leaders, when in fact they were more figureheads than leaders. Figurehead is an appropriate term for while rapidly becoming a central force in French society, the bourgeoisie still sought the symbols of the nobility.

72

The 18th century provided a golden opportunity for commercial success for between the years 1716 and 1789 there was a five-fold increase in foreign commerce (Manuel, 1951:63). The success that the bourgeoisie had during this period was accomplished by their labor alone, the nobility, because of its abhorance of work and its aloofness from the other classes, had not participated to any great extent. It might be said that the rise of the bourgeoisie had been at the expense of the nobility in terms of the possession of available wealth in the country. 
In addition to the fact that the bourgeoisie emerged as the consumer, and indirectly the director, of philosophy, a second manner in which the bourgeoisie became the motivator and director of French society in the 18th century came about through an increasing dissatisfaction with the avenues fox advancement within the social hierarchy. As earlier discussions pointed out, the status, recognition, and official power that the bourgeois experienced and exercised were rarely equivalent with the actual role that they performed and the actual wealth that they possessed. Unlike the bourgeoisie in other countries, the French bourgeoisie had:

. . wealth without responsibility, intelligence without authority, and ability without recognition. (Wallbank et; al., 1965b:71.)

In spite of the fact that it was the influence of the bourgeois' legal and official structure and the direction of men like colbert, as well as the intellectual leadership of bon bourgeois such as Racine, Boileau, Pascal, Descartes, and Malebranche that had created the "Grand Siecle" of Louis XIV, the bourgeoisie were still treated by the first two estates in Erench society as inferiors. In spite of the fact that it was the wealth of the bourgeoisie that consistentIy resurrected the financially floundering French state, paying for the territorial ambitions and economic mismanagement of the monarchy, the bourgeoisie were treated largely as a subserviant class. In spite of all of these contributions to the stability and growth of the French state, the bourgeoisie. were still less than full participating citizens, lacking any real input into the affairs of the country although they were greatly affected by the directions those affairs took. An intellectual awakening of the bourgeoisie and the 
frustration that they began to feel as the nobility attempted to restrict the possibilities of advancement and recognition even more made the bourgeoisie both conscious of the possibilities of change and desirous of that change. As the bourgeois involvement in the flow of ideas in the 18th century increased and their exposure to the conditions of other countries increased, they became increasingly dissatisfied with the direction of French society. They saw the power and the influence that the bourgeoisie had gained in such countries as England and the United States (or prior to 1776 the American colonies), they knew what existed in potential for them. Desirous of having the ideals by which they lived, and prospered, substantiated, they supported the popular philosophies that most closely expressed their ideals. There was a receptiveness accorded to Newton for the rationality that he imparted to the universe and to the utter simplicity in which he was able to express it, to Locke for showing that men by the strength of their own intellect could aid in the formulation of human nature, and to ideas such as natural religion that formulated a religious perspective that was quite complementary to the secular and individualistic tendencies of the bourgeoisie.

It was by and large this bourgeois support that gave the greatest amount of impetus to the French EnIightenment, as a result of which the Enlightenment became an effective expression of bourgeois ideas and ideals. In large part the bourgeoisie supplied the Enlightenment with the thinkers, the ideas; and the support. that allowed it to become the effective social force that it was. 
To the list of influential bourgeois minds elaborated earlier (Racine, Boileau, Pascal, Descartes, Malebranche) one might also add the distinguished names of Diderot, Voltaire, Rousseau, Condiliac, d'Alembert, and Helvetius among others. These bon bourgeoisie represented a virtual who's who of the French Enlightenment. For the most part, they were conscientious crusaders in the name of civilization against man's vices and shortcomings and honestly sought truth. It would be foolish, however, to see them totally as disinterested, objective, social scientists. Both intentionally and unintentionally they brought to bear upon the important ideas of the period, the bourgeois ideals in which they were reared. Contrary to the popular conception, they were not unduly preoccupied with the illumination of the totality of civilization but rather considered their most productive target, both in the sense of a receptive audience and in the sense of the most potential for enlightenment, the bourgeoisie. Once again one may tum to Voltaire for an insight into the feelings of the period and see that it was indeed the bourgeois in particular that the popular philosophy of the Enlightenment turned its attention. Voltaire again surprisingly stated that it "is not the worker we must instruct, it is the bon bourgeois of the townsman" (Dawson, 1975:29). Coming from good bourgeois stock, they were aware of the manner in which to best formulate and present their ideas for the audience to which they were presenting these ideas. Tocqueville (1955:142) again provided an insightful view of this when he stated that: 
- . there was no taxpayer aggrieved by the injustice of the taille who did not welcome the idea that all men should be equal; no farmer whose land was devastated by a noble neighbor's rabbits who did not rejoice at hearing it declared that privilege of any kind whatever was condemned by the voice of reason. Thus the philosopher's cloak provided safe cover for the passions of the day and the political ferment'was canalized into literature, the result being that our writers now became the leaders of public opinion.

Those men were both leaders in a social movement as well as being swept along by that movement, and the essentially bourgeois character of the Enlightenment accounted for the possibility of such a dual role.

If one were to list the fundamental ideas that en Iivened the Enlightenment, it would become readily apparent that those ideas and those customarily associated with the bourgeoisie were strikingly similar, if not directly equivalent. Such a list would include: tolerance for a variety of thought and belief; the beliefs in the equality of all men, in the power of mankind to control its own destiny, and in the rationality and calculability of the entire universe; a denigration of mythology and superstitution; a standard of reward based upon merit and not privilege or authority; ${ }^{73}$ an empirical and utilitarian approach to life; as well as a lack of extremity in thought and action. "Privilege, caprice, coercion, and restriction" (Pollard, 1971:50), the principles of French economics and perhaps society as a whole in the 18th century were as offensive to the ambitious bouxgeoisie as they were to the philosophes of the Enlightenment. The ideals brought forth by the philosophes

73

This, however, did not rule out the possibility of a hierarchical status that was based upon merit. 
and those brought forth by the bourgeois businessmen may have traversed a slightly different path but they arrived at roughly the same destination.

It was mentioned earlier about the bourgeoisie emerging as the primary consumers of and supporters of the philosophy of the 18th century, but beyond the great salons of the wealthiest bourgeoisie there were the salons of lesser grace and import, there were the numerous cafes where a tradition of discussing the important ideas and events of the day supplemented the published literature. Both the salons and the cafes multiplied in the midale and latter parts of the 18th century; in addition there was a great surge in the founding of societies of all kinds. There were:

- . agricultural societies, philanthropic associations, provincial academies, teaching institutions like the Museam at Paris, reading rooms . - . and above alI, Masonic lodges, brought over from England in 1775. (Lefebvre, 1973:49.)

The Masonic lodges were of particular import for in their support of civil equality, religious toleration, and freeing men from those social institutions that repressed rather than enlightened them, they perpetrated the best of bourgeois philosophy and yet included in their membership priests and nobles (including the brother of Louis XVI). By such means of contact as these, the bourgeoisie of the 18th century were thoroughly penetrated by the philosophy of the period and in turn the bourgeoisie influenced the thought of the period as well. 


\section{BOURGEOIS INFLUENCE UPON THE IDEA OF PROGRESS}

Indicating the influence of bourgeois philosophy upon the philosophical Enlightenment also provides an avenue for bringing to the fore the bourgeois influence upon the idea of progress itself, for the philosophy of the Enlightenment was ever involved with the movement of the idea of progress in the 18th century. In the latter part of the 17th century Fontenelle had elaborated a detailed discussion of the progress of knowledge, that, with the possible exception of whatever clerical opposition there was to the natural (versus the theological) sciences that occupied such a dominate position in that progress; was effectively without class related characteristics. The 18th century saw this necessary and unending movement of knowledge generalized and broadened so as to encompass the movement of the civilized whole toward a state of public felicity. Such a broadening of the idea of progress, the process that made the idea what it is known as today, was the result of several factors, not the least of which was a general concern for human welfare. Philosophically there was the influence of Iocke's sensationalist epistomology which gave men the idea that they were capable of changing human nature such that they would progressively eradicate the evil side of civilization, that wholesale changes in the social institutions of civilization were possible. In addition, in the philosophical realm there was the belief in the power of reason (as exemplified by the natural sciences) to guide and illuminate mankind. There was also a social influence upon the idea of progress from the mere movement (albeit necessary and unending) 
of knowledge to the movement of civilization itself. This social influence emanated from the bourgeoisie and consisted in the desire to bring about a social order that was more clearly reflective of those qualities that the bourgeoisie valued. This desire. harbored two divergent motivations. On the one hand there was the straightforward desire to obtain for themselves the power and status in society that the bourgeoisie believed they deserved, and on the other hand there was the honest desire to reform civilization born of a self-conception of the bourgeoisie as the haxbingers of a new world, as men with a universal mission. It was the belief that amid the:

\begin{abstract}
- . unchanging characteristics of human nature, hidden and wrongfully held back in former benighted ages, are all the specific character traits of the bourgeois; that men in other societies, with other value systems and other systems of motivation are in reality, all of them, bourgeois manques. (Pollard, 1971:70.)
\end{abstract}

In both instances the idea of progress came to be a bourgeois expression of what ought to he.

As the ideas of the Enlightenment came to influence the character of the idea of progress in its broadening from simply the advance of knowledge to the advance of civilization toward felicity so the bourgecis characteristics which they embodied came to be embodied in the idea of progress as well. In the idea of progress, the bourgeoisie saw an expression of meaning to their Iives, an expression and an outline of the mission that they saw themselves a part of. Reason, and the underlying force both of Enlightenment thought and the idea of progress would bring into the light and demonstrate as valid those characteristics that had been previously "hidden and wrongfully held back" (Pollard, 1971:70). The 
whole emotion that the idea of progress brought forth fit perfectly into the bourgeois self-conception.

In seeing their fundamental ideals brought forth by the philosophy of the period as the direction to which civilization ought to be moving the bourgeoisie saw a vindication of their belief in those ideals. In the assumption of the necessary movement of progress, derived from the necessary movement of knowledge and the permanence of nature and its laws, the bourgeoisie saw their emergence as a social force given a sense of necessity and inevitableness, a sense of moral conviction in their ideals, in their way of life. The righteousness that they felt toward their way of life was seemingly underscored by the movement of reason embadied in the progress of civilization.

To reiterate, as the bourgeoisie had supported the philosophy of the Enlightenment, and as the goals of the Enlightenment likewise came to be construed as the goals of the movement of progress, so the bourgeoisie came to believe in and support the idea of progress. Such support brings the discussion back to the twofold posture that the bourgeoisie manifested toward the idea of progress. On the one hand there was the support of the idea of progress and what it stood for because of a sincere belief in the righteousness of their "mission," a belief in the ideals that they held and their benefit for the whole of civilization. On the other hand there was the undeniable fact that the bourgeoisie would be among the first to benefit from the arrival of this "heaven on earth." 
As it was mentioned in earlier sections, the bourgeoisie had largely accepted the hierarchical structuring of society, given the ability to move through prescribed avenues into higher levels. But the hierarchy within which they lived, as with the entire social structure of society, was founded upon tradition and the authority that tradition provided. As the nobility saw that tradition threatened and closed down the avenues for advancement within that hierarchy, the bourgeoisie turned to alternatives. The thought of the Enlightenment had called for the rational ordering of society, where tradition and blind authority were subserviant to reason. Reason, the cornerstone of Enlightenment philosophy and the idea of progress, was no alien concept to the bourgeoisie. The bourgeois mind was by and large a ratiocinating entity and the bourgeois wealth was built upon reason and calculation. The nature of society that would emerge through the process of progress manifested these (or was thought to manifest these) same qualities. The bourgeoisie could ask for no more than to be involved in a social organization that placed its emphasis on the very qualities that had emerged so essential to their lives. A society based upon reason would mean that none of the previous restraints imposed by the nobility or the Church would be able to hinder man's application of his own talents and drive. A society that was rationally operated where there was complete freedom of investigation and where there was complete freedom of invention and enterprise truly was a heaven on earth for the bourgèoisie. The progressive social organization did not preclude the return of a hierarchical status system, only that it would be 
based upon the qualities of merit, initiative, function, and the reward that came from these qualities, wealth. The progressive society as it was envisioned in the 18th century would be capable of satisfying both the desire for social felicity and the desire for pecuniary gain. What was good for civilization as a whole was even better for the bourgeoisie, nothing could be more convenient than to aid civilization and oneself at the same time. 


\section{CHAPTER XIII}

\section{FRENCH REVOLUTION}

NOBILITY AND SOCIAI AND ECONOMIC CHANGES

The final chapter of this discussion of the idea of progress unfolded with the French Revolution of 1789. Among the basic emotions operative during the Revolution was the assumption that it was a step for mankind as a whole, a step toward the freedom and equality of all men, toward the institution of the rights, liberties, and justice due all men according to the natural order of the universe. In such an emotion one finds the practical implementation of the feelings and ideas that were fomented by the philosophy of the Enlightenment as well as the general movement of liberalism with its modern antecedents back to the Protestant Reformation. The idea of progress added an air of inevitability to these most fundamental revolutionary ideas. The contribution that the idea of progress made to the implementation of these feelings and ideas marked a certain maturation and acceptance in men's minds, an elevation to a major position in the ideational world of man. ${ }^{74}$

As the 18th century wore on, the nobility was faced with a continual diminution of its privileges, a continual dilution of the

\section{4}

One should actually qualify this by stating that it became an element of the ideational world of Western man for it has only been in the latter parts of the 19th century and into the 20th century that the idea of progress under discussion here spread beyond the bounds of the Western world. 
exclusivity of its ranks, and a continual diminution of its wealth and the power that was based upon that wealth. Earlier discussion has brought to the fore how the very prejudices and prerogatives that at one time had set the nobility apart from society and elevated them in everyone's eyes now cut them off from the only viable source of wealth that the future vista of civilization held. Cutting themselves off from the commercial enterprise had from the outset foretold the trouble to come. The ability of the bourgeoisie to gain entry into the:nobility or to simply display the style of life that had heretofore been reserved only for the nobility had subsequently reduced the only distinction that was still manifest in distinguishing the nobility from the roturiex.

The nobility fought these encroachments in the only means that it found still viable, increasing exclusivity. This exclusivity, beginning in the latter 1770 's became known as the "feudal reaction." The military, traditional ground of the nobility, began in 1781 to require at least four generations of nobility for any commission without coming up through the ranks. The upper clergy, traditionally populated by the nobility, was completely devoid of roturier bishops by 1789. With the exception of Necker, the ministers of Iouis XVI in his later years were all of noble bixth. On the legal and administrative side, the local parlements fought to exclude the roturier from their ranks, having become virtually hereditary. The intendencies, principally composed of roturier when colbert established them, were now composed of nobles. 
It was through this last element of the nobles holdings that the second estate was to make its last offensive in the 18th century to retain power and prestige. The times of trouble had brought a reconciliation between the sword and at least the older robe. The nobility. sought to curb the rise of the bourgeoisie and to bolster and sustain its ailing prerogatives through their effective control of the legitimate agencies of power; the intendencies, the parlements, and the provincial estates. These entities were of varying power, and originally at least, of varying composition. The nobility of the provinces and the power that they exerted in these areas was one of the greater threats to the centralization desixed by the capetian kings. Since the middle of the 16 th century France had been divided into "intendencies" which were territorial districts presided over by representatives of the King, originally chosen from the middle class officials that counciled the King. Given strong powers, these "intendents" were sent to disrupt the solidity of the local nobility and the power that they exerted. The parlements were simply courts of justice, roturier or noble, with no legislative power. There were 13 such parlements, with the most powerful being located in Paxis. While having no real legislative power, the parlements still wielded considerable influence through the tradition that they must approve (register) all royal decrees before they were felt to have the weight of law. The provincial estates were simply legislative bodies existent in some areas that exercised some control over local affairs. 
Several ministers of finance over the years ${ }^{75}$ had attempted to implement the necessary reforms in the structure of taxation, economic structure, and privilege, to bring the perpetual bankruptcy of the state under control. They were all thwarted at every turn by the noble dominated parlements and provincial estates. 76 While ostensibly assembled to carry out the will of the local people and to serve as a counterforce to royal despotism, the parlements and the provincial estates were in actuality the staunchest defenders of the privileged. The parlements were particularly effective counteracting royal authority through their remarkably independent position and the requirement that all royal edicts be "registered." The nobility, through such bodies as the parlements, were able to effectively counter any proposition aimed at remedying the problems of finance or administration, and did so with a blind conservatism. Because of their theoretical role as defenders of the people's rights against despotism, the parlements were able to justify the most conservative and privileged actions by the appeal to libexty and their protection of the rights of the citizen. Thus on the one hand they could justify theix conservative and obstructionist activities to the lawyers and to the bourgeoisie by referring to the defense of men's freedoms and liberties, and on the other hand gather support from the nobility by their staunch defense of privilege. The parlements sought popular support through

75 The latest of which were: Jacques Necker (1732-1804), Charles Alexandre de Calonne (1734-1802), and Lomenie de Brienne (1727-1794).

76 The intendencies did serve as a mediating influence in the decades that preceded the Revolution, but they too ultimately came to be dominated by the nobility as well. 
their professed resistance to despotism, yet their resistance was the staunchest when the despotism seemed the most enlightened. It was the nobility, in the form of the parlements, who were able to obstruct the necessary reforms successively and yet were the loudest in their own criticism of the government:

The nobility, in seeing the power that it was capable of wielding in this administrative/judicial capacity, saw the opportunity to expand this influence to a centralized and nationwide scale. Through their refusal to deal with new taxation, stating that it only was in the power of the Estates General to do so, the nobility sought to reconvene the Estates General. The motive behind this action was the belief that the nobility could, in conjunction with the clergy, dominate the Estates General as they had dominated the parlements and the provincial estates. In such a manner they could control the popular movements for reform with the force of law behind them.

The initiative by the nobility for the convening of the Estates General coincided with the popular fervor for a representative government, a fervor that was motivated in large part by the example of the American Revolution. Thus the camouflage that had been perpetrated in the name of the protection of liberty was now present again in the name of popular sentiment. The parlements had been hailed as prophets when they voted that only the Estates General had the power to solve the financial difficulties. Their misunderstood popularity was not to last long, and the very intrigue that sought to restore their power and prerogatives was to seal their doom, the 
doom of noble privilege and the doom of the parlements themselves. With the convening of the Estates General in 1789 the parlements vanished virtually overnight. Perhaps stating it a bit strongly, yet still capturing the important course of events, it has been said that:

- - if there had been no Parlement there would have been no financial crisis, that if there had been no financial crisis there would have been no states General and if there had been no states General there would have been no Revolution.' (Dawson, 1975:53.)

One cannot, however, accuse the nobility, here including the upper clergy, of being completely oblivious to the increasing needs of the nation. In the cahier de doleance of $1789^{77}$ there were many instances, both by the nobility and the clergy, of grievances and suggested reforms that would be beneficial to the nation as a whole. One finds, for example, the suggestions that:

- - selection of the militia by lots be suppressed, as even more burdensome to the people than the tax of the taille. (Stewart, 1951:20.)

- . that every arbitrary order prejudicial to the liberty of citizens be abolished entirely. (Steward, 1951: 65.)

- . that steps be taken to eliminate, as far as possible, the remaining vestiges of the feudal regime, respecting at all times the sacred right of property. (steward, 1951: 69.)

- . that all farmers who have a great area of land under one management, to the detriment of agriculture and the small cultivators, bear the greater part of the personal tax, of which the said less fortumate cultivators shall be relieved. (Steward, 1951:69.)

\section{7}

The "cahier de doleance" were the lists of grievances that the King asked the three estates to submit. so that he could understand their intentions and so that the Estates General could more effectively deal with the problems of the nation. 
These desires in addition to many others, including a written constitution, an end to the veniality of offices, and free election of municipal officials, showed the nobility willing to make certain sacrifices for the good of the nation. At a later date, as the organization of the Estates General was forming and the three estates were vying for power and support, the nobility agreed to relinquish (the August Decrees) many of its feudal dues, private hunting grounds, and othex such prerogatives, albeit with compensation where such sacrifices could be construed as private property. 78 There is no doubt that many of the bitterest complaints against the nobility, including its unequal contribution to the royal treasury, would be silenced by these measures. But while the nobility was willing to make these sacrifices, they would not surrender their preeminent status in the social hierarchy and their feudal rights, specifically the honorifics that marked the nobility as the superior class. They were willing to give up much that had brought them the wealth they enjoyed, but they wanted to maintain the exclusivity of their caste. Once more the cahier de doleance provide an insight into the desires of the nobility for in them one finds the nobility asking its quarter in return. As the cahier related:

\section{8}

It is interesting to note that through the entirety of the Revolution, from the cahier de doleance of 1789 through the Declaration of the Rights of Man and Citizen and the constitutions of 1791, 1793, Year III (1795), and the Napoleonic constitution of Year VIII. (1799) one finds reference to the inviolable rights of property. Even in the periods of 1793-4 where there was a movement in the direction of instituting more of Rousseau's ideas of equality (in response to the movement generated by men such as Jacques Roux) the property that had been divided among the people was only that which had been confiscated from the "enemies" of the people. The great landholdings of nobles and bourgeoisie who judiciously supported republicanism were left undefiled. 
The order of the nobility desires further that the distinction of the three orders in the Estates General be strengthened and regarded as inherent in the Constitution of the French Monarchy, and that opinions be given therein only by order (Stewart, $1951: 66)$.

Finally, the nobility declares that, in order to evince its sentiments of esteem, natural equity, and affection for its fellow citizens of the third estate, it wishes to share with them, in proportion to the property: and possesions of all orders, whatever imposts and taxes are approved by the nation; claiming to reserve only the sacred rights of property, the prexogatives of rank, honor, and dignity which must appertain to it according to the constitutional principles of the French monarchy. (Stewart, 1951:66.)

Had these concessions and demands occurred perhaps ten or more years earlier, they would have been accepted by.all elements of the social hierarchy. By the time of the Estates General, however, the bourgeoisie now had desires from which it would not retreat just as the nobility had certain uncontestable demands. The first and the foremost desire of the bourgeoisie was to no longer accept the subordinate position below the nobility. The cahier de doleance of the third estate revealed this position. One stated that:

- - his subjects of the third estate, equal by such status to all other citizens, present themselves before the common father without other distinction which might degrade. them. (Stewart, 195I:66.)

The snubs that nearly all roturier, whether high bourgeoisie or low peasant, had received at the hands of even the lowliest noble had steeled them in their task. Mathiez (1956:13), for example, recounts the episode in which the noted Mme. Roland and her mother, upon being asked to stay for dinner at the Chateau de Fotenay, were served their repast in the servants quarters. While the Estates General had ostensibly been called to deal with the 
financial plight of the nation, the bourgeoisie like the nobility saw it as their opportunity to implement their desired social and political changes.

\section{BOURGEOISIE}

The privileged position of the nobility had been based in religious doctrine and the weight of custom. As long as the bourgeoisie had accepted the legitimacy and the power of these sources then the disparagement in esteem between the nobility and themselves was at least bearable. The growing secularization of the 18th century and the increasingly apparent burden that the privileged classes had become to a strained society seriously undermined the persuasiveness of these arguments. Wany of the bourgeoisie had accepted the arguments of the philosophes that such an idle and fundamentally amoral social class represented a negative influence to society's progress. 'With the religious and customary justifications waning for the privileged class there simply were no rational or moral justifications for their exalted status to continue. The real crux of the problem lay in the fact that the bourgeoisie, representing at least the economic vitality of the nation, resented being treated as "nothing" by those who represented the greatest single strain upon France's solidity. This insult was made even more biting as the prosperity in the latter decaces of the 18th century allowed the wealth of the upper bourgeois to equal or exceed that of a great many of the "noble" families.

Thus it was that the Estates General and ultimately the Revolution represented to the bourgeoisie the opportumity to remedy. 
this unjust situation. The pamphlet by the Abbe Sieyes, What is the Third Estate (1789), was a masterpiece in the succinct statement of a grand problem. In this famous pamphlet sieyes (Guizot, 1898: 370) asked, "What is the third estate? Nothing. What has it been hitherto in the body politic? Nothing. What does it demand? To be something." As the nobility had come to the Estates General with liberal ideas on the reform of the nation and yet having that element of which they would brook no change or reform, so the bourgeoisie had come to the Istates General with the same liberal ideas for reform and yet holding out for the broader movement of the idea of equality, an equality of esteem, and would not renege on their desire for change for now they had the power to force that change.

It is well known that the bourgeoisie played a leading role in the Revolution. This role was a natural gestation of the social situation and the ideas of the 18th century. The bourgeoisie were in the best position to benefit from a revolution. They had endured the discrepancy between their wealth and potential power and their social esteem, and thus it was the bourgeoisie that most actively sought to change the structure of I8th century French society. In addition, part of their leadership role in the Revolution stemmed from the fact that they were well represented in the various sectors of society. The basic bourgeois outlook was shared by individuals from very near the poverty level of the peasants through the professionals and smail shopkeepers all the way up to the wealthier financiers. As the bourgeois origins of the philosophes had 
allowed them to understand the mind of the bourgeoisie and to formulate their ideas so as to gain the widest appeal, so the fact of the representation of the bourgeois through the spectrum of society allowed them to present the essentially bourgeois desires of the Revolution in a manner acceptable, at least temporarily, to all of society.

There was also the gestation of the philosophical ideas of the Enlightenment that contributed to the bourgeois role in the Revolution. The philosophers had done the thinking for the bourgeoisie in the earlier part of the 18th century, but in the Revolution it was the bourgeoisie (specifically the lawyers) that spoke for the "people." When the King convened the Estates General he had, in the eyes of the bourgeoisie, authorized them to speak. While a more in-depth look at the role of the ideas of the Enlightenment and the idea of progress in the Rovolution will be forthcoming, suffice it to say at this point that a number of nobles, the bourgeoisie, and the rest of the roturier, were very much influenced in the perception of the Revolution by what they had absorbed from the philosophes concerning the natural equality of man, his natural rights to a freedom of thought and expression, and the productive role that reason (vis a vis tradition and custom) could play in the administration of society. The Enlightenment had taught the bourgeoisie that their chief enemy was the despotic government and the privileges and privilegeholders who benefitted by that despotism. This perspective tended to portray the essential human liberties as existing in spite of the state, that the natural human freedoms must be secured in opposition 
to the state. As Iong as the despotic state existed apart from the will of the individuals that composed the nation, there was always the danger of the suppression of those freedoms. If the state suppressed the individual's freedoms against his will then the individual was bound to call the state to account for this violation, even if it meant the seizure of the state. Ultimately this seizure was what the bourgeoisie were moved to do, but in between the despotism of the late 17 th and early 18th centuries and this seizure of the state was the belief in the "enlightened despot." The one individual leader of the state that would use his, or her, unassailable power in accordance with the most advanced and enlightened thought of the day, such that the benefit of all could be obtained through the control that the enlightened despot could wield over society. Though bound to support the freedom and equality of men, the philosophes and the bourgeoisie of the 18th century displayed no great devotion to the idea of a popular democracy. They feared that such a potpourri of interests as would result would paralyze the necessary initiative that translated enlightened ideas into concrete practices. It was in this framework that one finds even the most infamous of the revolutionaries and proponents of the popular will still monarchists up until the very outset of the Revolution. Men such as Danton and Robespierre had hoped, as many others did, that the royal power and prestige could be used to bring about the necessary changes in the structure of French society. This faith in the monarchy was bolstered by the fact that the king had slowly but surely been destroying the feudal character of society, in light 
of this was there not room to hope that he was capable of finishing the deed? It was only when the king finally felt forced to ally himself with the privileged nobility and the clergy that the bourgeoisie and the rest of the nation abandoned the hope of obtaining the social reform through him and moved to appropriate the state.

In addition to a certain intransigence on the part of the nobility and the bourgeoisie, the monarchy itself, as alluded to above, contributed to the outbreak of revolution instead of the peaceful movement toward change. The French government revolved around the king and when the King lacked foresight, courage, and the will to govem decisively in times of trouble, the very elements of government that provided power in times of peace became an unbearable millstone.

In the past, the nature of the strength of the Capetian line had been its national character, that is, its apparent concern for and representation of the nation as a whole. It had been a character that was carved out of an alliance of the king and the people against the nobility. In addition to the pecuniary aspect, dilution of the power of the nobility and the enfranchisement of the roturier had been one of the motivations for the practice of selling offices and conferring nobility upon their purchasers. Within this structure of power, Iouis XIV had been able to secure the best equilibrium between satisfying the will of the people and mollifying the desires of the nobility. Louis XV, however, had begun to lose touch with this inherent power of the capetian line, lose touch 
with the people. Beginning with Louis XV, the court nobility had become the only influence (save some philosophexs of the day) upon the King, and while the armed uprisings that might have worried earlier monarchs were gone, the nobility exerted a much more subtle influence upon the direction of the state, an influence that was born of the isolation of the king from a feeling of the spirit of the people. Louis XVI Iived within this influence, and though he was a genuinely kind and conscientious man, he did not have the strength and the will to break free from this noble entourage and resume his role as the leader of the nation, of all the people. He was ultimately to choose to defend the parasitic nobility and clergy against the will of the nation, and so determine his own fate. Thel monarchy was to contribute to the outbreak not only by its fundamental adherence to the rights and the privileges of the nobility. and the clergy, but also by engendering a sense of indecisiveness and vacillation in the years before the Revolution as well as the period before the dissolution of the monarchy. This uncertainty was created and supported by the very arbitrariness of the moharchy's activities. In times when consolidation and solidification were needed the monarchy:

. - irritated the nobles while it paid their pensions; it taxed its allies the bourgeois to pay for the luxury and waste of its court; it created a sense of the precarious and insecure character of all rights, and turned reactionary whenever it seemed to have desired a decisive advance; and by yielding tamely to its own subject's commands it demonstrated its impotence even while asserting its omnipotence. (Ruggierd, 1959;53.)

In not understanding the nature of the movement that was building in the nation the King had failed to understand that he was 
in the best position to restore peace and tranquility by making the necessary reforms. Even after the convening of the Estates General, he did not understand that the same peace could be had by the execution of the popular will through his prestige and the power of his office. In missing both of these opportunities, Louis XVI had ultimately placed himself, and the ancien regime, against the populax will, and with the strength of 200 million Frenchmen behind it that will prevailed.

\section{INEVITABILITY OF THE FRENCH REVOLUTION}

\section{Reforms Needed}

It is natural enough to ask whether the Revolution was "necessary." Perhaps the most generally accepted answer to the inquiry was that change and reform were necessary in 18th century France, but that revolution as such was not necessary, nor. was it inevitable as has often been claimed. There were, no doubt, numerous abuses, hardships, and privileges that needed to be remedied. There were the abuses of personal liberty as witnessed by the ability of the state to arrest and detain prisoners with no charge and for indefinite periods of time, arid of the use of torture on accused criminals. There was the need for a change in the laws that would prevent food that was in abundance in one area of the country from reaching other areas where it was badly needed. There was a drastic need to revamp the tax structure such that those who had the best ability to pay would be compelled to do so and the burden of taxation that had almost singularly fell upon the lower roturier, 
particularly the peasant, would be lessened. There were areas of France in which feudal rights were still exacted with its

degradation of the human value, a practice which in a period that prided itself upon being enlightened was a black anachronism. At the risk of displaying too bourgeois an ideological position, perhaps it was time that the structure of French society that had rewarded the lax and the lascivious with the highest social honors at the detriment of the rest of society finally throw off these feudal trappings.

Onemust adaress the question of who was desirous of these :reforms as well. Nearly everyone, every class, that composed French society of the period was interested in changes. The nobility on one hand was interested in countering the rising power of the bourgeoisie by returning many of the feudal characteristics to society, while willingly giving up others. The bourgeoisie were interested in reducing the power of the nobility in the sense that the privileges that were bestowed upon them served to bldck the free enterprise necessary for sustained and lucrative growth of business, and in turn the bourgeoisie. In addition there was the interest on the part of the bourgeoisie to reduce the disparity of prestige between the bourgeoisie and the nobility. The peasantry, of course, was striving to rid itself of the excessive burdens of taxation and feudal. dues that have previously been mentioned.

There is, however, a fundamental difference between the felt need for change and for reform and the desire and execution of a revolution. The need for change and inevitability of such change 
were no doubt there, but why the Revolution? Part of the answer strangely enough lies in the old saying that a revolt is an act. of despair while a revolution is an act of optimism. Revolutions are not undertaken with simply the desire to destroy what exists, but rather to replace it with something better. Revolutions often come not when conditions are at their very worse but when they have begun an upswing, and so it was in the France of 1789. In nearly all domains of French society. things were getting better, a fact that the people were conscious of. In diplomacy and foreign policy the French contingent to the American Revolution had acquitted themselves admirably. With regards to justice and the law, changes for the better were being instituted as well. The torturing of prisoners had been abolished through edicts in 1780 and 1788. The abuses and restrictions that had been placed upon the Huguenots had been removed. Serfhood had been abolished at least on the royal domain in 1779. Economically speaking the French state had been making substantial advances in spite of the feudal residues that kept capitalism from developing as swiftly and as effectively as it had in England. Foreign trade had doubled between the middle of the century and the Revolution, and the trade figures for 1825 barely exceeded that of 1788. In spite of the restriction that kept industry from developing in France there was the increasing introduction of manufacturing and the heavy steam equipment that it used. All of the technical innovations in the textile industry that had arisen in England had been imported 'into France. France itself had begun to make some contributions to technological advance. In the 1760's and 1770's 
Nicolas Cugnot (1725-1804) was developing a steam automobile, the 1780's saw Jouffroy d'Abbans (1751-1832) develop a steamboat, and the $1780^{\prime}$ 's also saw the Montgolfier brothers (Joseph and.Jacques) inflate and ascend in the first practical balloon. This French inventiveness, however, was by and large lost in the course of the Revolution, not to resurface again until the ascension of Napolean.

Even the dreaded curse of taxation had seen some lessening in the latter decades of the 18th century. Rarely did the practice continue to exist of harassing with threats of confiscation, imprisonment, or corporeal punishment, people who were simply not in a position to pay. There seemed to emerge a genuine concern for the hardships of the poor, and even a certain amount of concern for their rights and liberties. During the 20 years prior to the Revolution the state had been gradually getting involved with ameliorative activities which in prior reigns had not even been considered. The King even had increased the amount of money that was destined to aid the poor and took a personal interest in the administration of such funds as well as other benefactions to aid the less fortunate. This personal interest by the King displayed another factor of French society of the period. In discussing the period one must not fail to state that in spite of the King's timidity and lack of great intellectual power, the 18th century saw few if any monarchs that were more benevolent or conscientious than Iouis XVI. And there were no countries nor monarchs that had gathered in a greater collection of ministers than France. In the shadow of names such as Turgot, Necker, Malesherbes, Vergennes, and Dupont de Nemours; the French 
state had attempted, on some level, reforms in the French economy and the judicial system since the middle of the century.

What these previous examples have offered was a view of a country that in spite of the persistent inequality of taxation, the internal restrictions on trade and commerce, and the remnants of : feudal privilege, was better off than it had ever been before. In 1760 there had been Iittle hope for the majority of people, but by 1780 that future looked very hopeful. But returning to the negative tone, such general advances in the condition of the French people could not solve the ever present problem of a bankrupt government. Many of the programs to help people had in turn aided the insolvency of the treasury through the finances that they required. The insolvency of the government, a chronic problem, had become even more important in the recent years as the number of persons having some sort of financial tie to the government (through loans, pensions, or speculations on government enterprises) had grown dramatically. Never in the history of the French state had the fiscal character of the govermment had such a direct effect upon the lives of the people. By 1789 By 1789. the govermment was in debt to the sum of $600,000,000$ livres. 79 Even the best ministers could not solve this fiscal problem for there was little or no desixe among the people to bend and compromise so that the strains in the society could be lessened and the economy grow even stronger and the state be relieved of

\section{9}

With the livre, the monetary unit until the introduction of the franc during the Revolution, being worth the equivalent of five dollars the debt of 1789 totalled some three billion dollars. 
many of the financial drains. It was an intransigence that marked the pre-revolutionary period.

\section{Prosperity Existent}

The prosperity that had been coming to France did not have a soothing effect upon the people's reactions to the still existent abuses and the government's indebtedness. The fact that things were getting better made them want even more. Instead of becoming more tolerant, they became less willing to put up with the feudal remnants that still operated to disrupt an efficient economy and liberal society, remnants that still operated to dismupt an efficient economy and liberal society, remnants that they had tolerated for centuries. In general the people may have suffered less but they were becoming more sensitized to those obstructions in society that made it operate in such. a ramshackle manner. Feudalism in all of its manifestations, both real and imagined, was in all probability more hated in the 18th century at the time of its eclipse than at its height in the Medieval period.

\section{Necessity of Change}

One can in part explain this growing impatience by relating to the saying that a person cannot miss what they do not know about. In earlier times when the general population was assured of a static existence with little potential for advancement or for amelioration in their lives, they had no taste for the "good life" and so could not relate directly to it. However, as a general prosperity occurred and such amelioration became accessible to more people, they 
became more aware of what potential the future held for them. They were faced with both a vista of what they might be able to acquire and concrete examples of how an ineffective government and a restrictive social structure was preventing them from realizing that vista. This returns one to the previous statement that a revolution is a statement of hope, and this hope was manifested primarily in the felicity that the future held out for a large portion of the society. In a most fundamental sense, the Revolution was an expression of impatience born of the hope of what the future held should the necessary social change occur. An impatience that found the slow and laborious changes that had been occurring unacceptable.

It was at this time of prosperity and impatience that the ideas of the perfectability of man and the idea of the continuous progress of man experienced their greatest vogue. The power of these ideas was something of a germination of the ideas of the Enlightenment, particularly the progressive quality of reason. Ideas particularly become persuasive when there is a concrete expression of them that makes the ideational empirical, something that people can actually see at work. This concrete expression was found in the measure of enlightening chat the government had undergone, the banning of torture and the easing of tax harassing, and the economic prosperity that the nation was experiencing. The ideas took fervor in the hearts of the bourgeoisie for they, as has been discussed, were in the best posjtion to profit not only from what reforms and prosperity that had occurred already but also from what the future held as well. They were in excellent position to benefit from a rationalization of 
society, which was construed as a necessary element of the progress of reason, itself the central aspect of the progress of man. The perfectability of man was, due to the nature of the Enlightenment ideas that framed it, couched in ideas of bourgeois origin. The theoretical elaboration of an idea of progress and perfectability. coupled with the concrete manifestations of at least the former, made these ideas seem ever so real.

\section{FACTORS IEADING TO THE FRENCH REVOLUTION}

Each of the major elements of French society in the 18th century played a contributory role in precipitating the Revolution, and thus each became in part a "reason" for it. It was a combination of desire for specific gains with a corresponding lack of willingness to compromise in order to achieve those gains that drove a movement for reform into revolution.

The outbreak of a revolution and not simply the eventual enactment of the necessary reforms was primarily the result of three factors. The first factor was the above mentioned intransigence on the part of the nobility and the bourgeoisie. Failing to compromise on the main point that separated them pushed events past the point at which simple reforms were acceptable and set the stage for grander social and political reforms, the real changes that the Revolution in France was to bring about. The second factor was the indecisiveness on the part of the monarchy when it was possible that the authority and prestige of the King in the eyes of the people could have rallied public opinion to a point at which the hostilities, 
still verbal rather than physical, between the contending factions could have been resolved short of armed insurrection. The third factor, yet to be discussed at length, that led to the Revolution was the intellectual influences of the day and their role in fostering a revolutionary spirit and a revolutionary optimism. Included in this category was the general thought of the Enlightenment (its rationalism, its liberalism, and its naivete), the particular thought of Jean Jacques Rousseau (1712-1778), as well as the ideas and the emotions that were generated by the American Revolution.

The philosophy of the day, in contrast to other periods was deeply interested in all that concerned the governing of a state, including the origin of society, the origin and nature of rights and liberties, the difference between the natural and the artificial relations between men, the value of custom, and the whole nature of law. There was, of course, a great variation in the depth and the seriousness which was devoted to these subjects. The great majority of writers dealt with these subjects on a rather superficial level, most of the material taking on a literary rather than a scholarly character. 80 This was in large part due to the fact that they were producing their works for public consumption rather than for the minority of educated men. The suggestions that were offered on the nature of how to reconstruct the state were of great variety as well, and very frequently of dubious mexit. Regardless of the variety, they all manifested a common principle that was found amid them all,

${ }^{80}$ For there were a large number of men of a more popular literary bent who wrote less for enlightenment than for fame and fortune. 
a common starting point that reflected the nature of thought in the

18th century. This common principle was:

... the belief that what was wanted was to replace

the complex of traditional customs governing the social

order of the day by simple, elementary rules deriving from

the exercise of the human reason and natural law. (Tocqueville, 1955 : 139.)

The philosophers believed that once a society was governed in accordance with the rule of reason that progress, and the justice and good life that it implied, would follow naturally. In this respect it did not matter what precisely the form of government was, democracy, monarchy, aristocracy, the rule of reason could operate in any one of them. In general they had a preference for an enlightened monarchy because of the power that the single muler could wield. Their very concern with reason as the tool of truth and knowledge led them to work out their political generalizations in a rather high level of abstraction, and inspixed a confidence in the practicality and viability of their generalizations far beyond their actual merit. Though actually unaware of the direction in which public opinion and public action might turn, they were following their belief that everyone would act exactly in the enlightened manner in which they themselves saw their actions, and that everyone would work for the goals that they were working for. Through this naivete the philosophers and literary men of the day:

- - became much bolder in their speculations more addicted to general ideas and systems, more contemptuous of the wisdom of the ages, and even more inclined to trust their individual reason . . (Tocqueville, 1955: 141j) 
One sees the characteristics of the philosophers and the literary men absorbed by the revolutionaries, the penchant for abstract generalities, the distaste for concrete facts, the belief in the ability of legislation to solve problems without engendering new problems, the belief in the rules of logic and reason as legislative guides, and in general the desire to forego the rectification of defective aspects of the existing system in deference to completely new and novel approaches to the practical problems of the social order. $^{81}$ But while the abstract and original approach to the problems at hand and the flowery speech of the oxators attracted many to the literature and to the streets they were not likewise successful approaches to the administration of a nation.

The men of letters, who by and large were without wealth, responsibilities, or official status, had in the 18th century acquired the role of the leading political scientists of the day and spoke with the greatest sense of authority, while it was a different class of men who actually controlled the government. The relation between the theorists and the practitioners was often quite distant. It was often the case that one group formulated the theories about the nature of government and all the attendent notions about human nature and social action, and another quite different group actually carried out the day-to-day administration of government. The former developed the abstract principles and the general

81

A great many of the writers of the day in fact became leaders in the Revolution. 
laws by which proper government should function, the latter simply enacted those measures that served the purpose of the moment. As a result "one group shaped the course of public affairs, the other that of public opinion" (Tocqueville, 1955:146).

As a result of this dichotomous situation there arose two quite different systems of government in France in the 18th century. On the one hand there was the existent. system which was a spector of chaos, ambiguity, and tradition. On the other hand there emerged from the minds of the philosophers and writers into the hearts of the people another system that was formulated in the rationalism and libexalism of the time and so displayed an edifice that was a model of simplicity, equality, and rationality. It was this latter system that had come to dominate the minds of the populace and, reflecting the naivete that was implicit in much of those formulations, gradually led the people to the belief that such a world was close at hand. Their system produced:

- . the foolish hope that a sudden radical transformation of a very ancient, highly intricate social system could be effected most painlessly, undex the auspices of reason and by its efficiency along. (Tocqueville, 1955:144.)

This was perhaps the greatest injustice that the philosophers and the writers of the 18th century bequeathed to those who followed them. They failed to understand the obstacles and problems that would be encountered in trying to effect the changes that they desired. They were unaware of the difficulties in trying to institute a free society based upon the liberal notions of natural rights, equality, and liberty in a society that had known virtually 
no political and civil freedom, nor a true freedom of speech and conscience. The populace lacked a first hand acquaintance with the fundamental elements of a truly free society.

In light of the belief in the possibility of sudden and radical change that they fostered, it is important to bring forth the fact that the intellects of the day were on the whole gradualists in temper. But while the men who propounded the ideas and ideals of what society should be like may well have been gradualists, their writings fostered an impatience in those who read their works and who had such a strong desire for change. They created the visions of what a perfect state would be like, and, while they were seeking to perfect society not simply destroy it, they did not go so far as to prescribe how this state of perfection was to actually be brought about. They believed in a gradual shift toward this described state but they had no conception of how to effect this gradual change without totally disrupting the social fabric. The fact of this omission and its impact can be seen in the chaos that too often characterized the course of the French Revolution.

In part one must explain the fact that there was such concern, not only among the men of letters but in turn the general public as well, with the nature of society by recourse to the very nature of the society in which they lived. At every turn they were beset with the spector of seemingly absurd and abusive privileges wrecking havoc upon the society, imposing the biggest burdens upon those that were the least capable of bearing it, privileges that fomented 
ridicule for the most productive elements of the society and created icons of the useless and the idle. Such vestiges of days gone by, devoid of any relevance to the changing face of modem society, pushed the men of letters, both through an intellectual interest and a certain class interest as well, to a dislike of what smacked of the ancien regime and motivated them to conceptualize on the project of remolding society anew within the circle of reason.

There were a number of reasons why the general public took to these ideas with such vigor. First of all, they had no real contact with the political and administrative systems since the dissolution of the Estates General in 1614. They were as naive about the true nature of government as were most of the writers and philosophers, and thus readily accepted on the basis of their belief in reason the ideas that were put forth concerning government, freedom, and equality. Besides a belief in the abstract, there were very practical reasons for the desirability of replacing the ancien regime with a new liberal form of government. The ideas of the detrimental effect of ancient privileges, of the natural equality of men, and of the rights of all men to liberty and freedom, were all excellent expressions of the anger and injured pride that resulted from having to support an idle class of parasites and from having to quietly accept the abuses and insults of this class. Thus while in addition to expressing a genuine desire for social change the ideas of the philosophers and writers also served as an expression of the dislike and anger for the very social structure that 
would subject people to such injustices. It was through the desirability of their ideas and the underlying discontent of the people that the leading philosophers and writers came to be charged with the duties of the political scientists and politicians.

The nobility were in one sense more perceptive of the actual. nature of the writings of the day, and yet at the same time more naive than anyone about the possible effects of those works. The nobility by and large saw the egalitarian thought of the 18th century as merely the fanciful imaginings of literary minds, passing off the fact that these writings challenged their very existence. They also ignored the fact that such writings, regardless of their serious political merit, were quite capable of arousing the passions for change in the people. So much did they overlook the potential dangex in these writings that they viewed them as something of a game, and themselves talked, perhaps tongue in cheek, about the absurdity of the ancient customs. Many of the philosophes were subsidized by such enlightened nobility while still attaching the vices of the ancien regime. ${ }^{82}$ In the first light of the Revolution such grand figures as Tallyrand (Bishop of Autun), comte de Saint-Simon, and even the Duc de Oxleans (first prince of the blood) came out on the side of the third estate and aided in

82

In part one can explain this situation by pointing out a certain lack of specificity on the part of the philosophers. While they would attack unjust taxation, despotism, and venality they would be able to do so without at the same time attacking specific individuals or without suggesting a specific remedy. This judicious amount of ambiguity helps to explain the tolerance that was extended to the philosophers and the writers of the day. 
the Revolution. It was only in the provinces where the influences of EnIightenment thought was nil was there any substantial armed resistance to the Revolution. As Segur has said of the nobility and its tacit acceptance of the ideas of the day, "they trod IightIy on a carpet of flowers toward the abyss" (Dawson, 1975:54). Though they opposed the violent overthrow of the monarchy, and with it the ancien regime, the intellectuals of the day prepared the way for that overthrow in additional. ways. In the latter part of the 18th century the teachings of the philosophes and other philosophers had become influential even in the houses of the nobles and the heads of state. With the disappearance of the Jesuits, the philosophers became heir apparent to the role of the state councilor and spiritual advisor. Under such tutelage there were a number of enlightened reforms undertaken in many of the nations of Europe. The extent of such changes were rather superficial however, and while the upper bourgeoisie and the courtiers may have benefitted by such enlightened measures, the working class and the peasantry throughout the greater part of Europe still lived in conditions one step removed from the 13th cenutry. This situation engendered a new barrier between the lower classes and the upper bourgeoisie (where it existed) and the nobility. The ancien regime had been, in large part, held together by the bond of a common religion: As it has been stated in earlier sections, that common faith provided an explanation and a justification for the structure of society and thus created a common acceptance of the status quo. With the intrusion of Enlightenment thought into this system and its fashionable harangue against 
religion (at least revealed religion) that situation changed. The acceptance, whether deeply held or not, of the deist or atheist viewpoints by portions of the upper classes helped to remove the sacred aura about them, helped to cast doubts upon the legitimacy of their revered status. Thus regardless of what was done legitimately in the name of human freedom and the progress of man by the upper classes under the influence of Enlightenment thought, without this sacred character the ancien regime had lost its soul, had lost its heart. When one speaks of the influence of the intellectual atmosphere upon the French Revolution, one must be careful to distinguish aspects of its character. There were two distinguishable trends to the thought of the Enlightenment, and through its influence, two trends to the Revolution. The first was the essentially liberal aspect that emerged as a concern with the freedom and equality of men, that sought to understand the nature of society and jurisprudence. There was a second aspect that was manifested in the rather voracious attacks upon revealed religions. In this aspect, the Church was attacked as being an obstruction to man's enlightenment and the true progress of knowledge and civilization as a whole. During the course of the Revolution, one saw an outgrowth of this antireligious feeling in the violence against the clergy, in the confiscation and the sale of church property, in the advent of the Goddess of Reason and the transformation of the cathedral of Notre Dame into the Temple of Reason. But the anti-religious activity of the Revolution was perhaps not so much an attack upon religion as the political position that the church itself had come to assume in the 
social structure. The Church represented one of the greatest privilege holders in the ancien regime. The Church benefitted from tax exemptions and yet owned great amounts of land, including numerous vineyards from which they sold the resulting wine, and numerous feudal manors which entitled them to collect their feudal dues from the peasants. The Church represented, perhaps more than the noblesse d'epee or the noblesse de robe, the unequal effects and benefits of privilege.

\section{INFIUENCE OF JEAN JACQUES ROJSSEAU}

\section{Criticism of Contemporary society}

In recounting. the effects of the intellectual atmosphere upon the Revolution, one must not forget to directly include the influence of Jean Jacques Rousseau. Though by no means noted as an exponent of the idea of progress, Rousseau was important for it was in his work that one found the most potent example of liberal thought in pre-revolutionary France. Fundamental in Rousseauan thought was the indictment of contemporary society. Though living in a period of grand style and culture, Rousseau was not distracted by such trappings and viewed them as cosmetic and illusory. As Rousseau (Cassirex, 1951:155) stated:

Just a lacquer of words everywhere, just a mad scramble for happiness which exists only in appearance. Nobody is concerned with reality any more; all suppose it to lie in illusion. They drift along through life as slaves of self-love; not in order to live, but in ordex to make others believe they have lived.

The growth of wealth within society and the increase in idle time that it afforded the wealthiest were not seen as a measure of 
society's advance but rather as manifestations of the increased corruption that had befallen society. Wealth and all the accoutrements that it brought were sought in order that the poverty of the soul that marked contemporary society might be all the more successfully masked. Rousseau saw the activities and the amusements that were used in contemporary society as a manner of refuge, a refuge from man himself because he could no longer bear to come to grips with what man and his society had become. Thus while many were taken with the increase in wealth and luxury that the 17th and 18th century brought, Rousseau saw it only as indicating that the underlying human relationships were becoming weaker and weaker. In such a world as this, Rousseau saw men as being alienated from their "original" nature and being progressively prevented from expressing themselves in the free and unencumbered manner that characterized man's natural state. Rousseau put much store in the qualities of friendship, esteem, and confidence in others that were outgrowths of the virtuous and unrestrained manner which at one time characterized human interaction.

Rousseau attacked contemporary society for its over concern with the "artificial" needs of the social realm, to the exclusion of the fundamental spiritual and moral needs of men. He counterposed society against virtue, with virtue tending to denote a stability and a unity of life and a concern with the moral rather than the social life. Where society encouraged idle speculation of dubious merit, the virtuous life focussed man's attention upon the development of an inner strength and a vigor that infused his 
existence with a permanence that was a stark contrast to the ephemeral existence of l8th century social life. Though contemporary society did exhibit a certain structure of coherence and vitality of its own, it nevertheless ignored the "duties of man and the needs of nature" (Grimsley, 7, 1967d:219). This fact conditioned a contradiction between the real (the natural needs of the human psyche and the species of man) and the apparent (the needs of the created social world). Men of the present social order had come to value the gift of hypocracy more than honesty. This is quite easily seen in the divergence between the politeness of the business entrepreneurs in their social gatherings and social situations and the ruthless and insensitive manner in which they carried out the affairs of business.

Within this contradiction, that is, within contemporary society, Rousseau saw no fundamental moral imperative nor any sympathetic self-feeling. that served as the basis of the bond of modern society. Rousseau rather saw that it was the illusion that he felt was fundamental to the social world that at present cemented the social whole together. Where men wanted to see concern and fellow feeling as the bonds of society, there was actually only "egoism and vanity, the impulse to dominate and impress others" (Cassirer, 1951:155). Rousseau was forced to conclude that contemporary society represented a fall from happiness to misery.

One interesting aspect of Rousseau's indictment of contemporary society was the role that he ascribed to the arts and sciences in the weakening of human relations and the degradation of contemporary 
society. In the work A Discourse on the Arts and Sciences (1750),

Rousseau (1923:130) began by discussing the greatness of the

contemporary enlightenment.

It is a noble and beautiful spectacle to see man raising himself, so to speak, from nothing by his own exertions; dissipating, by the light of reason, all the thick clouds in which he was by nature enveloped; mounting above himself; soaring in thought even to the celestial regions; like the sun, encompassing with giant strides the vast extent of the universe.

But returning to earth, Rousseau related how the growth of the axts and sciences had now ultimately led men to value their creative endeavors over their real lives, that men seek to be talked about and to distinguish themselves in the eyes of others before they seek to understand themselves and appreciate the fundamental human qualities. While men are constantly losing the natural qualities and happiness of their primitive existence, the very advances that take them away are revered as the tools of their salvation. As Rousseau stated in this Discourse. (1923:131), the arts, Iiterature and the sciences:

\footnotetext{
- . fling garlands of flowers over the chains which weigh them down. They stifle in men's breasts that sense of original liberty, for which they seemed to have been born; cause them to love their own slavery, and so make of them what is called a civilized people.
}

While this function of the arts and sciences was more pronounced in contemporary society due to their strength, it was not a function that was unique to contemporary times. Rousseau, in fact, saw it as a law of history which regularly occurred in the past. Morality had been corrupted in those periods of history in which the sciences and the arts achieved greatness, the Greeks, Romans, and 
Chinese for example. Rousseau compared the relative underdevelopment of arts and sciences and the resultant measure of happiness that was manifested in the fortunes of the Persians, the Scythians, and the ancient Germans. It is thus that:

- . luxury, profligacy and slavery, have been, in all ages, the scourge of the efforts of our pride to emerge from that happy state of ignorance, in which the wisdom of providence had places us. (Rousseau, 1923:139.)

One particularly disturbing feature of contemporary society for Rousseau was the unnatural inequality of wealth and power. Unnatural in the sense that it was an outgrowth of the process of civilization and not inherent in the primitive nature of men. Mankind in his original state differed from the other animals only by his possession of the faculty of improving himself (la faculte de se perfectionner). Man in his original state roamed the forest, living an isloated existence, and only occasionally entering into a cooperative effort with others. Passing through a stage in which the families quit their roaming activity and entered into a more settled formation, came a period in which groups of families lived together in a more or less definite area. Such groups manifested a unity that was the result of sharing a common geography and a common mode of sustenance, but still without a substantive social order and without laws or government as such. It was this latter state of man that Rousseau considers to be the Golden Age of mankind, lying as it were between the animal existence of the first men and the corrupt morality of contemporary society. Rousseau (Bury, 1960:181) saw that: 
- . all further progresses have been so many steps, apparently toward the perfection of the individual, and really toward the decreptitude of the species.

The movement away from the Golden Age came about through the developments in agriculture and metallurgy. Agriculture was particularly to blame for it eventuated in the idea of land as a private possession. Social inequality was introduced into human activity by whoever was the first to state that "this is mine" and by those who accepted such a division. From that time on developed the distinctions which separated men into the rich and the poor, the powerful and the weak. Such distinctions, such inequalities, were made permanent with the development of laws and government which sought to protect that which was.

\section{Self-Love vs. Selfish Love}

To characterize the changes in mankind as he became civilized, Rousseau brought out the distinction between natural man (I'homme naturel) and civilized man (I'homme artificiel) and that if one praised or attacked man, the distinction must be made between the two. The individual came into the world without the distinctions of good or evil, 83 and was guided by the instinct toward selfpreservation. This instinct in turn followed the dictates of mankind's self-love (amour de soi). Self-love in its pure state was good as well as spontaneous, and expressed at the most fundamental level the essence of human existence, for it was the source of the impulses and instincts that were natural in origin as opposed to

\section{3}

This denial of the inherent evil in men, tracing itself back to the fall in orthodox thought, placed Rousseau in direct ooposition to the Church. 
social. Rousseau saw the unfortunate fact that modem society tended to degrade this natural self-love (amour de soi) into a selfish-love (amour-propre). This selfish-love was an artificial response that found its satisfaction in the subjection of others. This desire to subject others induced men to be continually comparing themselves to others and developed in them desires and needs that natural man knew nothing of: Contemporary society, in part through the aid of the arts and sciences, developed without restraint or sense of morality means and ends to those needs. It was through selfish-love that man was taken from the pursuit of those fundamental human needs and imperatives spoken of earlier to seek satisfaction in the illusory world of the social convention and also in the inequality that was a part of contemporary society. Inequality played a fundamental role in that it was a primary means by which the desire to subjegate others and the desire to compare oneself with others found an outlet. Such selfish-love caused men to become tyrants.

The contradictions in human nature that allowed men to be both kindly and evil were for Rousseau the result of men's social existence and development rather than the result of some dual nature or extra-human force. But this existence must be traced back to the faculty that man had that differed him from other animals, the faculty of improving himself was the source of the desire for the development of the arts and sciences, with the attendent vices that Rousseau saw them bringing. This faculty was also the source of man's other faculties, primarily his sociability. 
As the circumstances that surrounded the early development of man fostered this faculty of sociability and thus the development of civilization, man was prey to the vices and moral depravity, to the vanity and the arrogance that permeated contemporary society. While contemporary men in contemporary society displayed a propensity toward a subjegation of others through the various means of social inequality, natural man manifested a fundamentally ambivalent stance in regard to his fellow men. A stance that was perhaps more characterized by separation and withdrawal than by cooperation. The instinctual sense of self-preservation was prevented from committing injustices by the counterbalancing faculty of sympathy or pity which prevented self-love from inflicting injury upon others in its drive for preservation. It was a capacity born of imagination, instead of innate sociability, in which natural man was capable of placing himself in the position of others and sensing their feelings, to empathize with them.

\section{Nature of Freedom and Liberty}

While such a sense of empathy or fellow-feeling may well serve as the goal of any society, it could not serve as the point upon which that society emerged. In the original state of nature, there was no harmony between the interests of the individual and the interests of the general population, the will for self-preservation presided. But there came a time when the forces in opposition to man's continued existence in the state of nature became too great for an aggregation of individuals to resist. At this point it became necessary for the aggregate of individuals to join forces 
and form of themselves a new and differently constituted aggregate. Just what might serve to be the best basis for such an aggreagte was the avowed topic of Rousseau's influential work, the Social Contract (1762). More specifically, Rousseau (1923:14) saw the fundamental problem as being how:
. . to find a form of association which will defend and protect with the whole common force the person and goods of each associate, and in which each, while uniting himself with all, may still obey himself alone and remain as free as before.

It was the force and the liberty of each man that acted as the principle means of his self-preservation, and as such the preservation of these qualities was paramount. The social bond must be consistent with the character of man as a liberated and rational being. There could be no social order that did not at the same time as it unified man also express his freedom, for:

- . to renounce liberty is to renounce being a man, to surrender the rights of humanity and even its duties. - . Such a renunciation is incompatible with man's nature; to remove all liberty from his will is to remove all morality from his acts. (Rousseau, 1923:10.)

Any lasting and valid social order must result from the uncoerced association of human beings who of their own volition chose the nature of society under which they lived and to which they gave their support. They bound themselves by a social contract.

In contemporary society Rousseau saw that there existed a "contract" between members of the social order, but it included none of the qualities of the expression of the freedom of individuals nor of the uncoerced character. The inequality of the present social structure took away the very freedom that was thought 
to be essential to the longevity and the validity of the social order.

In contemporary society it was as if one group said to the others:

- you need me, for I am rich and you are poor.

Let us therefore make a contract with one another. I

will do you the honor to permit you to serve me under the

condition that you give me what little you still have left

for the trouble I shall take in commanding you. (Cassirer, $1951: 260$. )

Such a bond was purely legalistic and lacked any moral imperative, consequently it was in reality unstable. Rousseau saw that for a social bond to have any substantive force, that is, any binding moral obligation, it was ncessary that individuals not be simply subjected to that bond but rather that they subject themselves. The bond of social unity cannot be lastingly formed by force and coercion alone; it must, again, be founded in the freedom that was the essence of natural man. But to state that it was necessary to form the social bond upon human freedom did not exclude the notion of submission, for while there no longer may be a submission to the will of an individual there still remained the submission of the individual wills to the general'will. Such a submission meant that:

- . the particular will as such ceases to be, that it no longer demands and desires for itself, but that it exists and wills only within the framework of the "general will" (volonte generale). (Cassirer, 1951:260.)

Such a bond as was envisioned here was based upon the obligation that each member of society feit within himself. The freedom spoken of before was retained even in the face of the submission to general will for each member willfully acknowledged the right of the general will. The freedom, or liberty, that Rousseau saw here was not found in the freedom from restraint, but in a free exercise of volition, the taking to the heart of the right of the volonte generale. 
Without doubt. this form of "freedom" entailed some loss of independence that was characteristic of natural man. It should be understood, however, that this natural independence that existed for natural man lacked any substantial sense of stability. The freedom of other individuals, of natural forces, or numerous othex occurrences could at any moment terminate this independence. In many respects this independence was simply an unacknowledged deference to the will of nature. But this loss of independence suffered in the deference to the general will was not without its recompense. For Rousseau, men were not born free but became truly free through the operation of society and the state (that is, as society and the state should operate). In leaving behind his natural independence, man had gained something much more stable and secure. The real' gain occurs when the individual "exchanges the uncertainty of natural liberty for civil libexty" (Ruggiero, 1959:32).

Rousseau's idea of the social contract when fully comprehended can be rendered to its essence by this single statement: "The total alienation of each associate, together with all his rights, to the whole community" (Rousseau, 1923:15). Thus all those that enter into this bond give themselves up entirely, as independent units, "the conditions are the same for all, and this being so, no one has any interest in making them burdensome to others" (Rousseau, 1923:15). Thus while all members give themselves to the whole, they do not give themselves to any individual. In this true democracy there was no individual who gained anything that was not gained by all of the others, nor was there anyone who gave up anything that was not given up by all other members as well. Rousseau saw that 
it was necessary to protect the freedom of all by assuring the equal contribution of all, for the whole bond was jeopardized when members began to gain more than they lost or lost more than they gained by the association. Again, the viability of this bond hinged upon the protection of all rights through the equal contribution of all. In light of this possible problem, Rousseau (1923:18) felt it was necessary that:

\footnotetext{
- . whoever refuses to obey the general will shall be compelled to it by the whole body, which is in fact only forcing him to be free; for this is the condition which guarantees his absolute personal independence to every citizen of the country--a condition which gives motion and effect to the political machine; which alone renders all civil engagements legal; and without which they would be absurd, tyrannical, and subject to the most enormous abuses.
}

In spite of the uses to which Rousseau's ideas were ultimately put, he himself had no desire to attempt such reforms in the large centralized and industrializing nations of Europe such as France of the 18th century. The kind of political and social equality that he envisioned in the Social Contract was feasible only if the social situation, including the economic and political structure, were amenable to such equalization. In reality he saw that the democratic character of this plan. was applicable only to small aggregations where all citizens could participate directly in the decision making process. The social contract notion of Rousseau was much more suited to the agricultural peasantry with its traditions of charity and the helping hand rather than the contemporary industrial society with its competitive individualism. 
Though Rousseau was aware of the potential consequences of sudden large scale disturbances in the social order, the power of his denunciations of the existing abuses and inequalities of the social order greatly overshadowed these cautious reservations. In the decades that immediately preceded the Revolution it was more toward Rousseau and less Voltaire and the Enlightenment tradition that he represented that the upcoming generation of intellectuals and social thinkers turned in search of inspiration. It was he who gave the sustenance to those that were to turn the new page of French and world history. It was Rousseau who, perhaps not intentionally, infused the social criticism with a revolutionary idealism, infused it with a "feeling" and a driving emotion. Among his contributions to the Revolution and revolutinary spirit was the fact that Rousseau (Dawson, 1975:36) was the first who:

- . fired men's minds with the ideal of democracy not as a mere system of government but as a new way of life, a vision of social justice and fratemity which is nothing else than the kingdom of God on earth.

While not advocating revolution as such, Rousseau's ideas certainly fit the needs of the coming revolutionaries, particularly men such as Maximilien Robespierre (1758-1794), Georges-Jacques Danton (1759-1794), and Jean Marie Collot d'Hexbois (1750-1796). The ideas of the natural necessity of equality, the corrupt character of the existing society, and the necessity of returning society to a more "natural" stance 84 were of overall great influence, but

84

It was not: until the days of the convention that serious attempts were made to realize Rousseau's state of nature. 
perhaps as potent in the ultimate path of the Revolution were the notions of the sovereignty of the people, the validity of the whole forcing the individual to submit to the general will, and of the righteousness of the people throwing off the yoke of oppression. As Rousseau (1923:5) stated:

As long as a people is compelled to obey, and obeys, it does well; as. soon as it can shake off the yoke, and shakes it off, it does still better; for, regaining its liberty by the same right as took it away, either it is justified in resuming it, or there was no justification for those who took it away.

Whatever Rousseau's stance toward revolutionary activity he was very aware of the forces that were at work in society. Neaxly 40 years before the outbreak of the Revolution in France Rousseau (Guizot, 1898:229) wrote to King Stanislaus:

In vain would you aspire to destroy the sources of the evil, in vain would you remove the elements of vanity, indolence and luxury, in vain would you bring men back to that primal equality, the preserver of. innocence and the source of all virtue: their hearts once spoilt will be so forever. There is no remedy now, save some great revolution, almost as much to be feared as the evil which it might cure, and one which it were blamable to desire and impossible to forecast.

In addition to the foresight that Rousseau displayed in this quote, one also can see that as much as he despised contempoxary society and desired a retum to the qualities of natural man, he was aware that those qualities could not be recovered as they had existed in primordial times, that nature was a dynamic entity and that the path to recover those desired qualities must begin at the present and move forward. 


\section{INELUENCE OF .THE AMERICAN REVOLUTION}

In the past, much has been made of the influence of the American Revolution upon the French people and the Revolution of 1789, and in light of this one must address to what degree there was an influence between the two nations. One of the most apparent effects of the American Revolution was the feeling that it gave to the Europeans that they were living in a unique period of change. The American Revolution was taken as the first motion of a greater movement of change. But while most of the European community saw the American Revolution as a rather unique and intriguing historical event, to the people of France it was a concrete proof that the ideas that had been circulating about the progress of man, about the nature of society that men ought to live under and ought to strive for were not merely phantasms of imagination by validated conditions of mankind. In fact, it seemed to many Frenchmen that the Americans were merely putting into practice the ideals that had been generated by the French intellectuals of the Enlightenment.

In America prevalent European, and particularly French, ideas were realizing their first concretization. It seemed to prove that it was possible to take the liberal ideas of the Enlightenment and execute them in the real world. The Amexican Revolution:

- . showed, or was assumed to show, that ideas of the rights of man and the social contract, of liberty and equality, of responsible citizenship and popular sovereignty, of religious freedom, freedom of thought and speech, separation of powers and deliberately contrived written constitutions, need not remain in the realm of speculation, among the writers of books, but could be made the actual fabric of public life among real people, in this world now. (Palmer, 1967:111.) 
The Enlightenment ideas of liberty, equality, and the state as built upon these ideas, were elevated to a new plane in light of the democratic revolution in America. These ideas seemed less specific to European or French minds and more universally valid in the face of the American example. With America as the example of such changes, the realization of these changes elsewhere in the world was felt to be following soon. There was created an expectancy of change, a receptivity for such change. This expectancy and anticipation fed the idea that a new era in the history of mankind was beginning to dawn. The philosophes were generally more intexested in eradicating the abuses and irrationalities of the old regime than in instituting a democratic system, and were by and large quite willing to work within the existent network of power. Although they were not predisposed toward the democratic system, feeling on the whole that it was a chaotic and slightly irrational system, they were not unaware of the powex that the democratic ideology might have upon the populace. Thus while not overtly underwriting the democratic government; they still gave moderate support to the ideas so that it may be used as a lever with which to force the monarchy to a more enlightened posture.

The influence of the American Revolution upon France of the 18th century was due as much to the ideas that were prevalent in France as to the actual conditions that sprang from America itself. It was perhaps the mythologized view of the American Revolution even more than the actual events that. were influential in the minds of the French. Through the influence of men such as 
Benjamin Franklin (1706-1790) and Thomas Jefferson (1743-1826),

the idealization that stood behind the American Revolution coalesced into a definite form in the minds of the French Iong before. it had actually developed into a coherent form in actuality. Seeing all the best in the American Revolution, the French viewed it as something of an expression of the ideal Rousseauan state, based in the natural liberty of men, the brotherhood of all men, and the equality of all men. Even in light of this idealized version of the Revalution, the importance of the changes occurring in America were not so much what it actually was but what it had the potential for becoming and accomplishing in the future. Perhaps even more important that than, the example of the American Revolution was important for what it showed to be possible for all of mankind.

In light of these statements, the American experience did not so much incite the French to revolt as to create in them by its example a confidence in the possibility of great social change, and a justification for those general and abstract ideas of the nature of society. It showed them the path rather than pushing them along it.

There will always be some ambiguity concerning the exact role of the intellectual influence upon the French Revolution, as there always are concerning the relation between the ideational and the physical worlds. The effect attributed to the various factors is often a condition of the particular view that is taken ragarding the political orientation of the Revolution. Thus:

If you are a democrat like Michelet or victor Hugo, you will say that the Philosophers guided the people out of the 
house of bondage; if you are. Taine, Maurras or

Ieon Daudet, the story will run: unpractical

logicians made the people drunk with their heady

doctrines, dissolved the historic bonds of society,

and let loose the uncontrollable fury of the rabble.

In both cases, it is voltaire's fault, unless it be

Rousseau's. (Guerard, 1965:302-303.)

Perhaps the most acceptable statement that can be made about this relationship was that the ideas of the Enlightenment, ideas that seemed to promise so much germinated in a situation that needed as much. As Gottschalk has perspicaciously pointed out, the common man does not become consumed in radical philosophy unless it addresses some injustice against him. When the common man:

- . has been roused to sufficient height, he accepts the philosophy nearest at hand which conforms to his. demands, not because the philosopher is a genius who leads him to better things that he has never dreamed of, but because the philosopher gives him a program for which he has already been groping. Two things, therefore, are necessary before a revolution becomes a possibility-dissatisfaction and a political philosophy promising immediate redress of grievances. (Gottschalk, 1929:87.)

Thus all that was left in 1789 was some event or sexies of events to precipitate that initial step of revolution. There was dissatisfaction (by and large the dissatisfaction of the bourgeoisie over the nature of privilege in society and their lack of esteem, and the nobility over the encroachment of the bourgeoisie into the realm of privilege) and there was the handy philosophy of the Enlightenment (equality, freedom, reason, and progress) that provided them with a philosophical justification for their dissatisfactions. The ongoing financial crisis of the government and the convening of the Estates General provided the necessary platform for all of these forces to operate. 
PHASES OF THE FRENCH REVOLUTION

Before finishing the discussion of the French Revolution, it is necessary to clarify a heretofore undiscussed ambiguity. It is rather a misnomer to speak of the French Revolution as if it were composed of one continuous expression stretching from 1789 to 1799 (at the time of the coup d'etat of XVIII Brumaire). There were three and perhaps four separate events of revolutionary stature and revolutionary consequence.

Bourgeois Liberal Revolution (1789)

The first event was the bourgeois liberal revolution of 1789 whose foundation has been the primary focus of the preceding discussions. The bourgeois liberal revolution emerged from the third estate's assumption of control of the Estates General and with the third estate then declaring itself a "National Constituent Assembly. "85 After such events as the storming of the Bastile, ${ }^{86}$ the August decrees of the nobility, and the Declaration of the Rights of Man, the National Assembly was successful in instituting a constitutional monarchy in which the King had limited veto power, while all substantial legislative and administrative power resided in the National

${ }^{85}$ This was necessarily accomplished with the help of certain liberal nobles and clergy.

${ }^{86}$ Though no one could deny the emotional effect that the storming of the Bastille had upon the mobs of Paris and its influence as a blow against oppression, the actual liberation that took place seems somewhat disappointing. Reputed to have been in the Bastille at the time of its storming were four counterfeiters, one habitual drunkard, and two lunatics. 
Assembly. The actual changes that resulted from the Revolution were perhaps unthinkable in earlier years and marked a qualitative change in the history of France, and in light of this deserve the appellation "revolution." There was an administrative reorganization of the government with a marked movement toward a decentralization and greater local autonomy, there was the renunciation of certain feudal privileges on the part of the nobility, and there was a written constitution and a statement of individual rights. There were, however, numerous aspects of the Revolution that resulted in business as usual in the operation of the state. While a great many feudal privileges were done away with, including individual servitude (though the serfs were required to buy their freedom), the situation bore a resemblance to that of the United States some 70 years later. In both situations the liberated ones (by they serfs or slaves) were still left prey to the existing socio-economic structure for while free they had no financial wherewithall to change their standard of living and the hunger of a free man is as painful as the humger of a man in servitude.

The nobility was to be repayed for those losses that were considered part of their property, for indeed property had still remained as strong a natural right as it had been in the ancien regime. The representative government that was to be set up was based upon the condition of property; only those with a certain amount of property were allowed to run for office, only those "citoyen" that were property holdexs were permited to vote. There was also the confiscation and sale of noble and Church property, but 
it was, however, acquired in large part by the bourgeoisie and not distributed to the needy. There was, in fact, very little change in the condition of the most needy elements of society. The changes that occurred in the Revolution of 1789 , like much of the thought of the Enlightenment, took place only in regard to the educated and well-to-do middle class. It was in respect of the nature of these changes that this bourgeois revolution in many respects resembled a coup d'etat rather than a revolution, the lives of the great majority of people in France remained essentially the same.

\section{Popular Uprising (1792)}

What actually marked the beginning of the popular revolution, the radical revolution in France, occurred late in 1792. This second Revolution was distinguished by the dissolution of the monarchy and the end to the constitutional monarchy as the existent form of government. Its beginning may be marked by several events such as the mob attack upon the royal family at the royal residence in Paris, the Tuileries, in August of 1792, or the prison massacres of September 1792, or the creation of the First French Republic also in September of 1792. The second Revolution was to signal the rise of the radical revolutionaries versus the bourgeois liberals, and the demise of conservative bourgeois politics. It was the rise of radical revolutionaries as exemplified by the Jacobin Club and the Paxis Commune. In rising against the King the second Revolution also rose against the National Assembly and the politics that it embodied. Though still existing, the National Assembly had effectively lost its powers and was forced to register all of its decrees 
with the Commune. Behind the Jacobins and the Paris Commune was the triumvirate of Jean-Paul Marat (1743-1793), Maximillian Robespierre, and Georges-Jacques Danton.

\section{Popular Uprising (1793)}

The third series of events which may be termed a revolution occurred in June of 1793 and resulted not so much in a change in leadership, as the previous two Revolutions had, but rather a change in the direction to which all revolutionary activity aimed. Up until this time the composition of the revolutionary leadership and to a great deal the temperment of the revolution itself was still largely bourgeois, in spite of the demise of the conservative bourgeois elements. The major elements of the contemporary legislative body (the National Convention), the Girondins and the Jacobins, were still largely comprised of bourgeois officials and lawyers. Perhaps as a testimony to this fact, one finds that the power of pxivate property was effectively perpetuated throughout the entire course of the Revolution. One finds references to the inviolability of property in the cahier de doleance, the Declaration of the Rights of Man and Citizen, and in the Constitutions of 1791, 1793, and Year III (1795). In the period of the Revolution in which the proletarian measures had gained support (to be discussed) it was still the lands of the enemies of the Republic, the emigres and the clerics, that were confiscated and distributed to the landless. The property of good Republicans was still inviolable.

Inflation, profiteering on the rising prices, and the lack of any substantial revolutionary benefits accruing to the working class, 
the peasants, and the poor had begun to cause unrest. It had been the sansculottes 87 who had carried out the actual revolutionary activity, the violence both in the streets and in the battlefield, and yet the equality of person that stemmed from the equality of economics was no where in sight. As Jacques Roux (Dawson, 1975: 86); a leader of this popular discontent, stated:

Equality is a mere phantom as long as the rich man has the power of life and death over his fellows by monopoly. Liberty is a mere phantom so long as one class of men can starve another with impunity.

The Jacobins began to incorporate. the less radical elements that had been put forth by men such as Roux in an effort to gain (or maintain) popular support, while the Girondins held more steadfastly (in part merely to oppose the Jacobins) to the more bourgeois outlook of the goals and paths of the Revolution. The reason for the incorporation of such popular measures by the Jacobins and not the Girondins comes into clearer perspective when one looks at the respective base of support of each faction. The Girondins, named by virtue of the fact that so many of the leaders came from the department of the Gironde, by and large represented the interests of the departments other than Paris. The Girondins were generally among the wealthiest men in the nation. The Jacobin leaders were generally of professional background, but while the Girondins had been elected by virtue of the power and prestige that they wielded in their local areas, the Jacobin leaders

${ }^{87}$ Culottes in pre-revolutionary France were traditionally worn by the nobility. The revolutionaries, as an expression of anti-noble sentiment and revolutionary egalitarianism, forbid the wearing of the culottes so that all legs might be considered equal. The lower class revolutionaries, those who had in pre-revolutionary days been forced to wear the long trousers (sans-culottes) by social convention; acquired the general name sans-culottes during the course of the Revolution. 
had come into prominence by virtue of the support that they ahd been able to muster among the lower classes, particularly those of Paris for the Jacobins represented the interests of Paris in contrast to the other departments. This meant that the Jacobins were much more the champions of the revolutionary movements. While both the Girondins and the Jacobins were from bourgeois lineage, it was the Girondins who represented the landed and conservative interests and the Jacobins who represented the desires of the unpropertied, the artisans, the workers, and the sansculottes.

After a period of agitation between the Girondins and the populace of Paris, the people of Paris rose against the Convention and forced the arrest of 32 Girondin members of the Convention. It was not an event that had been planned by the leadership of the Jacobins, though their battle with the Girondists, who held a numerical superiority, was won as a result, but was aroused by popular agitators from the various sections of the commune. The sentiment expressed by this popular action was gaining adherents throughout the full breadth of the Republic.

In spite of the fact that the Jacobins felt quite threatened by the independent and revolutionary action of the Parisian populace and wondered about their own security, they were able to retain control of the leadership of the Revolution by adopting a considerable part of the program of Roux and changing the face of revolutionary activity. Included in this program were:

- . the enactment of the death penalty against food hoarders or tradesmen who withheld any necessary articles from immediate sale (27 July); the law of the maximum prices, which made profiteering a capital offense (29 September); and the enrollment of the unemployment in "revolutionary armies" to execute these laws and to force the peasants to deliver their produce. (Dawson, 1975:94.) 
In addition the incomes of all citizens were made subject to loan by the government, with those incomes which exceeded 9,000 livres being subject to a 100 percent loan. The adoption of these measures marked the end of the influence of bourgeois idealism and liberalism upon the structure and temperment of the Revolution and a turn toward the adoption of a socialist stance through the adoption of the proletarian reforms that were demanded by the sentiment of the lower roturiex and the peasants. It was a shift that changed the direction of the Revolution from the ideas of the philosophes and the protection of individual freedom that had been a foundation of the bourgeois revolution of 1789 toward the goal of social equality and popular democracy in a Rousseauan mold.

\section{Fall of Robespierre}

Having survived the threat of both counter-revolution and proletarian revolution, the Jacobins realized that if control over the Revolution was to be retained, it was necessary that there be a centralization and a purification of the Revolution. It was at this time that one saw the emergence of the Terror as a manifestation of a deliberate policy of terrorism aimed at neutralizing through fear any aspirations of royalists, counter-revolutionaries, traitors, and even profiteers. Robespierre, as the catalyst of this direction, focused particularly upon the bourgeoisie as a dangerous element in society. As Robespierre (Dawson, 1975:91) stated in a private note:

A single will is necessary. It must be either republican or royalist. If it is to be republican there must be republican ministers, a republican press, 
republican deputies and a republican govemment. the internal danger comes from the bourgeois;

in order to defeat the bourgeois we must rally the people.

In rallying the people Robespierre saw an opportunity to channel the revolutionary fervor of the sansculottes in his direction. It would be this revolutionary fervor extended to the whole nation that would sustain the Revolution from the external as well as internal enemies. The Jacobin dominated Convention adopted the Constitution of Year I but deferred the establishment of the new government until the threats of war, revolt, and treason had been eradicated. The Convention then declared itself revolutionary until peace, giving virtual dictatorial powers to the Committee for Public Safety. The decentralizing tendencies existent in the Revolution since 1789 were reversed and revolutionary leadership gained an absolutism and a suppression of the Rights of Man and the political and economic liberalism that formed its foundation, a suppression greater than at the height of the absolutism of the previous century. It was a dictatorial power that was justified as necessary to insure the fruition of the Revolution in times of trouble.

There was one additional series of events that could, given some measure of flexibility, be construed as a revolution. It was of revolutionary importance for it marked the demise of the popular democratic character of the Revolution that it had acquired in 1793 and the assumption of a more moderate bourgeois influence upon the RepubIic. In the middle of 1794 the excesses of the Terror and the fears of the leaders of the revolutionary committees (the famous 
Committee for Public Safety and the Committee of General security) brought about the arrest of Robespierre and his closest cohorts. At this point the moderate elements asserted their power and effectively brought about the subduing of the Paris commune, the closing of the Jacobin clubs, the reorganization of the committees, and a return to leadership of the convention. The moderate elements brought an end to the Terror and, in addition, brought an end to the thrust for social and economic equality in the proletarian form that it had acquired in the previous year. With the return of the moderates the revolutionary leadership lost its religious fervor, as did the Revolution itself, and it rapidly became an unpopular arm of the nouveaux rich. With a return of the bourgeois influence came a return of the profiteering, the corruption, the shortages, inflation, and the speculation. The Revolution became a business rather than an experiment in the regeneration of society. Vices such as these and the hardships that had been endured in the earlier periods of the Revolution left the proletariat demoralized. The days until the assumption of power by Napolean saw the reaffirmation of many bourgeois ideals, particularly. the sovereignty of property. It was not so. much the role that the bourgeoisie played individually in the Revolution that marked it as "bourgeois" as much as the fact that after all had cccurred and a peace settled again in France, it was the bourgeois ideals and rights that had gained the power of law and it was the bourgeoisie who were at the center of society. 
The purpose of the preceding discussion was to bring to light the fact that in regard to underlying philosophy and goals, the French Revolution manifested itself in several phases. Each phase retained some of the underlying factors of the previous ones and yet also manifested differences as well. To analyze the influences of intellectual factors such as 18th century philosophy and the idea of progress, one must be aware that the motivations for the assumption of control of the nation by the bourgeois of the National Assembly were not entirely the same for the institution of the Terror or the proletarian reforms of 1793-4.

EFFECTS AND ACCOMPLISHMENTS OF THE REVOLUTION

At the end of the Revolution, what might be said for its accomplishments? In the France of 1789 there were little, if any, political liberties and rights as those that came to be embodied in the Declaration of the Rights of Man and Citizen. The statement by Louis XIV, "I'etat c'est moi," summed up the nature of the political structure in France before the Revolution. Their were no elected officials, either local or national, and participation in government was limited to a very select few. The France of 1789 saw no coherent codification of the laws, judicial procedure varied according to the position of the accused. Appointed, and venal, judges applied these varying legal procedures, often with very little regard for the well being of the accused should they be other than nobility. Laws came from the King alone, whose only countervailing force was the influence the nobility could muster through its control of the parlements and the custom of registering decrees. 
What of the France of 1799 on the eve of the Napoleonic dictatorship? By 1799 the idea of constitutionalism had been firmly accepted, in fact France was in the midst of its fourth constitution since 1791. In point of fact, however, the constitution of 1793 never saw the light of day thanks to the Terror and the constitution of 1799 was a farce, dictated by Napoleon himself and only marginally a part of the revolutionary period. Only three of the four constitutions had a statement of the rights of citizens, and more often than not the extraordinary or revolutionary activities of the day had allowed the circumvention of those rights. The constitution of 1799 made no pretense of including them in the first place.

Popular democracy had in the intervening ten years never really been given a chance to operate. The people had never been able to act as the sovereign and rarely had the government been an expression of the general will. In spite of the role that Rousseau's ideas of popular sovereignty and the general will played in exciting the fervor of the population in the period preceding the Revolution, as well as during the Revolution itself, the aspect of his thought that the people were made to feel the most was embodied in the statement:

- . whoever refuses to obey the general will shall be compelled to it by the whole body, which is in fact only forcing him to be free... (Rousseau, 1923:118.)

Too often had the general will been thrust aside and the revolutionary leadership simply compelled the people to obey their desires. At the end of the Revolution, while land and business opportunity were in point of law available to all, such opportunity was 
in reality still restricted to a privileged few. One had to be sufficiently wealthy to be able to purchase agricultural land, business property, or the raw materials for manufacturing. The number of property holders during the Revolution rose somewhat, as did that of tenant farmers, due to the division of the large estates, but true agrarian reform was circumvented. What the auction of confiscated lands really meant was that:

- - farmers who were already well off acquired more land, whereas in most districts the majority of peasants and especially the day laborers were pushed aside. (Lefebvre, 1964:150.)

Artisans and small merchants profitted from the suppression of the guilds, but the workers were without their right to organize or strike. The financial situation left by the Directory in 1799 equalled if not exceeded that faced by the Estates General a decade before.

In 1799 France was still a Catholic nation in spite of the attempts at destroying the church, attempts at secularization of the nation, and in spite of the proposed religion of Robespierre. Even in light of the oft promised freedom of religion feelings of anti-Protestantism and anti-Semitism were very much alive.

In spite of the supposed leveling influence of the Revolution, class consciousness still persisted, albeit modified by the changes that had occurred since 1789, and privilege was still sought. Socially the bourgeoisie had taken over the primary leadership roles formerly played by the nobility and the Church. The bourgeoisie were, afterall, in the best position. They had not been subjected to the kind of legislative and popular attacks that the nobility and 
the clergy had been. Neither had their property been threatened or actually confiscated merely because of their ecclesiastical or aristocratic heritage. While the classic needs and goals of the bourgeoisie had been eclipsed in parts of the reign of the Jacobins, the Thermidorean Reaction and the period of the Directory had brought a return of the fundamentally conservative forces of the bourgeoisie. Below the bourgeoisie, the situation of the majority of Frenchmen was not drastically changed during the course of the Revolution.

FRENCH REVOLUTION AND THE IDEA OF PROGRESS

If, as this paper contends, the French Revolution marked the emergence of the idea of progress to its maturity in the realm of ideas, then it is necessary to demonstrate that in fact the idea of progress was operative during this period and that it in fact had an influence upon the events. Starting from the beginning, one must reiterate to the degree possible what the notion of the idea of progress was at the outbreak of the Revolution. As discussed earlier, the popular idea of progress in the 18th century was closely tied to the fundamental ideas of the Enlightenment and the goals to which that movement was headed. The most optimistic men of the period saw progress as not just the movement of reason onward but saw in that movement the potential for the gradual perfection of both man and society through the influence of the environment upon the formation of the human charactex. 88 
The more conservative men saw progress as the gradual control over the social and physical environment brought about by the ever more effective application of reason, which really amounted to a belief in the possible perfection of society but not of man himself, not of human nature. Perhaps the archtypical statement of the general view of progress in the 18th century was elaborated by the Marquis de Condorcet in his work Sketch of a Historical Picture of the Progress of the Human Mind (1795). As discussed in the earlier account of Condorcet, he saw that as better.scientific generalizations were developed, the knowledge of science would be disseminated with greater ease and to a greater extent. He also saw that there would be advanced technologies that would allow increases in economic output and individual welfare. Progress in the field of medicine would make it possible to reduce the destructive effects of disease. The work in the tradition of men such as Locke and Condillac made it possible to elaborate the fundamental principles of a social science, thus allowing new minds to be more aware of the natural rights of men and the path of reason, helping to make them free of superstition and the political and moral errors that it begat. Condorcet (Baker, 2, 1967a:184) had also seen that the foundations of an acceleration to the rate of progress was being laid, that:

Elitism and tyranny on the one handi popular prejudice, ignorance and social and political subjection, on the other-were finally being destroyed under the joint impact of scientific, technological, and political revolution.

In general progress was to mean the creation of a society in which men were freed from the arbitrary abuses of power and free froin 
the shackles that ignorance and tradition had heretofore placed them in. It would be the realization of the ideals of liberty and toleration, it would be where men could freely exercise their natural rights, and it would be where the religion of humanity with its belief in man's power to change his life. It was believed that reason and science would lead the way to this society.

The idea of progress had also, thanks to the influence of Rousseau, taken on a certain democratic tendency that it did not have at the height of the Enlightenment. The philosophes believed that democracy was a political system that would result in chaos if it were ever to fully emerge. The idea of the sovereignty of the people would have been an idea that would not have found a particularly warm reception with men such as Voltaire, who in spite of their battle against superstitution and tradition were fundamentally elitist. The notion of the sovereign power lying in the hands of the people struck a very responsive chord in the populace. Not only did the bourgeoisie feel that such democratic ideas were means to subvert. the traditional structure of society, but the lower classes, in the past completely outside the political scheme, saw such Rousseauan ideas as theix only chance for a better Iife. The active role that the people took particularly the commune of Paris, in the events of the Revolution djsplayed the degree to which they had absorbed these democratic ideals. The manifestations of the ideas embodied in the idea of progress were to be found throughout the literature of the Revolution, from the very beginning to the very end. In the beginning, there was 
ample evidence of these beliefs in the Declaration of the Rights of Man and Citizen (1789). The opening body, displaying both the Enlightenment concern with ignorance as the source of misfortune and the liberal notions of the inalienable rights of man, stated that:

The representatives of the French people, organized in the National Assembly, considering that ignorance, forgetfulness, or contempt of the rights of man are the sole causes of public misfortune and of the corruption of governments, have resolved to set forth in a solemn declaration the natural, inalienable, and sacred rights of man... (Stewart, 1951:113.)

There were additional examples of this in Articles I, II, and VI particularly. Article I professed that men are "free and equal in rights" (Stewart, 1951:113). Article II stated that the "aim of every political association is the preservation of the natural and inalienable rights of man; these rights are liberty, property, security, and resistance to oppression" (Stewart, 1951:113). Article VI most importantly stated that "law is the expression of the general will" (Stewart, 1951:113). In addition, Axticle XI of the Declaration takes care to state that the "free communication of ideas and opinions is one of the most precious of the rights of man" (Stewart, 1951:113).

The three constitutions that were to be written in the course of the Revolution all displayed the characteristics of the Enlightenment idea of progress and the notions of natural rights and Rousseauan ideas on social democracy. The preamble of the Constitution of 1791 is particularly apropos for it forthrightly laid down the notions of the influence that social institutions may have upon the happiness of the people, it attacked the notions 
of privilege and tradition that were the focus of many an attack by the philosophes and other social critics alike. The preamble stated:

The National Assembly, wishing to establish the French Constitution upon the principles it has just recognized and declared, abolishes irrevocably the institutions which were injurious to liberty and equality of rights.

Neither nobility, nor peerage, nor hereditary distinctions, nor distinctions of orders, nor feudal regime, nor patrimonial courts, nor any titles, denominations, or prerogatives derived therefrom, nor any order of knighthood, nor any corporations or decorations requiring proofs of nobility or implying distinctions of birth, nor any superiority other than that of public functionaries. in the performance of their duties any longer exists.

Neither venality nor inheritance of any public office any longer exists.

Neither privilege nor exception to the law common to all Frenchmen any longer exists for any part of the nation or for any individual.

Neither jurandes nor corporations of professions, arts, and crafts any longer exists.

The law no longer recognizes religious vows or any other obligation contrary to natural rights or the constitution. (steward, 1951:231.)

The bodies of the Constitutions of 1791, 1793, and Year III (1795), were reasonably alike in their attempts to spell out the protection of the natural and inalienable rights of men, by they the rights to "speak, write, print, and publish his opinions" (Stewart, 1951: 232), or "equality, liberty, security, and property" (Stewart, 1951: 455). They prescribed the aim of society as "the general welfare" (Stewart, 1951:455) and that government was the expression of the general will and its power resided in the populace, "that nation, from which alone all powers emanate" (Stewart, 1951:232). It was the belief that "the totality of French citizens is the sovereigin" 
(Stewart, 1951:572), that "sovereignty resides in the people; it is one and indivisible, imprescriptible, and inalienable" (Stewart, $1955: 455)$.

As the work of Condorcet represented most of what was essential to the Enlightenment views of progress, so must the proposed Declaration of Rights written by Robespierre be taken as something approaching the essence of the thought of the Revolution, and itself is the embodiment of progress. In this document Robespierre stated that:

1. The aim of every political association is the maintenance of the natural. and inalienable rights of man, and the development of all their attributes.

3. These rights appertain equally to all men, whatever the difference in their physical and moral powers.

6. The right to assemble peaceably, the right to manifest one's opinions, either by mans of the press or in any other manner, are such necessary consequences of the principle of the liberty of man, that the necessity of enunciating them presumes either the presence or the recent memory of despotism.

9. Property is the right of each and every citizen to enjoy and to dispose of the portion of property guaranteed him by law.

13. Society is obliged to provide for the subsistence of all its members, either by procuring work for them, or by assuring the means of existence to those who are unable to work.

16. Society must favor with all its powex the progress of public reason, and must place education within reach of all citizens.

17. The law is the free and solemn expression of the will of the people.

20. The law must be equal for all. (Stewart, 1951:43I-2.) 
One cannot, without searching into the hearts of the men themselves, know how strongly the participants of the Revolution were committed to the ideals that have been written here, how serious they were about protecting the inalienable rights of man and providing for the general welfare. The revolutionaries believed by and large that they were indeed paxticipating in the dawn of a new age of mankind, that what was occurring was not simply a change in political leadership but rather the birth of a new moral order and the regeneration of humanity. With the opportunity to sweep aside the fetters of tradition, inequality, and tryanny it appeared as if the beginning of a new "social millenium and the birth of a new humanity" (Dawson, 1975:45), was at hand. In retrospect, Thomas Paine (Wheeler, 1908:196) wrote that what people had previously called revolutions were:

$\therefore$ - in. fact little more than a change of persons, or an alteration of local circumstances.. . But what we now see in the world, from the Revolutions of America and France, are a renovation in the natural order of things, a system of principles as universal as truth and the existence of man, and combining moral with political happiness and national prosperity.

And further, Paine (Wheeler, 1908:143) wrote that in the:

- Declarations of Rights we see the solemn and majestic spectacle of a nation opening its commission, under the auspices of its creator, to establish a government, a scene so new and so transcendently unequalled by anything in the European world, that the name of a Revolution is diminutive of its character, and it rises into a Regeneration of Man.

The magnitude of the act of disposing of a divine right king in the eyes of Frenchmen who for so long had never questioned the right of the King to rule, helped to define the events of the 
day as truly new in the history of mankind. Even the most radical and cunning revolutionaries, notably Robespierre, were imbued with the spirit of the enormity of the moment. The Revolution was the point at which men believed that they were at last going to be able to institute into direct action those beliefs they held concerning their rights as men and the form into which society should be molded for the greatest good. It was also the time at which men believed they were going to be able to institute those foundations of society that had been brought forth by the philosophes of the preceding years, the foundations that were believed to be the foundations of human progress as well. If they would be able to destroy the fetters of tradition and prejudice that had controlled society for so long, then they would be able to institute a rule of reason.

The record of events and what was actually accomplished in the ten years of the Revolution ${ }^{89}$. when compared with the lofty ideals and professions in the literature of the period reveals the fact that the ideas of the progress of man and the dawning of the period in which that progress might be fully accelerated became in large part rhetorical tools for aggrandisement or for the perpetuation of the Revolution itself irrespective of its professed goals. This must particularly be the case for the bourgeoisie which played such a large role in the direction of the Revolution. As the connection

89

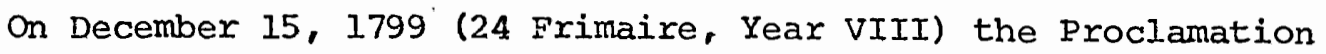
of the Consuls to the French People introduced the Constitution of Year VIII, but more importantly it ended with the sentence, "Citizens, the Revolution is established upon the principles which began it: It is ended" (Stewart, 1951:780). 
between the idea of the inevitableness of progress and the advance of the bourgeoisie was used by the bourgeoisie as a means of adding credence to their attempt for power and influence, so too did the Revolution itself become a manifestation of that attempt.

The Revolution provided the bourgeoisie with the requisite disruption of tradition social order, a chink through which their assumption of power, heretofore blocked by that formal order, could be consummated. The convocation of the Estates General had given them a forum for change that would not have been possible otherwise. If one examined the revolutionary ideals in light of the actual course of the revolution, the opinion cannot help but arise that on the whole the bourgeoisie seemed more concerned with their acquisition of position and power in society than with the attempt to bring about true revolutionary changes, more interested in their own socio-political progress than with the opportunity to facilitate the progress of the whole society.

Such a statement cannot be made without some qualification being necessary. One must be careful here to distinguish between the bourgeoisie and the rest of the third estate, as well as between the factions of the bourgeoisie itself. At the outbreak of the Revolution, the time of the Estates General and the drafting of the constitution of 1791 , the third estate presented a uniform front. The bourgeoisie, the urban proletarians, and the rural peasants were working for the same general goal. The principles of 1789 embodied in such documents as the Declaration of the Rights of Man and Citjzen served to display both the harmony and the underlying 
contradiction. The rights of men, most importantly the rights to freedom and equality, were the quintessential elements of this document. These two terms best captured the feelings and the needs, not to mention the imaginations, of the people of the time. It was perhaps a reflection of the influence of Rousseau, as much as the greater flow of liberalism in the 18th century, that the ideas of liberty and equality were so prominent. As Rousseau (1923:45) stated in the Social Contract:

If we ask in what precisely consists the greatest good of all, which should be the end of every system of legislation, we shall find it reduce (sic) itself to two main objects, liberty and equality--liberty because all particular dependence means to much force taken from the body of the state, and equality, because liberty cannot exist without it.

Freedom and equality were to be the foundations upon which the abuses of the past regimes would be halted, they would be the instruments though which the: obstacles of tradition, privilege, and the trappings of medieval society would be done away with. Equality and freedom would bring a peace and harmony in society that would regenerate society. The life that the philosophes and Enlightenment philosophy in general had been promising through the exercise of reason would emerge. But for the bourgeoisie itself these ideas of equality and freedom might lead to such progress through a different route than concieved of by the rest of the thixd estate. For the bourgeoisie, the ideas of equality and freedom allowed the emergence of a new privileged class, but this time not a hierarchy based upon tradition but upon the hierarchy of effort and initiative. 
For the bourgeoisie equality meant an "equality before the law."90 Freedom and equality meant the opportunity for success, or failure, in the market place, it meant the unleashing of the spirit of individual enterprise that had been stifled for so long in the 18th century French nation. It was through such interpretations that the ideas of man's inalienable rights to freedom and equality energized the third estate and served as the cement that bound it together in the struggle against the other estates. The fact that the ideas of liberty and equality could at the same time mean the end of privilege for the lower classes and the rise of a new privileged class (based on effort and initiative) for the bourgeoisie uncovered the essence of the difference and contradiction that would ultimately split the third estate.

The bourgeoisie were by and large desirious of order and stability, mutatus mutandus, 91 as desirious as the nobility of pre-revolutionary days had been. It was necessary to maintain stability in order for the mechanism of commerce to function. Such a view provides one insight into why there was the initial support for the establishment of a constitutional monarchy for such a form of government would work to protect men's freedoms and

90

Rousseau did not even advocate the equal distribution of power and riches. He stated by equality he did not mean "that the degrees of power and riches are to be absolutely identical for everybody. . (Cole, 1923:45.)

${ }^{91}$ It. was not an accident that the Declaration of the Rights of Man and Citizen as well as the Constitutions of 1791, 1793, and Year III (1975) make explicit reference to the right of security and the protection thereof. 
yet provide the requisite order to the social organization. Popular democracy was as abhorrent to the majority of bourgeoisie as it was to the ancien regime.

The underlying conservatism of the third estate, or more correctly the controlling bourgeois factions of the third estate, can be seen clearly when one compares the rhetoric of the third estate with the concrete actions and documents that were enacted. Equality was, as just shown, merely an equality of opportunity and an equality before the law. Thus while the appeal to the idea of equality conjured up in the minds of many the ideal of a society of equals living in harmony it actually resulted in a society were some were more equal than others. The right of equality in reality was to mean little for the average Frenchman in the end. The bourgeoisie were interested in their right to be exalted for their achievements. With the exception. of the new possibility that it presented for the bourgeoisie the realization of the right of equality meant business as usual. As Jacques Roux (Dawson, 1975:

86) stated earlier:

Equality is a mere phantom as long as the rich man has the power of life and death over his fellows by monopoly.

In the Declaration of the Rights of Man and Citizen the citizens were promised a representative government in which all would be free to take part, where:

Law is the expression of the general will; all citizens have the right to concur personally, or through their representatives, in its formation : .

and where: 
All citizens, being equal before it, are equally admissable to all public offices, positions, and employments, according to their capacity, and without other distinction than that of virtues and talents. (Stewart, 1951:114.)

But when the constitution of 1791 was ratified, the right of all citizens to concur had been severely curtailed by the institution of the property qualification and its bifurcation of society into "active" and "passive" citizens, or quite simply those capable of voting and those incapable of voting. Abbe Sieyes argued that both the voters and those elected carried out specific functions, which like other functions in society they should be required to qualify. In this instance the bourgeoisie "took care to conclude the qualification involved wealth, for if merit was not joined with money it could easily change into revolutionary ferment" (Lefebvire, 1964b:51.)

The Declaration of the Rights of Man and Citizen guaranteed the "free communication of ideas and opinions" (Stewart, 1951:114) and that "no one is to be disquieted because of his opinions, even religious" (Stewart, 1951:114). The Constitution of 1791 guaranteed the "liberty to every man to speak, write, print, and publish his opinions without having his writings subject to any censorship or inspection before their publication, and to worship as he pleases" (Stewart, 1951:232). Yet in spite of such declarations of freedom of conscience, the Le Chapelier law of 1791 banned trade associations, and later when it was thought that such clubs as the Cordeliers would be able to foment a tide of popular democracy among the lower classes they were outlawed as well. Finally, in the Declaration of 
the Rights of Man and Citizen there was a classic case of the right hand giving and the left hand taking away. Article I stated that: Men are born and remain free and equal in rights . .

and in Article III that:

The aim of every political association is the preservation of the natural and inalienable rights. of man; these rights axe liberty, propexty, security, and resistance to oppression.

But one finds that those inalienable rights have, by Article IV, dwindled to what have been circumscribed by law. Article IV stated that:

Iiberty consists of the power to do whatever is not injurious to others; thus the enjoyment of the natural rights of every man has for its limits only those that assure other members of society the enjoyment of those same rights; such limits may be determined only by law. (Stewart, 1951:114.)

The bourgeoisie were actually quite content for the most part with the changes that had been secured on the night of August 4, 1789, and generally sought no greater dismemberment of the ancien regime. Popular uprisings and riots that were part of the Great Fear of 1789 persuaded some of the more liberal members of the privileged classes to voluntarily sacrifice many of the privileges that had set them upon higher ground from the rest of the populace in the attempt to forestall further uprisings and to . salvage what they could in the face of the possibility of losing all. In many instances those prexogatives that were renounced in the egalitarian fervor of August 4 were doomed anyway, and while the formal statement of those renunciations may be said to have destroyed the manorial system in France the net result was indeed 
not what it seemed. Among the prerogatives that were lost were:

all seignorial courts of justice; venality with respect to judicial and municipal offices; exclusion from taxation; the requirement of nobility for ecclesiastical, military, or civil posts; and pensions for those who were not needy (Stewart, 1951:108-9). But while the National Assembly felt that it had abolished the feudal regime entirely,92 a surprisingly lively corpse was to remain for some time. The National Assembly decreed that:

- feudal and censuel rights and dues deriving from real or personal mainmorte and personal servitude, and those representative thereof, are abolished without indemnity. (stewart, 1951:107).

But in deference to the inalienable right of property, the National Assembly did also decree that those contractual or real dues (deeming them property not servitude) that were not abolished in the decree were redeemable by those losing the prerogatives, and redeemable at a price and in a manner that was to be set by the National Assembly. However, until such determinations were made, those:

- - dues which are not suppressed by the present decrees, however, shall continue to be collected until reimbursement has been made. (Stewart, 1951:107.)

In spite of these qualifications, in the August decrees of 1789 the bourgeoisie had finally achieved most of its long sought after goals, the nobility had been stripped of its exemption from taxation, and it had been stripped of the majority of those prerogatives (for there still existed the law of primogeniture and certain honorific prerogatives) that had rendered it a privileged class.

Axticle I of the August Decrees stated that the "National Assembly abolishes the feudal regime entirely . . . (Stewart, 1951:107.) 
The nobility had, more or less, been "reduced to a level with the rest of the nation" (Stewart, 1951:105). The ideas of the general or partial socialization of landed propexty, of capital, or of the instruments of labor, the ideas of the responsibility of the government to actively insure the welfare of the people, were ideas that as yet found. little widespread support.

Not all of the bourgeois members of the National Assembly were willing to terminate the Revolution with the August decrees and the constitution of 1791. The Constitution of 1791 had done much to break the third estate apart and the split was mirrored in the bourgeois ranks themselves with the constitutional monarchists on one hand and the democrats on the other. ${ }^{93}$ And while it is not entirely correct to infer that the totality of the bourgeoisie were of a single mind in regard to the extent of the Revolution, it is correct to note that even during the heights of the Jacobin experiment of 1793-4 their democratic tendencies were still cast in a bourgeois hue.

What of the ideals of progress and the regeneration of mankind that were part of the eruption of revolutionary sentiment; how did they fare alongside the bourgeoisie in the course of the Revolution? The discussion of the Revolution pointed out how there was often a vast gap between the expressed (and even legislated) ideals of the Revolution and what in actuality came to be exercised. One must, however, view these efforts in light of what they mean

History has tended to associate the Brissotins, or more popularly the Girondins, with the former and the Jacobins with the latter. 
for the larger movement of progress and the accomplishment of the ideals that it embodied. Certainly the advance of reason in the face of tradition and privilege made significant gains and its examples are legion. For instance: legally there was the codefication of law, an elected judiciary system which operated on the principles of trial by jury, the notion of habeus corpus prevented unnecessary imprisonment, a more humane system of penalties, an abolishment of slavery in the colonies, and there was equality before the law; politiclaly there was the establishment of a national rather than a provincial allegiance, the establishment of a tradition of popular participation in govermment (admitting though the influence of the general populace had been negligible), and the discussion of issues; economically the antiquated manorial system had been replaced by a "free" economy with land free to those who could afford it, the obstructions of local duties and customs were abolished, the restrictions placed on the workers by the guilds had been removed, careers were open to those with the requisite talent, and a uniform system of weights and measures had been established; financially there was a uniform currency and taxes, once the sole burden of the third estate, had been reduced in number and in severity and effoxts were made to levy them in an equitable manner; educationally the national system had been reorganized into a manner that it roughly assumes today, removed from the Church, free, compulsory, universalistic, and secular. Granting, as usual, that there was still a vast difference in the inactment and the actual execution 
of these measures, the fact that they were considered and legislated marked an advance or reason and a rational approach to life unseen in France before the Revolution.

The Revolution certainly did not result in the regeneration of man as it had been hoped for, but the rationalizing and the humanizing of the laws, the judiciary system, taxes, and the economy, as well as other changes, did present a foundation or potential for social progress found only in a few nations in the world. The changes attempted by the Erench Revolution were not without their cost for the idea of progress as well. Progress as it had emerged in the Enlightenment, with its abundant optimism and its naive myopia for the darker forces of evil in mankind, were effectively lost. It was lost because the nature of society upon which it was founded was lost as well. The rationalism and the optimism of the Enlightenment and the 18th century view of the idea of progress were the products of a prosperous age, a civilized and a sophisticated age. In the very attempts to bring about equality, freedom, natural rights, and to do away with tradition and privilege the Revolution destroyed that prosperous and civilized society, and with it much of the emotions and the ideals of the Enlightenment. Such events were perhaps forwarned by the very men of the Enlightenment who had fostered such an impatience with the status quo that burst forth with the Revolution. The philosophes were fundamentally gradualists, believing the emancipation of society from tradition, irrationality, and ignorance should be a transition and not an upheaval. They had, after all, wanted only to perfect society not 
destroy it. They had wanted to retain its refinements while eradicating its faults. It was a comment on the desirability of their goals persuasiveness of their optimism, and social conditions of the day that the Revolution arose and took such a cataclysmic turn. The harshness of the Terror, the startling efficiency of Dr. Guillotine's "humane" instrument of execution and the ability of men such as Fouche and Saint-Just to prosper in the course of the Revolution had caused many to lose the Enlightenment's exalted view of mankind. The suffering and the tragedy endured by countless people brought many back to the christian faith, but it also caused many to lose their faith, not only in God but in mankind and the idea of progress as well. For the idea of progress the Revolution in France was a bittersweet battlefield. If progress was not actually achieved there was at least the attempt on a large scale to bring about that achievement, at least the idea had provided a major focus for concrete human action. Yet in spite of the elevation represented by such a focus and its meaning for the import and the influence of the idea of progress, there was a certain fervor and commitment to the cause of mankind that was somehow jaded by the events of the Revolution. 
CHAPTER XIV

\section{CONCLUDING REMARKS}

As it was initially discussed, this thesis focussed upon two distinct factors that operated to bring the idea of progress into the limelight as one of the very important ideas in human intellectual and social activity. On the one hand there was the movement of ideas that slowly but surely moved to circumscribe the idea itself. On the other hand there were those social factors that facilitated or hindered that movement.

The idea of progress itself came into existence as much through the displacement of altemative ideas as through the generation of the idea itself. It represented a major shift in man's perception of both himself and the world around him; a factor that in part helps to explain the idea's somewhat long gestation period. The most fundamental change that needed to occur in this shift of perception was a change from viewing the world and man's place in it as a cyclical phenomenon to one that manifested a linearity. Such activities as the changing of the seasons and cycle of bixth and death had helped to condition in ancient men the idea that their world moved in circles. They saw their lot in life as playing a certain role in one of an endless series of cycles. The shift to viewing the history of the world (and all that occurred in it) as a linear process meant that man's existence 
on the planet had to acquire a direction, it had to be going somewhere. The idea that mankind was going somewhere naturally enough implied the complementary idea that there was a goal to which that directed movement was in fact heading. For the Christians, among the first to ascribe a Iinearity to history, the goal was salvation at the apocalyptic end of the world when Christ returned to call the saved to heaven. In such a view there was no need to project an extended future to mankind for at any minute Christ might return. Nor was there a need within this perspective to attempt to concern oneself with the mundane life, the goal of life was salvation and salvation meant leaving the mundane life behind.

As the intellectual changes emergent in the late Medieval period and the Renaissance moved to push men from the religious to the secular, to change from a belief in God's will operating through Providence to a belief in the power of reason operating through the human intellect, the specific character of this linearity changed. The most striking of which was the change in the perception of the role which man ought to take toward this earth and his stay on it. At the hands of men such as Francis Bacon (and reflecting a shift away from the Augustinian world) mankind came to believe in a more immediate mission on earth, a mission to ameliorate the hardships of life. Man had been given a great intellectual power and the belief grew that not only did he have the power to affect the course of his own life but that it was his duty to apply this power to make this life much more tolerable, to bring about a felicitous state for man. 
As the belief in the power of reason came to supplant the power of Providence in the minds of men, the linearity that marked man's: stay on earth came ever more to be associated with that reason. The advances that had been more rapidly occurring: since the birth of modern science in the late Renaissance period served to solidify this connection between history and reason. Had not the advances of science and the corpus of human knowledge grown as each year passed? Would not the future of mankind be taken up with advances undreamed of in contemporary times? The growing character of human knowledge, the idea that each generation could add to the body of knowledge bequeathed by precedinggenerations, conditioned the belief in the inevitability of the growth of knowledge. It was a belief in the inevitability of the growth of knowledge that was underwritten by a belief in the permanence of nature and the laws within which it operated.

This movement of reason, this advance of knowledge (and its benefit for mankind) was given even more coherence by the confiict between the philosophes of the Enlightenment and the religion of the day. In seeking to discredit "revealed" religion, the philosophes sought to create their own heaven, their own equivalent of salvation. That heaven must, in accordance with their secular orientation, be a heaven on earth in which all the ills and vices of mankind would be eradicated by the advancement of knowledge (and through the path described by Locke, its influence upon the nature of man). Given the belief in the permanence of nature, emerging through the thought of men such as Bodin, Descartes, and Fontenelle, 
and the power of man to control his institutions, it was natural enough that this inevitable movement of knowledge be seen as the necessary movement of man toward this heaven on earth. Within this view of the movement of knowledge, the idea of progress gained. its substantive form, attaching itself to the Enlightenment ideas : of reason, nature, liberty, equality, and of course knowledge (lumieres, the enlightenment of man). The path of progress became the path to heaven on earth.

As science pushed back the time of man's existence upon the planet, so: the future of man expanded. Given the nature of the cumulative characteristic of knowledge, there was no reason to expect that man would ever stop progressing, stop making life better so long as he continued to exist on the planet.

In deference to the twofold nature of this thesis it is necessary to take a more careful look at the mannex in which the social structure was influential upon the development of the idea of progress, or more specificaliy, to what degree the development of the idea of progress was dependent upon or independent of the social structure? In the development of the idea of progress there were those periods in which the social structure had a direct and a decisive influence, the Medieval period and 18th century France for example, and yet there wexe those periods in which the influence of the social structure upon the idea of progress was indixect or of less consequence, the Greek and Roman periods perhaps and the 17 th century are exemplary. An important aspect here is not to deny that 
both ideational and social factors were at work all the time, but only to state that in given periods one or the other of them might assume a more decisive role.

The Medieval period was particularly fruitful for the analysis of the influence of social factors upon the development of the idea of progress. As the discussion of this period brought out, there were two factors that were most influential in dixecting the social and intellectual dynamics of the period, commerce and the Church (which meant the catholic Church). The closing of the Mediterranean Ocean to the commerce of the West by the Moslems had the effect of stultifying the economic structure. Towns, which by and large subsisted upon the trade that was carried on within them, dwindled and disappeared as the population turned to the soil as a means of providing for their own subsistence. The result was the emergence of the feudal system and the rigid bifurcation of society between those who owned land and those who simply worked it. All the power resided in those who owned land for it was the source of life in this hard period.

The disappearance of many of the towns in Europe, the drastic reduction in the trade between the areas bordering the Mediterranean Ocean, and the return to an estate system had several consequences. There was the concentration of power in the hands of the relative few who were in possession of large tracts of land. As important, however, were the disappearance of what bourgeois structure had existed prior to this collapse and the lack of intellectual stimulus that the isolation of European culture and the concentration upon subsistence 
caused. With the task of merely supplying the essentials for living, there was very little time available for the rational reflection upon the nature of the world and the prospects of the future, prospects which were usually quite gloomy.

With economic and commercial structure of Medieval Europe at a standstill, there were no motives and no support for the rise of an active bourgeoisie. The lack of a bourgeois element in society cleared the way for the greater bifurcation of society between the haves and the have nots. The lack of a bourgeoisie also provided little opposition to the power and domination of the single most influential force in the Medieval period, the Church.

The dominant position of the Church resulted from the privileged position that it came to occupy. It was the undisputed spiritual and intellectual leader of the whole of Europe and as such had a centralized power that was not to appear in a secular form for centuries. It was the spiritual and intellectual leader of the period because it was the only element of the social structure that was capable of presenting an ideational system. The Church was the only source of a systematized body of thought covering mankind and the world, the past and the future. Due to the pervasive character of Church orthodoxy and the power that it controlled, it was influential in every aspect of the individual's life, not just the religious but the social and economic as well. The Church exercised a total influence over the life of the individual. The Church was able to exercise both direct and indirect influence in the political sphere as well through its control of learning and the need of the 
secular powers to recruit their counse lors and lettered men from the ranks of the ecclesiastically educated. The Church was also able to exercise considerable social and political authority as a consequence of the fact that it owned great amounts of land and the fact that through the contributions of its members and revenue that came from its land the Church was in possession of sizeable amounts of money at a time when money was a very scarce commodity.

With the absence of the bourgeoisie and the domination of the Church, it was little wonder that the ideas of the Medieval period were dominated by Christian orthodoxy. Of great importance in that orthodoxy was the idea of Providence, particularly as stated by Augustine. As the discussion of the Medieval period brought out, the idea of Providence was embodied in a view of history (separated into sacred and gentile) which saw the existence of mankind as a period in which the depleted ranks of the City of God were to be replenished by saints from the earthly city. The course of human history was like a play which the creator had written and directed, and only the creator knew the ultimate ending. In the play, Providence was the "scxipt," in the actual course of history it was a transcendent guiding force. It was through Providence that the will of God was carried out.

Equally important in the Medieval ideational realm was the idea of salvation. It was the ultimate goal to which human activity moved, the end of the play. For man all activity was directed toward being saved when judgment day, the return of Christ and the replenishment of the City of God, came about. There was no greater task than to 
Iive the holy life with the hope that the City of God awaited when the life on earth ended. The arts and sciences, all earthly concerns, palled in the face of the question of salvation. As Augustine had warned, a greater concern with the secular life (as necessitated by an idea such as progress) might lead to a lesser concern with holy salvation. Given the domination of Christian orthodoxy few were willing to threaten their chance of salvation.

There were several ramifications of these ecclesiastical ideas. Embodied in the ideas of salvation and Providence was the apocalyptic end to the earthly world in what was generally through to be a brief period of time. While any amount of time in the future allows for the possibility of positive change, the idea of progress as it has become known in the modern day was built around a great vista in the future, both as a recognition of the changes that were yet to come and as a recognition of the gradual nature in which fundamental traits of the human character change. Modern views, coming to be in the 18th century, saw the limits of human society as being set by the geologic future of the earth.

Another ramification of these ideas, and a direct result of Christian orthodoxy, was the belief fostered among the people that the individual, or even the sum of all individuals, were powerless to control their lives. Man viewed himself as powerless in the face of the will of God manifested through Providence. Such feelings of powerlessness fit well with the actual lifestyle of most men in the Medieval period. Such a perception was capable of singlehandedly precluding the emergence of the idea of progress 
for the idea of progress first and foremost conceded to man the power to facilitate and direct his future.

The whole character of the Medieval period was one of very slow change, or outright stagnation. The absence of the development of the idea of progress only serves to underscore the general lack of a dynamic social and intellectual milieu. Mannheim (1936: 274) stated that the absence of ideas. often stermed from both the absence of certain points of view as well as from the lack of a drive to come to grips with certain life problems. There was certainly the lack of a dynamic idea of social change (even though the Augustinian view of the course of human history provided an important framework for one), but also there was the lack of a desire on the part of the Church, as the dominant force of the period, to foster any idea of secular change, change leading to qualitative human "improvement." As Augustine had protested, such a view might well tie the fortunes of salvation too closely to the secular state in the mind of the people. With an eye toward the preservation of its power, the Church could have no motivation for supporting àn idea whose very quintessence was change. The implications of the idea of progress (as was born out in its development) was a diminution of the need for the Church, the idea of Providence, and the whole social, intellectual, and spiritual supremacy that it enjoyed. The preclusion of the idea of progress in the Medieval period existed because the social structure was not conducive to its development. With the Church as the dominant force in society, with the absence of the bourgeoisie offering an, alternative to that force, and with the whole milieu of the period one of nearly 
imperceptable change, there were no elements in that social structure capable of fostering the idea of progress.

The end of the domination of the. Church and the beginning of the emergence of a new social structure characterized what has become known as the late Medieval period. 94 The late Medieval period may be distinguished by the beginning of the crusades and the establishment of trading posts in the Holy Lands. As a result of the Crusades, the Mediterranean Ocean was again open for trade and with such trade the sedentary nature of European society began to break down.' The crusaders returned with stories of the goods available in the East, and with a desire for the amenities that they had grown accustomed to. A dynamic character began to take shape in Europe. With this dynamic character came the reemergence of towns and their economies and the reemergence of the bourgeoisie that lived on those economies.

The most profound change to come from this renewal of Medieval society was the secularity that it brought. As previous discussions have brought out, the secular nature of Moslem life gradualiy filtered into European society when its influence was brought back by the returning crusaders and merchants. It was a secularity found in the science and the philosophy of the East, found in the variety of expression existent there, as well as through their very approach to the task of living. The Moslems were concerned with living for its

${ }^{94}$ As it was brought out when this period was dealt with' in the body of the thesis, such convenient periodizations as Medieval period, late Medieval period, and Renaissance period owe: their origin more to the heuristic assistance they can provide in understanding the changes in history than to the actual existence of such marked periods. 
own sake rather than living so as to procure salvation. Their importance was placed upon the life here on eaxth not in the hereafter in heaven.

Another avenue for the rise of a more secular approach to life in Europe came about through the rise of trade and commercial activity and the necessary approach to life that success in those fields required. Heretofore, due to the domination of the Church, the notions of Christian morality had controlled the nature of commerical relations. Commerce was considered dangerous to salvation in relation to the pecuniary interests that it aroused. Wages for work done and income commensurate with one's station in life were the rule throughout the Medieval period, anything more was avarice. But in the late Medieval period the exigencies of successful commercial activity required a more pragmatic approach to business, required less of a concern with the danger to salvation and more of a concern with the practical necessities of business.

What one saw occurring in the late Medieval period was the beginning of the emergence of alternative perceptions of the world that came to challenge the dominance of Christian orthodoxy over the life of the individual. The alternatives arose first through contact with the East and the opening of the Mediterranean Ocean again, and then in the reemergence of the bourgeoisie that accompanied the increased social and commercial activity.

In the period of the Renaissance came a greater maturation of the alternative ideas and activities that emerged in the Medieval period. There was the emergence of the humanists and their revival of 
classical culture ${ }^{95}$ so long held in disfavor, and more importantly for the development of the idea of progress was the gradual emergence of what has become known as modern science. It was here that the role of the bourgeoisie in relation to the idea of progress expanded, and the influence of the social structure upon the development of the idea of progress was found once more. The bourgeoisie contributed to the breakdown of the domination of Christian orthodoxy and its preclusion of the idea of progress through the very nature of their commercial and social interests. They came to realize that they possessed a political and social power and that such power was contingent upon the concrete results they could obtain in their commercial activities. The bourgeoisie saw that the new science offered to bring them greater results. It offered to augment their power and it provided them with an approach to life (business, social, spiritual) that was unhampered by mythology and antiquated ways of viewing the world. As it was quoted before (Pollard, 1971:28) it was the bourgeoisie:

- who took the methodology of science to be a reasonable way of looking at the world and who, in turn, gave the scientists the confidence that their thinking was corxect and was socially desirable, and the material backing to continue in the same direction.

This support of the advancement of science was of the utmost importance for it was from the perspective of the advancement of knowledge through the advancement of science that the idea of progress drew its impetus. It was from this science that the secular alternative to Christian orthodoxy and the idea of Providence emexged.

95 with that revival came a renewed confidence in the power of man to affect the coures of his own life. 
With the new science came a new view of nature and its relation to the divine. In the past, nature was subordinate to the divine and knowable only through revelation. With the new science not only was nature thought of as a divine creation but also as being imbued with the divine character, thus raising nature to the level of the divine. No Ionger was the revelation of the organized Church required to understand nature for it now become knowable through direct investigation. No longer was the earthIy life and nature itself thought to be a distraction from the true purpose of life (salvation), but now became an avenue for the communion with the deity. Thus concern over the nature of life on earth was seen not as a movement away from the divine but as an immersion in the creations of the divine. The effect was to turn man's attention back upon the earthly life without incurring a sense of guilt.

Gradually those social factors that had served to circumscribe an ideational milieu devoid of any notion of dynamic social change and the betterment of the mundane life began to be disrupted and diminish. The idea of progress could not arise during the Medieval period because of a lack of the idea of change, because of the lack of a belief among the people of the possibility of participation in the affairs of their Iives, and because of the effects of the domination of such ideas as the primacy of salvation and the power of Providence. The existence of these obstacles was dixectly related to the domination of the Church, social and cultural stagnation born of commexcial collapse, and to the lack of alternative elements in the social structure to challenge the domination of such ideas. But in 
the late Medieval period, with the renewal of commerce and the rise of the bourgeoisie, and in the Renaissance period with the advances in modem science, there arose the potential for a very different view of the course of human history and the priorities that each individual had available. Gone was the domination of all aspects of Iife by Christian orthodoxy, gone was the sedentary character of the social structure, and gone was the uniformity of thought and the one perspective of the world and man's place in it. The character of society had taken on a new sense of activity, a new connection between the individual and the course of humankind. It was from this social milieu that the idea of progress developed. Following the Medieval/Renaissance period where the ideational realm, specifically the idea of progress, was largely dependent upon the social structure was the conflict between the ancients and the moderns that occurred during the 17 th century. In this conflict the social structure did not exert the same influence that it did in the previous period. To understand why the diminution of influence occurred, one must look at the nature of this conflict and the nature of the social structure during the same period. The conflict between the ancients and the moderns was a continuation from the late Renaissance of the attempt to free men's minds from the "tyranny" of the ancients. It was the attempt to free them from the idea that the ancients marked the apex of human civilization and the accompanying notion of a subsequent degeneration of man's abilities. The attempt to deny this exalted position of the ancients first emerged explicitly in the literary field and it 
was there that the most heated debates of this conflict were found. For the greater part. of its 100 year duration, the conflict was focussed around the question of whether the literary works of the moderns were better than those of the ancients. The conflict, however, did not reach a large portion of the population until the Iiterary aspect of the discussion was slowly dropped and the conflict came to focus upon the question of the nature of knowledge and the character of its movement. As the literary aspect was dropped, the idea, traceable at least to Bodin and Descartes, that the power of nature were permanent and undiminishing gained in importance. The moderns sought to demonstrate that any distinction between the two periods would be due to causes other than unequal natural abilities. In shifting the focus to the nature of the growth of knowledge, the moderns sought to show that there were in fact differences between the ancients and the moderns but that the very nature of knowledge assured them preeminence over the ancients.

The moderns contended, through the works of men such as Saint Sorlin, Perrault, and Fontenelle, that the creations of human civilization were continually being refined. Those who lived in the later periods had the benefit of the refinements of previous periods and so were capable of greater creations. The moderns specifically held that the creation of knowledge increased with time and experience. Each period of human civilization inherited much from its predecessors and would bequeath even more to those who followed. It would thus be the great exception, an unnatural aberration, if the most modern period of civilization did not possess a greater amoung of more sophisticated knowledge. Assuming the 
invariable and undiminishing character of nature's powers and the cumulative nature of knowledge, the moderns felt they had established the necessary superiority of their period.

The development of the idea of progress was not dependent upon the social structure during this period in large part because it was first and foremost an intellectual, ideational, question. Both the initial adoration of the ancients by the Renaissance and the subsequent attempt to curtail that adoration were activities that had their basis in the ideational realm. The Renaissance had turned to the ancients not with the hope of actually living like them but rather of being able to think like them. While the Renaissance had sought guidance away from the thought of the Medieval period by turning to the ancients, men now sought to fxee themselves from the authority of the ancients so that they may think and create for themselves. The conflict was fought between adherents of litexary styles and tastes and fought over the question of the nature of the advance of knowledge. While there was much debate among men of varying literary persuasions, the question of knowledge had many proponents and few opponents for few people wanted to deny the ' advanced natuxe of the knowledge of their own period, a feeling owing in large part to the perceived advances of modern science. It was only later with men such as the Abbe' de Saint Pierre that the advance of knowledge was necessarily connected with the social structure and the inexorable character of knowledge and its benefit for society used as a tool for change. 
To say that this was a conflict that centered upon the ideational realm and involved intellectual issues is not to say that there were no influences emanating from the social structure. There always have been and will be pressures and influences that are derived from the social structure but over the different historical periods they vary in effect. As the discussion of the Medieval period brought out, the social structure exerts an influence on the ideational realm through such avenues as the nature of the questions society addresses, the variety of perspectives present in society, and the goals toward which society aims. The period in which the greater part of this conflict occurred was the reign of Louis XIV, Le Roi Soleil. It was a period that strongly believed in its own superiority. As Perrault (Bury, 1960:87) stated: "Our age has, in some sort, arrived at the summit of perfection." The rich and the poor, the noble and the bourgeois alike were capable of taking pride in the fact that they lived in the greatest period of human civilization the world had yet seen. In such a milieu there was a less visible contrast between the haves and the have nots. There was a broader spectrum to society due to the existence of a successful bourgeoisie. The divisive character of Medieval society that motivated people to seek change was absent to a great degree. The underlying question of degeneration versus the permanence of nature's powers also tended to diminish the conflict between. science and the Church. As clearly expressed in the work of Hakewill, the Church felt that Christianity had exerted a positive moral influence upon the nature of human civilization. The acceptance of 
the superiority of the ancients and the subsequent degeneration of man would have in some manner called that positive moral contribution into question. Thus while in the Medieval period the conflict between the power of the Church and the power of science had been a major source of social dynamics, in the conflict between the ancients and the moderns both tended to support the case of the moderns.

There wexe then influences from the social structure but the genexal uniformity of perspective and the general acceptance of the same societal goals by the various elements of that structure created at best merely a receptive base of support for the case of the moderns rather than generating direct influences over the course of the conflict and in turn its influence upon the idea of progress. This fact coupled with the largely ideational character of the conflict itself accounts for the fact that the conflict between the ancients and the moderns was largely independent of the social structure.

It was in 18th century France that one again finds another example of how social conditions affected the development of the idea of progress in a direct manner, and again it involves the needs and the desices of the bourgeoisie. To understand the manner in which the idea of progress was dependent upon the bourgeoisie in this period, it is necessary to reiterate some of the nature of the social structure existent at the time.

The most outstanding feature of French society of the period was its structured nature. While politically there were three 
divisions (the three estates), in actuality there was a bifurcation between the noble and the commoners (roturier). Mobility was possible between the bourgeoisie and the nobility through purchase, marriage, or enoblement. The newly enobled, however, were often looked down upon by the older nobility for the manner in which they had acquired their rank and the commoness of their heritage. It was this difference in esteem that separated the bourgeoisie from the nobility more than a mere difference in wealth. The 18th century had been much more profitable for the French bourgeoisie than it had been for the nobility and frequently they had amassed fortunes equal to or greater than the nobility.

Though they lacked a direct input into the affairs of state, the bourgeoisie came to represent a major source of motivation, direction, and spirit in French society. This was for the most part the result of the increased wealth that they had experienced, a wealth that afforded them both the time and the financial resources to become educated, a wealth that turned their attention to the structure of the society in which they lived. As Gottschalk (1929:

43) wrote, the bourgeoisie:

- could afford to mingle in society, to attend the fashionable salons, and to join clubs, where they discussed the latest radical literature, aired their grievances and propounded their panaceas.

As a result of this dynamic character, the bourgeoisie came to be the chief supporter and consumer of philosophy. This was a fact that did not escape the interest of the philosophers of the day, who, coming from good bourgeois stock themselves, knew how to. formulate and present their ideas so as to captire the attention and the 
support of the bourgeoisie. Voltaire (Dawson, 1975:29) made clear the bourgeois element in Enlightenment philosophy when he stated that "it is not the worker we must instruct, it is the bon bourgeois of the townsman."

In spite of this dynamic character of the bourgeoisie, in spite of the leadership that they assumed in the intellectual and Iiterary fields, the bourgeoisie were still considered socially and politically to be roturier, one with the peasants and the proletarians. As such they were expected to assume a subordinate position in the social hierarchy. By all measures of social contribution the bourgeoisie should have been highly esteemed in 18th century France, but it was an irrational social structure that elevated the idle and lax rich to the pinnacle and demeaned all that was bourgeois.

The intellectual and social awakening of the bourgeoisie began to create in them a feeling of frustration. When the nobility sought to restrict the mobility between the bourgeoisie and the nobility in the latter part of the 18th century, this sense of frustration increased. As the bourgeois involvement in the ideational flow of the 18th century increased (amid ideas such as Iiberty, freedom, equality, and justice) and theix exposure to the conditions of other countries, notably England, increased they became ever more dissatisfied with the nature and the direction of French society. It was the bourgeoisie viewing the idea of progress through this perspective of dissatisfaction that made it such a desirable idea. The arrival of a rational society that was founded upon the qualities 
of freedom and equality, a society that allowed all men to rise as far as their capabilities would take them, appeared as a heaven on earth for the bourgeoisie.

The analysis of the way in which the idea of progress was dependent upon the social structure in 18th century France is not so much one of the manner in which one social element (the bourgeoisie) generated the idea of progress in response to its social interests, although it certainly influenced the chaxacter of that idea through its influence upon 18th century thought, but rather the influence of the bourgeois social situation upon the utilization, the goals, and the methods of that idea. Society in general supported the idea of progress, particularly in the form of an advancing base of knowledge and the aid that it could give to society. In this respect. the bourgeoisie shared the dominant ideas of the period with the other elements of society, most important of which were the nobility. There were in fact many nobles who actively supported the liberal changes that accompanied the idea of progress and were embodied in it. Few would consciously oppose the general notions of liberty, freedom, equality, and justice. The nobility, however, operated on a different level of abstraction than the bourgeoisie. 'While the nobility believed in liberty, freedom; equality, and justice, the bourgeoisie believed in equal taxation and representation, uniform justice for all, freedom from the prerogatives of an artiquated social and economic system, and the liberty to express themselves in thought and action without regard to social censure: Above all, they were in search of the esteem that had heretofore been denied them. 
The greater context and utilization that the idea of progress had both in the years preceding the Revolution and during the Revolution, as well as the ultimate influence such a usage was to have, was in large part the result of the bourgeois attempt to remedy their inferior social and political status, not necessarily the inherent worth or applicability of the idea itself. The desire to escape this inferior status, consciously and unconsciously, influenced the nature of the idea of progress and the bourgeois utilization of it. The idea gave the bourgeois desires a sense of inevitability. While the idea of progress did not arise for the sole purpose of being used by the 18th century French bourgeoisie, it did in the course of that century come to closely represent their interests.

Though it is hard to prove what is in the hearts of men, that is; hard to prove that the bourgeoisie used the idea of progress as a means of rationalization, the ulterior motive of their support and the specific social influence becomes more clear in the course of the Revolution. 96 The history of the Revolution more than once demonstrated that the progress that the bourgeoisie were more likely to be following was the progress of the bourgeoisie. The Declaration of the Rights of Man and Citizen, the three revolutionary Constitutions, and documents such as Robespiexre's proposed Declaration of Rights were expressions of the idea of progress, a

${ }^{96}$ It is important not to lose sight of the fact that the bourgeoisie did have a strong belief in the righteousness of their style of life and thought. To many, the bourgeoisie had a "mission" to bring that style to the whole of civilization. 
belief in the power of mankind to bring about such goals, the inevitability of their arrival, and the assciation of right and reason with them. But during the course of the Revolution, one saw such affronts to the idea of progress and the liberal notions embodied in these documents as the distinction between active and passive citizens based upon the possession of property, the distribution of the confiscated property to those who could afford it and not to those who needed it, and at some time during the course of the Revolution one saw the freedoms of the priests, the nobility, the emigres, and even the Jacobin Club among others curtailed and their lives threatened (and quite often taken). In fact, in the course of the Revolution one saw all the notions of freedom, liberty, equality, and justice compromised for the good of the "people."

The record of the Revolution proffers well for the belief that the bourgeoisie were interested in restoring the status quo, mutatus mutandus. At the eve of the Napoleonic period, the life of the great mass of Frenchmen was not greatly different from the pre-revolutionary period, with the exception of the fact that the bourgeoisie were now in control of the nation.

Again as Mannheim (1936:274) stated, the absence of ideas often meant the absence of the drive to come to grips with certain life problems. In the instance of the bourgeoisie of 18 th century France, their acceptance of the idea of progress and the particular ends to which they saw it taking them, the converse was shown to be true as well. The idea of progress was the tool that could provide 
the organization and the justification for the attempt to remedy the Iife problem that most affected them, their second-rate status in society. Though, as has been mentioned numerous times, there were Iiberal ideas that existed outside of the idea of progress (though they were most often embodied in the idea as well), it was the inevitable character that the idea of progress possessed since the battle of the ancients and the moderns that provided a necessary element for the bourgeoisie. It underscored the sense of "mission" they fancied themselves a part of and to which they could offer justifications for the changes they instituted.

In the two factors (ideational and social) that have provided the focus for this thesis, one has the essential forces that gave rise to the idea of progress and that in some manner still operate to maintain the idea as a preeminent idea in the life of mankind. What, however, can be said in general now about the idea of progress and its implications? The idea of progress amounts to a statement of the grandest arrogance, made initially by the western world. It is a denial of the historical trend that societies, even the most grand and powerful, have eventually declined and given way to other societies. The idea of progress is a statement, founded in the hubris present even in the infant science, that rational and scientific civilization has developed a way to circumvent all the fatal errors that have ever caused the great to become the humble. It is an explicit repudiation of the relative character of human social organization. It has been and still is the perceived power. of science and the scientific method to lead civilization away from 
the destructive path to an ever advancing vista that has been the dynamic element of the idea of progress. It is this perceived power of science and the readily apparent advances that science indeed seems to generate that has made science an intimate bedfellow of the idea of progress.

There are two different motifs in which science's contribution to the idea of progress is viewed. The one seen most often focusses upon the specific discoveries of the particular scientific disciplines. These discoveries are believed to lead to progress through their access to an understanding of the rational principles that underlay all nature, and the material benefits that such undexbrings. The other motif focusses upon the self-corrective characteristic of the scientific method. This second motif is not as certain as the first about the existence of progress and the role that science has to play in it. This motif concentrates more upon the capacity of science to continually correct its previous errors, and though this corrective process appears to manifest great progress it does not necessarily imply that it entails a goal or even a direction for that matter. Either one of these or a combination of them has been the essence of the belief in progress. Science without doubt has played a pivotal role in the existence of the idea of progress.

One particularly perplexing aspect of the idea of progress and its association with science is the belief that the advances in science will in turn lead to advances in virtue. The very nature of science, however, attempts to divorce itself from such questions of 
virtue and has from the very beginning sought to carve an isolated and "neutral" domain for its actions and its products. It seems the grandest illusion to build a belief in the advance of man upon a rational science that seeks to remove the uniquely human characteristics of virtue and morality from its method. Man seeks to build a more vixtuous and ethical world through the advance of a system that in its quintessence has no virtue or ethics. Tolstoy (Weber, 1956: 143) stated this problem in the extreme, but with great profundity, when he said "science is meaningless because it gives no answer to our question, the only question important for us: 'what shall we do and how shall we live?" Yet in spite of this deficiency, men still look to science as the counselor to and the criterion of progress.

Though it has been science that has provided the dynamics for the idea of progress and it has been thought that the rationality of science has been the cornerstone of that idea, it is in fact the case that belief in the idea of progress is not founded upon that rationality but rather an act of faith. As Bury (1955:4) has cogentiy pointed out, the idea of progress "belongs to the same order of ideas as Providence or personal immortality. It is true, or it is false, and like them it cannot be proved either true or false. Belief in it is an act of faith." It was the faith in science and the faith in the progress to come that eventually displaced the faith in God and providence to provide for man. The faith, the belief in science and the progress that it was associated with, was simply a perspective that more closely fit contemporary ideas and more closely. fit the 
views that men wanted to have about themselves and the world in which they lived. The belief in secular progress over the belief in Providence was merely a question of one manner of faith over another, not one of rationality versus faith.

The idea of progress has been inculcated into the mind of every child, at least those exposed to the influence of western culture, as a domain assumption about the nature of the world. This need not be viewed as a form of coercion for there are some attractive reasons for believing in the idea of progress, social, intellectual, and spiritual ideas. The existence of progress would seem quite evident, a great many ills of man have been ameliorated, there seems to be moxe available for consumption than ever before, there have been discoveries in the social sciences that have brought man a better understanding of the nature of society, and in general man has accomplished feats undreamed of only decades ago. Belieif in the idea of progress has also provided a great means of rationalizing anything that has transpired, for by accepting the inevitableness of progress all activities good or bad can be viewed as contributing positively to civilization, the good by the strength of their direct contribution, the bad by disclosing unproductive avenues. Voltaire's Candide might be as apropos today as it was in the 18th century. Above aIl, though, the belief in the idea of progress is quite easy for it only requires that there be advancement in any given period, not necessarily that perfection actually be reached. In fact, implicit in the idea is that a state at which the appetite of progress becomes satiated cannot be reached, that as long as man exists he will be 
progressing. The size of man's progress need not become increasingly great, it need only be essentially continual.

The most potent of all answers to the question of why we still believe in the idea of progress is that we must believe in progress because it provides the meaning for our existence in this world. For the vast majority of the world's population even today life is a struggle. Take away the hope, the belief that the future holds something better both for them and their descendants and one takes away the motivation to continue the struggle and endure the hardships. As Pliny $(1963: 128)$ is quoted as saying, "hope is the pillar that holds up the world." The power of the idea of progress lies not so much in its explicit form as what it holds implicitly for men, the hope that it gives to men.

If any sense is to be made of the idea of progress and the motivating quality that it has one must look beyond the external (social, technological, and scientific) trappings that have heretofore been the focus of popular analyses of progress and turn attention back to man himself. Is it not man's development, the development of the sentient being, that ought to be the measure of man's progress? What can be more natural in an analysis of man's progress than to ask how man himself has progressed? This means to ask what can actaully be said of the lability of mankind to live in harmony with himself and with the natural world around him? The crux of the question of progress revolves around the question of whether in the centuries, or millenia, gone by man has come to accept all races as brothers, whether man has come to understand his own nature and the 
nature of his impact upon the world? If man is still prey to the same vices of jealousy, hatred, prejudice, greed, and ignorance that have characterized his existence from perhaps the time when he first stood erect, dare we say that he has progressed? We live differently, no doubt, but have we as men come to learn how to ensure our survival as a species any better than the first caveman? This is a question whose affirmative answer can no longer be taken for granted and progress an idea that is coming under increasing scrutiny.

Perhaps it is time to discard the arrogance and the myopia that the idea of progress, particularly in its technological and scientific aspects, generates and find a new source of meaning for our lives, a new source of motivation for human action that would focus more directly upon man himself. Such a reordering may be approaching of its own volition, as Bury (1955:352) stated in his epilogue:

A day will come, in the revolution of centuries, when a new idea will usurp its place as the directing idea of humanity. Another star, unnoticed now or invisible, will climb up the intellectual heaven, and human emotions will react to its influence, human plans respond to its guidance. It will be the criterion by which Progress and all other ideas will be judged. And it too will have a successor.

In other words, does not Progress itself suggest that its value as a doctrine is only relative, corresponding to a certain not very advanced stage of civilization; just as Providence, in its day, was an idea of relative value, corresponding to a stage somewhat less advanced?

If one calls the idea of progress into question and states that there may arrive in the future some different idea that could take its place, then perhaps it is incumbent upon the writer to offer suggestions as to what the nature of these alternative ideas might be: Without knowing what changes in thought and what social changes 
may come about in the future, one obviously cannot predict the exact nature of the ideas that are to emerge. One can, however, offer what alternatives are seen as existing fxom the perspective of the present day.

The following is a framework within which any idea of a social dynamics must operate.

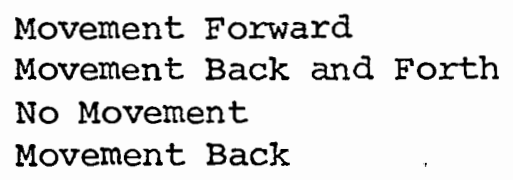

Ideas that could emerge through this framework would cover the spectrum from continued support of the idea of progress to the complete rejection of it. Any idea that emerged from the first category would quite naturally enough still maintain the existence of the idea of progress. But the acceptance of the continued movement forward of civilization may imply two aspects of the idea of progress. On the one hand, there may be the continued belief in the rapid (even accelerating) pace of progress. An accelerated rate of progress might pursue the avenue presented by the latest utopian thinkers--outer space. Such an attempt to temper the idea of progress might start with the pursuit of a clearer understanding of just what is really meant by the idea of progress. Eugene Schwartz (1971:31-2) suggests six criteria which could (and should) be applied to any idea of progress, or any like idea of social change, to render much clearex the intentions and implications of the idea. Those six criteria are:

1. Element: what progresses?

2. Motive: what axe the causal factors? 
3. Process: how do the elements change with time?

4. Path: what is the route of change?

5. Ends: toward which goals are the elements moving?

6. Criteria: how are the goals measured?

An analysis based upon these criteria would help to curtail the more cavalier and naive ideas of change by forcing men to look more closely at the overall nature and effects of any idea, forcing them to realize that quite often the chain of effects from a given idea carries for a great distance in the social realm, forcing them to see that the most well intentioned ideas often are capable of generating regretable effects.

A tempered belief in the idea of progress would be an expression of the belief that human change can continue for the betterment of the human condition but that such change must be slow and deliberate for the sake of insuring truly beneficial change. Too often in the past the mere reference to the idea of progress was a sufficient justification for a given activity. Underlying such a tempered view implicitly lies the acceptance of an "ecological" point of view that stresses the need to moderate the consumption of the earth's resources and implicitly accepts the notion that a heaven on earth must given way to the hope that most people could live a comfortable; but not luxurious, life. In the face of growing questioning of the validity of the idea of progress, this tempered position may be what the immediate future holds for the idea of progress since it can still retain the basic implications of the idea and yet hold in check the flights of fancy that the idea of progress tends to generate. 
Moving down the spectrum of social change outlined in the original framework, if the idea of forward movement is rejected then the next alternative is the idea of movement back and forth. Such a notion might still embody an idea of progress for even in the early history of its development it was believed that in spite of periodic regression there was an overall movement forward. Even if one rejects this notion as a manifestation of the first category it is still possible to have an idea of progress within a framework of alternating periods of advance and decline. For those who "lived in the ascendancy phase of the cycle there was the prospect of participation in perfection. If one lived in the descending phase, then there was the glory of the past and the certainty of eventual good tidings again" (Bok, 1978:45). In any given cycle one might experience the goal of progress under the given conditions. In this notion one has the old idea of cyclical change only in new vestments. If one rejects the alternatives that assume forward movement and alternative back and forth movement, the next possible alternative is an idea that is based on the assumption of no movement. The existence of no social movement may be the result of civilization's inability to generate change, a situation not unlike the nature of Medieval society, or it might follow from a social decision to stop so-called. progress. The search for an alternative is really a-search for ideas that arise out of a choice, and so the lack of social movement as a result of involuntary stagnation is of little concern here. The choice to develop a social structure involving no progress is the desire to construct a society with the greatest degree of equilibrium, 
neither rising nor falling but simply maintaining an internal vitality. Such a social organization may loosely be called a steady-state model.

The steady-state alternative elevates to a position of prime importance the one factor that any view of human history and the future of man must come face to face with, the finite character of the earth's resources. The steady-state model is an ordering of life in accordance with the longest perspective of mankind, and an implicit denial of the unlimited vista of human activity. That is, it bases its social structure upon that organization of mankind that provides the combination of the best conditions for living with the greatest conservation of resources. ${ }^{97}$ The steady state places prime importance on the simple survival of mankind. The idea of human survival does not necessarily carry the same implications as does the idea of progress. While the idea of progress operates with the notions of expansion, growth, and consumption, the idea of survival operates with the idea of stability. While any social structure must consume to exist, the idea of survival, the idea of the steady' state, attempts to restrict growth and expansion.

Such an idea of survival as is implied above necessarily requixes the improvement of human relations for presently they compose one of the most unstable elements in human civilization.

97

As the following discussion will bring out, this steadystate idea implies no need for that combination to be "modern" in the sense of the accoutrements of living. Any given level of. organization from the Stone Age to the Space Age might be legitimately deemed the best intersection of human welfare and available resources. 
These notions of the steady-state and the idea of survival (vis a vis advance) bring one back to the statements made earlier that the true test of man's progress ought to be in his ability to get along with his fellow man, to insure his survival. The true test of man's worth and the record of his accomplishment ought to be found within man himself.

Rejecting all of the above alternative areas, one is only left with a movement "back," that is, anti-progress viewed within the popular definitions of progress. Such a movement backward could be the result of either a breakdown in' the social system or a conscious decision to change the social structure. Because of the focus here upon the choices that are available for alternative ideas to the contemporary view of progress that area of social breakdown may be disregarded. Certainly one alternative to the idea of progress is the antithetical movement away from what the idea of progress intends to convey. But this movement backward can hardly be considered a viable one for the movement backward would either have to continue to pexhaps the stone Age and beyond or it would of necessity become one of the other alternatives. Unless the movement back continues ad infinitum it will eithex become a steady-state (at any given level of social organization), be involved in a progress-regress cycle, or become involved in the forward movement of progress again. The idea of movement back could only serve as a transition phase to some other idea.

Even if one can suggest some vague alternatives to the modern idea of progress; what does the idea of an alternative mean in terms 
of its affect upon the human psyche? Having been inculcated with the idea of progress for the past two centuries, any idea that was devoid of the emotions of betterment that are implicit in the idea of progress is hard to imagine. Intellectually and spiritually, modern man has grown accustomed to seeing that idea in terms of "moving forward," and seems to believe that anything less is stagnation. Certainly any change away from the popular idea of progress couched in these terms would be one of the greatest changes in the social and intellectual history of man, and cextainly would take an extended period to affect. But perhaps it would be possible to sustain this fundamental human drive for their betterment and yet do away with the idea of progress as commonly accepted. Being without the idea of progress does not mean necessarily that men are without hope, for the idea of man's survival embodied in the steady-state idea would trade man's continued| movement forward for the long term survival of mankind. Such a shift might require a significant change in the whole attitude of man. What is good for the individual is not always good for the stability and the perserverance of the social whole. The idea of progress largely ignored such distinctions as this, its focus was upon movement and change. ${ }^{98} \mathrm{~A}$ shift to the

\section{8}

The idea of progress ignored such distinctions largely because of the fact that there were so many perceived manifestations of progress and so little agreement on a uniform criterion of progress. As it was discussed in the introductory chapter, the idea of progress is at its essence an idea of change with some criterion attached to that change. Legitimately every individual alive could have a different idea of progress with each individual detrimentally affecting the progress of all other individuals. 
acceptance of the idea of survival with the same intensity displayed in the acceptance of the idea of progress would require a much more altruistic approach by all and a much more uniform idea, accepted over the whole society, of what was required to insure stability and survival. Where under the idea of progress the hope and the meaning of life that motivated men was in the hope for their own improvement, under the idea of survival the hope and meaning for individual might become the perpetuation of mankind, the mere assurance of survival. The notion of betterment involved here is certainly more nebulous and less substantial for the individual, but it is not an idea without merit and possibility.

Whether one believes in the most optimistic ramifications of the idea of progress and the psychological and social reasons for its maintenance or whether one believes in the need to curtail the inherent dangers of the idea, no one can deny that it has been an idea of premier importance and impact and is an idea that has perhaps to play its most crucial role in the movement of civilization. 


\section{BIBIIOGRAPHY}

Aulard, Francois V. The French Revolution: A Political History. 1. Trans. Bernard Miall. New York: Russell \& Russell, 1965.

Baker, Keith M. "Marquis de Condorcet," The Encyclopedia of Philosophy, 2 (8 vols. in 4 books), 182-4. New York: Macmillan Publishing Co., Inc., and The Free Press, $1967 \mathrm{a}$.

Barber, Elinor. The Bourgeoisie in 18th Century France. Princeton, New Jersey: Princeton University Press, 1955.

Becker, Carl I. The Heavenly City of the Eighteenth-Century Philosophers. New Haven, Conn.: Yale University Press, 1965.

Becker, Carl I. and Harry Elmer Barnes. Social Thought From Lore to Science. 1. Third edition. New York: Dover Publications, Inc., 1961a.

Becker, Carl I. and Harry Elmer Barnes. Social Thought From Lore to Science. 2. Third Eaition. New York: Dover Publications, Inc., 1961b.

Beik, Paul., Ed. The French Revolution. New York: Walker, 1970.

Boas, Maria. The Scientific Renaissance 1450-1630. New York: Harper, 1962 .

Bok, Kenneth. "Theories of Progress, Development, and Evolution," A History of Sociological Analysis. Tom Bottomore and Robert Nisbet, eds. New York: Basic Books, 1978.

Brinton, Crane. "Enlightenment," The Encyclopedia of Philosophy, 2, 519-25, New York: Macmillan Publishing Co., Inc., and The Free Press, 1967a.

Bury, J. B. The Idea of Progress: An Inquiry Into Its Origin and Growth. New York: Dover Publications, Inc., 1960.

Cassirer, Ernst. The Philosophy of the Enlightenment. Trans. Fritz C. A. Koelln and James P. Pettygrove. Princeton, New Jersey: Princeton University Press, 1951.

Condillac, Etienne Bonnot de. Treatise on Sensations. Trans. Geraldine Carr. Los Angeles: University of Southern :". California, 1930. 
Condorcet, Marie Jean Antoine Nicolas Caritat, Marquis de. Sketch for a Historical Picture of the Progress of the Human Mind. Trans. June Barraclough. New York: Noonday Press, 1955.

Dante, Aligheri. Monarchy and Three Political Letters. Trans. Donald Nicholl. New York: Noonday Press, 1955.

Dawson, Christopher. The Gods of Revolution: An Analysis of the French Revolution. New York: Minerva Press, 1975.

Descartes, Rene. The Philosophical Works of Descartes. I. Trans. Elizabeth S. Haldane and G. R. T. Ross. New York: Dover Publications,. Inc., 1955.

Diderot, Denis. Rameau's Nephew and Other Works. Trans. Jacques Barzan and Ralph H. Bowen. Indianapolis: The Bobbs-Merrill Company, Inc., 1964.

Edelstein, Ludwig. The Idea of Progress in Classical Antiquity. Baltimore: Johns Hopkins Press, 1967.

Fellows, Otis. "Bernard le Bovier de Fontenelle," The Encyclopeida. of Philosophy, 3, 208-9, New York: Macmillan Publishing Co., Inc., and The Free Press, 1967b.

Gilbert, Neal W. "Renaissance," The Encyclopedia of Philosophy, 7, 174-9, New York: Macmillan Publishing Co., Inc., and The Free Press, 1967d.

Gottschalk, Louis R. The Era of the French Revolution. San Francisco: Houghton Mifflin Company, 1929.

Grimsley, Ronald. "Jean-Jacques Rousseau," The Encyclopedia of Philosophy, 7, 218-25, New York: Macmillan Publishing Co., Inc., and The Free Pres\$, 1967d.

Guerard, Albert. France in the Classical Age: The Iife and Death of an Ideal. Evanston, Illinois: Harper \& Row, Publishers, 1956.

Guizot, M. and Madame Guizot de Witt. The History of France From the Earliest Times to 1848. V. Trans. Robert Black. New York: American Publishers Corporation, 1898 (?).

Harding, Samuel Bannister. New Medieval and Modern History. Chicago: American Book Company, 1920.

Havelock, Erik. The Liberal Temper in Greek Politics. New Haven, Conn.: Yale University Press, 1957.

Helvetius, Claude Adrien. Treatise on Man. Trans. W. Hooper. Iondon: Albion Press; 1810. 
Hume, David. Essays and Treatises on Several Subjects. I. London: J. Jones, 1822 .

Jones, W. T. A History of Western Philosophy. III. Second edition. San Francisco: Hourcourt, Brace \& World, Inc., 1969.

Lefebvre, Georges. The French Revolution. 2 Vols. Trans. Elizabeth Gaunson. New York: Columbia University Press, 1964.

Lefebvre, Georges. The Coming of the French Revolution. Trans. R. R. Palmer. Princeton, New Jersey: Princeton University Press, 1973.

Lovejoy, Arthur and George Boas. Primitivism and Related Ideas in Antiquity. New York: Octagon Books, 1965.

Manuel, Frank. The Age of Reason. Ithaca, New York: Cornell University Press, 1951.

Manuel, Frank. Shapes of Philosophical History. Stanford, California: Stanford University Press, , 1973 .

Marcus Aurelius: Medj.tations. Trans. George Long. South Bend, Indiana: Gateway Editions Ltd., 1956.

Marsak, Leonard M., Ed. French Philosophers From Descartes to Sartre. Cleveland: The World Publishing Company, 1961.

Mathiez, Albert. The French Revolution. Trans. Catherine Phillips. New York: Russell \& Russell, 1956.

Meinecke, Friedrich. Historicism. Trans. J.E. Anderson. Iondon: Routledge \& Kegan Paul Ltd., 1972.

Mommsen, Theodor. "St. Augustine and the Christian Idea of Progress," Journal of the History of Ideas, XII, no. 3 (June, 1951),

Montesquieu, Charles Louis de Secondat, Baron de la Brede et de. The Spirit of Laws, 2. vols. Trans. Thomas Nugent. New York: P. F. Collier \& Son, 1900.

Morley, John. Diderot and the Encyclopaedists. II. New York: The Macmillan Company, 1897.

Palmer, R. R. "The Impact of the American Revolution," The Fulfilland Collapse of the Old Regime. Norman F. Cantor and Michael s. Werthman, eds. New York: Thomas Y. Crowell Company, 1967.

Pirenne, Henri. Economic and Social History of Medieval Europe. Trans. I.E. Gregg. New York: Harcourt, Brace \& World, Inc., 1937. 
Plato. Laws. III. Trans. R. G. Bury. New York: G. P. Putnams Sons, 1936.

Pliny (Gaius Plinius Secuncus). Treasury of Familiar Quotations. New York: Crown Publishers, Inc., 1963.

Pollard, Sidney. The Idea of Progress: History and Society: Aylesbury, Great Britain: Pelican Books, 1971.

Rousseau, Jean-Jacques. The Social Contract and Discourses. Trans. G. D. H. Cole. London: J. M. Dent \& Sons, Ltd., 1923.

Ruggiero, Guido de. The History of European Liberalism. Trans. R. G. Collingwood. Boston: Beacon Press, 1959.

Sampson, Ronald. Progress in the Age of Reason: The Seventeenth Century to the Present. Cambridge, Mass.: Harvard University Press, 1956.

Sklair, Leslie. The Sociology of progress. London: Routledge \& Kegain Paul Itd.; 1970.

Sorel, Georges. The Illusion of Progress. Trans. John and Charlotte stanley. Ios Angeles: University of California Press, 1969.

Stewart, John Hall. A Documentary Survey of the French Revolution. New York: The Macmillan Company, 1951.

Tawney, R. H. Religion and the Rise of Capitalism: A Historical Study. New York: New American Iibrary, Inc.; 1954.

Thatcher, Virginia S., et a].., Eds. "Progress," The New Webster Encyclopedic Dictionary of the English Language, 664. Chicago: Consolidated Book Publishers, 1971.

Thompson, J. M. Robespierre and the French Revolution. London: English Universities Press Ltd., 1952.

Tocqueville, Alexis de. 'The Old Regime and the French Revolution. Trans. Stuart Glibert. Garden City, New York: Doubleday \& Company, Inc., 1955.

Van Doren, Charles. The Idea of Progress. New York: F. A. Praeger, 1967.

Vyverberg, Henry. "Anne Robert Jacques Turgot, Baron de I'AuIne," The Encyclopedia of Philosophy, 8, 164-6. New York: Macmillan Publishing Co., Inc., and the Free Press, 1967d. 
Wailbank, Walter T., Alastair M. Taylor, and George Barr Carson, Jr. Civilization Past and Present. 2 Vols. Fifth edition.

Palo Alto, California: Scott, Foresman and Company, 1965.

Wallis, Wilson. Culture and Progress. New York: McGraw Hill Co., Inc., 1939.

Weber, Max. "Science as a Vocation," Fron Max Weber: 'Essays in Sociology, 129-56. Trans, and ed. H. H. Gerth and C. Wright Mills. New York: Oxford University Press, 1972.

Wheeler, Dan Edwin., Ed. The Life and Times of Thomas Paine. IV. New York: Vincent Parke \& Company, 1908.

Williams, Bernard, "Rene Descartes," The Encyclopedia of Philosophy. 2, 344-54. New York: Macmillan Publishing Co., Inc., and The Free Press, 1967a.

Wilson, Arthux. "Encyclopedie," The Encyclopedia of Philosophy, 2, 505-8. New York: Macmillan Publishing Co., Inc., and The Free Press, 1967a. 
APPENDIX

This new, superior, system of thought that Descartes took so much stock in and that has been of some influence ever since its inception was a rather nebulous entity in its formal elaboration. In spite of the central desire of Descartes to formulate irrefutable knowledge the fundamentals of his system were surprisingly vague. The system itself was founded upon four rules that served as guides to inquiry. The first was not to accept anything as true that could not clearly be recognized as such. This required that one surpress prejudices and hasty judgment, ultimately accepting only that which offered no reason for doubt. This rule was the source of the famous "Cartesian doubt," the cornerstone of the attempt to generate clear and distinct knowledge that has become syronomous with the intention of Cartesianism, and rationalism in general. The second rule was to divide inquiry into as many parts as were necessary for the generation of knowledge and truth. Rule three was to proceed in the search for knowledge from the most simple and easy to apprehend objects bit by bit to the most complex and the most general. The last rule was "in all cases to make enumerations so complete and reviews so general" (Descartes; 1955:92), that one could be certain of omitting nothing. In themselves these rules would seem to have provided little concrete aid to the methodology of the Cartesian system. Ieibriz was so little taken with them that he felt that they added up to nothing more than a 
prescription to "take what you need, and to do what you should, and you will get what you want" (Williams, 2, 1967a:345). Descartes realized in paxt that alone as abstract formulations of a system they possessed no great merit, but believed that in application to a specific problem their true profundity would become apparent.

Two features of Descartes' new system of knowledge came to the fore. The first was that it was an analytical one in which its rules were applied to a prablem which then led to knowledge. The answer was arrived at by reducing the problem into its most elemental forms then building from those elements, which could not be doubted, into a greater corpus of knowledge. It was a method that was geared to the "discovery" of krowledge rathex than, in contrast to traditional logic, the presentation of existent knowledge. The second feature of the system was that it was in reality a system that was applicable to any rational method of inquiry rather than merely science, philosophy, or logic. This perhaps was the result of Descartes' underlying belief in the unity of all knowledge, that a system for the generation of knowledge in science would be as applicable in the generation of knowledge in metaphysics, for:: example. 